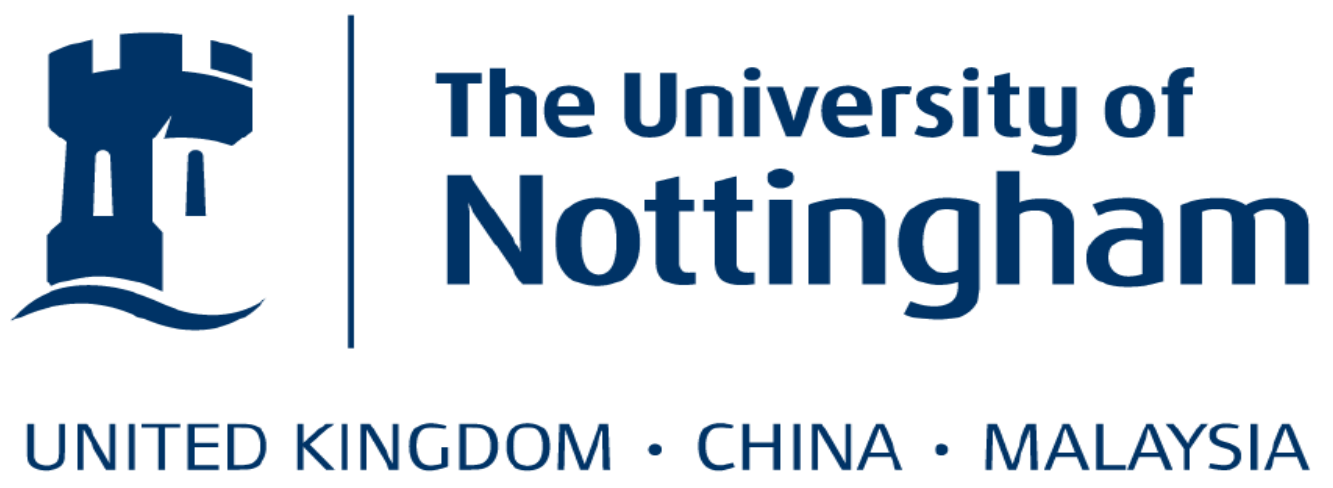

Academic Division of Child Health

\title{
Children's Access to Medicines
}

\section{By}

\section{Saad Ahmed Alkahtani}

Thesis submitted to the University of Nottingham for the degree of Doctor of Philosophy

February 2013 


\section{ABSTRACT}

Access to health care for children is important. It is dependent on access to health professionals and also parental attitudes towards illness.

Children have the right to receive medicines that are scientifically evaluated for both efficacy and safety. Counterfeit and substandard medicines unfortunately result in the death of many children worldwide. There have been particular problems with diethylene glycol which has been used as a solvent in counterfeit medicines. It has also been found in contaminated substandard medicines. It has been responsible for the death of many children in different countries throughout the world. I performed a literature review of all cases of diethylene glycol poisoning that have been published. I have described the clinical signs and symptoms and hope that these findings increase the awareness of diethylene glycol poisoning in children.

It is well known that there are clear inequalities in health and access to health care in the UK. This inequity has been particularly noticed amongst certain minority groups. Children of "at risk" groups, such as Asylum Seekers and Refugees, and Gypsies and Travellers, were recognised as having possible barriers in accessing health care and medicines.

I conducted a study to explore children's access to medicines in the East Midlands area in the UK. Alongside determining accessibility to health care the study also wished to explore parental attitudes towards receiving treatment for pain, asthma and epilepsy. 
Both quantitative and qualitative research methodology was used in this study. The research data was gathered with the aid of semi-structured interviews with parents from the "at risk" groups and control parents. Fifty parents from each group were selected and interviewed regarding their children's health and their access to health care and medicines. The semi-structured interviews allowed participating parents to state their opinions about any barriers they had encountered to their children receiving medicines.

Parents from both "at risk" groups and children from the Traveller group had more health problems than the controls. The attitude of some Gypsy and Traveller parents $(11 \%)$ not to immunise their children was a significant problem. One in six Refugee parents reported difficulties while obtaining medicines. The two main barriers were language/communication problems and financial difficulties. Both Refugee and Traveller children received fewer OTC medicines than the children of the control group. It was not clear from the interviews whether this was due to financial difficulties or reluctance to use medicines without a doctor having seen the child first.

Parents from both "at risk" groups were less likely to give analgesics for treating earache than those in the control group. Parents of Refugee children were more reluctant to tell others about their child's epilepsy.

Access to health care is an essential human right. Children are dependent upon both their parents and the health system for ensuring access to health care. This study has identified problems both within the system and also in relation to parental beliefs that may affect the access to health care and treatment for children. It is important that both of these 
potential barriers are addressed in order to improve the health of children of "at risk" groups. It is hopeful that the findings in this study will help to identify ways of improving access to health care and medicines for these groups. 


\section{ACKNOWLEDGEMENTS}

Praise be to Allah, most Gracious, most Merciful without whose gift of life and knowledge, among other things, this thesis would not have been.

I wish to thank profusely my sponsors, the government of the Kingdom of Saudi Arabia.

I am firstly indebted to my inspirational supervisor, Professor Imti Choonara for his invaluable support, advice, understanding and thoughtfulness especially at the most demanding periods. It would be impossible to overstate my gratitude to him.

It is a pleasure to thank Dr. Helen Sammons, my co-supervisor, for her guidance and critical advice throughout the study.

My thanks, too, to Dr. Sharon Conroy for encouragement and advice during my first year; all the staff at the Academic Division of Child Health at the University of Nottingham, especially Janine Cherrill for her invaluable help with the interviews; and to all the administrative staff at the Medical School in Derby.

My gratitude goes to Refugee Action in Nottingham, and the Derbyshire Gypsy Liaison Group.

No words can express my gratitude to my mother and father, my wife and my three sons and the rest of my extended family. For all their love, emotional support and the sacrifices they have made. May Allah bless them, Amen.

I thank all my friends, and my PhD student colleagues who made my stay here more comfortable.

Without the support of all these people, I would not have been able to complete this work. Thank you. 


\section{PUBLICATIONS ARISING FROM THIS THESES}

The following publications and presentations are based on the research and findings from this thesis:

\section{Journal article and Abstract}

\section{Publication:}

Alkahtani S, Sammons H, Choonara I. Epidemics of Acute Renal Failure in Children (diethylene glycol toxicity). Arch Dis Child 2010; 95: 1062-1064.

\section{Published abstract:}

Alkahtani S, Sammons H, Choonara I. Children's Access to Medicines. Arch Dis Child 2012, 97:5,e19,doi

10.1136/archdischild-2012-301728.39

\section{Conference proceedings}

Alkahtani S. (2011, November). Children's Access to Medicines. Paper reviewed and presented at the $17^{\text {th }}$ Annual Conference and Exhibition of the NPPG, Bristol, UK.

Alkahtani S. (2011, June). Children's Access to Medicines. Paper reviewed and presented at the $5^{\text {th }}$ Annual Saudi International Conference, University of Warwick, Coventry, UK.

Alkahtani S. (2011, June). Children's Access to Medicines. Paper reviewed and presented at the $13^{\text {th }}$ ESDPP Congress, Oslo, Norway.

Alkahtani S. (2011, May). Children's Access to Medicines. Paper presented at the Annual National workshop of Paediatric Clinical Pharmacology and Child Health, Royal Derby Hospital, Derby, UK. 
Alkahtani S. (2010, July). Epidemics of Acute Renal Failure in Children (diethylene glycol toxicity). Paper reviewed and presented at the 4th Annual Saudi International Conference, University of Manchester, Manchester, UK.

Alkahtani S. (2010, May). Children's Access to Medicines. Paper presented at the Annual National workshop of Paediatric Clinical Pharmacology and Child Health, Royal Derby Hospital, Derby, UK.

Alkahtani S. (2009, June). Epidemics of Acute Renal Failure in Children (diethylene glycol toxicity). Paper presented at the Annual National workshop of Paediatric Clinical Pharmacology and Child Health, Royal Derby Hospital, Derby, UK. 


\section{ACRONYMS AND ABBREVIATIONS}

\begin{tabular}{|c|c|}
\hline WHO & World Health Organisation \\
\hline WHA & The World Health Assembly \\
\hline UNHCR & United Nations High Commission for Refugees \\
\hline UNICEF & United Nations International Children's Emergency Fund \\
\hline NGOs & Non-Governmental Organisations \\
\hline FDA & Food and Drug Administration \\
\hline FDAMA & Food and Drug Administration Modernisation Act \\
\hline $\mathrm{NIH}$ & National Institute of Health \\
\hline PDCO & Paediatric Committee \\
\hline NHS & National Health Service \\
\hline EMA & European Medicines Agency \\
\hline GMP & Good Manufacturing Practice \\
\hline WTO & World Trade Organisation \\
\hline TRIPS & Trade-Related Aspects of Intellectual Property Rights \\
\hline ICESCR & International Covenant on Economic, Social and Cultural Rights \\
\hline MSF & Medecins Sans Frontieres \\
\hline IP & Intellectual Property \\
\hline MHRA & Medicines and Healthcare Products Regulatory Agency \\
\hline DMRC & Defective Medicines Report Centre \\
\hline IFPMA & $\begin{array}{l}\text { International Federation of Pharmaceutical Manufacturers } \\
\text { Association }\end{array}$ \\
\hline
\end{tabular}




$\begin{array}{ll}\text { DEG } & \text { Diethylene glycol } \\ \text { EU } & \text { European Union } \\ \text { UK } & \text { United Kingdom } \\ \text { USA (US) } & \text { United States of America } \\ \text { UN } & \text { United Nations } \\ \text { ILR } & \text { Indefinite Leave to Remain } \\ \text { PTSD } & \text { Post-Traumatic Stress Disorder } \\ \text { GPS } & \text { General Practices } \\ \text { ASBOs } & \text { Anti-Social Behaviour Orders } \\ \text { IPPR } & \text { Institute for Public Policy Research } \\ \text { REC } & \text { Research Ethics Committee } \\ \text { GCP } & \text { Good Clinical Practice } \\ \text { RATS } & \text { Qualitative Research Review Guidelines } \\ \text { OTC } & \text { Over-The-Counter } \\ \text { IQR } & \text { Inter Quartile Range } \\ \text { AED } & \text { Anti Epileptic Drug } \\ \text { ADRs } & \text { Adverse Drug Reactions } \\ & \end{array}$




\section{TABLE OF CONTENTS}

ACKNOWLEDGEMENTS

\section{CHAPTER 1: GENERAL INTRODUCTION}

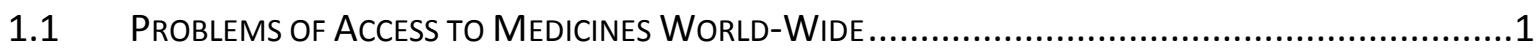

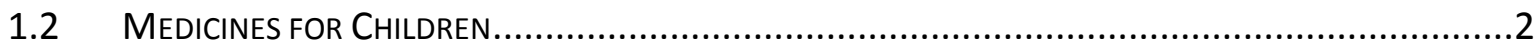

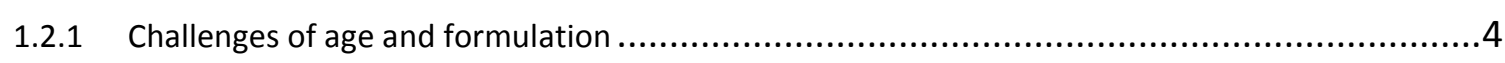

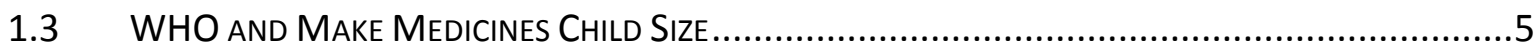

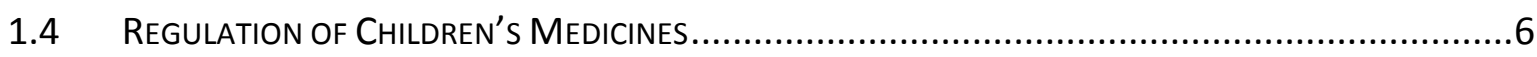

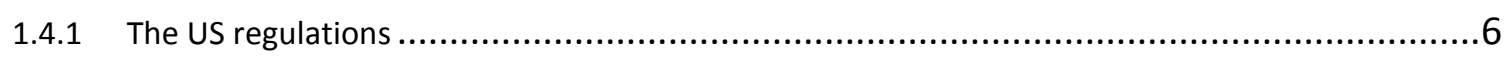

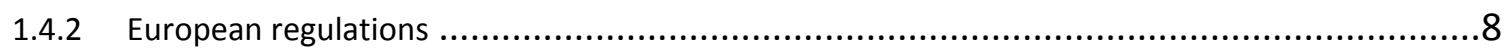

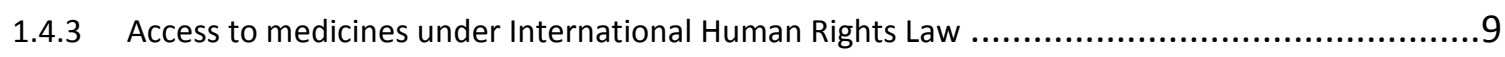

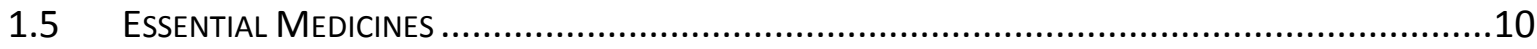

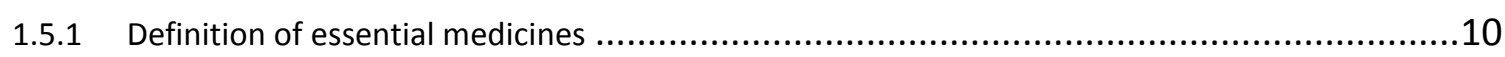

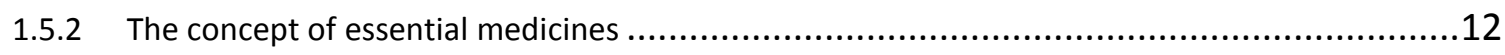

1.5.3 Problems of access to essential medicines in low-and middle-income countries ......................13

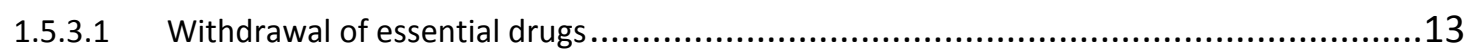

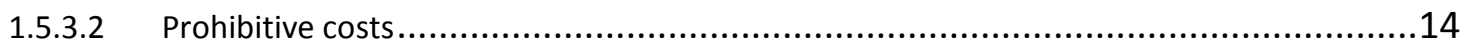

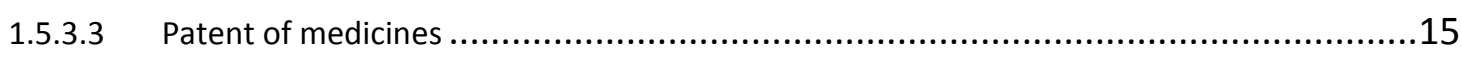

1.5.4 Problems of access to essential medicines in high-income countries.................................17

1.6 The Global Problem of the Quality of Medicines and Counterfeiting ...........................18

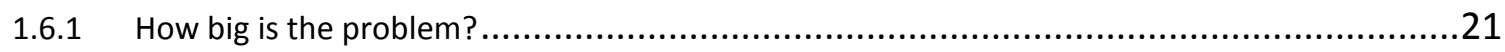

1.6.2 Underlying causes of counterfeit and substandard medicines ........................................22

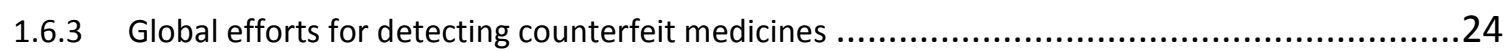




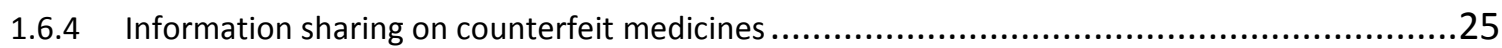

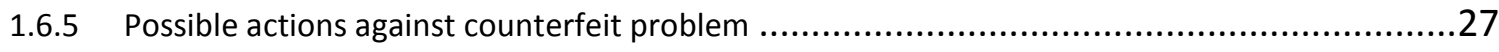

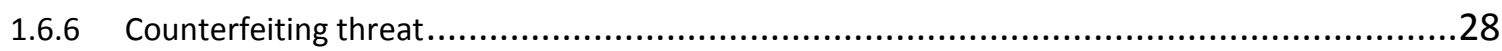

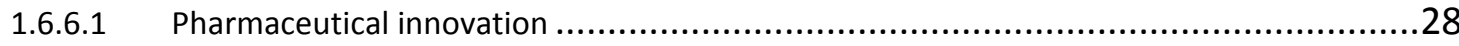

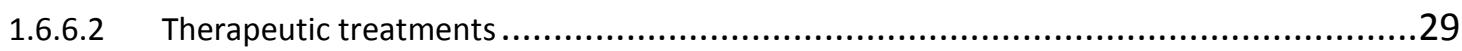

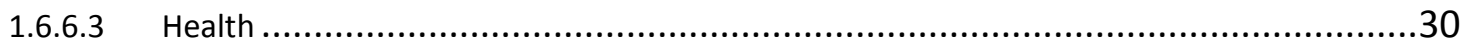

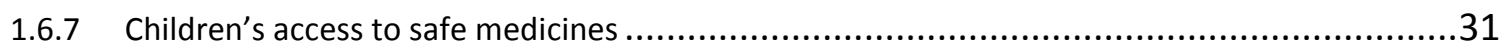

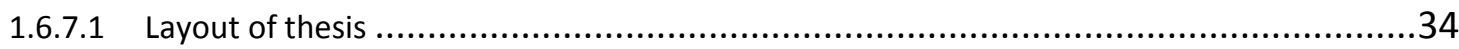

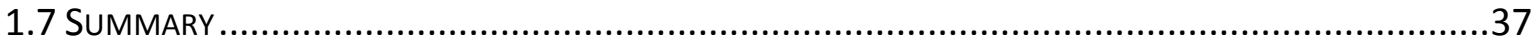

\section{CHAPTER 2: DIETHYLENE GLYCOL TOXICITY IN CHILDREN}

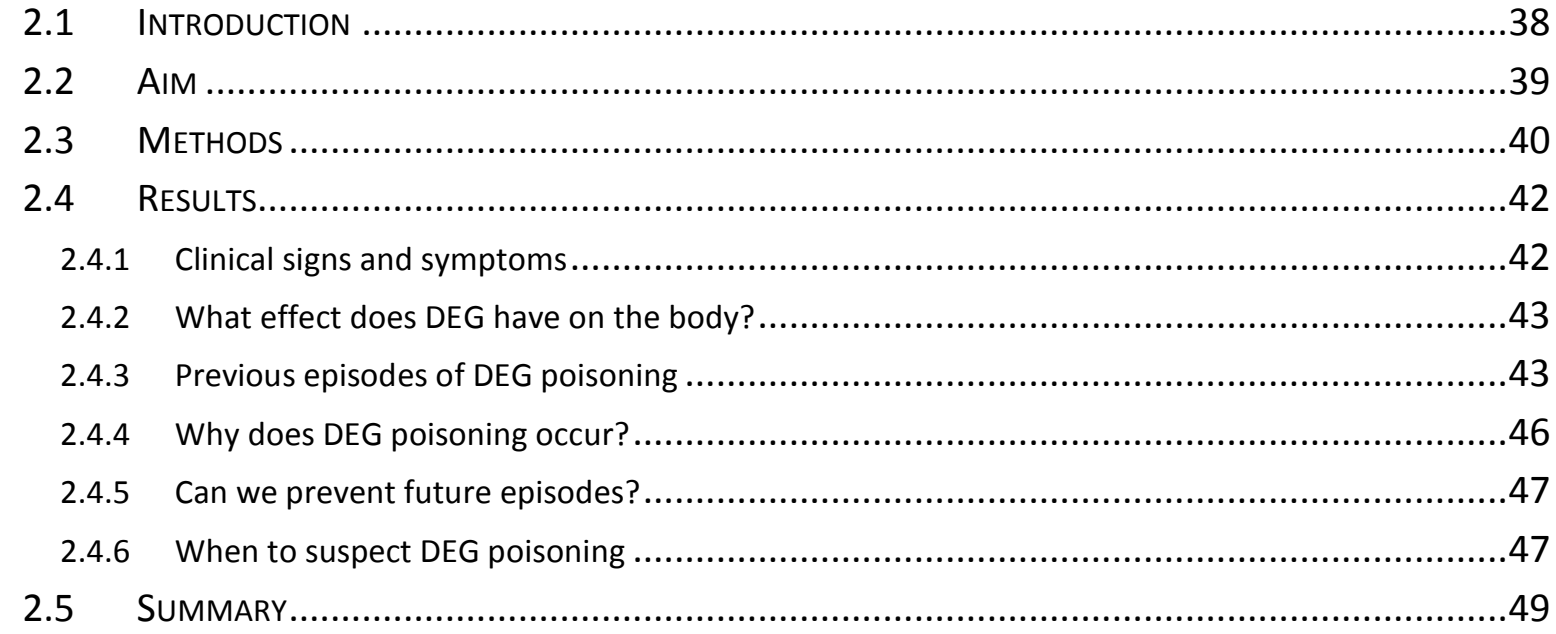

\section{CHAPTER 3: PROBLEMS OF ACCESS TO HEALTH CARE AND MEDICINES FOR ASYLUM SEEKERS AND REFUGEES}

\section{REVIEW OF LITERATURE}

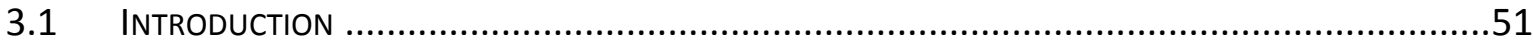

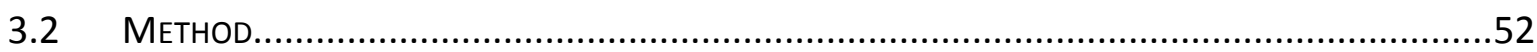

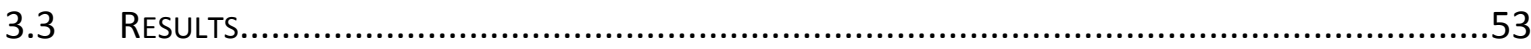

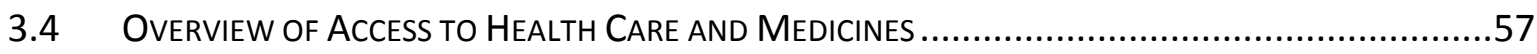

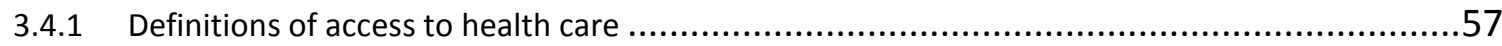

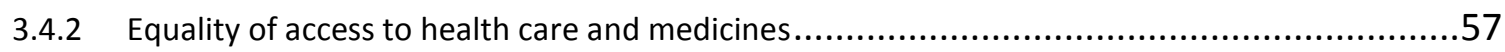

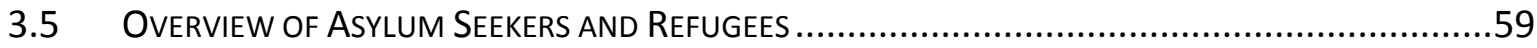

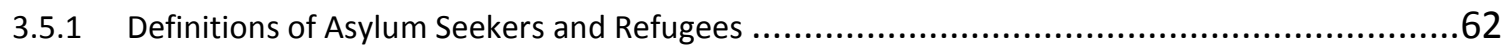

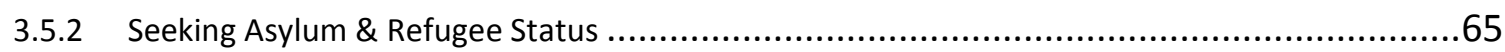

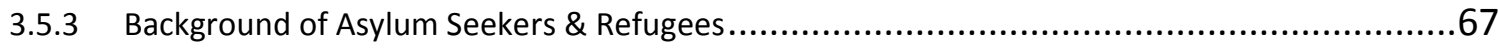


3.6 Overview of Access to Health Care for the "At Risk" Children ....................................70

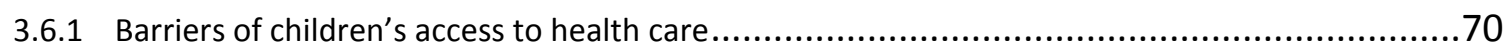

3.7 Overview of Barriers to Access Health Care And Medicines ......................................74

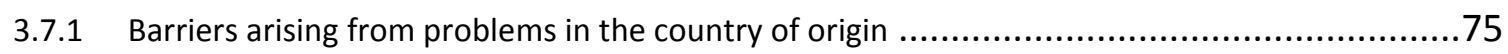

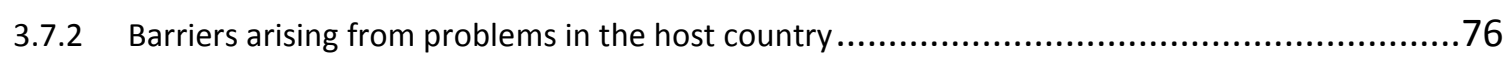

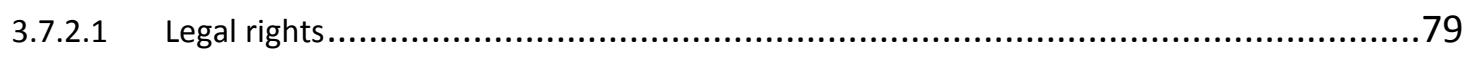

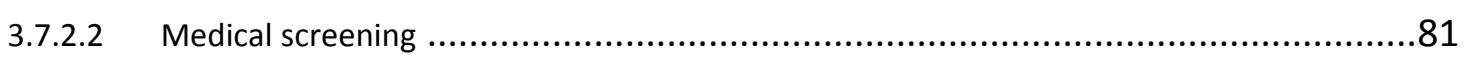

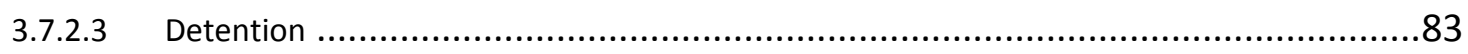

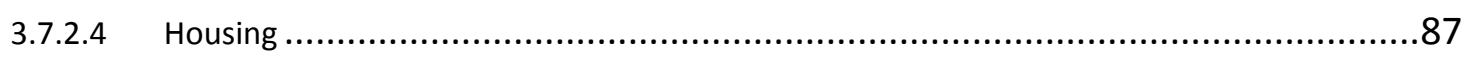

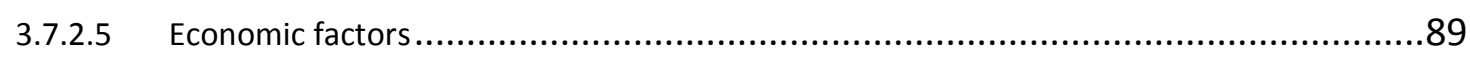

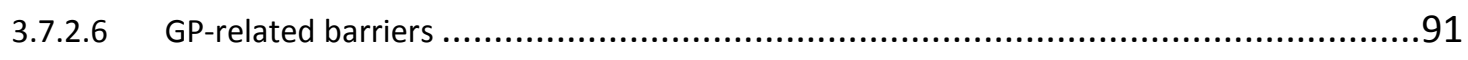

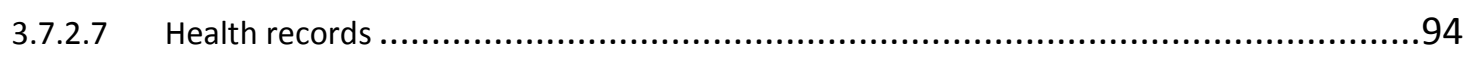

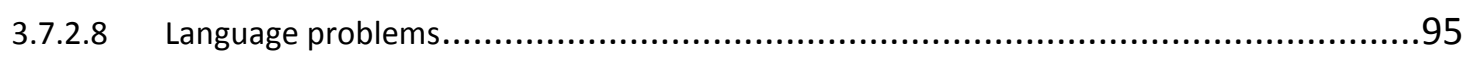

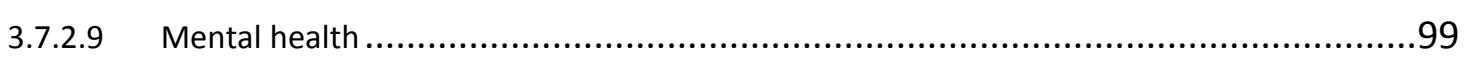

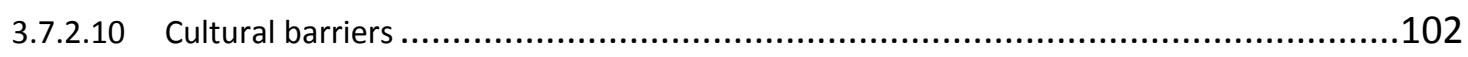

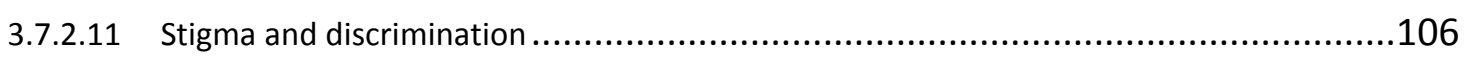

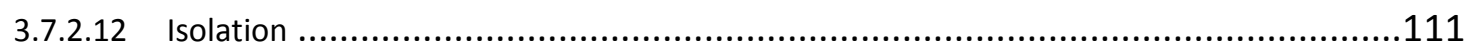

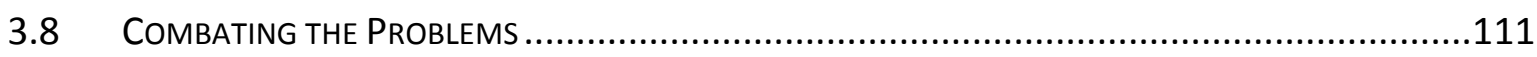

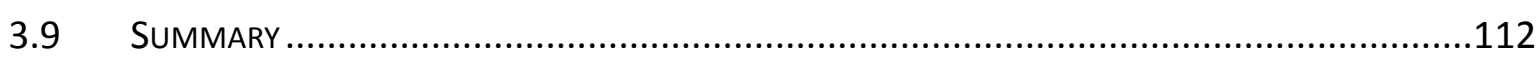

\section{CHAPTER 4: PROBLEMS OF ACCESS TO HEALTH CARE AND MEDICINES FOR GYPSIES AND TRAVELLERS}

\section{REVIEW OF LITERATURE}

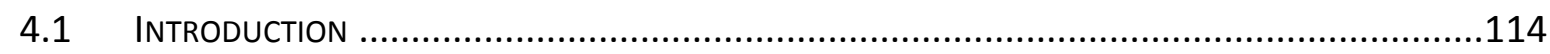

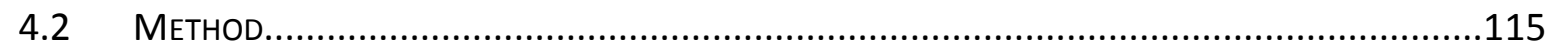

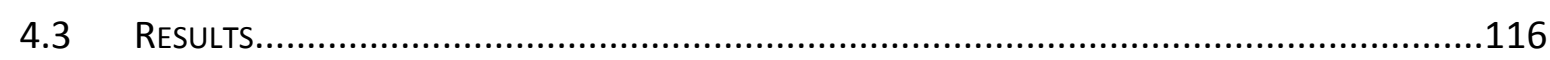

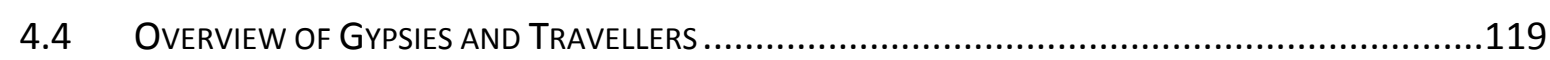

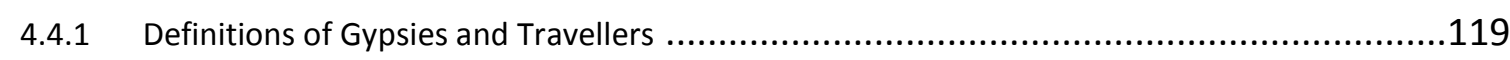

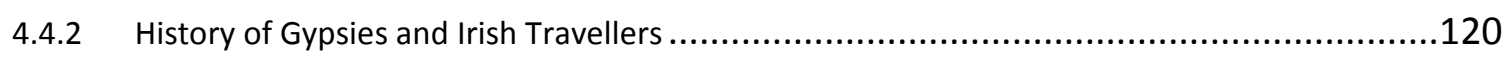

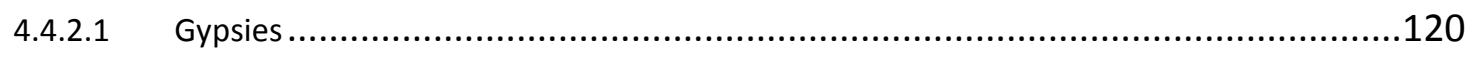

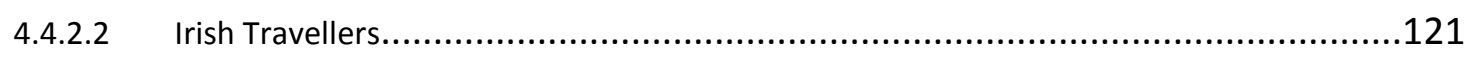

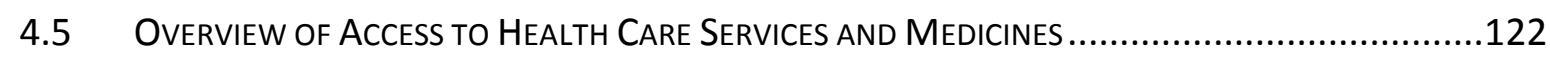

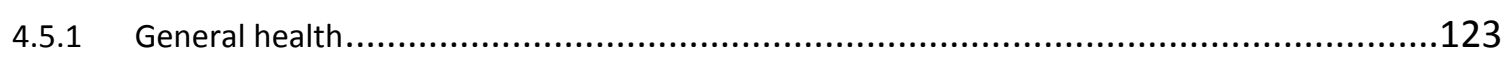

4.6 Overview of Children's Health and their Access Barriers to Health Care ...................125

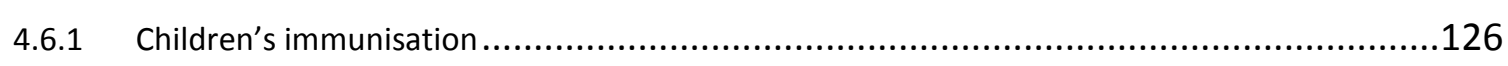

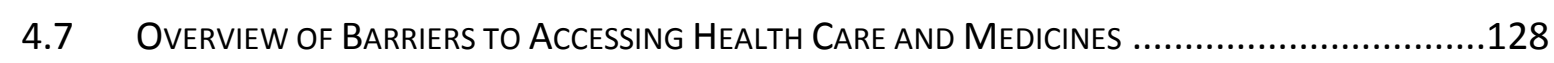

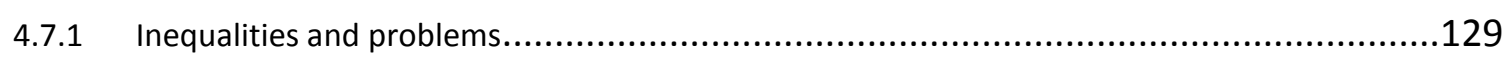




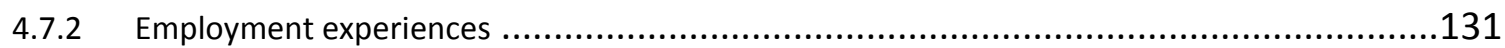

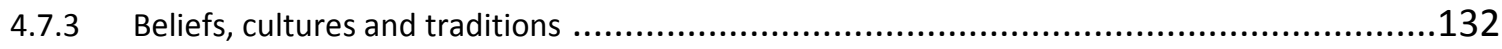

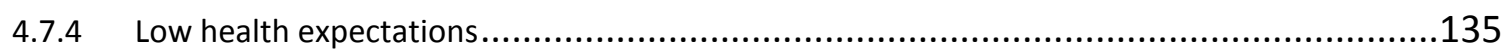

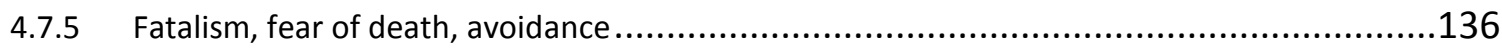

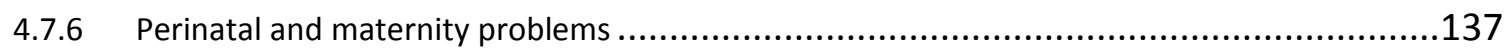

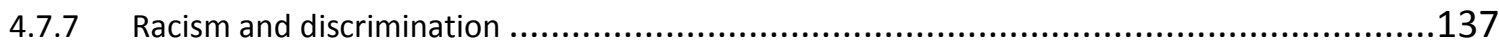

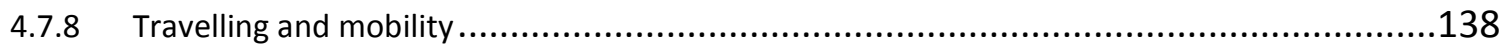

4.7.8.1 Health-related benefits of travelling ......................................................139

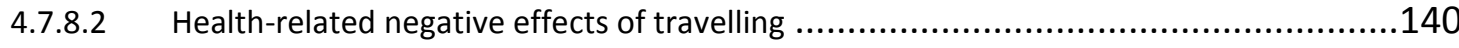

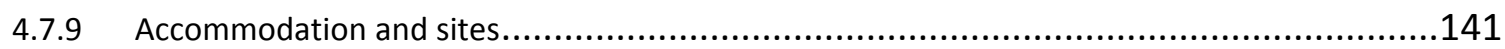

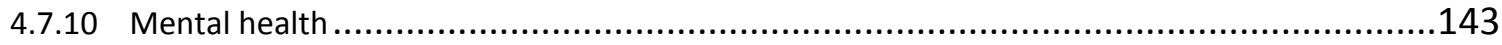

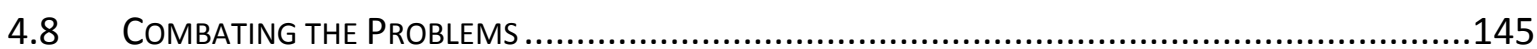

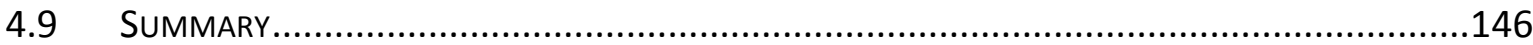

\section{CHAPTER 5: METHODOLOGY}

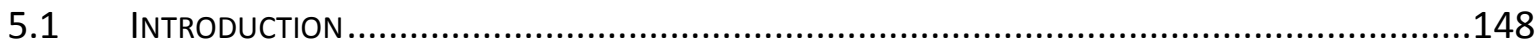

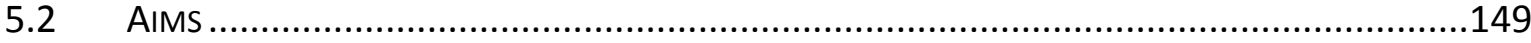

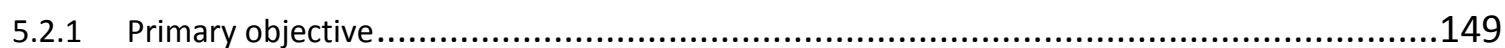

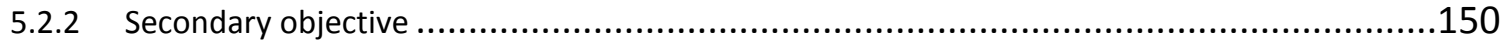

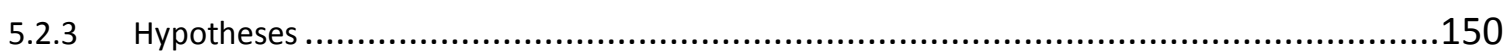

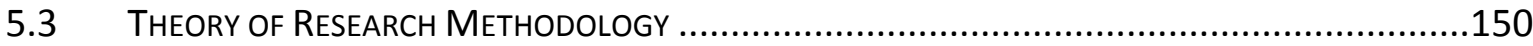

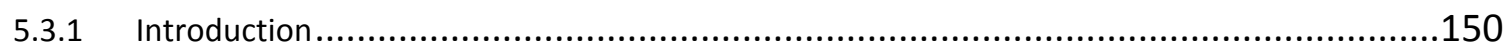

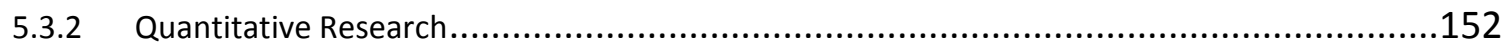

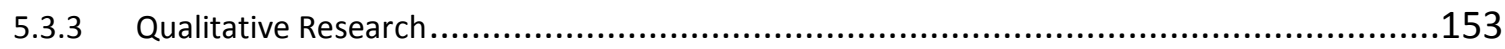

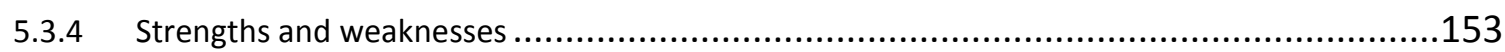

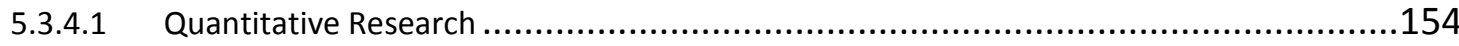

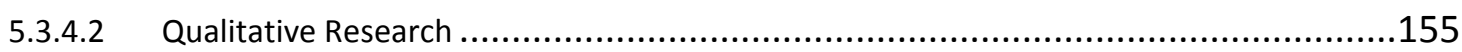

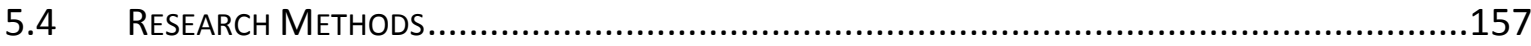

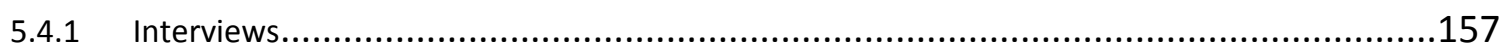

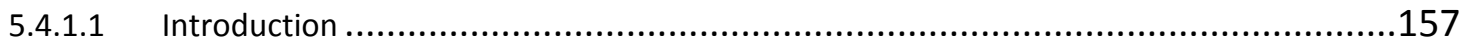

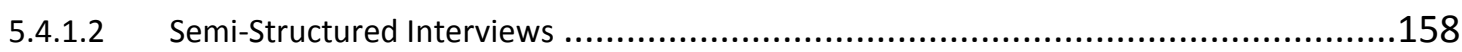

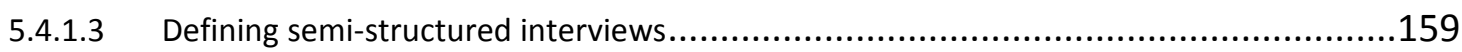

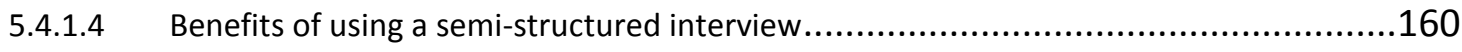

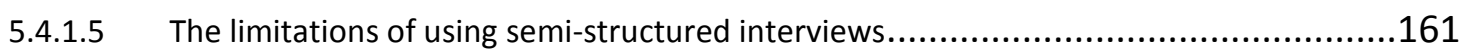

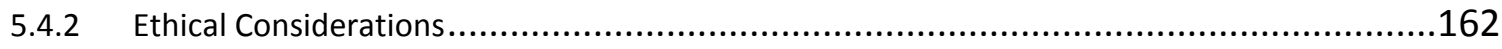

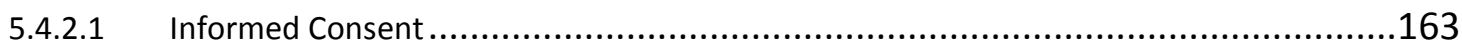

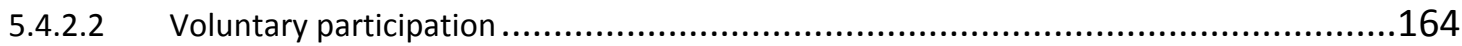

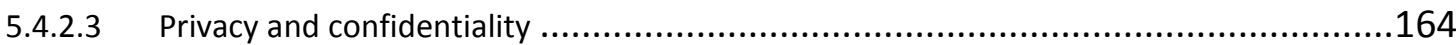




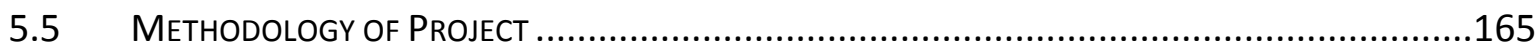

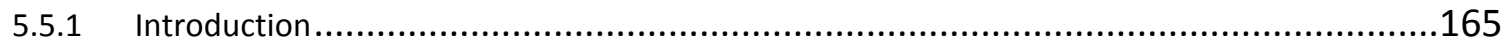

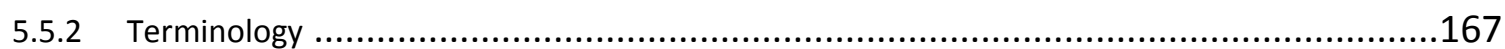

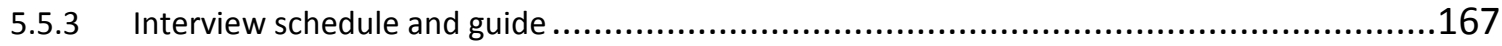

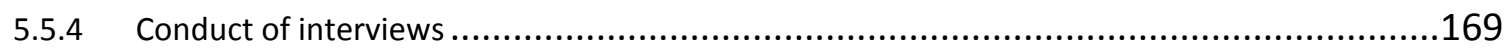

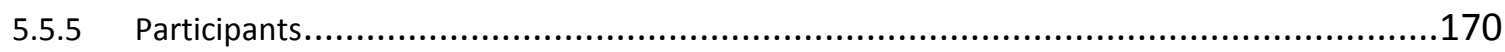

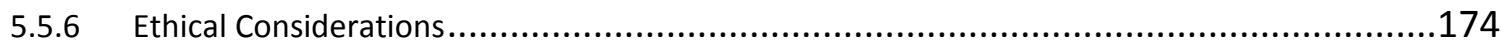

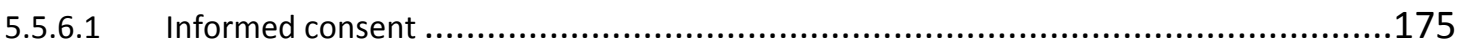

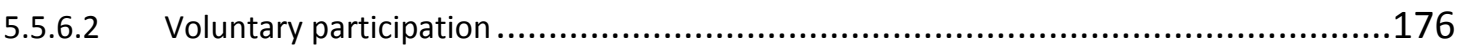

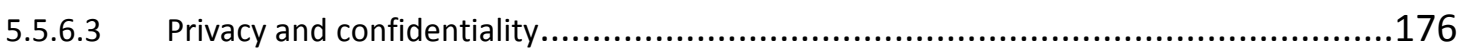

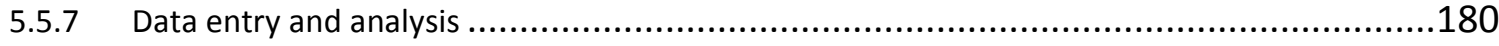

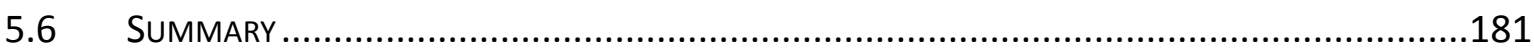

\section{CHAPTER 6: RESULTS AND DISCUSSION (ASYLUM SEEKERS AND REFUGEES)}

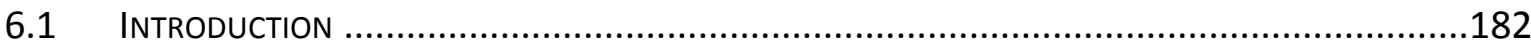

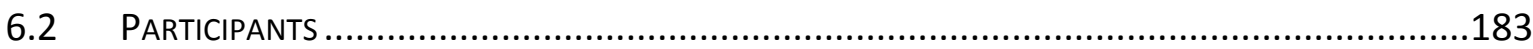

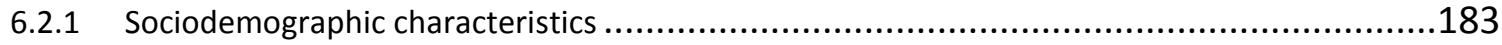

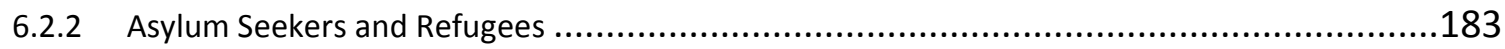

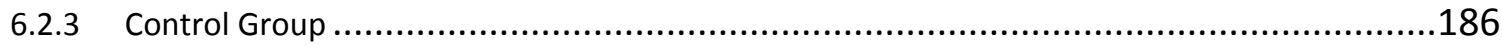

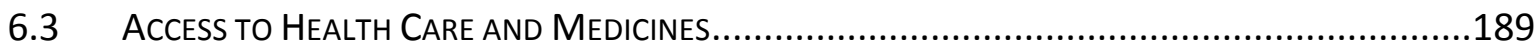

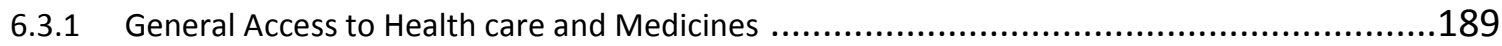

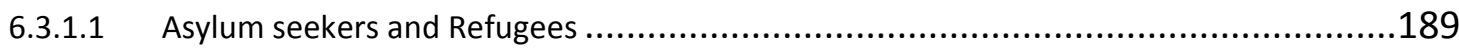

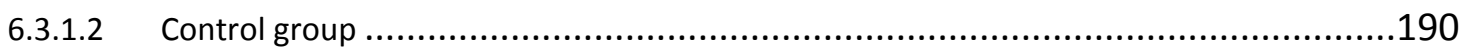

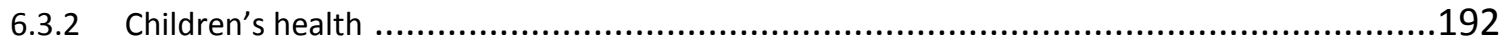

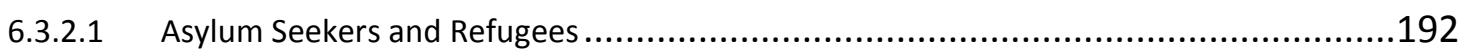

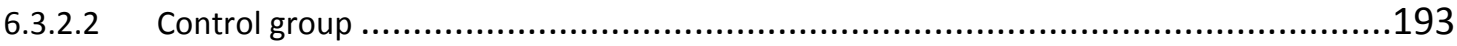

6.3.2.3 Number of illnesses and medicines in the last month .............................................194

6.3.2.4 Number of illnesses and medicines in the last six months....................................197

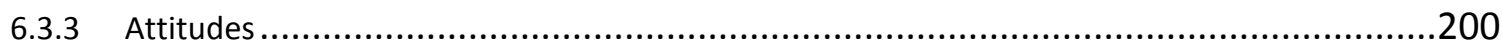

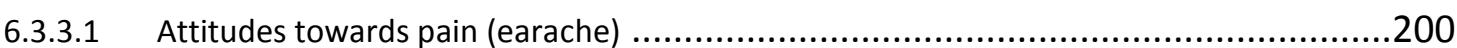

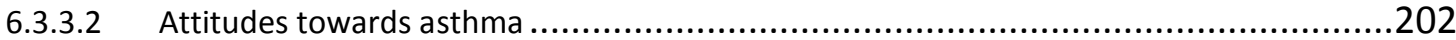

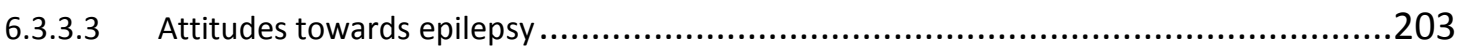

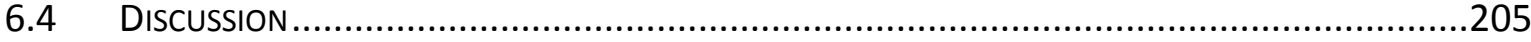

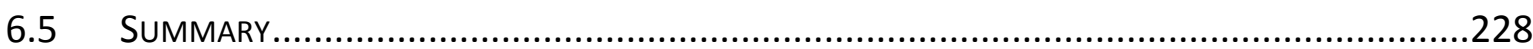




\section{CHAPTER 7: RESULTS AND DISCUSSION (GYPSIES AND TRAVELLERS)}

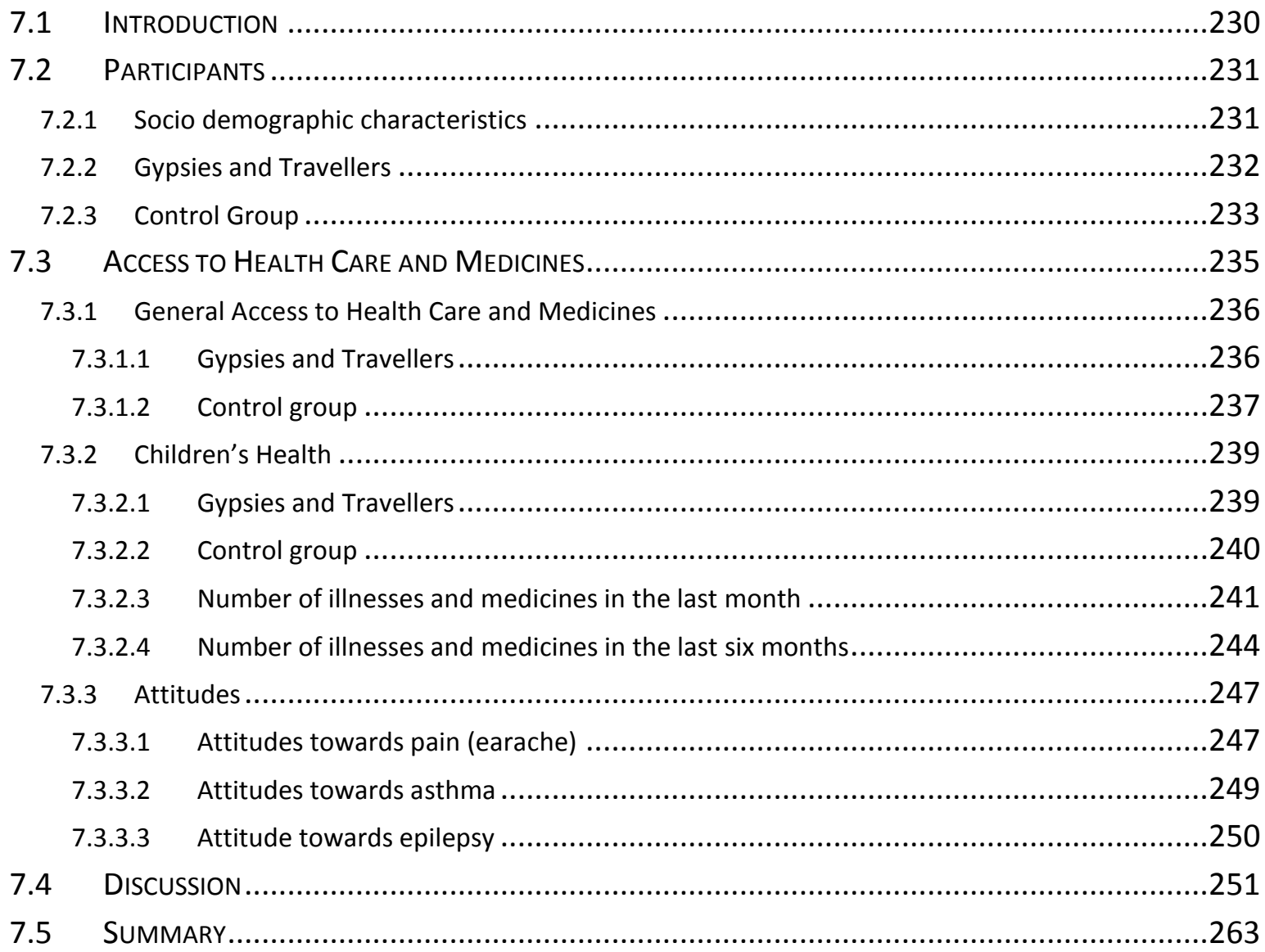

\section{CHAPTER 8: GENERAL DISCUSSION AND CONCLUSION}

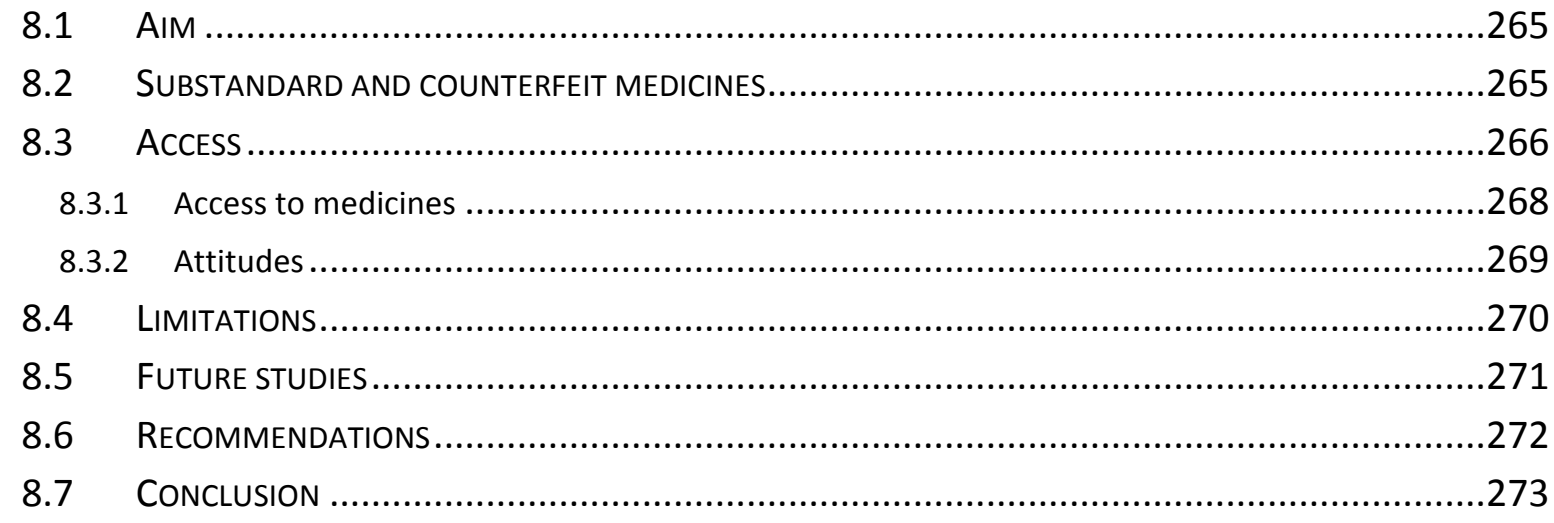

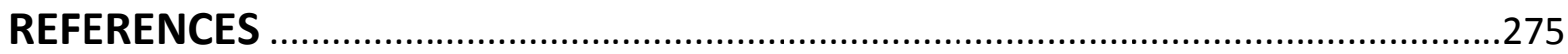

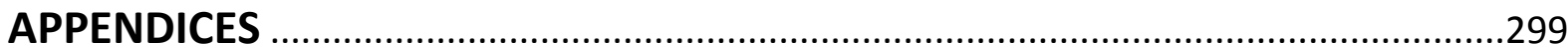




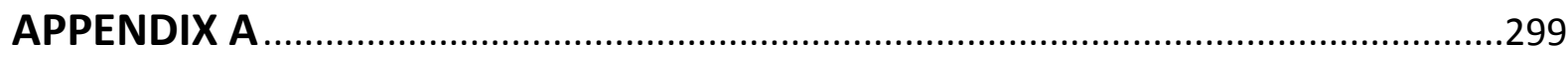

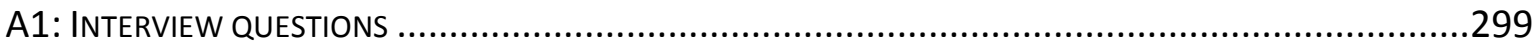

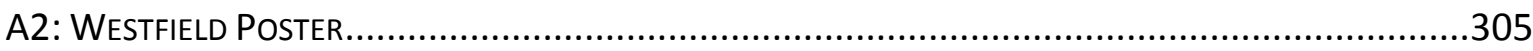

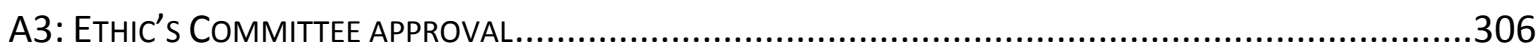

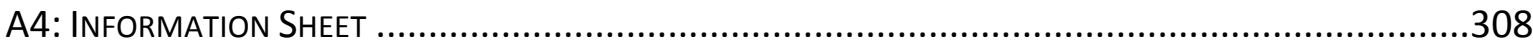

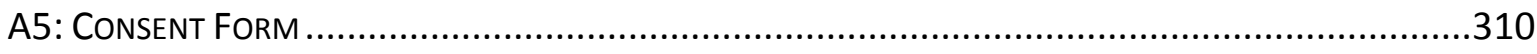

APPENDIX B

APPENDIX C

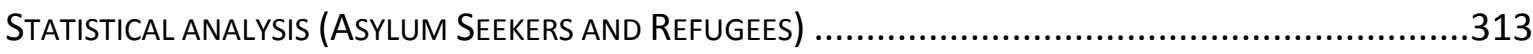

APPENDIX D

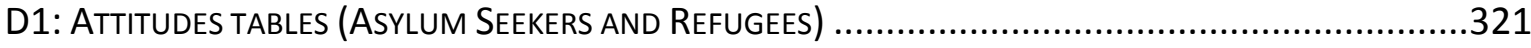

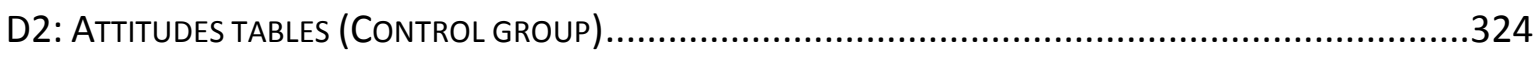

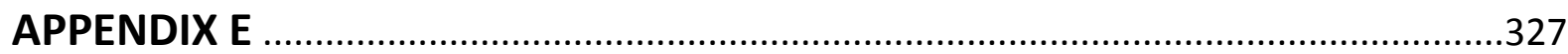

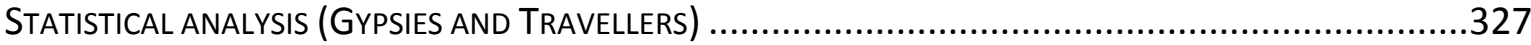

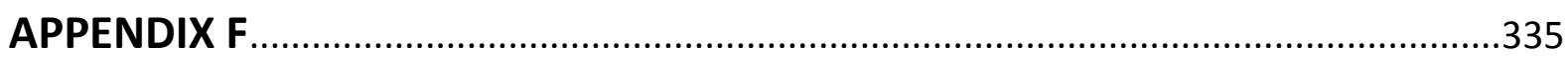

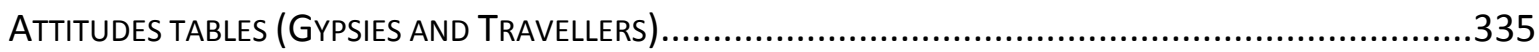




\section{LIST OF TABLES}

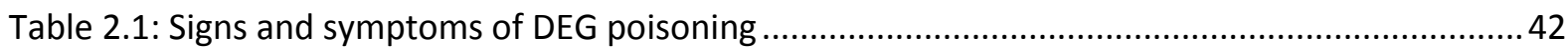

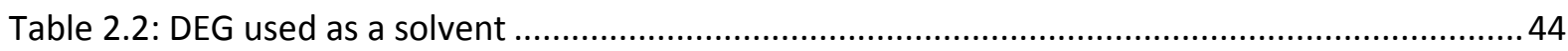

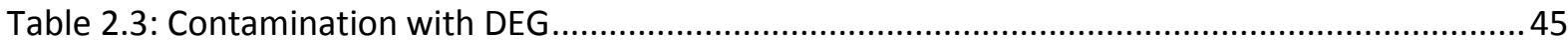

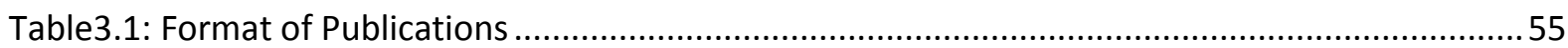

Table3.2: List of barriers to accessing health care and medicines ...............................................56

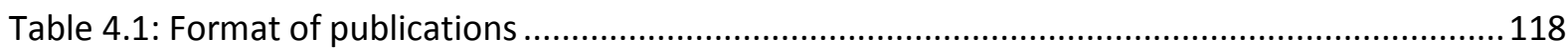

Table 4.2: Health status of Gypsies and Travellers ...................................................................123

Table4.3: Percentage of children completing the primary course of immunisation ..........................127

Table 4.4: List of barriers to accessing health care and medicines................................................. 129

Table 6.1: Country of origin of "at risk" group (Asylum Seekers and Refugees)..............................184

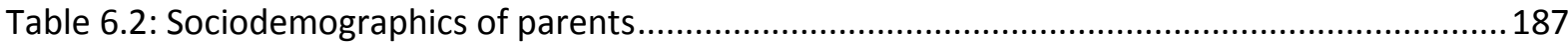

Table 6.3: General access to health care and medicines ................................................................... 191

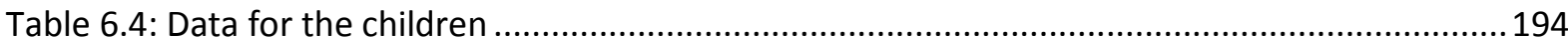

Table 6.5: Number of illnesses and medicines in the last month ................................................... 195

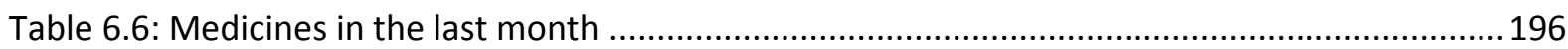

Table 6.7: Number of illnesses and medicines in the last six months ............................................198

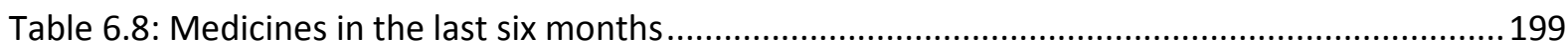

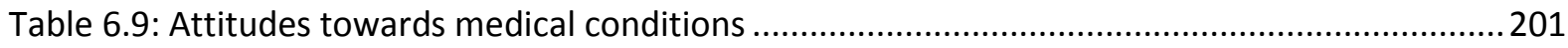

Table 6.10: Comparison across Refugee and Control group (Indepensdent ample t-test) ................313

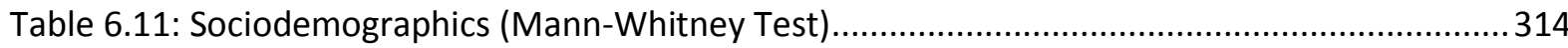

Table 6.12: General access to healthcare and medicines (Mann-Whitney Test) ...............................315 
Table 6.13: Data for the children (Mann-Whitney Test)

Table 6.14: Frequency of illnesses experienced during the last month ...........................................317

Table 6.15: Frequency of medicine used during the last month .....................................................317

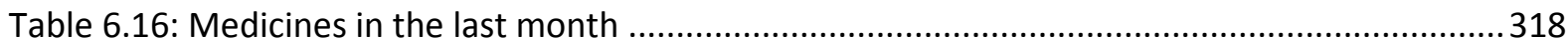

Table 6.17: Frequency of illnesses experienced during the last six months...................................318

Table 6.18: Frequency of medicine used during the last six months ............................................319

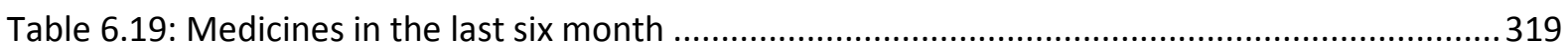

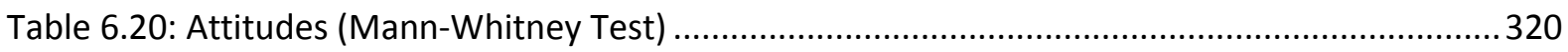

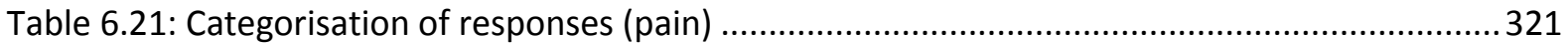

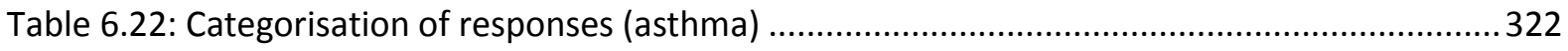

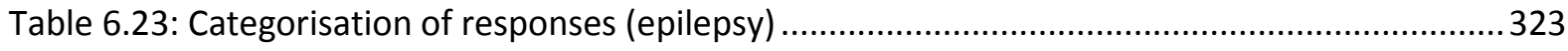

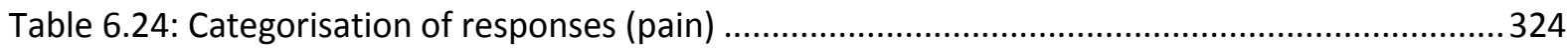

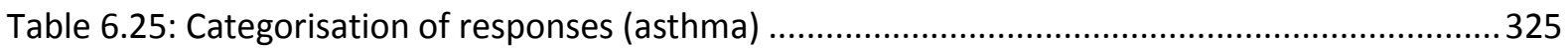

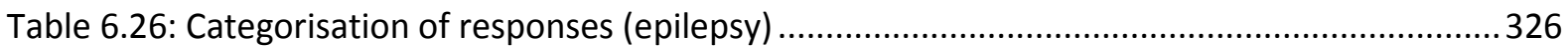

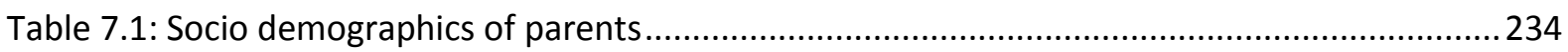

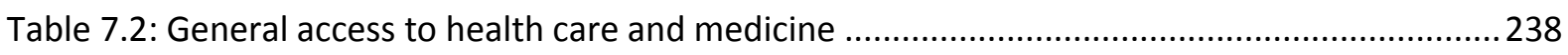

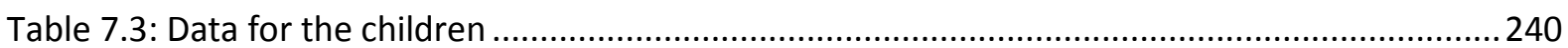

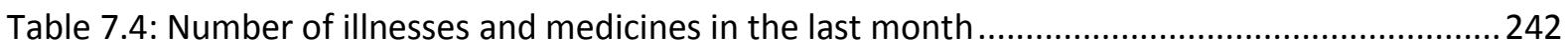

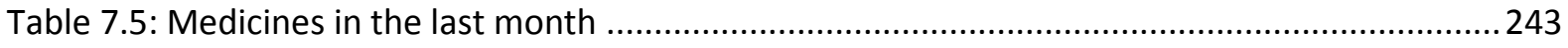

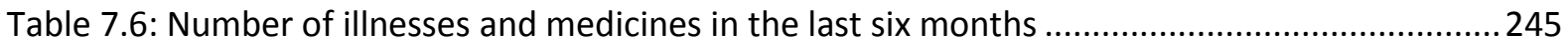

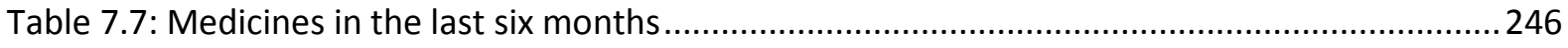

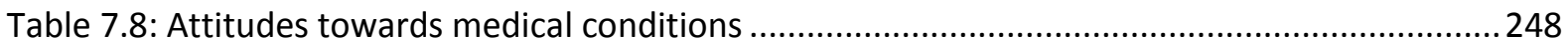

Table 7.9: Comparison across Traveller and Control group (Independent sample t-test) ..................327

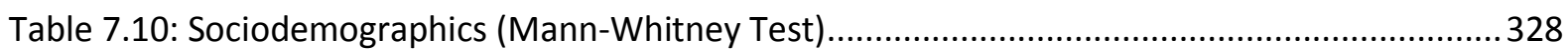

Table 7.11: General access to health care and medicines (Mann-Whitney Test) .............................329

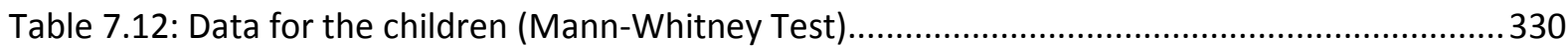


Table 7.13: Frequency of illnesses experienced during the last month

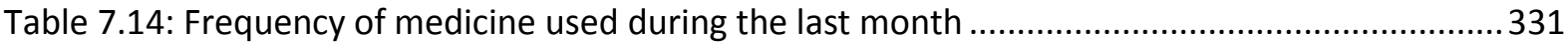

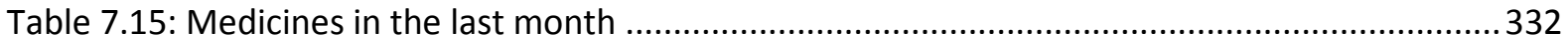

Table 7.16: Frequency of illnesses experienced during the last six months.....................................332

Table 7.17: Frequency of medicine used during the last six months .............................................333

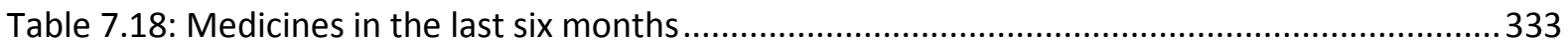

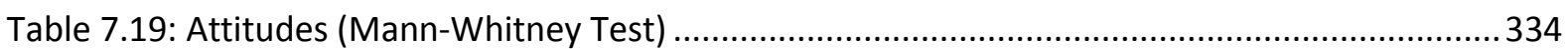

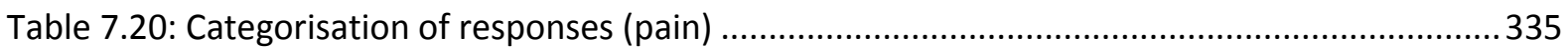

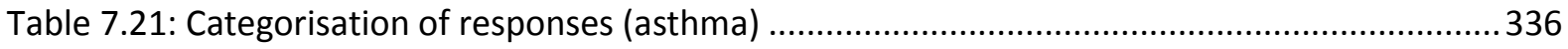

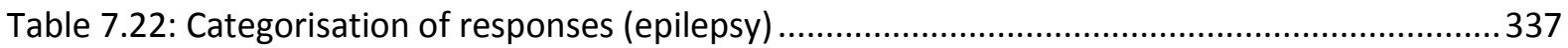




\section{LIST OF FIGURES}

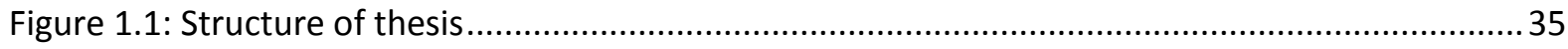

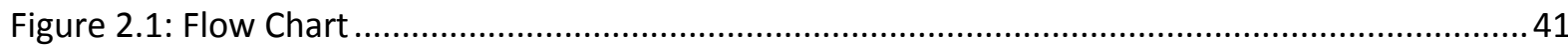

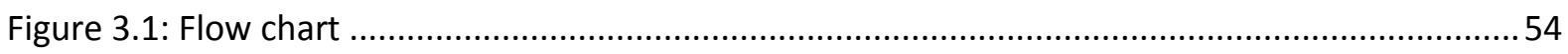

Figure 3.2: Asylum Applications submitted in UK 2006-2010.....................................................60

Figure 3.3: Top-10 population of asylum applications in UK 2009-2010.........................................62

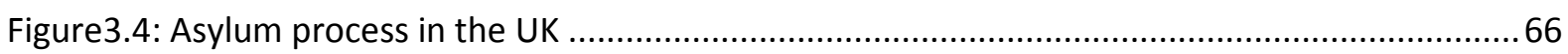

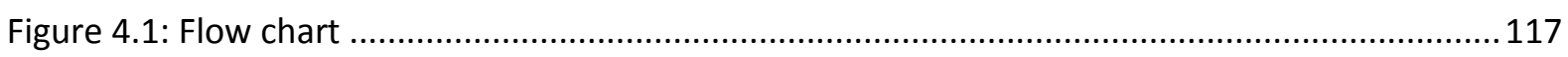

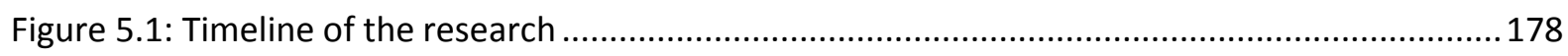

Figure 6.1: Reasons for leaving country of origin ................................................................. 185

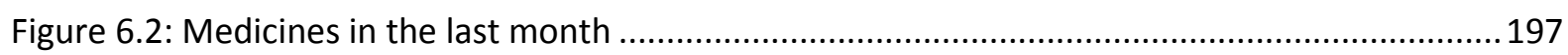

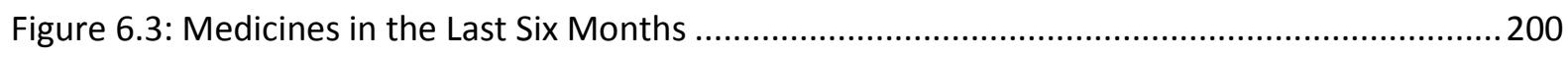

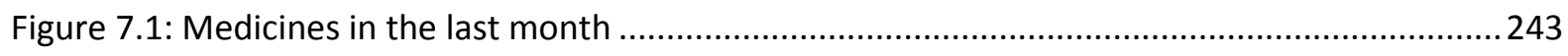

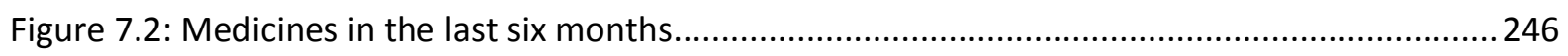




\section{CHAPTER ONE}

\section{GENERAL INTRODUCTION}

\subsection{Problems of Access to Medicines World-Wide}

The issue of children's access to medicines has been considered as one of major concern, because health care professionals recognise that a lack of access to essential medicines of assured quality continues to form significant risks to children(1).

It is unacceptable that thousands of children around the world still die needlessly every day because they do not have access to the essential medicines that could save them(2). In many different parts of the world children are still at high risk from many life- threatening diseases. Many children, for example, are not even immunised (3).

Medicines are an important component in treating diseases and in improving human health. They are one of the most cost-effective healthcare interventions in saving lives and alleviating the suffering of patients. 
Medicines must be effective, safe and of acceptable quality, as well as being used rationally to produce the desired effect $(4,5)$.

\subsection{Medicines for Children}

Accessing appropriate medicines for ill children has always been a significant problem. The challenges to develop safe, appropriate, and effective pharmacotherapy for children are still a major global concern (6). Children suffer different diseases from adults, such as bronchopulmonary dysplasia in neonates and bronchiolitis in infants, and effective treatments are often not available $(7,8)$.

The use of medicines for children is in general less evidence-based than for adults (1). It is recognised that few medicines are licensed for children, whereas most medicines are licensed for adult use. This is one of the reasons why off-label prescribing of medicines is more common for children than adults (9).

Unlicensed and off-label medicines are licensed medicines being used outside the terms of the product licence (10). For example, they may be licensed for adults but not for paediatric patients. Children suffer from different diseases from adults and therefore require different medicines (11). 
Unlicensed medicines may not have been subjected to the licensing process at all (10). The safety, efficacy and quality of these prescriptions therefore cannot be guaranteed, since no pharmaceutical company has performed any clinical trials on them. However, the terms off-label and unlicensed medicines do not necessarily imply disapproval of, or improper practice in, their use $(1,12)$.

Using off-label and unlicensed medicines for children is a matter of considerable concern within the United States and Europe (13). Many formulations dispensed in hospitals to treat children are considered as off-label or unlicensed medicines (10). For example, diazepam rectal solution, which has been used for children under one year of age is not licensed for this age group (14).

A study was conducted in five centres in Europe where 624 children were admitted to the paediatric wards and received 2262 prescribed drugs (14). About $46 \%$ of these drugs were off-label [872] or unlicensed [164]. Two thirds [421] of the inpatient children received off-label or unlicensed drugs.

More studies have been conducted in relation to medicines given to children (15). For example, studies conducted in the UK, Australia and 
New Zealand showed some improvements in children's access to medicines and the number of medicines licensed for children between 1998 and 2002, but a serious imbalance between children's and adults' access still exist in all three countries (16).

\subsubsection{Challenges of age and formulation}

The size of a dose administered to a child varies with age and weight (17), and therefore different formulations are required for children of different ages.

Formulations for children are needed in different ranges of concentrations, and different forms including liquids and solids. However, the availability of appropriate forms may be limited by factors such as solubility, chemical and physical stability, formulation microbiology and homogeneity. The volume and dose of liquid medicines may be limited by the solubility of the active ingredients of a drug in solvents or flavouring and sweeteners (17). The development of these formulations has also been limited by the financial returns for such a small market.

Appropriate formulations for children, such as suitable oral formulations, are essential in medical treatment. Such formulations result in better adherence to treatment and enable individualised dosing. Lack of 
availability of suitable dosage forms can impair children's access to safe medicines. (16).

The persistent problems of limited numbers of paediatric medicines and inappropriate dosage forms can result in difficulties in the availability and supply of appropriate medicines for children (18). Therefore, regulatory authorities and the pharmaceutical industry need to ensure that children have access to appropriate formulations of medicines $(19,20)$.

\subsection{WHO and Make Medicines Child Size}

The World Health Organisation (WHO) has taken many steps to map the global situation concerning children's access to, and use of, medicines. It has also designed specific strategies to fill existing gaps, and to raise awareness and accelerate action to address the importance of improved access to and availability of safe and specific medicines for children (1). WHO has launched a campaign in 2007, entitled 'Make Medicines Child Size' (21). A key feature of this campaign is the importance of access to health care and medicines for children, an area that has been inadequately explored (22). For example, world-wide two million children die each year from pneumonia $(3,23)$. The majority of these children would survive if they received an appropriate antibiotic. 
The World Health Assembly (WHA) discussed the topic of paediatric medicines in depth and the Department of Essential Medicine and Pharmaceutical Policies initiated many actions to lead to 'better medicines for children'. These actions include many aspects such as ensuring that existing and new medicines are safe for use with children, ensuring that requirements of labelling and licensing for medicines are upgraded, and ensuring that skills and resources are available to improve use of medicines in children (1).

\subsection{Regulation of Children's Medicines}

\subsubsection{The US regulations}

Several tragedies involving children have led to an increase in drug regulation in the US. In 1902, the contamination of diphtheria toxin with live tetanus bacilli led to the deaths of many children (24). Therefore, the Biologics Control Act was passed to ensure the safety and purity of vaccines. In 1939, at least 105 people, 33\% of them children, died after ingesting poisonous diethylene glycol mixed as a vehicle with sulphanilamide elixir and distributed for use without safety testing (24). This episode led to legislation by the Food and Drug Administration (FDA), which required new medicines to be tested for safety (25). Since this time the US has led the way in new legislation to promote the testing of all appropriate new medicines for children $(24,25)$. 
In 1997, the US Congress enacted the Food and Drug Administration Modernisation Act (FDAMA). It contained provision establishing economic incentives for the pharmaceutical industry to conduct paediatric studies. This was soon recognised to be an insufficient incentive therefore the 1998 Paediatric Rule was enacted. This required the pharmaceutical industry to test drugs and biological products for children. It applied to new licensing applications for active ingredients, dosage forms, indications, and routes of administration (24). This was an important change to try to ensure paediatric safety in drug dosing, and efficacy (24, 26).

In support of these initiatives, guidelines were passed by the National Institute of Health (NIH) to increase the number of child participants in federally-funded research (27). Consequently, the FDA was authorised by Congress to grant a six month extension to patent protection of new pharmaceutical products that were labelled for use in children. This rule was applied through the programme of paediatric exclusivity for pharmaceutical industries completing FDA-requested paediatric studies. The success of this programme led to an increase in paediatric drug studies, in addition to an increase in the number of drugs that had labelling changes for use with children. Consequently, the net economic return to the companies from the participation in this programme was high due to the extension to patent protection $(28,29)$. 
European regulations were strongly influenced by both the experiences of the US paediatric exclusivity and the European regulation in 1999 on orphan medicines (24). The major goal of the European regulation was the improvement of children's health in Europe, by improving the development of medicines, increasing information on the use of medicines with children and ensuring the appropriate evaluation and labelling of medicines $(24,28)$.

\subsubsection{European regulations}

After the US efforts at the end of the last century, European regulatory changes were seen as the start in improving knowledge of drugs given to children. In the latest development (2007) (30), the European regulation on paediatric medicines added a legal requirement that all commonly used medicines are tested on children. The regulation requires that the pharmaceutical company's paediatric investigation plan describes measures to develop an appropriate formulation for paediatrics and make its use more acceptable, safer, easier and more effective (30).

Within the January 2007 updated European legislation, new regulations were introduced to govern the authorisation and development of medicines for use in children aged 0 to 18 years (30). The European Medicines Agency (EMA) established a Paediatric Committee (PDCO) to support the legislation on children's medicines. Their aims are to ensure that there is scientific evidence for using medicines in children and that 
they have an appropriate formulation $(13,30)$. All these efforts set the scene for more developments affecting legislation covering the clinical trials for paediatric medicines in the $\mathrm{EU}(13,30)$.

\subsubsection{Access to medicines under International Human Rights Law}

Access to essential medicines is considered a basic human right. However, these essential medicines are often denied to poor people in low- and middle- income countries (31).

The lack of full access to essential medicines or vaccines due to economic problems raises new issues in human rights among both high income countries and the rest of low- and middle-income countries (31).

According to human rights principles, health care must be provided without distinction of any kind on the basis of ethnic group, race, religion, language, colour or any other status. A human rights framework also emphasises the importance of non-discrimination for marginalised and vulnerable groups. Moreover, it sets out the connection between access to medication and the right to adequate standards of health care (32).

Both the Convention on the Rights of the Child and the European Convention for the Protection of Human Rights state that access to 
appropriate medication is a critical component of children's rights to standard health(32). The international framework of child rights also, plays a major role in taking action to improve child health and ensure that all children have the same opportunity to access necessary medical assistance and health care (33).

All the efforts in this area go towards improving health care services and access to appropriate medication. Equality and human rights legislation have been passed by the British government to ensure that health staffs do not discriminate against individuals because of their race, religion or colour, and that equal opportunities exist for optimum treatment. This legislation gives everyone the right to equal treatment (34).

\subsection{Essential Medicines}

\subsubsection{Definition of essential medicines}

Essential medicines are considered as fundamental to every public health programme (35). The main aim of these medicines is to reduce morbidity and mortality rates in all countries around the world. Most of the important public health programmes which mainly depend on essential medicines include child health and survival programmes, control of epidemic diseases such as tuberculosis and malaria, antenatal care, and medications for respiratory and enteric pathogens (31). 
Essential medicines are defined, by the World Health Organisation (WHO) as those "medicines that satisfy the priority health care needs of the population" (36). They are selected according to strict criteria:

- evidence of safety and efficacy

- prevalence of disease

- with due regard to cost effectiveness.

The first WHO Model List of Essential Medicines for Children, the purpose of which was to 'make medicines child size', was published in October 2007. In compiling the list, preparatory work was carried out by a special subcommittee formed to work on the selection and use of essential medicines based on the WHO treatment guidelines. The subcommittee also emphasised the importance of establishing mechanisms to control the prices of these essential medicines for children $(1,18)$. The WHO library for essential medicines is considered to be one of the most valuable information databases for drug and therapeutic committees in all member states, international organisations and health insurance organisations $(37,38)$. Model lists of essential medicines are also used by the United Nations High Commission for Refugees (UNHCR), the United Nations International Children's Emergency Fund (UNICEF) and many other non-governmental organisations (NGOs) to raise awareness of, and to promote, the availability, affordability, accessibility, and quality of medicines (38). 
Careful selection of essential medicines leads to better health care, better access to medicines and acceptable prices. All essential medicines should be available at all times in sufficient amounts and suitable dosage forms, with assured quality and at an affordable price to all individuals in the community(31).

\subsubsection{The concept of essential medicines}

The concept of essential medicines is international. It was launched with the first publication of the Model List of Essential Medicines in 1977 by WHO (37). Since then the List remains a strong tool within public health and has been revised and updated every two years (38). Both its process and the content by which it is updated are intended as models for lowand middle-income countries. Today, many of these countries have their own national list of essential medicines, most of which have been updated in the past five years. The original concept of essential medicines is seen nowadays as a breakthrough in global public health (37, 38).

It is recognised that in many low-and middle-income countries the lack of a free and accessible health care system and poor access to essential drugs result in many children being deprived of appropriate treatment. Today, over one-third of the world's population, and over half of the 
poorest people in Africa and Asia, still suffer from lack of access to essential medicines (1).

\subsubsection{Problems of access to essential medicines in low-and middle-income countries}

Essential medicines for the main diseases should be both available and affordable in the low- and middle-income countries. Problems related to access to essential medicines in many low-and middle-income countries around the world include the lack of availability. This is due to prohibitive cost, poor quality and counterfeit medicines, and the potential impact of the agreements of the World Trade Organisation (WTO) on drug availability world-wide. These agreements resulted in patents for many medicines which invariably are associated with higher prices and often result in such medicines being too expensive for poor countries. All these issues may result in significant difficulty in accessing essential medicines in low- and middle-income countries $(31,39)$. The following sections highlight these issues in detail.

\subsubsection{Withdrawal of essential drugs}

Essential medicines which have been used for the treatment of diseases, including tuberculosis and African trypanosomiasis, have become unavailable because they are no longer considered to be profitable (31). Many old essential medicines are no longer available in high-income 
countries. An example of this was in Nigeria in 1996 when more than 100,000 cases were reported in an epidemic of Neisseria meningitis. An effective treatment for meningococcal meningitis is chloramphenicol in oily suspension. This medication is a tenth of the cost of ampicillin. Its simple administration orally makes it a suitable treatment for patients in rural areas in low-income countries. However, the manufacturer (Roussel-Uclaf) stopped producing chloramphenicol in oily suspension in 1995 and the availability of this product is no longer guaranteed $(31,39)$.

\subsubsection{Prohibitive costs}

The purchase of medicines represents a major expenditure of total health spending for both individuals and governments (31). It is also one of the main causes of household impoverishment in high-income countries as well as low- and middle- income countries. The high price of medicines affects access to them, even in countries such as the UK which have universal insurance with co-payments (40).

Prohibitive pricing is another issue in access to essential medicines in many low- and middle-income countries (31). This is well known with regard to acquired immunodeficiency syndrome, which is best treated with antiretroviral medicines that are, however, often inaccessible due to their high cost. New vaccines such as the ones against Haemophilus and hepatitis B are other examples of essential medicines which are not 
affordable to many of the poorest and most at risk populations around the world, due to their high cost $(31,41)$.

Since 1979, Shigella dysenteriae type 1 has been the cause of large epidemics in the poorest countries in Africa. Unfortunately, this disease became resistant to nalidixic acid, the traditional medication, and the only effective treatment today is fluoroquinolones (31). Fluoroquinolones are approximately ten times more expensive than nalidixic acid ( $\$ 20$ vs \$2) per course of treatment (31). Without introducing regulations and changes into the pharmaceutical market, significant improvements will not be achieved.

\subsubsection{Patent of medicines}

Patents of pharmaceutical products give the owners the exclusive right to make, sell and distribute their products. The price of a medicine only comes down when the patent expires. Therefore, essential medicines are initially less affordable for the poor in low- and middle-income countries (31).

Furthermore, access to essential medicines remains poor, mainly due to inadequate purchasing power and infrastructure (transportations to clinics, and storage places) (31, 39). Directors of pharmaceutical industries in high-income countries also indicate that the lack of 
protection for innovations is the main reason for their limited investments in low- and middle-income countries (31).

Pharmaceutical companies must be compelled to choose whether to protect their patents of new medicines in high-income countries, or in low- and middle-income countries, but not have the option of both. For diseases which affect countries all around the world like cancer, companies could choose to protect their patents in high-income countries. However, for those diseases which almost entirely affect low- and middle-income countries like malaria, they could choose to protect their patent in high-income countries only, so the treatment cost would not be prohibitive(34, 39).

Formerly, many low- and middle-income countries and some high-income countries excluded medicines from being patented, even if they met the criteria of being inventive and new. Today, all these countries are members of the WTO and implement the agreement to trade-related aspects of intellectual property rights (TRIPS) in their systems. This agreement probably has the greatest effect on the access to medicines. It set some standards, such as 20 years of patent for pharmaceutical products, by dealing with the laws of patent $(29,42)$. By establishing the priorities of public health, expensive medicines similar to other medicines which are supplied by international organisations like UNICEF must now be provided to poor countries. This can be achieved by cooperation 
between pharmaceutical companies and governments, or between the companies themselves. For example, Bayer laboratories and Medecins Sans Frontieres (MSF) reached a special agreement in 1997 to produce ciprofloxacin treatment for 50,000 patients with a price of $\$ 2$ per treatment. Such examples demonstrate the ability of pharmaceutical companies to find short-term solutions between themselves $(31,39,41)$.

\subsubsection{Problems of access to essential medicines in high-income countries}

The increasing demand for medicines and their rising costs are international problems not limited to low- and middle-income countries. Over the last decade, expenditure on pharmaceutical products in the USA rose dramatically due to an ageing population, an increase in the basic cost of medications (5-6\% per year) and consumer advertising (38). Problems of access to medicines and health care in high-income countries are related to living in rural settings, belonging to certain minority ethnic groups, socioeconomic status and communication issues (43). Immigrant populations in some high-income countries are affected disproportionately by the lack of health insurance and their inadequate knowledge of the health care system in the host country $(43,44)$. More recent research in North America has revealed that in both the United States and Canada, children of different ethnic groups or without insurance may be less likely to receive medicines(45-47). 


\subsection{The Global Problem of the Quality of Medicines and Counterfeiting}

The quality of medicines is a comprehensive concept which includes the identity, purity, efficacy and safety of all chemical products contained in each medicine. History has shown that poor quality products still exist in both low- and high-income countries. Therefore, the quality of medicines is a major concern for drug regulatory agencies, health organisations and healthcare professionals $(48,49)$.

The assessment of drug quality is a very complex process. Scientific regulation is essential from the pharmaceutical manufacturing operation till the pharmacovigilance stage (49). Poor manufacturing practices or inappropriate storage can result in products of poor/low quality (50). For this reason all governments should make it a priority to regulate the process of drug manufacturing, storage and distribution. Medicinal preparations must be prepared according to good manufacturing practices (51). These standards assure the quality of administered medicines. The three most important criteria for medicines are quality, safety and efficacy. These criteria are used by governments to regulate pharmaceutical products (52), and should be verified at all stages throughout all the processes of manufacturing, distributing, storage and dispensing. Such specifications are cornerstones of the functioning of each public health care system $(48,53)$. 
Medicines, unfortunately, are not exempt from counterfeiting (54). The problem of substandard and counterfeit medicines has a long history. In earlier centuries, herbal medicines were often adulterated; for example, Valeriana officinalis root was adulterated by mixing congeners with root to treat cholera which reduced their effectiveness and led eventually to loss of faith in genuine treatment (55). In the $17^{\text {th }}$ century, the first effective treatment of malaria, Peruvian Cinchona bark (48), was adulterated with aloes and other astringent barks. Huge demand from Europe for the bark, because of endemic malaria, precipitated this adulteration. After a while, loss of confidence in this herbal medicine induced a decrease in demand and a price decline, leading to a temporary ruin of the exporting markets (48-50).

Any manufactured medicinal product is at risk of imitation. Such medicines are often marketed under the name of the original commercial product (54). Pharmaceutical companies worry about the imitation of their products because they may lose the confidence of both prescribers and patients. Since these counterfeit products may be difficult to distinguish from the genuine products, they present great danger to the public and patients' health (54). 
The dangers to public health of counterfeit and substandard drugs have been well documented and crucially the problem has now reached global proportions due to easy access of these products through internet technology and the ease of transportation and travel (54).

Counterfeiting is the mimicking of an original product (56). The WHO defines counterfeit medicines as those which are mislabelled deliberately and fraudulently with respect to identity or source $(51,57)$. Counterfeit medicines may include products without active ingredients, with insufficient active ingredients, the wrong ingredients or even the correct ingredients. They may also include products with fake packaging (58).

Substandard medicines are genuine medicines produced by legitimate manufacturers that fall short of meeting the required quality specifications (50). Substandard medicines may contain less or even more of the active ingredient than specified on the package. Unfortunately, many low- and middle-income countries do not possess sufficient resources (financial, technical, or human) to apply appropriate manufacturing standards and controls which safeguard medicines. Furthermore, some pharmaceutical companies in some industrialised countries such as India and China tend to apply fewer restrictions to manufactured products designed for exportation (56) because this lowers 
the cost of production, thereby giving them a competitive advantage in the global market.

For example, Malaria is an infection which is curable when an antimalarial drug with the correct quality is taken. A recent study by Nayyar et al (59) reported that one-third of anti-malarial medicines were fake. The study included anti-malarial drugs from 28 countries sold between 1999-2010. $36 \%$ of 1437 tested drugs from Southeast Asia and $20 \%$ of tested drugs in the sub-Saharan Africa were fake (59).

\subsubsection{How big is the problem?}

The WHO has said that it is difficult to estimate the level of medicinal counterfeiting accurately (60). $15 \%$ of all medicines worldwide are believed to be substandard or counterfeit (54). A wide variation has been noticed in the prevalence of counterfeiting between countries. In the markets of low- and middle-income countries, $10-30 \%$ of medicines are estimated to be counterfeit (60). This percentage increases with the high demand during epidemics and the presence of poor drug regulations. For example, approximately $30 \%$ to $50 \%$ of an important anti-malarial treatment 'Artesunate' bought in Southeast Asia was counterfeit (54). Moreover, a high percentage of discovered counterfeit medicines in central Africa were the antiretroviral agents, such as lamivudinezidovudine and stavudine-lamivudinenevirapine(54). 
In contrast, in high-income countries, the percentage of counterfeit medicines is estimated to be only $1 \%(60)$. This is clearly related to the strict enforcement of drug regulations in countries in North America, European Union, and Japan which enhance protection against counterfeiting(60).

\subsubsection{Underlying causes of counterfeit and substandard medicines}

The prevalence of counterfeit medicines is a global problem(60). Intellectual Property (IP) Laws and the global markets of medicines create the opportunity for counterfeit medicines. Counterfeiters always follow the money. High pricing ratios attract them to counterfeit expensive patented and trademark medicines (58).

In sub-Saharan Africa many counterfeit and substandard medicines are sold at lower prices than expensive patented products. For example, in the US the triple combination of antiretroviral treatment costs over $\$ 11,000$ per year. However in Africa, unlicensed generic companies sell an annual supply of a similar but poorer quality treatment for $\$ 244$ (a "pricing ratio" of 45:1) (58). Others have found that vaccines and contraceptives are much more highly priced (pricing ratio 200:1). Despite the efforts of relevant pharmaceutical companies and IP laws, criminal counterfeiting is still present (58). 
The increasing pharmaceutical trade via the Internet has a significant impact on the entry and availability of counterfeit products into the international markets (61). This facilitates the availability and the spread of counterfeit medicines worldwide.

Less quality assurance in low-and middle-income countries are the most common reasons for producing substandard medicines (50). Poor quality control, a limited number of Good Manufacturing Practice (GMP) certified manufacturers and the challenges of limited resources result in a widespread use of substandard and counterfeit drugs and few childfriendly formulations in these poor countries $(1,50)$.

The problem is not confined to low- and middle-income countries. Individuals from high-income countries are at risk, especially those who purchase substandard or counterfeit medicines from poorly regulated markets when travelling or through ordering via the Internet (61). Recently, in North America, a number of drugs such as atorvastatin, filgrastim, growth hormone, erythropoietin, paclitaxel, and gemcitabine were found to be counterfeit (54).

Unfortunately these poor quality products still exist in both low-income and high-income countries. In the UK, counterfeit Serotide 250mcg, 
Plavix 75mg, Zeprexa 10mg, and Lipitor 20mg have been reported recently (62). To date little evidence has been identified that NHS patients are at risk from counterfeit medicines (60).

There are many other reasons for the spread of substandard and counterfeit medicines worldwide. High costs often coupled with a shortage of genuine products, additionally, lack of legislation, inadequate liaison between drug regulatory authorities, police, customs, and a lack of publicised information among health professionals and the public, all encourage the counterfeiting of medicines and make detection difficult $(48,52)$. Presence of counterfeit and substandard drugs in the international markets is a result of ineffective regulations and inadequate quality control by both importing and exporting countries (51). For this reason all governments need to make the regulation of drug manufacturing, storage and distribution a priority.

\subsubsection{Global efforts for detecting counterfeit medicines}

Drug regulatory authorities and the pharmaceutical industry have been criticised for not doing enough to tackle the problem of counterfeit medicines (54). In the mid-19 $9^{\text {th }}$ century, widespread adulteration of medicines in the UK and USA, particularly quinine, enhanced both the regulation of medicine's trade, and detection techniques of counterfeit medicine (52). The first resolution against substandard and counterfeit 
medicines was adopted by the WHA at an international health meeting in $1988(50,63,64)$.

In the UK, regulatory guidelines were introduced in order to deal with counterfeit medicines. The Trademark and Copyright Act was also passed in 1988 to protect owner copyright and patent (54).

A cooperation between the MHRA and the Royal Pharmaceutical Society creates a system for checking random samples both from pharmacists' shelves and during their inspections of the facilities of manufacturers and distributers. The Medicines Testing Unit of MHRA and the Defective Medicines Report Centre (DMRC) collaboratively analyse and assess these collected samples in order to detect counterfeit medicines. The MHRA has also collaborated with the Royal Pharmaceutical Society to publish guidance for helping pharmacists to ensure the security of a legitimate supply chain and to recognise counterfeit medicines (60).

\subsubsection{Information sharing on counterfeit medicines}

Pharmaceutical companies often keep the information they have about counterfeit medicines secret. They believe that informing the public about counterfeit medicines deters them from taking genuine medications (54). 
It is difficult to obtain factual data on the extent of the drug counterfeiting problem. Unfortunately, information on the epidemiology of counterfeit medicines is also hidden from the public by governmental agencies. Health workers and the public do not have access to the databases which would tell them which products are being counterfeited at any particular time (54).

Legal pressure on the pharmaceutical industry to take more responsibility for informing the public about the counterfeiting of their products has increased. Fortunately, some noticeable changes have occurred. The Pharmaceutical Security Institution has been established under the authority of the International Federation of Pharmaceutical Manufacturers Association (IFPMA) to investigate the incidence of counterfeiting and report their findings. Most of their reports are only provided to the pharmaceutical industry. However, they should make their information available both to the competent authorities to enable them to take action, and, ideally to the public (54).

In the UK in 1989, after discovery of counterfeit Ventolin inhalers for asthma, the British Department of Health and Glaxo Wellcome pharmaceutical company faced strong criticism for hiding information from the public. In the UK it has been suggested that a charge of 'corporate killing' should be applied to pharmaceutical companies who do 
not take responsibility for alerting the public to counterfeit products which may contribute to the deaths of patients (54).

In the USA in 2005, the Partnership for Safe Medicines started an information programme to alert the public to counterfeit medicines. This indicates the importance of reporting unexpected therapeutic failure, in case it is related to substandard or counterfeit medicines $(48,63)$.

\subsubsection{Possible actions against counterfeit problem}

The quality of purchased pharmaceutical products is now accepted as an important issue (49). Global efforts should be made to combat counterfeit drugs and ensure that high quality drugs are readily available (61).

Industry should collaborate with governments and support them financially and technically; and share their information in order to curb drug counterfeiting (54). Moreover, the availability of inexpensive or even free essential medicines, with international technical or financial support, will contribute to prevent the spread of counterfeit medicines $(52,63)$.

With the high prevalence of counterfeit medicines, regulatory authorities recognise that they have to be stricter in identifying areas of risk and 
eradicating these illegal products (61). Drug regulators in each country should have analytical laboratories for testing suspect samples. Collaboration with police forces and customs to create a network for exchanging relevant information may help to detect the illegal importation or exportation of counterfeit and substandard pharmaceutical products (54). Low- and middle-income countries with limited resources must make the effort to verify the quality of imported medicines in order to reduce the rate of mortality and morbidity caused by substandard and counterfeit medicines $(51,53)$.

Every person who deals with medicines should be alert. Drug prescribers and pharmacists should report any incidence of ineffectiveness or absence of quality to the national adverse drug reactions monitoring system(54).

\subsubsection{Counterfeiting threat}

\subsubsection{Pharmaceutical innovation}

Drug counterfeiting is a concomitant risk to innovation. It is growing rapidly in the global pharmaceutical markets. In 2000, the value of pharmaceutical counterfeiting in the EU was estimated at around $€ 1.5 \mathrm{bn}$. In 2003, it had been estimated by the UK-based Anti-Counterfeiting Group that pharmaceutical companies lost $5.8 \%$ of their annual income to drug counterfeiting. Recent estimates of the global market for 
medicines indicated that it exceeded $\$ 500 \mathrm{bn}$, and the annual loss of this market from counterfeiting may be over $\$ 30$ bn (58). If true, drug counterfeiting must be recognised not only as a major threat to public health care, but to innovation also. Therefore, criminal counterfeiting must be challenged (58).

\subsubsection{Therapeutic treatments}

Substandard medicines may have a detrimental effect on the success of treatments. This is mainly due to the complete absence of quality assurance during their manufacturing process. Many low- and middleincome countries in particular suffer from insufficient financial, technical or human resources to apply such standards. Therefore, they are more likely to have substandard and counterfeit products on their markets (54).

In many low- and middle-income countries, treatment failure has been linked to the use of substandard and counterfeit drugs. It has been estimated that malaria kills $1,000,000$ people every year in Africa, predominantly children under five (54). It is largely acknowledged that the high percentage of substandard or counterfeit anti-malarial drugs contributes to these deaths (52).

Serious implications for health may arise from poor quality medicines, such as drug resistance, adverse drug reactions and treatment failure 
(50). For example, the poor quality counterfeit pyrazinamide and rifampicin was one of the reasons for the common resistance of Mycobacterium tuberculosis $(48,63)$.

The high prevalence of substandard or counterfeit anti-infective medications containing a subtherapeutic quantity of active components, exacerbates the increasing rate of drug resistance (52). In Burma, substandard cotrimoxazole and chloramphenicol may be the reason for the resistance of typhoid to these antibiotics. These negative therapeutic results will lead eventually to the failure of treatment and increase the demand for the development of new treatments (63).

\subsubsection{Health}

The prevalence of counterfeiting appears to be increasing and responsible for a large impact on public health. It is a major cause of unnecessary morbidity and mortality in poorer countries (54). The most vulnerable and poorest people in low- and middle-income countries are at the greatest risk of counterfeit drugs because these countries have the weakest drug regulatory programmes (61).

The threat of counterfeit medicines on patients and public health are difficult to evaluate and quantify. In 2001 , it was estimated that 192,000 patients were killed in China by counterfeit medicines (54). Chinese 
authorities investigated 480,000 cases of counterfeit medicines estimated to cost $\$ 57 \mathrm{~m}$ (US). Consequently, they closed 1300 factories involved in this tragedy (54). This gives an indication of the scale of the problem and the attendant health risk.

Vaccination programmes in many low- and middle-income countries may be jeopardised by counterfeit vaccines. In 1995, Niger received a donation of meningitis vaccines from Nigeria. Local health authorities working with Medicines Sans Frontieres (MSF) discovered these vaccines were counterfeit after more than 60,000 people were inoculated with fake ones with no traces of active product (31).

\subsubsection{Children's access to safe medicines}

The problem of access to safe essential medicines in many low- and middle-income countries is often associated with substandard and counterfeit medicines (52). The following tragedies involving drug counterfeiting indicate the scale of the problem and the need to apply quality control on drug manufacturing to ensure drug safety and efficacy for children (51). A high percentage of deaths in children around the world are associated with acute infectious diseases treated with fake paediatric formulations (65). Therefore, counterfeit medicines are considered to be a serious threat to children worldwide $(66,67)$. 
History has indicated that replacing or adulterating intended components with toxic ones is responsible for several major incidents of severe mortality and morbidity in both adults and children (54). The catastrophic results which occurred during the last few decades after giving medications containing the industrial solvent diethylene glycol (DEG) are clearly illustrated by the large number of deaths $(51,64)$.

In this thesis, I will explore the effect of substandard and counterfeit medicines containing diethylene glycol (DEG) in children. A systematic literature review will be performed in order to identify all cases and provide guidance to health professionals to hopefully identify future cases quickly.

Problems with acccess to health care and medicines are well recognised in some developing countries and in developed countries (45-47). Accessibility is dependent on attitudes towards childhood illness as well as access to health professionals. For example, a health professional/parent who does not consider that a child is in pain is highly unlikely to ensure that the child receives analgesia. Medical conditions such as epilepsy are, unfortunately, associated with a considerable degree of stigma in certain societies. Parents may therefore choose not to have their child treated (68-70). 
We therefore also aimed to study two groups of children who might be less likely to have full access to medicines and health care than others. These are: (1) children of Asylum Seekers and Refugees; (2) children of Gypsies and Travellers. The Royal College of Paediatrics and Child Health have identified these two groups as children who are likely to experience inequalities in their state of health (71) resulting from significant problems in accessing health care and medical treatment $(72,73)$. There have been relatively few studies looking at access to health care for children from these groups and to date there have been no studies in the UK on whether these children receive satisfactory drug therapy.

The research reported in this thesis investigates whether children from the "at risk" groups (children of Asylum Seekers, Refugees and Traveller communities) are likely to receive fewer medicines than other children. It seeks to fill a gap in the literature regarding children's access to medicines and analyses the impact of identified factors on their access to health care and medical treatment $(43,73,74)$.

My study aims to identify the potential barriers to access to safe medicines, then determine whether they are due to problems in relation to access to health care. It also will explore attitudes towards the treatment of medical conditions such as pain, asthma and epilepsy. 
The results of my study will have direct implications for healthcare services and seeks to develop better health care for children (67). This study will also give individuals who have difficulty accessing health care the opportunity to state their opinions on any barriers they have encountered to their children receiving the medicines that they require.

\subsubsection{Layout of thesis}

This thesis is structured in eight chapters, including the present chapter, summarised as follows and in Figure (1.1). 
Figure 1.1: Structure of thesis

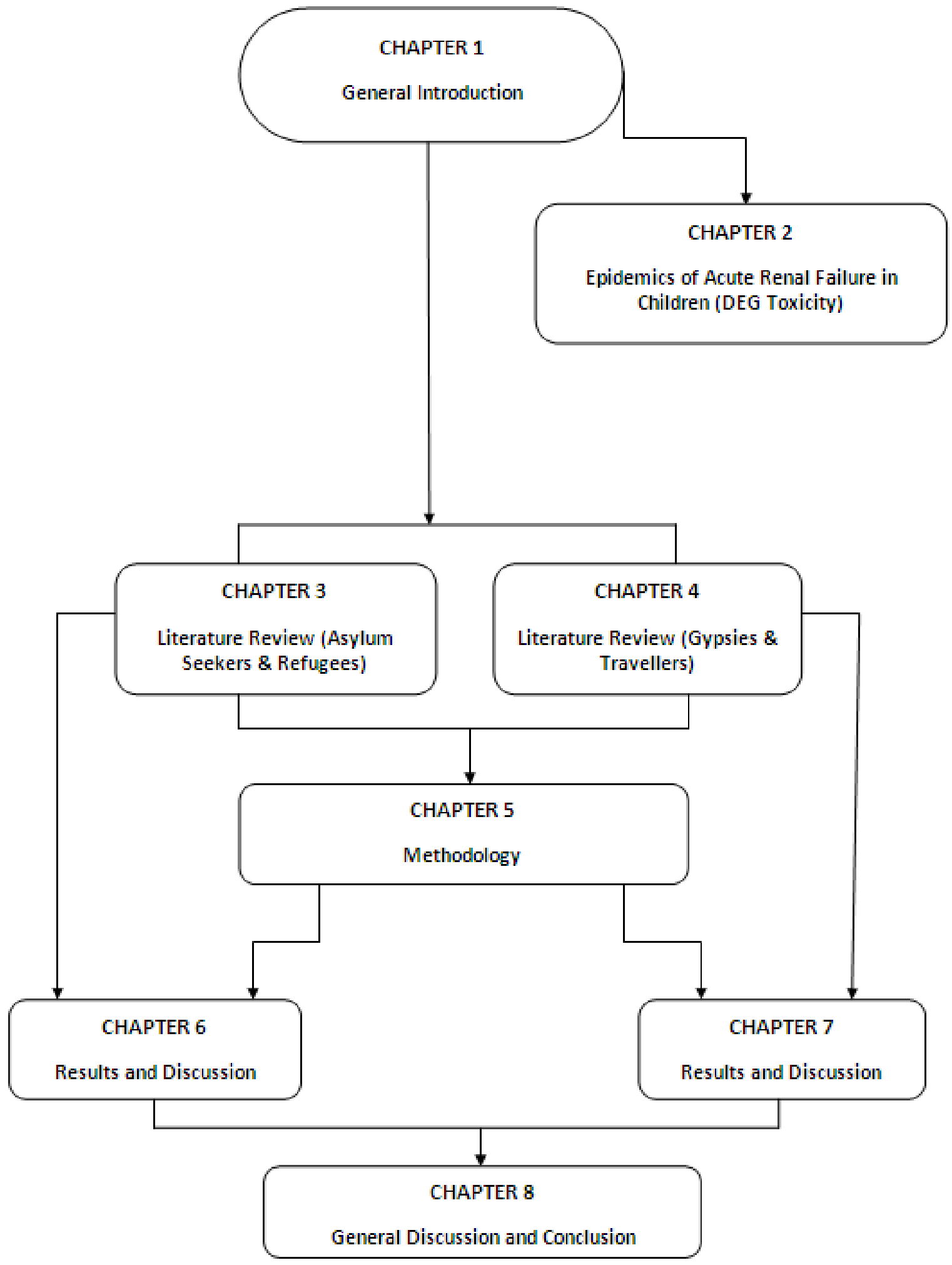


Chapter 1 - "General Introduction": this acts as a preface to the thesis by introducing the key concepts of relevance to the research, defining the problems of children's access to medicines, highlighting the concept of drug quality, defining the problem of drug counterfeiting and outlining the aims and objectives of the study and the structure of the thesis.

Chapter 2 - "Diethylene Glycol Toxicity in Children": this presents a review of all the relevant publications to date so as to summarise all the main aspects of DEG poisoning including epidemiology, toxicity, mechanisms of toxicity, clinical features, diagnosis and management. It also demonstrates what can happen in the absence of drug quality control.

Chapter 3 - "Problems of Access to Health Care and Medicines for Asylum Seekers and Refugees - Literature Review": this discusses the published literature concerning barriers to health care for Asylum Seekers and Refugees. It starts with a general overview first of their background, then of the barriers they might encounter in accessing health care including cultural, communication, financial and health problems.

Chapter 4 - "Problems of Access to Health Care and Medicines for Gypsies and Travellers - Literature Review": this presents the literature review related to the current investigation into the "at risk" groups Gypsies and Travellers. The chapter discusses the relevant published 
literature and addresses all the aspects of, and barriers relating to, their access to health care.

Chapter 5 - "Methodology": this concerns the data-gathering instrument for this study. The last parts of this chapter describe the interview schedule and guide, the ethical considerations and analysis processes.

Chapter 6 - "Results and Discussion": this presents and discusses the data gathered from the interviews of the Asylum Seeker and Refugee parents who were involved in this study.

Chapter 7 - "Results and Discussion": this presents and discusses the data gathered from the interviews of the Gypsy and Traveller parents who were involved in this study.

Chapter 8 - "General discussion and Conclusion": this brings together all the key findings from this work. The discussion considers and highlights the main research findings and their wider implications, while the conclusion summarises them. It also offers recommendations and suggestions for both future research and further improvements.

\subsection{Summary}

Children have the right to access to safe and effective medicines. This means that work needs to be done to improve the availability of safe standard paediatric formulations and, simultaneously, to ensure better access to them (75). Therefore, this study considers children's access to safe medicines and highlights the problem of substandard and counterfeit medicines. 


\section{CHAPTER TWO}

\section{DIETHYLENE GLYCOL TOXICITY IN}

\section{CHILDREN}

\subsection{Introduction}

The problem of substandard and counterfeit medicines has been highlighted in the previous chapter. In this chapter, I have focused on the specific problems associated with a highly toxic excipient - diethylene glycol (DEG). This example illustrates the significant toxicity of substandard and counterfeit medicines especially in children.

There have been several epidemics where predominantly young children have presented with an acute onset of renal failure. Incidents of mass poisoning with DEG have occurred in a variety of countries over the last 20 years, with more than 300 children having died as a consequence. These deaths have occurred in separate incidents in different countries from three continents $(64,66,76-78)$. The deaths were due either to the contamination $(64,66,78)$ of medicinal products by DEG or the deliberate illegal use of DEG as a solvent in a medicinal product $(76,77)$. 
Symptoms of DEG poisoning include renal and liver failure, seizures and gastro-intestinal bleeding. Outbreaks of unexplained renal failure should raise particular concern. Early recognition of DEG poisoning within the community is likely to prevent further deaths, by the removal of the contaminated/illegal medicines.

DEG consists of two ethylene glycol molecules joined by an ether bond. Although first produced in France in 1869, commercial production did not begin until 1928. It proved useful in a variety of industrial settings as an excellent solvent or ingredient in consumer products including antifreeze, brake fluids, lubricants, cosmetic creams, inks, dyeing agents and binding adhesive (75). It has also been used as a softening agent for textiles, paper and packaging materials. It unfortunately has a sweet taste which makes it appealing to children.

\subsection{Aim}

The aim of reviewing the literature was to summarise all the main aspects of DEG poisoning including epidemiology, toxicity, mechanisms of toxicity, clinical features, diagnosis and management. 


\subsection{Methods}

A review of DEG poisoning was undertaken. A literature search in the MEDLINE, EMBASE, and Pub Med databases (1960-2009) was performed (Figure 1). Key words were diethylene glycol, toxicity, symptoms and management. The search was restricted to data from humans and papers published in English. All articles that mentioned diethylene glycol were reviewed. The following data from the publications were extracted; number of children and adults affected, clinical signs and symptoms, management and the cause of the outbreak. Duplicates and unrelated abstracts were excluded. 
Figure 2.1: Flow Chart

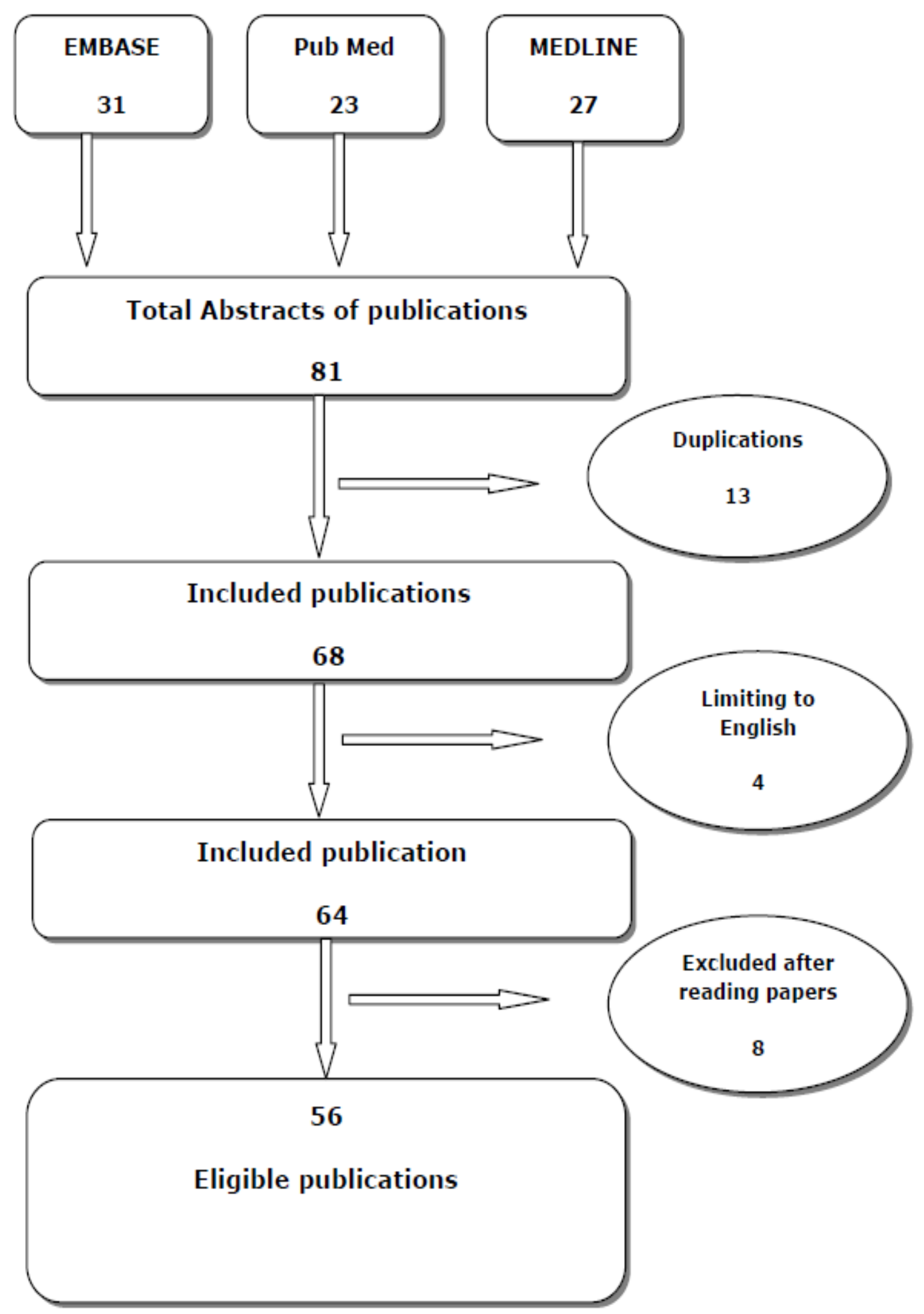




\subsection{Results}

Eighty one abstracts were identified. The 13 duplications were removed leaving a total of 68 publications. Four of these were in languages other than English. The 64 remaining articles were read and eight of them were considered to be not relevant. This left a total of 56 publications from which the data was extracted.

\subsubsection{Clinical signs and symptoms}

Most victims of DEG poisoning have a variety of clinical signs and symptoms depending on the amount and duration of the exposure. During the first period of ingestion, intoxicants stimulate gastrointestinal discomfort which usually begins with nausea, vomiting, diarrhoea, abdominal pain and bleeding. Other later symptoms include oliguria, anuria, metabolic acidosis, liver failure, seizures and acute renal failure (Table 2.1).

Table 2.1: Signs and symptoms of DEG poisoning

\begin{tabular}{|l|l|}
\hline Gastrointestinal & Nausea, vomiting, diarrhoea, abdominal pain and bleeding, anorexia \\
\hline Urinary & Diuresis, oliguria, anuria, acute renal failure, flank pain, proteinuria \\
\hline Neurological & $\begin{array}{l}\text { CNS depression, encephalopathy, seizures, tremors, weakness, lethargy, } \\
\text { malaise, coma }\end{array}$ \\
\hline Hepatic & Hepatitis, hepatomegaly \\
\hline Cardiovascular & Hypertension, hypotension, cardiac dysrhythmias \\
\hline Respiratory & Dyspnoea, tachypnoea, pulmonary oedema \\
\hline Metabolic & Metabolic acidosis \\
\hline Haematological & Anaemia \\
\hline Others & Fever \\
\hline
\end{tabular}




\subsubsection{What effect does DEG have on the body?}

Information obtained over the past few decades has demonstrated that DEG is a powerful nephrotoxic and neurotoxic poison $(75,79)$. There are some uncertainties regarding the principle cause of renal toxicity and neurological effects in DEG poisoning. Some have raised concern that renal toxicity may be induced by the parent compound, but others feel that toxic effects are related to the metabolites. DEG is converted to 2hydroxyethoxyacetic acid (HEAA) via oxidation by alcohol dehydrogenase.

The minimum lethal dose of DEG in humans is uncertain. There appears to be a wide range in relation to toxicity. Analysis of the data from an outbreak in Haiti suggested that the minimum lethal dose was 0.35 $\mathrm{mg} / \mathrm{kg}$ (64). However, an outbreak that occurred in Argentina involving adults (age range 50-93 years) suggested that the minimal lethal dose for adults is likely to be between 0.014 and $0.170 \mathrm{mg} / \mathrm{kg}$ (79).

\subsubsection{Previous episodes of DEG poisoning}

The first reported episode of poisoning in association with the use of DEG in a medicine was in 1938 (80). DEG was used as a solvent in the preparation of sulphanilamide elixir. The makers of the product were unaware of the toxicity of DEG. It is estimated that there were 105 deaths of which one third were those of children (80). Following this episode, legislation was introduced in the US that required formulations of new medicines to be tested for safety. Since then there have been 
numerous other reported cases of DEG poisoning. Following the episode in the USA in the 1930s, there have been five other instances where DEG has been used as a solvent $(76,77,80-83)$ (Table 2.2$)$.

Table 2.2: DEG used as a solvent

\begin{tabular}{lccccccc}
\hline Year & Country & $\begin{array}{c}\text { Deaths } \\
\text { in } \\
\text { children }\end{array}$ & $\begin{array}{c}\text { Overall } \\
\text { deaths }\end{array}$ & $\begin{array}{c}\text { Overall } \\
\text { cases }\end{array}$ & $\begin{array}{c}\text { Duration } \\
\text { (months) }\end{array}$ & Drug & Reference \\
\hline $\mathbf{1 9 3 7}$ & USA & 34 & 105 & 353 & 2 & $\begin{array}{c}\text { Sulphanilamide } \\
\text { elixir }\end{array}$ & $(80)$ \\
$\mathbf{1 9 6 9}$ & $\begin{array}{c}\text { South } \\
\text { Africa }\end{array}$ & 7 & 7 & 14 & 2 & Sedative & $(81)$ \\
$\mathbf{1 9 8 7}$ & Spain & 0 & 5 & 5 & - & $\begin{array}{c}1 \% \text { Silver } \\
\text { sulphadiazine }\end{array}$ & $(82)$ \\
$\mathbf{1 9 9 0}$ & Nigeria & 47 & 47 & 47 & 4 & $\begin{array}{c}\text { Paracetamol } \\
\text { elixir }\end{array}$ & $(77)$ \\
$\mathbf{1 9 9 0}$ & Bangladesh & 51 & 236 & 339 & 36 & $\begin{array}{c}\text { Paracetamol } \\
\text { elixir }\end{array}$ & $(76)$ \\
$\mathbf{2 0 0 8}$ & China & 0 & 12 & 15 & 0.5 & Armillarisin-A & $(83)$ \\
\hline
\end{tabular}


There have been eight episodes where a medicinal product has been contaminated with DEG $(64,66,78,79,84-88)$ (Table 2.3).

Table 2.3: Contamination with DEG

\begin{tabular}{|c|c|c|c|c|c|c|c|}
\hline Year & Country & $\begin{array}{l}\text { Deaths } \\
\text { in } \\
\text { children }\end{array}$ & $\begin{array}{l}\text { Overall } \\
\text { deaths }\end{array}$ & $\begin{array}{c}\text { Overall } \\
\text { cases }\end{array}$ & $\begin{array}{l}\text { Duration } \\
\text { (months) }\end{array}$ & Drug & Reference \\
\hline 1986 & India & 14 & 14 & 14 & 0.5 & Glycerine & $(84)$ \\
\hline 1992 & Argentina & 0 & 15 & 29 & - & $\begin{array}{c}\text { Upper } \\
\text { Respiratory } \\
\text { Tract } \\
\text { infections } \\
\text { (URIs) } \\
\text { medicinal } \\
\text { agent } \\
\text { (Propolis } \\
\text { syrup) }\end{array}$ & (79) \\
\hline 1995 & Haiti & 85 & 85 & 109 & 21 & $\begin{array}{l}\text { Paracetamol } \\
\text { elixir }\end{array}$ & (64) \\
\hline 1998 & India & 33 & 33 & 36 & 3 & Cough syrup & (78) \\
\hline 1998 & India & 8 & 8 & 11 & 2 & Paracetamol & (85) \\
\hline 2005 & Australia & 0 & 1 & 7 & 0.1 & Cleaning fluid & (86) \\
\hline 2006 & Panama & 0 & 78 & 119 & 10 & Cough syrup & (87) \\
\hline 2008 & Nigeria & 84 & 84 & 111 & 2 & $\begin{array}{c}\text { Teething } \\
\text { formula ('My } \\
\text { Pikin') }\end{array}$ & $(66,88)$ \\
\hline
\end{tabular}

The number of deaths per outbreak has ranged from one to over 200 . The time taken to recognise that the outbreak was associated with DEG poisoning has been a major contributing factor to the number of deaths; i.e., the sooner it is recognised that this is DEG poisoning, the fewer the deaths. Unfortunately, even with prompt recognition, as in Nigeria 2008, following the use of a teething formula that was contaminated with DEG, there can still be a large number of deaths $(66,88)$. This particular incident was probably associated with a high number of fatalities (84 
children died) because of the young age of the patients exposed to the contaminated product. There have also been cases of contamination of toothpaste affecting adults in both the USA and Spain (89, 90). Fortunately there were no deaths.

\subsubsection{Why does DEG poisoning occur?}

All medicines contain a variety of excipients and solvents alongside the active drug. This is to make the medicine palatable or soluble. No major pharmaceutical company would deliberately use DEG as a solvent because they are all aware of its toxicity. Unfortunately the financial profit from medicines is huge and because of this there is a proliferation of smaller manufacturers who will make unacceptable economies to maximise profits $(91,92)$.

In many cases, the individual/company responsible for the use of DEG as a solvent is not identified. However, judicial investigations in China identified the pharmaceutical company that deliberately used DEG as a solvent (83). Five individuals from the company were subsequently jailed for between four and seven years and the Deputy Director of the Food and Drug Administration of the region was sacked for negligence (93). 


\subsubsection{Can we prevent future episodes?}

The WHO has recognised the importance of ensuring that medicines are prepared safely. They have established WHO Good Manufacturing Practice Guidelines (1969) and also established a certification scheme (1975) to ensure the quality of pharmaceutical preparations sold in international markets $(66,94)$. These efforts will help to improve the quality of medicines available especially within low and lower-middle income countries. It is essential that Departments of Health and national regulatory agencies support these efforts.

\subsubsection{When to suspect DEG poisoning}

Despite the numerous deaths that have occurred in children due to DEG poisoning, the vast majority of health professionals worldwide will fortunately never see a case. The key issue, however, is for health professionals who see more than one case of acute unexplained renal failure in children to be aware that DEG poisoning is a possibility. It is established that adverse drug reactions are often not recognised (95). The lack of awareness of possible drug toxicity is even greater in relation to the toxicity of excipients (96). Additionally, the signs and symptoms in association with DEG poisoning (Table 2.2) are extremely diverse. Rare causes of acute renal failure such as primary hyperoxaluria may affect a single individual but will not result in an outbreak. Doctors and pharmacists involved in renal units alongside those involved in public 
health, however, should be aware of the possibility of DEG poisoning, especially if they work in low- and middle-income countries.

\subsubsection{Management}

A case report of young children ingesting poisons such as brake fluid which contains DEG has highlighted the possibilities of enhancing the clearance of DEG (97). This case report alongside others (98) has suggested the use of fomepizole which is an alcohol dehydrogenase inhibitor that can be administered intravenously $(97,98)$. Fomepizole (4methylpyrazole) is increasingly being used in adults and children following poisoning with methanol or ethylene glycol (99). It has minimal toxicity and a dose of $15 \mathrm{mg} / \mathrm{kg}$ is recommended over a 30-minute time period. A further $10 \mathrm{mg} / \mathrm{kg}$ can be administered at 12 hour intervals (99, 100).

In the case report involving a child (97), haemodialysis was used and this was associated with a fall in the plasma concentration of DEG. If concurrent haemodialysis is used then the fomepizole can be administered over four hours (99). These case reports were associated with a good clinical outcome, but hospitals in communities where poisoning usually occurs are extremely unlikely to be able to cope with an outbreak involving large numbers of children experiencing acute renal failure. DEG poisoning unfortunately usually occurs in those communities with the poorest access to health care. If available, fomepizole and 
haemodialysis are the treatment of choice for children with acute renal failure (101). Options which are more likely to be available in low-income countries include peritoneal dialysis and oral ethanol $(0.8-1.0 \mathrm{ml} / \mathrm{kg}$ loading dose followed by $0.15 \mathrm{ml} / \mathrm{kg} / \mathrm{h}$ of $95 \%$ ethanol diluted in orange juice)(101). Ethanol, although cheaper, is more toxic than fomepizole and is often not available $(102,103)$.

\subsection{Summary}

With the increase in proliferation of counterfeit medicines, DEG poisoning is unfortunately likely to occur again. The sudden outbreak of an epidemic of acute renal failure among children should make individuals consider the possibility of DEG poisoning as a cause. Without any action against this kind of medicines counterfeiting, the problem will increase and the result will be further deaths of children due to poisoning outbreaks (51).

The episodes of DEG poisoning illustrate the problems associated with counterfeit medicines. They also illustrate what can happen if there are no strict regulations on drug manufacturing (54). It is highly likely that not all outbreaks of DEG poisoning have been identified. 
This chapter has focused on reviewing the literature in relation to DEG poisoning. The following chapter reviews the literature in relation to the problems experienced by Asylum Seekers and Refugees. 


\section{CHAPTER THREE}

\section{PROBLEMS OF ACCESS TO HEALTH CARE AND MEDICINES FOR ASYLUM SEEKERS AND REFUGEES}

\section{Review of Literature}

\subsection{Introduction}

This chapter will explore the literature related to the access to health care and medicines in some groups of ethnic minorities such as Asylum Seekers, Refugees, Aboriginals, and Latino American.

This will encompass a number of areas in order to provide a comprehensive background to the exploration of the concept of access to health care, identification and categorisation of specific barriers to medicines and healthcare. It will also examine access among the children of these minority groups. 


\subsection{Method}

Literature searches of computer databases were performed using OVID, MEDLINE (data range, 1950-April 2012), EMBASE (data range, 1980April 2012), CINAHL and Pub Med (updated to April 2012), Google Scholar (updated to April 2012), published in English, with text and medical subject headings. In addition, manual searches of the reference list of relevant studies were used to identify further appropriate papers.

\section{Main inclusion criteria}

The following key criteria were used to refine the search and to identify material that would be included in this literature review:

- Sources covering the last 30 years

- Evidence-based research

- Publications in English, including peer review articles, extracts from books, case studies, anecdotal reports, government and other reports, and primary researches

- Articles relating to the following terms, health care access, utilisation, ethnic minorities, Asylum Seekers, Refugees, children's access, and access barriers to health care and/or medicines. 


\section{Main exclusion criteria}

- Unrelated abstracts

- Duplicate articles

- Non- English sources

- Other publications not compatible with the inclusion criteria.

\subsection{Results}

680 abstracts of publications were identified. Duplicates and unrelated abstracts were excluded. The resulting publications were then limited to papers published in English of which full texts were obtained and screened further to exclude studies not compatible with the inclusion criteria. Ultimately, 104 published papers relating to children's access to health care were included in this literature review (Figure 3.1). Many of the articles I have referred to are review articles. However to further explain specific points in these review articles I have referred back to the original papers mentioned in these reviews. This is the reason why my literature review contains references to many old papers. The format of these papers is presented in table (3.1). 
Figure 3.1: Flow chart

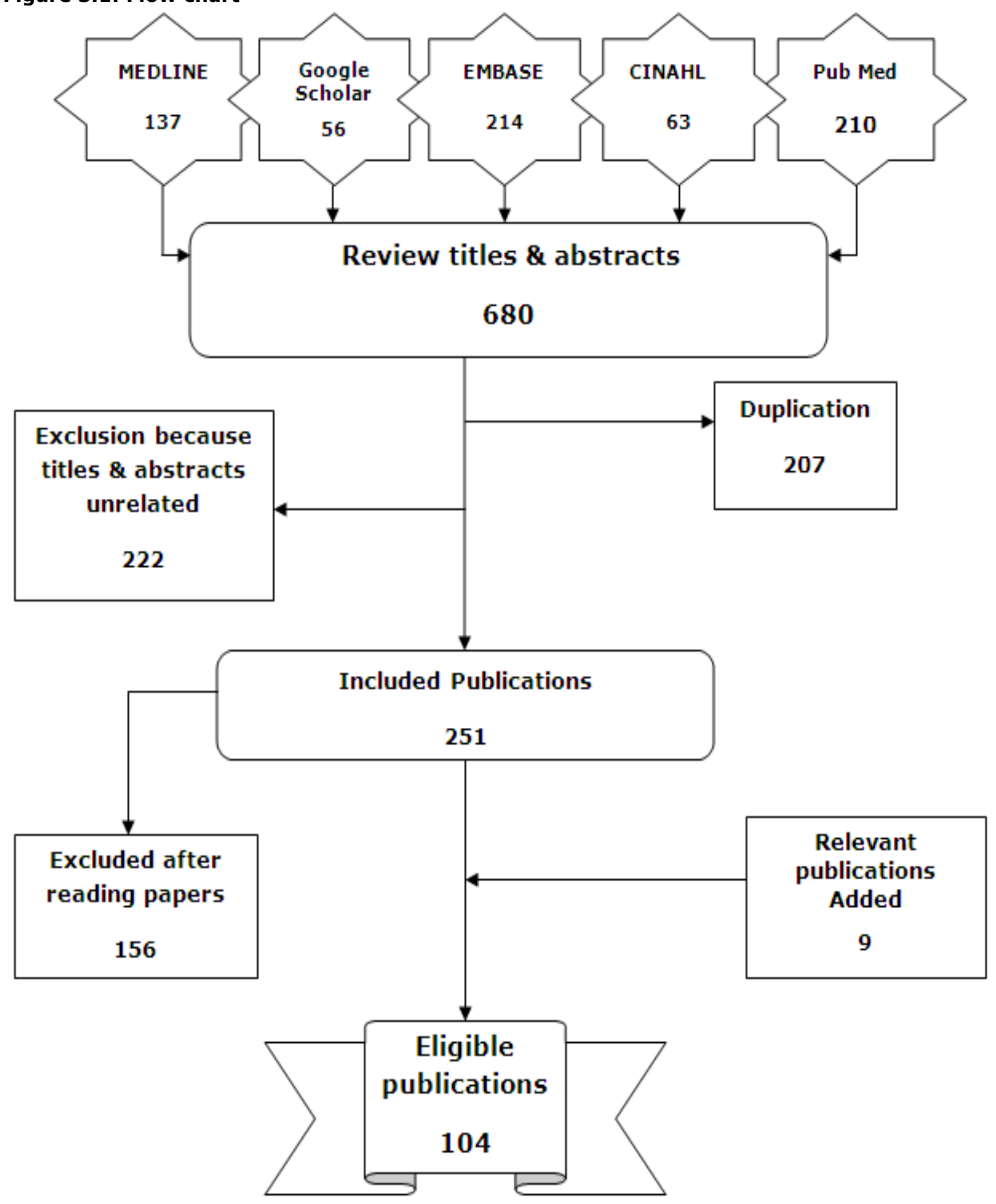


Table3.1: Format of Publications

\begin{tabular}{|l|c|c|}
\hline Format & No of papers & Percentage \\
\hline Review & 17 & $16 \%$ \\
\hline Case report & 23 & $22 \%$ \\
\hline Overview & 2 & $2 \%$ \\
\hline Personal opinion & 8 & $8 \%$ \\
\hline $\begin{array}{l}\text { Study } \\
\text { retrospective, observational) } \\
\text { Others }\end{array}$ & 33 & $32 \%$ \\
\hline Total & 21 & $20 \%$ \\
\hline
\end{tabular}

The results will be presented and discussed in four broad themes which have emerged from reviewing the literature:

- The first section explores the concept of access to health care and medicines, involves definition of access to health care and discusses equality of access.

- The second section presents an overview of the concept of "at risk" groups, defining the terms 'Asylum Seeker' and 'Refugee' and providing background information for both groups.

- Section three presents an overview of the 'at risk' children's access which also considers the barriers to health care they experienced. 
- Section four focuses on both general and specific barriers to accessing health care and medicines which arise from problems not only in the country of origin but also in the host country.

These include legal rights, medical screening, detention, housing, economic factors, GP-related barriers, health records, language barriers, mental health barriers, cultural barriers, stigma and isolation (table 3.2).

Table3.2: List of barriers to accessing health care and medicines

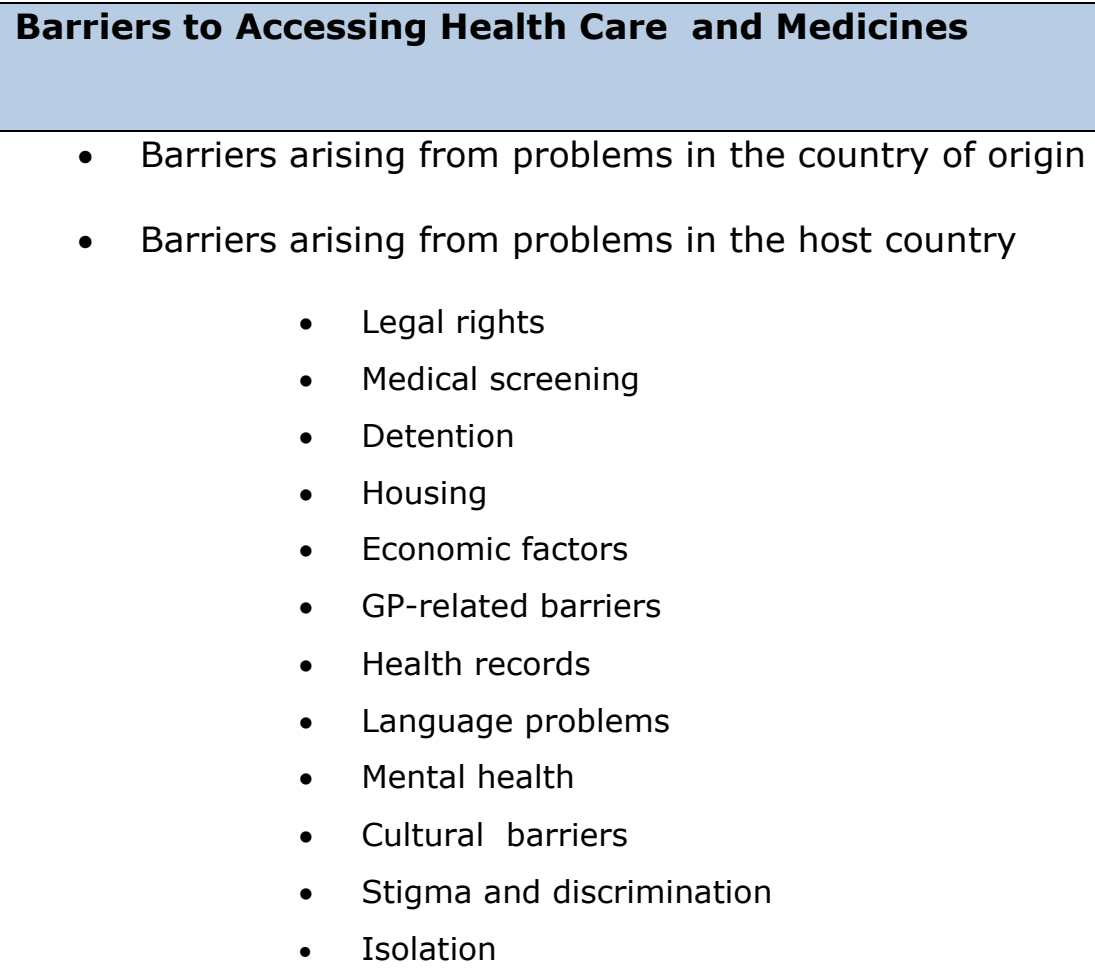




\subsection{Overview of Access to Health Care and Medicines}

\subsubsection{Definitions of access to health care}

Six papers (four from the USA - 104, 105, 107, 109 and two from the UK $-106,108)$ gave definitions of access to health care. Access to health care and treatment can be defined as "actual and potential entry into the health care system" (104). The US Institution of Medicine defines it as "the optimal use of health services to gain the best possible outcome", while for Rogers et al it is "providing the right service, at the right time, in the right place" $(105,106)$. A group of researchers found access to be a multi-faceted concept and suggest that it describes the "degree of fit" and interaction between patients and healthcare services (107).

Maxwell et al (108) and Cunningham et al in a prospective study (109) identify access as one of the most important factors in achieving high quality health care. However, perceptions of the standards of accessibility and acceptability of services may be affected by the attitudes and beliefs of both patients and health care providers.

\subsubsection{Equality of access to health care and medicines}

Seven papers (four from the UK - 110-112, 114; two from other European countries - 43, 113 and one from the USA - 45) discussed equality of access to health care. Individuals seeking asylum sometimes 
encounter difficulty through not having the same rights to access health care as citizens. This is especially the case when having resided in a new country for a year or more while waiting for decisions on their asylum claims. Such difficulties may adversely affect their physical and mental health $(110,111)$.

Although international regulations exist to protect immigrant parents and their children and ensure that they, especially the children, have the same rights to health care and medicines as the indigenous population, it has been recognised and acknowledged that even in developed countries not all do have the same access $(112,113)$. Many studies have been conducted in different parts of the world to evaluate the relationship between ethnicity and access to medicine. In most of these studies, disparities between different groups within a population have been recorded and rated in relation to such access. St Clair et al (114) indicate that the rate of utilisation of health services may be an objective indicator of the availability of access: that is to say, equality of access may be assessed in terms of the availability and utilisation of services and the health outcomes of such utilisation.

The inequalities in health provision in the USA are well recognised in the literature. A prospective study has shown that adult patients from nonwhite ethnic minority groups, whether immigrant or indigenous, are less likely to receive appropriate analgesia following trauma than white adult 
patients (45). The provision of health care for some heterogeneous marginalised groups in EU countries also seems to be variable in quality and quantity, and is often based on minimal standards (43). It has been found that access to medicines and treatments for Asylum Seekers in some EU countries (such as Austria) is restricted to emergency care only $(43,115)$.

\subsection{Overview of Asylum Seekers and Refugees}

Seventeen papers (ten from the UK - 72, 119-122,124, 126, 127, 132, 137; three from other European countries - 43, 123, 135; three from the USA - 104, 125, 134 and one from Australia - 116) in this literature review discussed definitions and background of Asylum Seekers and Refugees. The United Nations High Commission for Refugees (UNHCR) was established in 1951. At that time the number of Refugees internationally was approximately 1.5 million (116). By the end of 2010, the number had increased to 15.4 million Refugees and about 850,000 Asylum Seekers worldwide $(117,118)$. Particularly distressing are the

applications for asylum by 15,000 separated or unaccompanied children, most of them Afghan or Somali (117).

There has been a fall in the number of people seeking asylum in the UK over recent years. In 2008, there were 31,320 people seeking asylum. 
This had fallen to 22,090 people seeking asylum in 2010 (figure 3.2)(117).

Figure 3.2: Asylum Applications submitted in UK 2006-2010

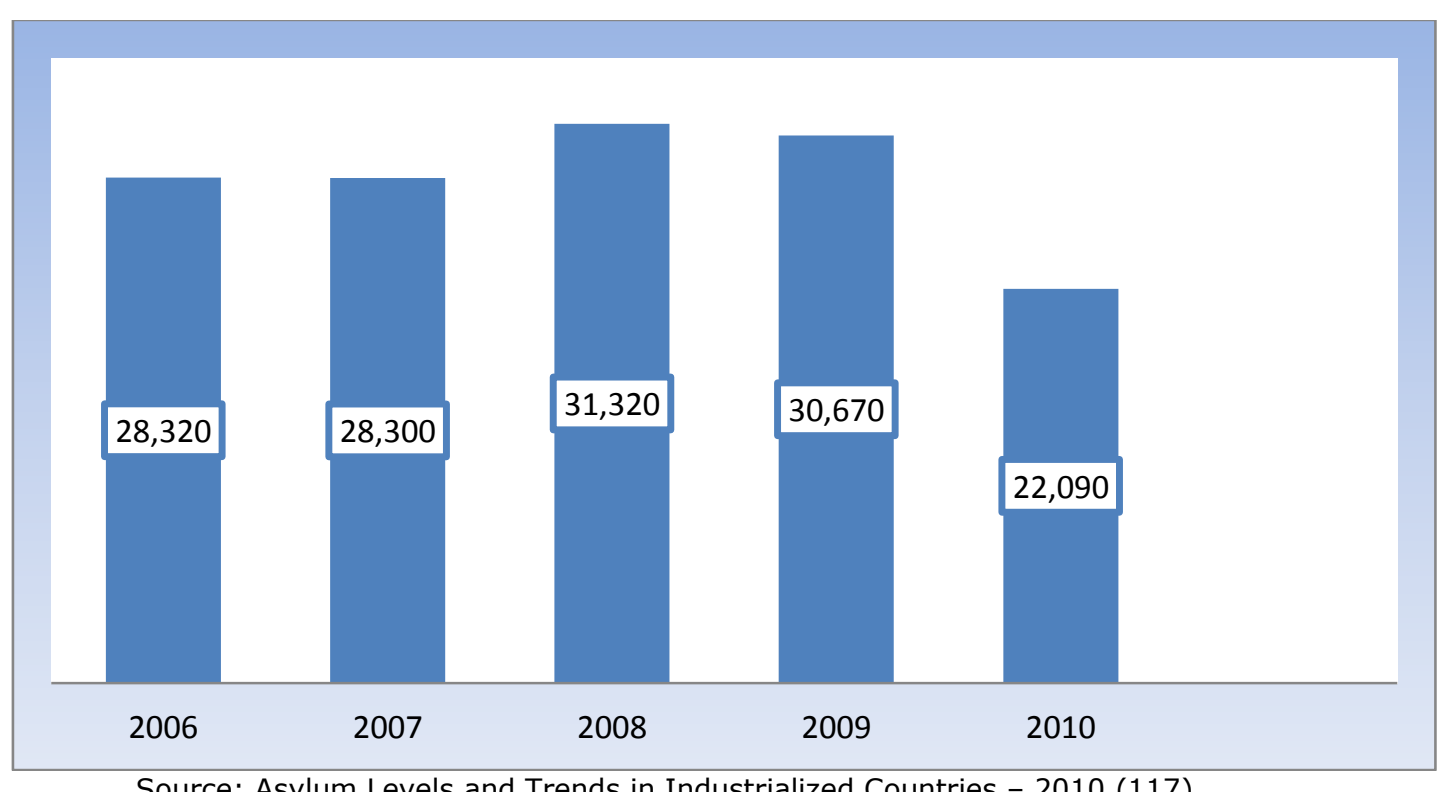

Source: Asylum Levels and Trends in Industrialized Countries - 2010 (117)

Legal restrictions in access to health care for children and adults in some minority groups have been found in many countries. A better understanding and increased awareness of the racial, religious, and socio-cultural differences of minorities such as Asylum Seekers and Refugees seeking care are essential. Such awareness and understanding may have an effect on the interaction between these groups of people and health care providers and increase their opportunity to access health care and medicine (43). 
Mobile populations (including Asylum Seekers and Refugees) are considered as ethnic minorities in the UK. Most Asylum seekers and Refugees now living in the UK are drawn from a variety of countries including Zimbabwe, Pakistan, Iraq, Afghanistan, Somalia, Palestine, Sri Lanka and Kosovo (119) (figure 3.3). The reasons behind the dramatic fall in the number of Asylum Seekers and Refugees from Zimbabwe in 2010 may be related to the updated regulation of immigration in the UK and that the government of the UK classified Zimbabwe as a safe country. Many Asylum Seekers and Refugees are being forced to live in poor accommodation and below the poverty threshold due to unemployment, both of which threaten their physical and mental health (120). These people may experience significant problems in accessing health care and medical treatment $(43,72,121)$. There have been relatively few studies of access to health care for children from these groups and to date there have been no studies in the UK on whether these children receive satisfactory drug therapy. The Royal College of Paediatrics and Child Health has identified children from these two groups (Asylum Seekers and Refugees) as likely to experience inequalities in access to health care (72). However, in line with the International Convention on Economic, Social and Cultural Rights (ICESCR), they should have entitlement to free health care and free prescribed drugs if needed (119). According to the Convention, governments are under specific obligation to place no limits on access to medicines for all people (122). 
Figure 3.3: Top-10 population of asylum applications in UK 2009-2010

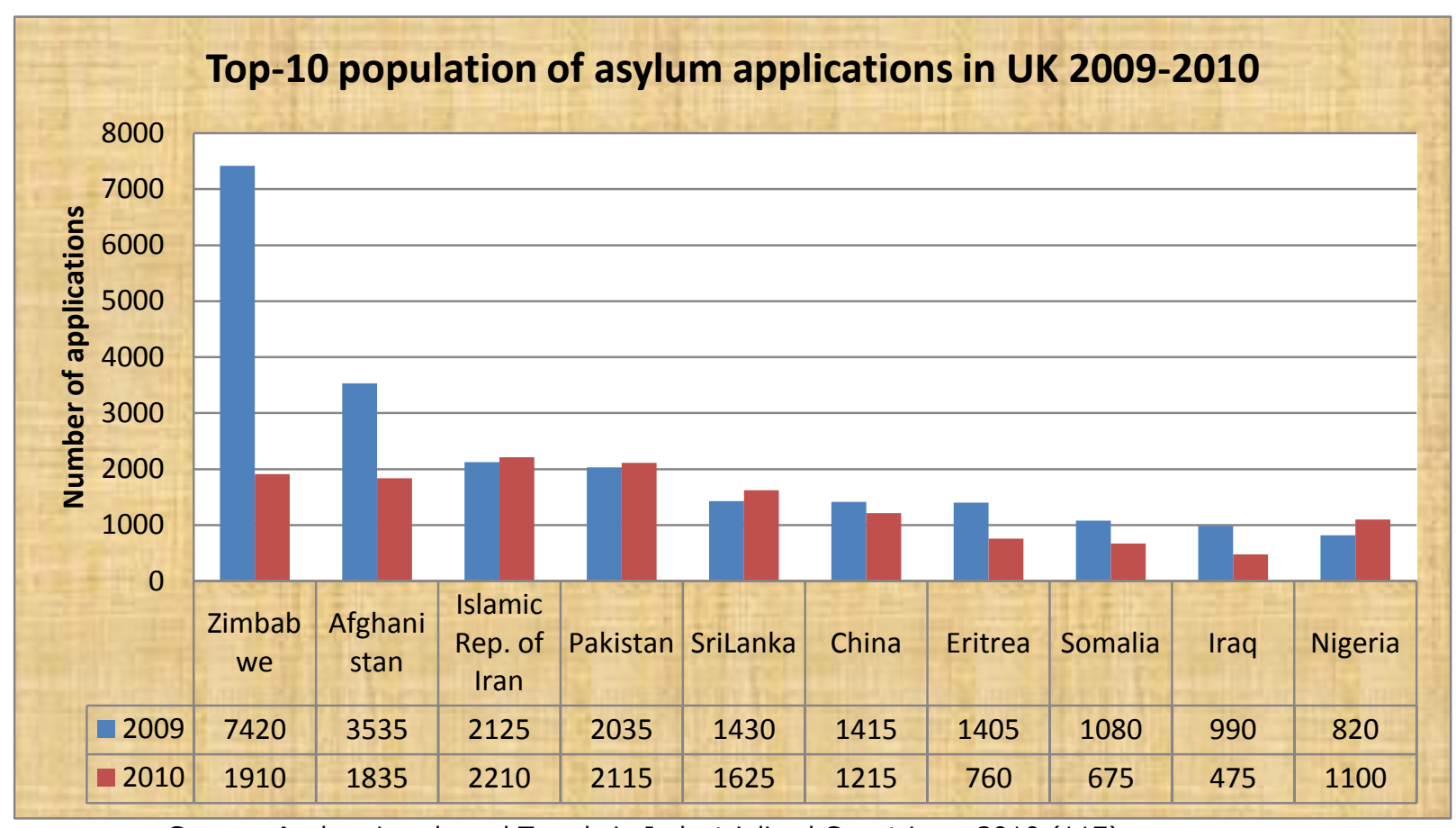

Source: Asylum Levels and Trends in Industrialized Countries - 2010 (117)

\subsubsection{Definitions of Asylum Seekers and Refugees}

The terms Asylum Seeker and Refugee are often used interchangeably or incorrectly. There is a difference between them in relation to claim status.

An Asylum Seeker is an individual who is seeking international protection and his claim for refugee status has not yet been determined (73). Groups of Asylum Seekers are often included with minorities. They find themselves in a difficult situation as they do not have the same legal 
rights as the indigenous population or Refugees, and may face limitations on many aspects of their daily lives, such as access to health care, while they are waiting for decisions on their cases $(73,120)$.

A Refugee is recognised as such under the 1951 Convention relating to the status of Refugees. The Convention defines a 'Refugee' as any person who:

"owing to well-founded fear of being persecuted for reasons of race, religion, nationality, membership of a particular social group or political opinion, is outside the country of his nationality and is unable or, owing to such fear, is unwilling to avail himself of the protection of that country; or who, not having a nationality and being outside the country of his former habitual residence as a result of such events, is unable or, owing to such fear, is unwilling to return to it" (123).

Apart from this definition, the Refugee Council in the UK defines a 'Refugee' as "a person who, owing to a well-founded fear of being persecuted for reasons of race, religion, nationality, membership of a particular social group or political opinion, is outside the country of his nationality and is unable or, owing to such fear, is unwilling to avail himself of the protection of that country" (124). 
Refugees were defined by the Geneva Convention as "those persons who are forced to leave their countries of origin due to well-founded racial, religious, social, political persecution or of its possible persecutory threat"(125).

Jones et al (119) defined a Refugee as any person who falls into one or more of the following categories (given verbatim):

- $\quad$ those applying for asylum (refugee) status in the UK

- those who have been given temporary admission by the immigration service while their applications are considered

- $\quad$ those who have been given exceptional leave to remain in or enter the country

- $\quad$ those who are required to renew their status at the Home Office at regular intervals

- $\quad$ those given refugee status

- $\quad$ those who gain the right to stay in this country indefinitely

- $\quad$ those who have had their application refused and are going through the appeals process

- dependants of the above groups

- $\quad$ other individuals or groups who may fall outside the legal definition but who face similar problems-such as those entering the country under family reunion rules, policy, or discretion. 


\subsubsection{Seeking Asylum \& Refugee Status}

The process of individuals seeking asylum and refugee status is, according to Burnett et al (126) as follow (given verbatim):

- Asylum Seeker-asylum claim submitted, awaiting Home Office decision.

- Refugee status (accepted as a Refugee under the Geneva Convention)- given leave to remain in the UK for four years, and can then apply for settled status (ILR).

- Indefinite leave to remain (ILR)-given permanent residence in Britain indefinitely. Eligible for family reunion for one spouse and all children under 18 years, but only if able to support family without recourse to public funding.

- Exceptional leave to remain (ELR)-the Home Office accepts there are strong reasons why the person should not return to the country of origin and grants the right to stay in the UK for four years. Expected to return if the home country situation improves. Ineligible for family reunion.

- Refusal-the person has a right of appeal, within strict time limits.

In figure 3.4, the Faculty of Public Health (2008) presented a basic overview of asylum process in their briefing statement of the health needs of Asylum Seekers $(127,128)$. 
Figure3.4: Asylum process in the UK (source: Faculty of Public Health, 2008)(128).

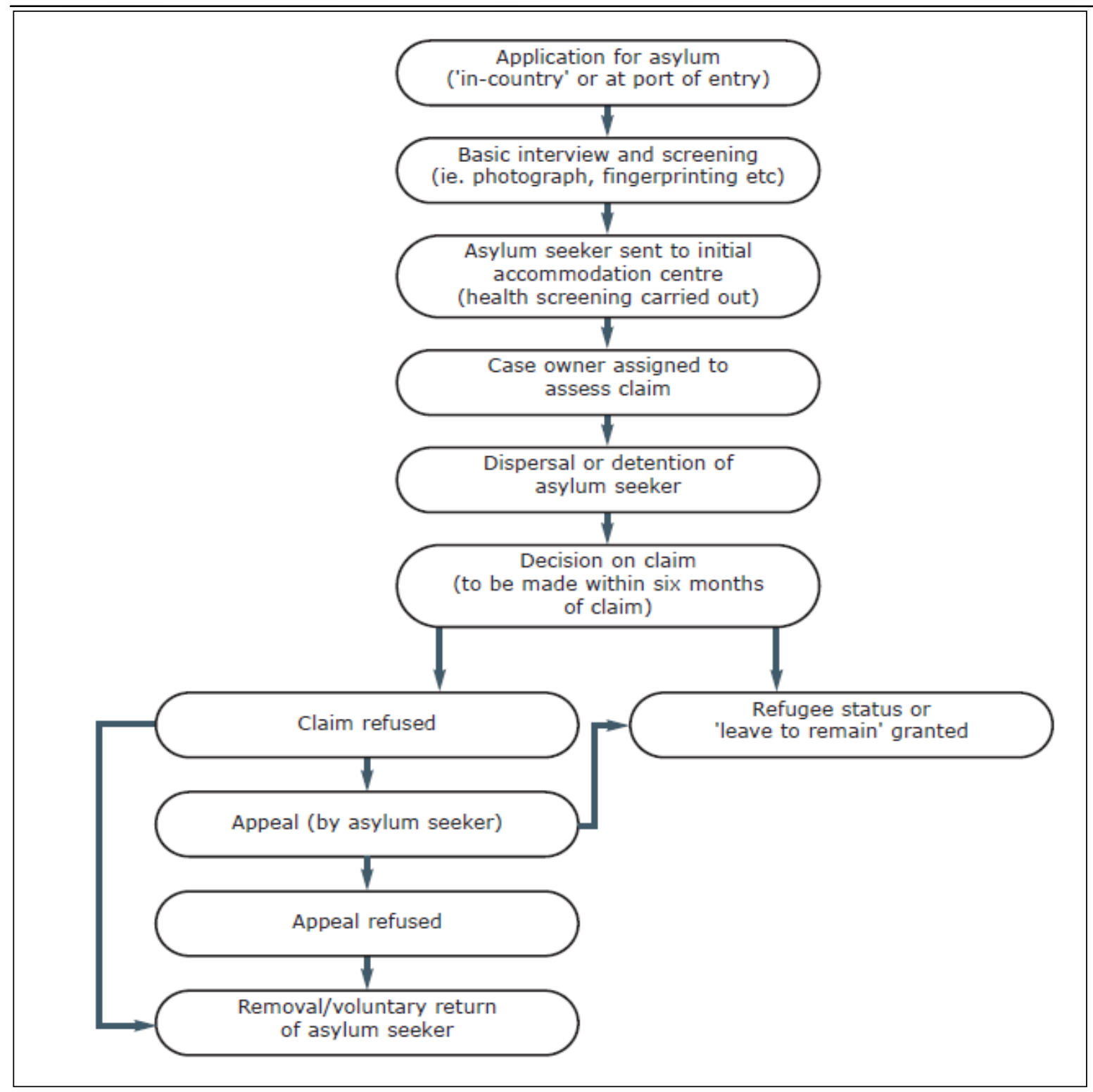

Groups of people or individuals, who leave their original country for reasons such as other civil disturbance, natural disasters, famine or in order to seek a better life, are not covered by the definition of Refugee. This was explained by UNHCR as follows: 
"Refugees flee because of the threat of persecution and cannot return safely to their homes in the prevailing circumstances. An economic migrant normally leaves a country voluntarily to seek a better life. Should they elect to return home, they would continue to receive the protection of their government" (129).

\subsubsection{Background of Asylum Seekers \& Refugees}

Asylum Seekers and Refugees come from many different cultures and countries. In 2007, the largest group of applicants to the European Union (EU), representing about $14 \%$ of all claims, came from Iraq. The second highest percentage of claims, about $6 \%$, came from China. However 4$5 \%$ of claims were from Serbia, Pakistan, the Russian Federation and Montenegro (130, 131). Therefore, they are not a homogenous population.

In a prospective study, Aday et al (104) indicated that in the EU, most Asylum Seekers cross the borders illegally to seek asylum. However, everyone has the right to seek asylum if he matches the UN Refugee Convention's definition of having a "well founded fear of persecution on the grounds of race, religion, nationality, membership of a particular social group or political opinion" (104).

In EU countries, the provision of health care for Asylum Seekers varies widely in availability and quality. It is worth noticing that in some EU 
countries where asylum applications are refused, their rights to health care are restricted to emergency treatment (43). They may also be stripped of their rights and forced to leave the host country even though if they return to their home countries they will be in danger (43).

In the UK, free access to the NHS was formerly offered to failed Asylum Seekers, but since 2004 the government has strict regulations for failed Asylum Seekers and they only have access to some primary care which could soon be withdrawn $(43,115)$. Now, failed Asylum Seekers are denied treatment in NHS hospitals, with the exception of emergency treatment or continuing treatment they are already receiving. However, a joint review of the policy by the Home Office and the Department of Health ruled that children and those who could not return home would be allowed free health care (132).

Despite all the efforts by the Committee on Economic, Social and Cultural Rights which, in their 2002 UK monitoring report, stated that Asylum Seekers and Refugees are a vulnerable population who must be protected from discrimination, the government has failed to incorporate access rights within the legislature (122).

Asylum Seekers and Refugees have a wide range of experiences in their own and other countries which may create difficulties in their access to 
health care and impact negatively on their health. Many of these vulnerable groups leave their home countries in difficult circumstances, often having been exposed to violence or persecution. Their countries of origin are often unsafe and unstable politically, economically and socially, so they escape and look for another home (131).

Asylum Seekers and Refugees from countries with no developed system of primary care will often have a poor knowledge of the UK health care system. They therefore expect hospital referral for some medical conditions that in the UK are normally treated in primary care. Because of their many and varying needs, this often causes Refugees disappointment and health workers irritation. However, addressing even a few of their needs may result in considerable benefits (120).

It has also been recognised that Asylum Seekers and Refugees are vulnerable due to certain pre- and post-migration risk factors. Premigration factors such as refugee trauma and torture affect their health, and may result in physical and mental illness. Moreover, those who seek asylum have often not had full access to health services in their countries of origin because they have been in conflict areas. Post-migration factors include language barriers, the length of immigration procedures, detention and a lack of knowledge about the health system in the host country $(43,133-137)$. 
The numbers of Asylum Seekers and Refugees around the world continue to increase annually, so health care professionals will similarly be increasingly finding themselves having to provide optimum health care for this subset of the population (125).

\subsection{Overview of Access to Health Care for the "At Risk" \\ Children}

Access of ethnic minority children to health care has been reported in 11 papers in this review (four from the UK - 112,120, 145, 146; six from the USA - 138, 140-144 and one from Canada - 47). Since this research focuses on children's access to medicines, especially children of "at risk" groups, this section of the literature review provides an overview of access barrier to health care and medicines experienced by those children. It includes many evidence-based publications from developed countries such as the USA, Canada, the UK, and Australia.

\subsubsection{Barriers of children's access to health care}

Children of Asylum Seekers and Refugees who come from unsafe countries may have experienced torture or violence. Consequently, some of these children may have mental health problems. Some psychological symptoms, such as anxiety, withdrawal, nightmares and hyperactivity, are common and may need psychiatric treatment. Furthermore, the children of such groups may not have had the opportunity to complete 
their immunisations, and records of any immunisations they might have received may be unclear (120).

Some marginalised groups encounter specific multiple barriers in accessing medicines, barriers which may directly or indirectly affect children in these groups more than those in any other groups in society (31). These barriers include background issues deriving from the country of origin such as relevant reasons for, and method of, immigration; legal restrictions; poverty; language and communication problems; difficulties in registering with a doctor; a lack of medical records; cultural background and beliefs; ethnic issues; mental health problems and patients' priorities regarding treatment (112). These barriers will be discussed in detail in the following sections of this chapter.

Minority group children in some developed countries are affected disproportionately by the lack of health insurance and their parents' lack of knowledge of the healthcare system in the host country $(43,44)$. Recent research in North America has revealed that in both the USA and Canada, children of different ethnic minority groups and/or those without insurance may be less likely than indigenous children to access health care $(45,47,138)$. Wasserman et al (139) indicated that the children of Latino immigrants were given a preschool vision test less frequently than any other ethnic groups, while Wood et al reported that these children 
also missed vaccinations, thus decreasing their immunisation rates (140).

Many studies over decades have investigated such reasons for disparity in access to medicine by minority groups, and tried to establish ways of improving access for poor minority children. Summersett et al (2) in a retrospective cohort study found that large numbers of children in the developing world suffer from an absolute lack of access to essential medicines, caused mainly by the shortage of medical health resources, rising unemployment and decreasing or no health insurance.

One US retrospective study found no difference in the treatment of children from different ethnic backgrounds presenting with long bone fractures in the emergency departments (138). Another, however, found that black American children were less likely than their white counterparts to receive a prescription medicine. Similarly, uninsured American children were less likely than those with private insurance to receive a prescription medicine (46), while a recent prospective study in Canada (2007) highlighted that premature white Canadian neonates were more likely to receive a variety of medicines and interventions than aboriginal (Northern First Americans, Inuit and Metis) premature neonates (47). 
In a US cross-sectional study, Halfon et al (141) examined the relationship between immigration status and access to health care, finding that citizens' children had easier access than non-citizens', and that children whose parents had lived in the US for less than five years were less likely to have health insurance than other groups within the population. Halfon (141), and Newacheck (142), also recorded that these children received fewer prescriptions, and were at a higher risk of not getting specific treatment plans for certain moderately severe medical conditions, than white children or African American children $(141,142)$.

A further barrier may relate to the negative attitudes of health care professionals. Two studies in the US indicate that Latino parents claim the attitudes of healthcare staff towards their asthmatic children could well deter them from seeking treatment for the condition, with mothers citing their lack of confidence in the healthcare staff as another barrier $(143,144)$.

With some medical conditions, minority groups may register high rates of healthcare service use, which may be influenced by behavioural and cultural factors in addition to possible variations in disease prevalence. For example, children of South Asian migrants have high emergency hospital admission rates for asthma (145). The lack of interaction between medical staff and the children's parents, and/or parental beliefs, can have a negative impact on the management of this condition (145). 
Multifaceted support needs to be provided to the children of Asylum Seekers and Refugees through local schools, by learning and making friends (120). Social services can help to provide a sense of security and promote self-esteem, as well as supporting the parents to lead as normal a life as possible $(120,146)$.

\subsection{Overview of Barriers to Access Health Care and}

\section{Medicines}

Barriers arising in the country of origin and the host country have been discussed in a total of 63 papers of this review.

- forty one were from the UK $(115,120,126,148,150-156,158$, 159, 163, 171, 175-178, 180,181,184-186, 189-194, 196-200, $224,225,234-237)$;

- thirteen were from the USA (149, 157, 172-174, 187, $188,211,212,229,230-232)$;

- five were from Australia (166-170);

- three were from other European countries ( $43,161,169)$;

- one was from Canada. 
Problems with access to primary health care and medicines are recognised in both developing and developed countries, and identifying such problems or barriers is essential for the improvement of access for both adults and children $(2,147)$.

Although accessing health care remains an entitlement for such socially vulnerable groups as Asylum Seekers and Refugees, the literature shows that they experience difficulties in achieving it (110). A study in Islington in 1992 , reported that $38 \%$ of Refugees experienced difficulties when trying to register with a GP where prospective patients are asked for a valid passport, a document which a Refugee may not have (119). Providing health care to these vulnerable people is likely to be associated with barriers which may present at any time and at different points on the pathway $(110,120)$. These barriers will be addressed in detail in the following sections.

\subsubsection{Barriers arising from problems in the country of origin}

Problems originating in the country of origin impact negatively on Asylum Seekers' and Refugees' access to health care. Primary care in the home country may be poor, with low immunisation rates and limited or no records being kept or available (119). Health systems there have frequently collapsed $(115,148)$. These people may have experienced or witnessed physical or mental torture, and sexual and other organised violence, since most come from countries where there is upheaval and 
violent conflict $(115,149)$. They are coping with cultural bereavement, traumatic escape histories and family separation - many, including children, have no other relatives in the UK (119). They have had no choice but to leave their country of origin, and fear for their safety if they are returned by the host country (115). Thus, throughout the period of temporary residence they are inordinately preoccupied by worry about the future, all of which impacts on the physical and mental health of both them and their children (150-152).

\subsubsection{Barriers arising from problems in the host country}

Primary care for Asylum Seekers and Refugees needs to start with understanding their reasons for flight, psychological traumas and their history of exposure to infectious diseases, which may then help to collate the medical history and provide appropriate treatment (149). However, gaining such understanding is very time-consuming, which in itself acts as a deterrent to GPs to register them fully. Their situation may be exacerbated by other factors, including language difficulties, the lack of an advocate who understands the belief and cultural implications of the Asylum Seeker or Refugee and a lack of knowledge of how the health system in the host country works $(150,151,153-156)$.

A number of these barriers in accessing health care were classified by Norredam et al (43) as: 
I. barriers raised by the ways in which different cultures view illness, and the attitudes of health care providers towards their ethnic minority patients;

II. communication or language barriers related to the lack of provision of interpreters, resulting in inaccurate information;

III.lack of Asylum Seekers' and Refugees' knowledge of health care services, due to inadequate information about the health system in the host country;

IV. structural barriers such as the need for identity and medical cards in some European countries before they can access health care services (43).

A national survey in the US (1976) indicated that the Hispanic population of the southwestern United States encounter particular barriers to health care arising from (157):

I. a lack of information about, and familiarity with, the services available;

II. negative social implications;

III. concerns over discrimination by a service provider and their own eligibility to use the services,

IV. perceived stigma associated with medical diagnosis (157).

Many Asylum Seekers and Refugees have difficulty in accessing health care and treatment because of the negative attitude of some of the host 
country's population (119). Ramsey et al (158), reported that a diverse range of problems had been identified by 50 GPs, at least 5 of whom stated their own anxiety in dealing with Refugee patients with language difficulties who therefore consume more time in consultation (158). Asylum Seekers and Refugees have been dispersed to places away from London and the south-east with no influence in the choice of where they are sent by either themselves or the local people in the places to which they have been sent, which creates resentment (148). Consequently, already traumatised by their experiences, they have become the targets of racism and discrimination, both face-to-face and in the local and national media (126). The Refugee Council has recommended that all service providers should look to combat negative and racist media coverage concerning Asylum Seekers and Refugees. Instead, they should promote positive images taking account of the oppression and discrimination they have suffered, such as recognising them as resourceful and capable survivors whose numbers include healthcare and other skilled and experienced professionals. Such positive media coverage could benefit both hosts and Asylum Seekers and Refugees. However, such recommendations have by no means always been adopted (148).

Asylum Seekers and Refugees are often given poor housing far from any others of their own nationality or culture, which results in further feelings of isolation. They are forced into long-term poverty by regulations which 
prevent them from working. Such destitution leads to further damage to physical and mental health $(126,148)$.

Problems of access for these groups are also compounded by the length of time the asylum claims process can take, which can range from a few months to several years. The legal access of Asylum Seekers and Refugees to health care has changed and varied over time in some European countries. In Germany, for example, Asylum Seekers and Refugees are given access to the same health care as German nationals three years after arrival. However, in Luxembourg, this is granted after three months (43). In the UK, Asylum Seekers and Refugees are entitled to all NHS services without payment and those who failed are restricted to primary care only (119).

\subsubsection{Legal rights}

The International Covenant on Economic, Social and Cultural Rights (ratified by the UK in 1976) guarantees the right of everyone to the highest attainable standards of physical and mental health, including Asylum Seekers and Refugees who are desperately in need of health care. Denying them this only brings negative public health and economic consequences (159). 
However, while local authorities are obliged to house those who have achieved refugee status, Asylum Seekers have few rights in UK law (148). Legislation in 2000 aimed to reduce the NHS services that could be accessed free by overseas individuals to treatment for emergency and life-threatening conditions, and some infectious diseases only (though excluding HIV/AIDS-positive); and there was a proposal to withdraw primary care (115). In the context of the abject poverty of failed Asylum Seekers who largely have to survive below subsistence level, this is considered by the UNHCR to be unrealistic, impractical and unkind, and to raise further barriers to accessing the standard of health care that they are entitled to in international law (115).

The legislation also raises ethical questions, and a mechanism needs to be established to ensure ethical standards are adhered to (119). Apart from the fact that Asylum Seekers and Refugees may be in desperate need of health care, who decides what is an 'emergency', 'lifethreatening' and 'infectious'? (159). Doctors' professional ethics oblige them to put their patients' needs first, and reception staff and healthcare managers are not competent to judge. If untrained personnel make inaccurate and arbitrary decisions, these could affect access even where there is entitlement (115).

Currently, Asylum Seekers in the UK can apply for free prescriptions, dental and optical treatment, and travel costs to and from hospital; but 
to access these they have to complete a 16-page form which is only available in English from the Health Benefits Division, for a certificate which is only valid for six months. These factors may present serious barriers to accessing health care especially for those on low income and poor or no English (126).

Hargreaves et al (115) noted that the consequences of these regulations, on both individuals' and national health care, had not been thought through, and the restrictions are inconsistent with vaccination priority and TB control which require prompt diagnosis and treatment (115). Health providers challenged these government policies on the grounds that they would create further significant damage to health and access to health care $(150,156)$.

\subsubsection{Medical screening}

Three categories of medical screening usually apply to new arrivals.

1) The most common strategy aims to protect the population of the host country from any disease brought in by Asylum Seekers and Refugees which may affect public health.

2) Some countries, such as Australia and Canada aim to exclude those having health disorders such as HIV/AIDS in order to avoid their demands on national 
health insurance programmes. For this reason, the International Health Regulations (IHR) permit the application of health screening measures for Asylum Seekers and Refugees(160).

3) Screening is important for Asylum Seekers and Refugees to improve their general health outlook, for example in checking the immunisation status of their children (131).

In most European countries, medical screening is systematically offered to new Asylum Seekers on arrival. However, in some countries, such as France, Austria and Britain, medical screening is carried out in induction or reception centres and those who do not enter such centres access medical screening randomly $(43,131,161)$.

Screening programmes in some European countries, such as Greece, are only offered to Asylum Seekers who have applied for permission to work, pregnant women or in connection with children's vaccination programmes (43).

The screening of Asylum Seekers is still a debatable matter, based on the principles of medical ethics and fundamental human rights which insist on respect for human freedom, dignity and cultural differences (131, 162). Despite the introduction in many countries of screening 
programmes for tuberculosis, HIV infection and other disorders, such procedures are also criticised on both ethical and epidemiological grounds. A positive HIV diagnosis for example, often leads to discrimination and stigmatisation. Mandatory screening and the lack of confidentiality over test results run counter to WHO's guidance on HIV testing and counselling(131, 163, 164). Furthermore, the International Organisation for Migration (IOM) indicates that it is not fair to refuse or exclude admission of those whose test positive for HIV. Such action may deny appropriate treatment to people in need of it $(131,165)$.

Many countries clearly implement such screening programmes in ways which act against both the spirit and the letter of such recommendations. However, WHO does not have the power to enforce them because each country has the right to control its own border (131).

\subsubsection{Detention}

Children may be held in detention with their parents who are the primary detainees. Because detention centres are usually in isolated areas, and are surrounded by barbed wire, social, health and legal staff find them difficult to access. Violence among inmates is an endemic risk, yet children are held for indeterminate periods of social and cultural isolation in close confinement with adults in these centres (166). 
In a study by Mares \& Jureidini (167) of 16 adults and 20 children in detention for 1-2 years in Australia, all the children had at least one parent with mental health problems (only two of whom had these prior to arrival in Australia). Of the adults, $87 \%$ suffered from major depression, $56 \%$ showed clinical symptoms of Post-Traumatic Stress Disorder (PTSD), 25\% had a psychotic illness and $31 \%$ had made significant repeated attempts to self-harm. All this impacted on the children's mental health and wellbeing. Ten of the children were under the age of 5 years and five of them exhibited delays in language development. Social and emotional development problems, difficulty in accepting regulations and attachment problems were also observed. There were nocturnal symptoms such as enuresis, and sleep disturbances including nightmares, sleepwalking and night terrors. In some cases, severe symptoms of distress included mutism, refusal to eat and drink and other stereotypical behaviour (167).

Among the six to 17 -year-olds there were also extensive mental health problems. All ten had PTSD, major depression and suicidal ideation, while eight had self-harmed - indeed, a culture of self-harm among detainees was noted. Seven showed symptoms of anxiety disorder while five had persistent physical health symptoms; and boredom, a sense of injustice, difficulty in sleeping, anxiety over delays in educational progress and a sense of shame were consistently reported (167). At a 12-month followup assessment the well-being of the five families still in detention had further deteriorated. Furthermore, among those who had now been 
released an initially improved sense of well-being had proved to be transitory $(167,168)$.

Steel et al (169) also conducted a study of mental health difficulties among 10 detained families in Australia. 14 adults and 20 children were detained for a minimum of two years. All the adults had experienced traumatic events prior to leaving their home country as well as en route to Australia (169).

The prevalence of psychiatric disorders in both adults and children showed a marked increase during detention. While $21 \%$ of adults retrospectively reported symptoms that would lead to a diagnosis of major depressive disorder, and 50\% were also retrospectively diagnosed with PTSD, the proportion after detention was $100 \%$ and $86 \%$ respectively. Two (14\%) were diagnosed in detention with severe depressive disorder with psychotic features. Prior to detention none of the participants had experienced suicidal ideation, nor had they selfharmed, whereas following detention $93 \%$ of adults experienced permanent suicidal ideation. Overall, a threefold increase in psychiatric problems was reported $(169,170)$. Furthermore, parents reported a marked decrease in their parenting abilities as a result of detention, which caused them distress. Only one felt 'able to care for and support children' in detention, whereas all stated they could do this prior to detention (169). 
Among detained children, a tenfold increase in psychiatric disturbance and disorders, compared with retrospective pre-detention diagnoses, was reported. At the time of assessment all were diagnosed with at least one psychiatric disorder, while $80 \%$ exhibited multiple disorders. In detention, $50 \%$ were diagnosed with PTSD, including some reexperiencing symptoms directly related to events in detention. All but one was diagnosed with major depressive disorder, $50 \%$ with separation anxiety disorder and $45 \%$ with oppositional defiant disorder. Of the $20 \%$ suffering from enuresis four out of seven children were in the normal age range for this disorder. Suicidal ideation affected 55\%, while $25 \%$ had self-harmed by head-banging or wrist-cutting. Before detention, by comparison, only one child had exhibited criteria for multiple disorders (depression, PTSD and separation anxiety), while two others were retrospectively diagnosed as suffering from either depression or separation anxiety $(169,170)$.

All the participants in these studies reported experiencing traumatic events during detention. Upsetting memories of the time in detention, and 'images of threatening or humiliating events in detention' caused distress to all the adults and $90 \%$ of children in one study. The adults all reported 'feeling extremely sad and hopeless', and feelings of increased anger, while all the other detention-related symptoms discussed above caused distress in $86-100 \%$ of adults and $53-90 \%$ of children. The negative effects of detention on children derive from both the effect of 
detention on their parents' mental health, to which children are highly sensitive, and the detention environment itself, with children exhibiting separation anxiety, disruptive behaviour and impaired cognitive development (169).

Although both studies are limited by methodological problems, the findings nevertheless suggest that an overall deterioration occurs as a result of both the detention process itself and specific negative experiences while in detention; and that children's mental health is directly affected both by the effect of detention on their parents and by their own first hand experiences $(169,171)$.

\subsubsection{Housing}

While Asylum Seekers in the UK have no rights to housing, local authorities are obliged to find accommodation for those who have achieved refugee status (119). However, there is widespread and dissatisfaction among Refugees over the location of housing, which is concentrated wherever local authorities have made it available rather than near others from the same or similar ethnic or cultural backgrounds (119).

The quality is often poor. In the early years of the $21^{\text {st }}$ century, up to 2,600 people per month were dispersed in this way to regions outside 
London and the south-east. Children's health is especially sensitive to poor accommodation and the resulting parental stress, to the extent where both the physical and mental health of the whole family are affected (148). Furthermore, if such housing is distant from appropriately developed health services, these will be difficult to access especially if there are no other people of the same ethnic origin established in the area who might help them do so. This is also the case for Asylum Seekers who, though they may have been given access to some free NHS services in theory, in practice these can be hard or impossible to reach and therefore use $(126,148)$.

In previous studies conducted with families from different population groups in the US, such as Hispanics, Wood et al (140) and Lewis et al (172) reported claims from parents in such vulnerable groups that transport difficulties and excessive waiting times for medical care also further caused them to defer their children's medical visits. In these studies parents also cited transport problems to routine clinic visits for their children as among their most common difficulties, with more than $35 \%$ of Latino mothers of children with asthma reporting that lack of transport reflected negatively on their children's access to treatment $(140,172)$.

The area of residence itself was considered to be a further barrier to health care. Geographical inequalities affecting service provision remain 
significant, especially in rural areas. In the US, for example, children living in suburbs were more likely to be up to date with vaccinations than those living in urban or rural areas, and those who were not covered by health insurance. Where people live in relation to healthcare providers plays a significant role in accessing health care (173). A study of Latino immigrants in the US indicated that their children with chronic illnesses living in the south or west were more likely to be uninsured than those in the north-east or mid-west (174).

\subsubsection{Economic factors}

Health is affected by poverty, and many Asylum Seekers in the UK live below the poverty line (126). Legislation introduced at the turn of this century allowed Asylum Seekers a maximum of $70 \%$ of the state benefit level (then $£ 36.54$ ) for a single adult person per week. Of this, $£ 10$ was paid in cash, the remainder in vouchers to be exchanged for goods in participating shops. However, retailers were not allowed to give change when exchanging vouchers, which, combined with Refugees' difficulties in understanding the system, ensured that the allowances were in practice, worth less in actual use than their face value suggests $(126,148)$.

Asylum Seekers are forbidden to work and therefore prevented from supplementing their income, and as a result they are trapped in a humiliating poverty and absolute dependence likely to have serious consequences for their psychological and mental as well as their physical 
health (120, 126). Connelly et al (148) suggested that all service providers should monitor sensitively the health of Asylum Seekers forced to live below the poverty line in this way, devoid of human right (148). Hargreaves, Hogan, Singer, and Williams (156, 175-177) found that poverty combined with social dislocation is especially liable to affect the mental health of both parents and their children. Health care provision must be complemented by housing, income and social support to achieve an individual's good health(150).

Hargreaves et al (115) concluded that it is important to manage the health problems that are in themselves important but not urgent, lifethreatening or emergencies, to prevent future illnesses and emergencies. It is not cost-effective to make treatment for these inaccessible, or even forbid them, if in-patient treatment is consequently needed later. Similarly, blocking access to primary care may later put pressure on hard-pressed A \& E departments through failing to treat symptoms at an early stage (115).

Poverty is also a very real barrier to access to medicines in the US, where the cost of medicines and doctors' fees were the most frequently cited problems for parents from minority groups who do not have health insurance (172). Low income was also found to be associated with the decrease in the number of children whose parents could not afford health insurance visiting emergency departments (142). Previous studies have 
shown children from most poor Latino families, compared with other US children, to be uninsured, a situation which is considered to be a significant cause for delaying necessary immunisations $(141,142,174)$.

In another US study of Latino parents, more than $60 \%$ reported that they were unable to afford medicines for their asthmatic children, and that they were therefore much less likely than those with higher incomes to have access to immunisations and optimal treatment (140).

\subsubsection{GP-related barriers}

Difficulties in obtaining full registration with a GP, and the entitlement to benefits that this brings, are widely identified in the literature from the UK as major barriers to accessing health care, treatment and medicines for Asylum Seekers and Refugees (119, 150). Previous studies indicate difficulties in obtaining GP registration, with lack of language support and a failure to meet mental health and chronic illness needs $(150,178)$.

In a previous study in the UK (1992), 38\% of Asylum Seekers and Refugees in Islington are recorded as having difficulty in registering (119). They may be asked for documentation such as passports, which they do not have. Because of their special needs, including language problems and other multiple difficulties of which health problems are only

a part, consultations take a disproportionate amount of GPs' time 
especially when an interpreter is needed. Additionally, they are not adequately resourced or compensated for this extra work. But if the necessary time is not taken, it leads to unsatisfactory consultations. GPs are also uncertain how to manage Asylum Seekers' and Refugees' mental health problems, and where to refer them; they are therefore reluctant to take on people from these minorities, and so they register them temporarily rather than fully $(119,153,154)$.

New arrivals to the UK may be identified and directed to dedicated services where these exist, rather than mainstream practices, because the latter find large influxes of new patients - especially those with such complex problems - difficult to cope with $(150,152)$. Temporary registration also prevents their access to past records if they exist, and removes the entitlement to, and therefore the need for financial incentives given to encourage immunisation, smear tests and other preventive diagnostic measures not available to the temporarily registered (119).

Asylum Seekers in the UK are entitled to all NHS services; and though they can be registered with a GP, can only be issued with an exemption certificate for prescription, dental and optical care charges once accommodation has been allocated(126, 148). 
However, Jones; Healy; and Trafford (119, 153, 154) recognised that many GPs are unsure of Asylum Seekers' entitlements. While only they are qualified to judge what constitute the 'emergency', 'life-threatening' and 'infectious' conditions for Asylum Seekers and Refugees, their ethics oblige them to put the patient first. But some health problems are important rather than urgent, creating dilemmas in such fields as antenatal screening and care, child immunisation, and asthma and diabetes care. Though these conditions may not be life-threatening all the time, it is important to manage them so as to prevent future serious illnesses and emergencies (115).

Feldman (150) has suggested that to benefit fully from the UK healthcare system Asylum Seekers and Refugees need access to primary care and full registration. Jones et al (119) indicated that providing all practices with guidelines for registering Asylum Seekers and Refugees would help to improve primary care for them. Feldman and Aldous $(150,151)$ conclude that full registration with a general practice would enable access to all mainstream services and a new patient full health assessment, and suggest that as part of core services for Asylum Seekers and Refugees practices might be given incentives to register and improve provision for these people. 


\subsubsection{Health records}

A major barrier to access to health care for Asylum Seekers and Refugees in the host country is poor primary care in the country of origin such as Bosnia (179), resulting in unavailable health records (119). Asylum Seekers and Refugees may have collections of drugs and medicines from the country of origin, many of which are inappropriate, but on arrival in the host country language problems mean that health workers are unable to take an adequate medical history (126). Availability of medical records in the host country would improve continuity of care and primary care for Refugees, as would recruiting healthcare facilitators from each specific Refugee population to help establish accurate and detailed medical histories (119).

A further major problem highlighted by Aldous and Wilson $(151,180)$ is the lack of written reports and evaluations by the host country. Problems of provision are worsened by poor information on new arrivals and difficulty in estimating numbers, especially in London. Such a lack of published evaluations and reports constrains further policy development that could build on strengths and interventions.

Little evaluation has been undertaken of the effectiveness of interventions, and therefore little evidence exists to guide Primary Care Trusts (PCTs) and others (150). Wilson (180) and Johnson (181) suggested that, PCTs should establish and improve data collection 
systems to facilitate the planning and development of healthcare services, for example numbers and demography, by area.

\subsubsection{Language problems}

To benefit fully from the UK healthcare system Asylum Seekers and Refugees need access to translation, interpretation and advocacy services for their own languages (150). Without them they cannot access information, communicate with health and social workers and receive through them appropriate care $(120,150)$, nor can medical records be accessed where they do exist or created where there are none. Though Asylum Seekers and Refugees may have free access to NHS services in theory, in practice such language barriers in consultations may make these very hard to access $(140,148,172)$.

Furthermore, health authorities are often ignorant of which languages are spoken by Refugees in their areas, and the extent of the need for interpreters. The lack of professional interpreters makes the situation even worse for Refugees with psychological and emotional problems (119). This lack of translators and failure to use interpreters has been identified by health professionals as the largest barrier to accessing healthcare services (150) and one that affects most Asylum Seekers and Refugees. Language barriers are encountered when trying to travel to healthcare facilities, at the reception desk and when trying to make appointments, as well as in the consulting room (119). 
Translators are also able to mediate, explaining the cultural context of symptoms. Health professionals need to know the 'life stories' of Refugees if they are to be able to help them. Understanding a patient's trauma history, which may include witnessing or experiencing physical violence including torture and or sexual violence including rape, often in war situations, is vital for effective treatment, especially where such experiences may have led to psychiatric, trauma-related or other disorders. Primary care for Refugees begins with understanding their reasons for flight and their psychological traumas (149). Burnett et al (126) indicated that talking about abuse for the first time is therapeutic, but health workers are short of time and access to interpreters is limited-significant obstacles to accessing such therapy.

A short semi-structured interview was undertaken by Ramsay and Turner in London 1993 (158). It demonstrated that because of their special needs, Asylum Seekers' and Refugees' consultations with GPs take a disproportionate amount of their time, with communication problems increasing the time needed even more. Yet if this time is not taken, consultations may be unsatisfactory (119). Previous studies indicate a lack of language support with GPs experiencing increasing pressures of work as a result $(150,153)$. 
Where specialist clinics using interpreters and nurse practitioners exist within general practices, problems can be identified in the first consultation, meaning that the second and subsequent consultations can be shorter (150). Bilingual link workers can liaise between health professionals and minority communities, keep healthcare staff informed, facilitate health promotions and increase all-round awareness of the services available to Asylum Seekers and Refugees (150, 182). Training not only health workers but also reception staff is also important and has been requested by both Asylum Seekers and Refugees and their professional workers; and the value of training and supporting bilingual clerical staff, especially interpreters, has also been remarked on (150, 182).

Provision for translators and interpreters was found to be variable by health authorities. In some areas in London, there was little use of bilingual health advocates, owing to the heterogeneity and changes in the population of Asylum Seeker and Refugee communities $(150,183)$. In other areas in East London, information is already being produced in appropriate languages to improve access to, and the use of, healthcare services $(150,184)$.

In Doncaster in the UK, the use of a specific interpretation service (Dove) facilitates continuity with health services, especially where sensitive consultations concerning such subjects as rape, torture and mental 
health problems are involved $(150,185)$. Harpweb, the Health for Asylum Seekers and Refugees Portal, provides electronic multilingual resources such as a translated appointment card, and has links to other agencies' resources; Language Line was also widely used for interpretation services, while all the healthcare services in Doncaster's study said they could access their local PCTs' interpretation provision(150, 186).

Similar conclusions were reached by Glenn Flores et al (173) in the US, where over $25 \%$ of Latino parents cited language problems as the greatest barrier to accessing health care, resulting in serious consequences for their children's health. Approximately $75 \%$ of those spoke English either not very well or not at all, and therefore some parents did not bring their children for primary or emergency health care $(173,187)$. Several parents also mentioned that, because of their language problems, their children received poor medical care resulting from misdiagnosis and inappropriate medication(188).

The availability of appropriate interpreters and advocates is essential unless health care workers and their Refugee patients speak the same language. Using interpreters trusted by those patients, rather than family members or friends, provides health workers with valuable information on cultural and other relevant issues (120). Such interpreters can also 
help to discuss such sensitive issues as gynaecological problems, sexual health and violation, torture and domestic violence (120).

\subsubsection{Mental health}

Asylum Seekers and Refugees are known to be at high risk of psychiatric and mental disorders. However, they often do not have access to appropriate treatment (189). Social and psychiatric aspects represent most of the problems of Asylum Seekers and Refugees. Previous surveys $(120,163)$ on Asylum Seekers' and Refugees' health in the UK have found that infectious diseases and mental health problems are both considered major concerns for healthcare professionals. These surveys also indicated that approximately two third of such groups of people have mental disorders such as depression, anxiety and stress disorders. Furthermore, due to their experience of torture and organised violence, one in every six Refugees has a physical health problem severe enough to impact on him/her for life $(131,190)$.

In the UK, those who are seeking asylum often face many factors which may undermine their physical and mental health even further, such as lack of social support, racial discrimination, absolute dependence and poverty. These factors induce inequalities in access to health care and affect Asylum Seekers' opportunities and quality of life $(148,191)$. 
Identified incidences of depression, PTSD and suicidal thoughts have been recognised amongst Asylum Seekers and Refugees. All these are identified as consequences of political oppression, torture, separation from families, bereavement, isolation from social help and leaving their country, along with cultural and social factors, the effects of detention and the legal complexities and uncertain drawn out timescale of the asylum process. Policy makers and service providers therefore expect high demands on health services by Asylum Seekers and Refugees (189, 192).

Asylum Seekers and Refugees may come from countries where there is upheaval and violent conflict, where the health systems have collapsed and where they fear for their lives if they are returned (115). The high incidence of mental illness among them is due to a combination of factors, and primary care needs to start with understanding their trauma history which may include experiencing or witnessing physical and/or sexual violence, including rape and torture, as well as their anxiety until their future is decided $(115,119)$. This stress may lead to psychiatric illness, trauma and disorders in addition to the poor physical health resulting from what they have been through - PTSD is known to be a common consequence of violence - necessitating a holistic approach to their treatment (149). 
Once they are in the UK many of them are trapped in poor housing, poverty, social dislocation and the humiliation of absolute dependence, all of which is likely to endanger their mental health still further (148). Children are especially sensitive to poor accommodation and parental stress and may exhibit symptoms of mental illness (148).

Asylum Seekers and Refugees are at much higher risk of psychiatric disorders than others, and may not respond to drugs alone as trauma treatment. Behaviour therapies may be appropriate too (149). To get full benefit from UK health care these people need full mental and physical health assessments, and responses to their mental health problems as much as their physical ones $(193,194)$. Furthermore, western diagnostic categories may not describe Refugee problems adequately: for instance, symptoms of bereavement and demoralisation may be diagnosed and treated as depression(149).

Mental illness coupled with inadequate mental health services constitute major problems for survivors of torture and organised violence (163, 195). The Scrutiny Report on Access to Primary Care recorded that in London 2003, mental health provision needs to double or treble to be adequate, and the lack of psychiatric care appropriate to a patient's culture and language may represent another barrier to effective treatment $(186,196)$. Limited mental health services are available within mental health trusts, or run by independent bodies. Some of these 
include survivors of torture and violent conflict in their remit, but they may not be available to Asylum Seekers and Refugees (197-199). Some specialist practices have in-house staff, or in-house sessions with community health professionals such as nurses and counsellors. Therefore, only more serious cases are referred to mental health services. Pilot schemes offering mental health provision in Humberside and Yorkshire said they felt under-resourced(150, 200).

\subsubsection{Cultural barriers}

Asylum Seekers and Refugees suffer from 'cultural bereavement and deeply disruptive changes to their lives (119). Problems for the health workers caring for them include a lack of understanding of the cultural difficulties they encounter in a host country with different cultures, practices and values: for example, it is not in the culture of many Refugees to make demands $(119,126)$.

Cultural bereavement is hard to address if Refugees are dispersed to areas with no others of the same ethnic origin and without appropriately developed services and language support (148). These cultural barriers may be addressed through involvement with existing Refugee communities which can source interpreters, advocates and link workers, and where partnership initiatives have been developed with these communities to supply social and counselling services. These links are vitally important in disseminating information, and can facilitate PCTs' 
planning and development of appropriate healthcare services. Training health workers and reception staff is important and has been requested by both Asylum Seekers and Refugees and their professional workers, especially in the field of cultural awareness $(150,181)$.

Advocates from within Asylum Seeker and Refugee communities in particular can play an important role in overcoming cultural barriers. Incomers can find it easier to talk about experiences involving personal violation and other traumas with an advocate or interpreter who is a comparative stranger than with family members, especially those of the opposite sex, which their culture may not allow. This can lead more quickly to appropriate diagnoses of, and treatments for, physical conditions and mental illnesses $(120,150)$.

Uba (201) highlighted the types of cultural barriers to health care for south-east Asian Refugees in the US. These barriers included cultural beliefs, and unfamiliarity with western diagnostic techniques and treatments leading to misunderstandings over realistic expectations and outcomes.

This group of Refugees believed that suffering is unavoidable and the length of life is predetermined; therefore, medical care is inappropriate and life-saving care is worthless, both of which inhibit them from seeking medical help (201). Stoicism in the face of suffering is also believed to be 
commendable, causing further delays. Beliefs concerning the sources of illness differ from western beliefs, leading to a preference for traditional herbal medicines over western treatments (201-204). Since the help sought varies with the believed source or cause of the illness, it includes the involvement of faith healers and shamans as well as western providers $(205,206)$. Western medicine is widely mistrusted, and often sought only when traditional treatments have failed, frequently delaying until it is too late and leading to an association of western medicine with death (207). Some believe that surgery upsets the soul and immunisation endangers a baby's spirit, beliefs which are clear barriers to accessing treatment $(201,208,209)$.

Once help is sought, unfamiliarity with western diagnostic techniques can easily lead to a misinterpretation of their function and further disillusionment with western medicine. The use of X-ray is given as an example: a doctor uses X-ray as a diagnostic tool, but if a patient thinks it is a treatment and experiences no cure as a result, it appears that the 'treatment' has failed $(208,210)$.

If patients believe they have different constitutions from whites, western dosages can seem inappropriate. Therefore prescriptions do not get dispensed, correct dosages are not taken and the patient may stop taking the medicine if he feels 'cured'. Since the importance of taking medicines as prescribed is also not appreciated, their resulting 
ineffectiveness is attributed to western medicines being inappropriate for Asians, and they avoid further encounters with it $(201,204,209,211)$.

Mikhail et al (212) found that the use of home remedies presented other significant barriers to health care. Parents in some vulnerable groups in the US preferred to use a combination of over-the-counter (OTC) preparations and home remedies as the treatment of first resort for fever, cough, rashes, diarrhoea and vomiting, rather than seeking professional medical care $(173,212)$.

Western health care providers' ignorance of south-east Asian cultures leads to problems in delivering health care effectively. As with many Refugee populations, poor doctor-patient communications, often resulting from inadequate translation services, create barriers to health care delivery (213). Lack of cultural awareness can affect non-verbal communication, too. In one culture, pointing one's foot at another person is seen as insulting. Therefore, a doctor trying to create a relaxed atmosphere in a consultation by sitting back and crossing his knees may unwittingly be insulting a patient if his foot points towards him as a result (201).

Misinterpretation of some of the results of south-east Asian medicine has also created barriers. Where traditional treatments have included cutting or marking the skin, for example, this has been interpreted as self or 
domestic abuse (201). Refugees have therefore become wary of seeking western medicinal help after some traditional medicines have proved ineffective, for fear of the law $(115,201,214)$.

Cornelius et al (187) found that differences between Latino and US culture were identified as a barrier to accessing health care, with some Latino parents stating that it was because healthcare staff did not understand their culture that they did not take their children for medical care (187).

\subsubsection{Stigma and discrimination}

\section{Stigma}

Link and Phelan's (215) definition of stigma is based on their conceptualisation of it as a process whereby stigma can be generated by one or more of five interrelated components:

1) involves labelling and identifying human differences such as ethnicity and skin colour, which are significantly noticeable in social contexts;

2) involves stereotyping, when undesirable characteristics are associated with a person or group;

3) involves separating and setting stigmatised groups apart from others in the population; 
4) involves the stigmatised groups losing its status and experiencing discrimination through exclusion and being linked to undesirable characteristics;

5) involves the stigmatisation most often associated with the exercise of power. Therefore, a reverse stigmatisation will be visited on the low-power groups.

\section{Discrimination}

According to Link and Phelan's (215), there are three forms of discrimination:

1) Direct discrimination includes the overt refusal to engage with ethnic minorities and rejection of their work applications;

2) Structural discrimination is more subtle and indirect for example, not providing treatment of stigmatised diseases such as schizophrenia in isolated area or dangerous and poor neighbourhoods;

3) Insidious discrimination which includes stigmatising through negative labelling, rendering individuals vulnerable to accusations of being stupid and less trustworthy than others. 
Individuals who experience these forms of discrimination may avoid contact, and act more defensively and less confidently with others. Therefore, strained and constricted social interactions may result (216).

Some ethnic groups seeking asylum in the UK may avoid seeking health care due to the stigma associated with their refugee status (217).

Cultural and language barriers, in addition to poor experience of healthcare professionals treating Refugees as a burden on NHS resources, may play a major role in making some Refugees and Asylum Seekers feel stigmatised (217). The impact of such attitudes affects the extent to which they access health care and reduce the number of their visits to GPs or hospitals $(217,218)$.

A case study in the US by an American psychologist showed the perceived stigma attached to mental illness is a potential barrier in accessing Western psychological services by some ethnic groups (219). For example, south Asian Refugees believe that alternative Asian treatment is better than Western health care. Confidence in their indigenous treatment and fear of shame induces a reluctance to seek healthcare $(69,70,220-222)$. 
Refugees and Asylum Seekers from south Asia show unfamiliarity with mental health services (223). Individuals and families from the south Asian community in England, for example, have relatively low hospital admission rates for mental illness compared with the indigenous population (224). This may be because of the perceived stigma of mental or emotional illness, leading to reluctance to accept appropriate treatment $(189,224,225)$.

Reidpath et al (226) indicated in a prospective study that some cultures believe that mental illness is inherited. Consequently, such illness in one member of a family could have serious implications for other members' marriageability and damage the family reputation (226). Furthermore, some south Asian families believe that the identification of such illness might lead to the curtailment, or even cessation, of benefits by the host government, and this information may spread through government with detrimental effect on their applications to stay in the country (227-230).

The stigma associated with those classed as Refugees creates a significant barrier to accessing health care and medicines not only for themselves but also for their children $(217,230)$. These groups of people want the attitude of society towards them to change, and for the indigenous population to understand the real reasons behind their coming to this country instead of assuming they are only coming to get free access to treatments and healthcare services (217). Many Refugees 
expressed the view that non-discrimination, by healthcare professionals, allowed them to feel more comfortable with the health system in the host country (217).

Good communication between experienced healthcare professionals and Asylum Seekers or Refugees by understanding their needs leads to improvement in their access, and reduces the stigma that might be associated with refugee status (217). More appropriate health-seeking behaviour can be achieved by such communication. Furthermore, effective mental health services to all ethnic minorities are provided by many agencies which mainly reduce the attached stigma and allow Asylum Seekers and Refugees to avoid it $(230,231)$.

Stigma has a significant negative effect on many of life chances. For an Asylum Seeker or Refugee stigma may affect access to medicines and medical care or an opportunity for employment and housing (215).

\section{Stigma and stress}

Stigma also generates a constant threat to good health outcomes, both mental and physical (215). Denying positives and suffering negatives are both considered as major sources of chronic stress and other related health problems. The fear of some ethnic groups of being labelled with 
stigmatised diseases such as epilepsy may cause individuals to delay or avoid seeking appropriate treatment altogether $(232,233)$.

\subsubsection{Isolation}

A study conducted in London which focused on Iraqi Asylum Seekers found there was a clear link between poor social support and depression (234). Therefore, developing friendships with people and communities in the host country, in addition to maintaining contact with other people from their own country but elsewhere in the UK, was found to be the best way to achieve optimum mental health. However, hostile media headlines have sometimes prevented the establishment of such relationships and increased the negative feelings towards minority groups, leading to racist attacks (120, 234-237).

There are many community and religious organisations supporting Asylum Seekers and Refugees. They provide them with useful information and orientate them, helping to reduce the isolation which many of them are known to experience (120).

\subsection{Combating the Problems}

Burnett et al (120) stated several suggestions need to be made as to how the situation for Asylum Seekers and Refugees might be improved. Local councils, health authorities and voluntary agencies need to co- 
operate to plan and co-ordinate services. An information pack needs to be created to include a certificate of entitlement to NHS services, with the NHS also providing primary care. The goal needs to be integration of these with existing mainstream services, with Asylum Seekers and Refugees having the same rights to health care as the rest of the host country population. If actioned, all these would contribute significantly to removing some of the main barriers to accessing health care. Poor access for these minorities to primary health care in the host country may mean that many medical conditions will not be treated (120).

\subsection{Summary}

The literature review begins to explain the barriers faced by Asylum Seekers and Refugees in accessing health care. These are many but those of most significance are related to inequality, stigma and discrimination.

This inequality is related to place of residence, ethnicity, socioeconomic status, culture, language competence, health records, mental health and regulations. These widespread factors create barriers which may limit or prevent children and their parents within particular groups from access to medicines, and deny them optimal treatment (112-114, 238). 
Thus, strategies for the $21^{\text {st }}$ century need to focus on ensuring that all barriers to accessing health care are recognised and removed (31). Only then will there be a guaranteed universal healthcare provision for all children (239). Social, cultural and behavioural barriers to optimise health care need to be eliminated (240).

This review of the literature demonstrates that these minority groups of Asylum Seekers and Refugees have significant barriers to health care and medicines. Further research is needed, particularly focussing on children and their use of medicines, and whether this is affected by their parents' status and background.

Following the literature review of work covering Asylum Seekers and Refugees, chapter 4 similarly reviews the literature on Gypsies and Travellers. 


\section{CHAPTER FOUR}

\section{PROBLEMS OF ACCESS TO HEALTH CARE AND MEDICINES FOR GYPSIES AND TRAVELLERS}

\section{Review of Literature}

\subsection{Introduction}

This chapter reviews the current literature relevant to another group of minorities in the UK - Gypsies and Travellers. It will explore the key issues and problems that these groups may encounter.

It begins with important background information on Gypsy and Traveller history and lifestyle. This considers their way of travelling and their experiences, before focusing on children's health and types of barriers and difficulties they face in accessing healthcare services. It finally presents some suggestions for combating the problems, and conclusions based on the review findings. 


\subsection{Method}

Literature searches of computer databases were performed using OVID, MEDLINE (data range, 1950-April 2012), EMBASE (data range, 1980April 2012), CINAHL and Pub Med search of documents published from 1995 to 2012, Google Scholar (updated to April 2012), published in English, with text and medical subject headings. In addition, manual searches of the reference list of relevant studies were used to identify further appropriate papers.

\section{Main inclusion criteria}

The following key criteria were used to refine the search and to identify material that would be included in this literature review:

- Sources covering the last 30 years

- Evidence-based research

- Publications, in English, including peer review articles, extracts from books, case studies, anecdotal reports, government and other reports, and primary researches.

- Articles relating to the following terms, health care access, ethnic minorities, Gypsy, Traveller, children's access, and access barriers to health care and/or medicines.

\section{Main exclusion criteria}

- Unrelated abstracts 
- Duplicate articles

- Non- English sources

- Other publications not compatible with the inclusion criteria.

\subsection{Results}

95 abstracts of publications were identified. Duplicates and unrelated abstracts were excluded. The resulting publications were then limited to papers published in English of which full texts were obtained and screened further to exclude studies not compatible with the inclusion criteria. Ultimately, 46 published papers relating to access to health care and medicines for Gypsy and Traveller groups were included in this literature review (Figure 4.1). Some of the articles I have referred to are review articles. However to further explain specific points in these review articles I have referred back to the original papers mentioned in these reviews. This is the reason why my literature review contains references to many old papers. The format of these papers is presented in table (4.1). 
Figure 4.1: Flow chart

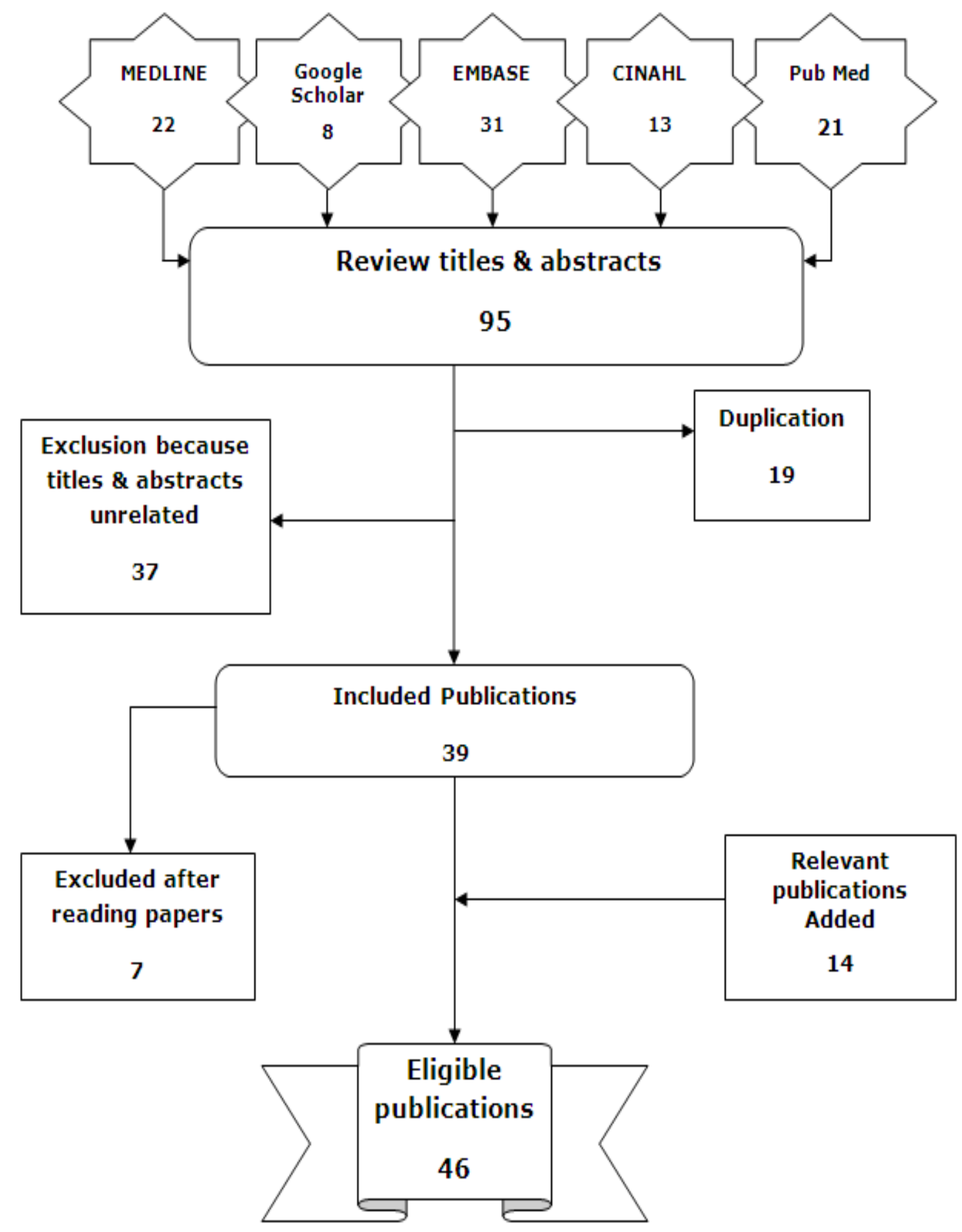


Table 4.1: Format of publications

\begin{tabular}{|l|c|c|}
\hline Format & No of papers & Percentage \\
\hline Review & 6 & $13 \%$ \\
\hline Case report & 10 & $22 \%$ \\
\hline $\begin{array}{l}\text { Personal opinion } \\
\text { (case, prospective, } \\
\text { retrospective, observational) }\end{array}$ & 8 & $17 \%$ \\
\hline Others & 13 & $28 \%$ \\
& 9 & $20 \%$ \\
\hline Total & 46 & $100 \%$ \\
\hline
\end{tabular}

The results will be presented and discussed in four broad themes which have emerged from reviewing the literature. The first section consists of the definitions of 'Gypsy' and 'Traveller', with an overview of their background and history. The second section explores the concept of access to healthcare services and medicines for Gypsies and Travellers. It evaluates the health status of this community. The third section presents an overview of their children's access to health care and medicines with a focus on the immunisation status of those children. The forth section presents an overview on specific barriers to accessing health care and medicines which mainly relate to the lifestyle of these groups of the population. 


\subsection{Overview of Gypsies and Travellers}

\subsubsection{Definitions of Gypsies and Travellers}

The legal definition of Gypsies was first introduced in the 1968 Caravan Sites Act, which defined "Gypsies" as:

"persons of nomadic habit of life, whatever their race or origin, but does not include members of an organised group of travelling showpeople or persons engaged in travelling circuses travelling together as such"(241).

Nowadays, Gypsy and Traveller groups are defined together as:

"persons with a cultural tradition of nomadism or living in a caravan; and all other persons of a nomadic lifestyle, whatever their race or origin including such persons who, on grounds only of their own or their family's or dependants' educational or health needs or old age, have ceased to travel temporarily or permanently"(241).

However, according to the Housing Act 2004 they are defined as: "persons with a cultural tradition of nomadism or of living in a caravan; and all other persons of a nomadic habit of life, whatever their race or origin, including: 
I. such persons who, on grounds only of their own or their family's or dependants' educational or health needs or old age, have ceased to travel temporarily or permanently; and

II. members of an organised group of travelling showpeople or circus people (whether or not travelling together as such)"(242).

\subsubsection{History of Gypsies and Irish Travellers}

\subsubsection{Gypsies}

Four papers, in the UK (242-245), summarised the history and background of Gypsy and Traveller populations. Historically, about 1000 years ago Gypsies left their country of origin in the northern Indian subcontinent and headed towards the west. Over the centuries they were thought to have travelled and settled where they were welcomed (242). They are thought to have arrived in England during the reign of Henry VIII and at that time the indigenous people thought they had come from Egypt (242). Therefore, they were called 'Egyptians'. The name changed over time to 'Gyptians' and finally to 'Gypsies'. Their original language is Romany which has its roots in Hindi but developed over the years as influenced by the host language $(242,246)$. Today, many of them are bilingual which means they speak Anglo-Romany at home. This is the reason behind the absorption of some Romany words into English: for instance, 'pal' can mean 'brother' and 'mush' can mean 'man' $(242,243)$. 


\subsubsection{Irish Travellers}

There were nomads in the UK when Gypsies arrived (242). Irish Travellers moved around the country in bender tents and wagons. Until the $19^{\text {th }}$ century they were commonly known as Tinkers which came from 'tinceard' which means 'tinsmith' in their ancient pre-Gaelic language (242). This language is called Shelta and some Travellers still use it alongside English. Though called 'Irish Travellers' by the English, they call themselves 'Pavee'. They consider themselves to be the indigenous population of Ireland like Native Americans in North America and Aborigines in Australia. Although there is occasional intermarriage between Irish Travellers and English Gypsies, they remain two distinct groups (242).

It is difficult to establish accurately the number of Gypsies and Travellers in the UK as they typically live in caravans (245). This is because these caravans need to be distinguished from other types of caravans or mobile homes. The first official count of such caravans was made in 1979 and recorded about 8,000 in England. This rose in 2000 to about 13,000 caravans that are considered to represent about 10,000 families (244). Recent estimates of the Gypsy and Traveller population in the UK vary widely from 82,000 to 300,000 including those living in bricks and mortar housing $(244,245)$. 


\subsection{Overview of Access to Health Care Services and Medicines}

Nine papers (all from the UK $-72,74,247-253$ ) discussed accessing of Gypsies and Travellers to healthcare services. Gypsies and Travellers are considered the most socially excluded groups in the UK. Despite some legal protection, social and cultural differences as well as their travelling lifestyle result in poor access to healthcare (74). These issues are often consistent with low expectations of access to healthcare $(72,247)$.

Gypsies' and Travellers' access to healthcare services has been researched by Hawes (248) and Jenkins (249). These two case studies indicate that, for a wide variety of reasons, Gypsies and Travellers tend to make less use of health services than other members of the population, despite having greater need of them.

The Scottish Executive found there was little advocacy support for Gypsies and Travellers who have difficulties in accessing health services $(250,251)$. Beach's work on childhood accidental injury rates has shown that Gypsies and Travellers regularly use A\&E departments for treatment for their children, since they have no other option (252). As a result of being compulsorily moved on, Travellers have to depend increasingly on walk-in centres and A\&E departments. Follow-up is therefore difficult, 
especially in the absence of GP registration. This results in interruption, delays and discontinuity in medical treatment and care (253).

\subsubsection{General health}

The health of Gypsies and Travellers is likely to be worse than the rest of the population at large, even when compared with other deprived groups and taking socio-economic status into account (254). Arthritis, asthma and chest pain were found to be more prevalent in a group of 260 Gypsies and Travellers than in an age- and sex-matched comparator group (254). Chronic cough or bronchitis was more than three times as common as in the comparator group. Results also showed a high rate of long-term illness and difficulty with mobility in the Gypsy and Traveller Group (table 4.2) (254).

Table 4.2: Health status of Gypsies and Travellers (254)

\begin{tabular}{lcc}
\hline & Gypsies and Travellers & Comparator group \\
\hline Arthritis & $22 \%$ & $10 \%$ \\
Asthma & $22 \%$ & $5 \%$ \\
Chest pain & $34 \%$ & $22 \%$ \\
Long-term illness & $38 \%$ & $26 \%$ \\
Difficulty with mobility & $25 \%$ & $15 \%$ \\
\hline
\end{tabular}

Lower exercise levels among Gypsies and Travellers, and a significant lack of fresh foods within an overall much poorer diet, were reported in an outreach project in Wrexham (255). These groups were compared 
with a control group from a deprived local area. The project also identified much greater self-reported depression and anxiety rates in the Gypsy and Traveller group, and risk of early death from heart disease among the men (255).

In a survey of 89 Travellers in the south-west of England, 39\% admitted to ill-health (256). This included chronic liver disease related to substance abuse, and other conditions associated in some cases with addiction. Ignorance throughout the community, many of whom were diagnosed with diabetes, of the risks factors involved or the significance of such a diagnosis, was discovered by Saunders (257).

Phal and Vaile (258) found that infant mortality among these communities was three times higher than in the population at large. Stillbirth and miscarriage rates were also found to be high $(258,259)$. Brack reported that road traffic accidents, regularly related to speeding and alcohol abuse, are causes of premature death among young members of these groups (260). Road traffic accidents were responsible for $16 \%$ of deaths among Irish Travellers in a study in Dublin (260). 


\subsection{Overview of Children's Health and their Access Barriers to Health Care}

Nine papers (all from the UK - 252, 254, 256, 261-264, 266, 267) summarised children's health status of Gypsies and Travellers and their barriers to access. Phal and Vaile (261) found Gypsy and Traveller children to be suffering higher rates of illness than their peers (261). These children not only encounter many of the same barriers as Asylum Seekers and Refugees but their traditional nomadic way of life also creates barriers of its own that have major implications for health care. Such barriers include a lack of safe, healthy sites for their trailers and the constant fear of eviction from roadside and illegal sites. In addition, there is a constant fear of active hostility from the local population(261, 262).

Where families are living on inadequate sites, a higher accident rate among children, especially for under-fives, including burns, scalds and lacerations has been reported (252). Road accidents result from living on roadsides and in trailers (254). The typical isolation of their accommodation sites make it difficult for them to reach minor injuries units, immunisation programmes, dentists and opticians (263). Furthermore, complicated registration processes have been seen to be strong deterrents (264).

Difficulty in obtaining full registration with a GP often leads to incomplete immunisations and a lack of medical records and diagnostic screening 
(261). This situation is exacerbated by the families frequently living at some distance from healthcare facilities (262). The attitude and behaviour of some GPs create barriers for Travellers. 'The most common problem for Travellers is difficulty in accessing primary care through GPS because of the latter's insistence on their having a permanent address' (243). Other GPs will only provide temporary registration, thereby excluding them from screening and a range of other services. In extreme cases registration is allegedly refused altogether. Those who move most frequently have the greatest problems (243, 248, 249).

\subsubsection{Children's immunisation}

In a highly mobile population, without access to specialist health visitors and with only intermittent access to health care, low levels of immunisation can pose specific problems $(256,265)$. This is particularly so in a community in which there is already cultural resistance and concern over the possible side-effects of immunisation (266).

In a case study by Hollinger et al (267) in 1993, the immunisation rate for diphtheria/tetanus and poliomyelitis (64\%) was significantly lower for Gypsy and Traveller children than for the general population (90\%). Lack of knowledge and illiteracy, resulting in the inability to read promotional literature, were significant factors in compounding the low rates. Furthermore, district child health record systems and parental recall methods are unreliable for this mobile population (266). Evidence by 
Feder suggests that parental choice not to have pertussis vaccines, perhaps due to pollution taboos or adverse MMR TV campaigns, still plays a significant role in the low figures $(246,266)$. Other parents have been shown to believe that pertussis and measles were 'normal' or even 'strengthening' illnesses (267). Many unvaccinated Gypsy and Traveller children caught measles in the $2006-7$ epidemic, leading to a subsequent debilitation in their general health, more permanent disabilities and even, in one instance, death (268).

In their East London study, undertaken between July 1988 and February 1990, Feder et al (266) compared a group of 72 Traveller and Gypsy children with a control group of 106 children. Both groups of children were aged between 10 months and six years and both were attempting to access two GPs and the paediatric A\&E department at Queen Elizabeth Hospital in east London. The study revealed that Traveller and Gypsy children had significantly lower rates for the completion of immunisation programmes for pertussis, measles, diphtheria/tetanus and poliomyelitis than the control group (table 4.3).

Table4.3: Percentage of children completing the primary course of immunisation(266)

\begin{tabular}{lcc}
\hline & $\begin{array}{c}\text { Travellers and Gypsies } \\
\mathbf{n = 7 2}\end{array}$ & $\begin{array}{c}\text { Controls } \\
\mathbf{n = 1 0 6}\end{array}$ \\
\hline Pertussis & $15 \%$ & $71 \%$ \\
Diphtheria/tetanus & $33 \%$ & $85 \%$ \\
Poliomyelitis & $31 \%$ & $87 \%$ \\
Measles/MMR & $20 \%$ & $71 \%$ \\
\hline
\end{tabular}


The study also indicated that the low immunisation rates were attributable to both poor access to health services and the rejection of certain vaccines by the Traveller and Gypsy parents (266).

Parents have the right to refuse immunisation for their children. Such refusal may seem a rational choice to an individual in a particular culture even if it may not be in the best interests of the whole community. Indeed, the rejection of pertussis vaccine may even have become symbolic of the boundary between Traveller Gypsies and settled people, though evidence also indicates that if access to immunisation were improved the uptake would increase $(266,269,270)$.

\subsection{Overview of Barriers to Accessing Health Care and Medicines}

Specific barriers to accessing health care and medicines for Gypsies and Travellers have been discussed in 24 papers (all from the UK - 74, 243, $247,248,254,261,262,271-286)$. These include inequalities,

employment experiences, beliefs, cultures and traditions, low health expectations, fatalism, fear of death, avoidance, perinatal and maternity problems, racism and discrimination, travelling and mobility, accommodation, and mental health (table 4.4). 
Table 4.4: List of barriers to accessing health care and medicines

\section{Barriers to Accessing Health Care and Medicines}

- Inequalities and problems

- Employment experiences

- Beliefs, cultures and traditions

- Low health expectations

- Fatalism, fear of death, avoidance

- Perinatal and maternity problems

- Racism and discrimination

- Travelling and mobility

- Accommodation and sites

- Mental health

\subsubsection{Inequalities and problems}

Although published research has not covered the inequalities experienced by, and familiar to, Gypsies and Travellers and those working with them in equal depth, these inequalities are wide-ranging. Cemlyn et al (243) highlights many serious, pervasive, and mutually influential difficulties and inequalities suffered by the travelling communities. It is possible to identify a smaller number of specific areas of concern, though there could be said to be others of equal significance (243).

Clark et al (271) in another case study reported that life expectancy is lower than for the population at large. The probability of receiving good, 
continuous health care is less than for the general population despite their greater need. While national educational standards in school are rising, their children's educational achievements are lower and falling. As a result of abusive and discriminatory behaviour on the part of both pupils and staff in secondary schools, Gypsy and Traveller children frequently leave the education system when still under age, and attendance at secondary level is poor. Furthermore, their children and young people are often unable to access pre-school, extra-curricular and leisure services (271).

The children are perpetually surrounded by intense and public antagonism. This results in insecurity and family tension. Additionally, repeated violent removals from campsites may occur. Children are likely to have suffered severe psychological damage (272).

The criminal justice system also treats them unfairly at different stages (243). This, combined with additional inequality of treatment affecting members of these communities, results in a process of faster and younger criminalisation and consequently consignment to earlier custody. This process includes bypassing alternative processes for resolving disputes in favour of Anti-Social Behaviour Orders (ASBOs) which are awarded disproportionately (243). Judicial assumptions about the risk of the accused absconding, because they are more likely to skip bail, and a lack of secure accommodation result in a high use of remand in custody. 
The police and the judiciary all exhibit levels of prejudice against Gypsies and Travellers within pre-sentence reports, and acute distress resulting from perpetual discrimination and separation from their cultures within the prison system itself, often leads to suicide $(243,273)$.

According to the report of Cemlyn et al (243) in 2009 which evaluates the available existing evidence on inequalities and discrimination affecting Gypsies and Travellers in England, Scotland and Wales, these communities are also frequently excluded from community development and cohesion programmes, and political structures, initiatives and systems designed to promote inclusion and equality. Furthermore, women who are the victims of domestic violence and others in these communities who find themselves in similar highly vulnerable situations do not have access to support services appropriate for their culture and backgrounds. Indeed, since overall their cultural identity is barely acknowledged, if at all, there is substantial negative impact on their selfesteem and sense of self-worth(243, 274).

\subsubsection{Employment experiences}

Little research has been undertaken on the employment traditions of Gypsies and Travellers. However, what there is reveals that males tend towards self-employment (272), preferably in family groups. Employment is usually in areas such as market trading, gardening, building, and collecting and dealing in scrap metal. One of the most socially 
marginalised ethnic groups, and with literacy problems stemming from their cultural reluctance to access secondary education, Gypsies and Travellers find it difficult, if not impossible, to find work $(243,272)$. Consequently, they live in poverty with all its attendant and problematic implications for health care for both adults and children $(261,262)$. Poverty is endemic, since few are able to find work, and the unemployment situation breeds disaffection leading increasingly to substance abuse among the young. Levels of suicide are high in these communities (243).

The increase in numbers of incoming eastern European farm workers has impacted severely on opportunities for women, who have traditionally undertaken harvesting work and such seasonal crafts as making holly wreaths (275). They have further been hit by decreasing outlets for these crafts, increasingly expensive raw materials and the cost of renting market stalls in the face of low sales (243).

\subsubsection{Beliefs, cultures and traditions}

Gypsy and Traveller beliefs, cultures and traditions also create barriers to health care. The findings of Van Cleemput's qualitative study (74) in (2007) described important health beliefs and attitudes among Gypsies and Travellers. Poor health was directly attributed to social hardship and a poor environment, and the distress they caused (74). Considerable distress resulted from the feeling of being confined, the erosion of 
freedom on a site, and the isolation from both extended family and the wider Gypsy and Traveller community and culture resulting from being housed. The perception that these hardships were imposed by a hostile and racist society also caused great distress (247). Negative social attitudes and social exclusion were perceived as damaging to health, especially mental health, but there was equal dismay at the prospect of social assimilation (276).

Perceptions of what constitutes illness, especially chronic illness, stoicism in the face of pain and suffering, and the fear of death leading to a refusal to acknowledge symptoms that might portend serious illness such as cancer, of which there is universal fear, all prevent medical help being sought in good time if at all (254). A traditionally relaxed attitude to timekeeping results in missed appointments (72).

Stoicism and self-reliance arise from their adverse experiences, and are felt as essential for survival for Gypsies and Travellers (254). Commonly expressed as 'being tough' and 'not admitting or succumbing to minor health complaints', the characteristics are associated with the understatement of chronic ill health especially with men (74). Parry et al (254) compared a group of 293 Gypsy Travellers across 5 locations in the UK with a control group of 260. Gypsy Travellers were likely to take pride in their self-reliance and spoke of their responsibility to share care for their elderly or sick extended family members, deploring particularly the 
idea of a relative going into a care home (254). There are additional health problems related to heredity deriving from generations of inbreeding, since Gypsies and Travellers traditionally marry within their own communities (74).

Self-reliance is also related to a need to retain control, with failure to do so causing high stress levels and citing lack of control over their destinies under policies that restrict their self-determination, and authorities that exclude them in various ways, as real hardships (254). For some the impotence results in despair; others resist and fight hard to achieve as much control as possible. Gypsies and Travellers express a sense of living in a society that has been hostile for generations, seeming to reinforce their belief that they should be wary and slow to trust others (254). Such lack of trust and low expectations are sometimes manifested as stoicism and increased self-reliance $(74,254)$.

Strict cultural factors, in particular those relating to women, were found by Lehti and Mattson (277), in their study of attendance patterns and approaches to health care among Gypsy women on the European mainland. These factors had a potentially detrimental effect on their willingness to attend for treatment. Relationships with opposite sex doctors and sensitivities about medical examinations can be influenced by strongly held taboos. A woman would, for example, be particularly reticent about discussing issues of a sexual or reproductive nature with 
male health workers. In the UK, Richardson et al (253) found in their case study that women living by the roadside in Kent, with similar inhibitions with regard to male staff, reported that inability to access female staff had a harmful effect on their health.

\subsubsection{Low health expectations}

Acceptance and expectation of ill-health is pervasive, and chronic illhealth is accepted as long as symptoms can be managed. According to Van Cleemput (74), some participants from Gypsies and Travellers gave a long list of complaints suffered and they did not consider themselves unhealthy. This acceptance is consistent with an inverse relationship of access to health care in relation to need, though the relevance of some symptoms is not always understood (74).

Long lists of complaints are suffered without considering that this makes them 'unhealthy'. States of health are described in terms of restrictions on ability to perform daily tasks. Many Gypsies and travellers in the Van Cleemput Study (74) described inability to obtain relief for unmanageable symptoms, and were resigned to low expectation of improvement. Many were surprised to learn how poorly their state of general health compared with other matched groups (74). 


\subsubsection{Fatalism, fear of death, avoidance}

A qualitative study was undertaken where 27 gypsies and Travellers were recruited in an epidemiological survey of health status (74). Participants expressed fatalism regarding health problems, but without evidence of acceptance of life-threatening diseases or the experience of dying (74). Fear of death was associated with a dread of cancer, seen as leading inevitably to death. Therefore, they avoided any possibility of hearing that diagnosis. Ignorance, low expectations and fear reduce the chances of seeking treatment where early detection is most likely to affect prognosis $(247,278)$.

The study of Van Cleemput indicated that bereavement was also feared, and the intensity of grief was universally severe and prolonged, with conflicting benefits from close family involvement. Close family ensure that bereaved relatives are never left alone - being alone is so unusual, it adds to the acute sense of loss - so family members experience added grief in witnessing the grief of close relatives (74).

Bereavement grief is seen as a cause of illness and, indirectly, of death. Bereavement coping strategies, notably drug and alcohol abuse, were recognised as an added cause of ill health(74, 279). 


\subsubsection{Perinatal and maternity problems}

In a study of 150 Gypsy and Traveller women and 141 settled comparators, the Gypsy and Traveller mothers had more pregnancies and deliveries than the settled group, and experienced significantly more miscarriages (29\% as opposed to $16 \%)(280)$. More $(6.2 \%)$ had lost one or more children than the comparators $(0 \%)$ with nine reporting one or more stillbirths or neonatal deaths. One had undergone multiple stillbirths. Difficulties in accessing maternity care and pregnancy screening by mothers living in mobile communities who are often not registered with GPs are significant barriers to safe deliveries and healthy infants $(247,280)$.

\subsubsection{Racism and discrimination}

Cemlyn's report (243) in 2009 indicated that, for the most part, racism aimed at the majority of ethnic minorities today is more covert and widely regarded as unacceptable. However, that targeted at Gypsies and Travellers is still everyday, overt and regarded as warranted. The latter includes attacks by the media and blatantly racist pronouncements from politicians at both town hall and national level. The frequent failure of those in authority to challenge any or all of these contributes to the bigotry and ignorance of the majority of the population who live in permanent housing (243). 
Despite the mass of anti-discrimination, equality and human rights legislation passed in recent years, Gypsies and Travellers continue to be targets for hatred just as they have for centuries (271). Many complaints of withdrawals of offers of employment and workplace harassment or dismissal, in addition to services being refused or provided with grudging reluctance, have been made by members of those communities (243).

\subsubsection{Travelling and mobility}

Van Cleemput et al (74) demonstrated that, the 'travelling way' emerged as a central concept for Gypsies and Travellers. Social and cultural issues permeated accounts of health and illness. Key issues concerned accommodation and travelling. All described their current situations in relation to their ability to travel and all had experienced the traditional travelling lifestyle at some time. Accommodation difficulties and the threat to the travelling lifestyle dominated (74). Many referred to the effect of a travelling lifestyle when describing their experiences of health and illness, especially the adversity in the limited accommodation options open to them. These issues were often described as the perceived benefits and disadvantages of the travelling lifestyle (74).

Mobility results in having 'no fixed address' and therefore little chance of having a bank account, or accessing benefits and postal services. This means Gypsy and Traveller patients cannot be contacted for appointments, and miss appointments made orally (and therefore 
treatment) since reminder letters are not received; while tests may be duplicated unnecessarily, due to a lack of patient-held medical records $(243,248)$.

It also means that any local unskilled employment that may be found is lost as the community moves on. Mobility also accounts for a lack of primary school continuity, while the traditional resistance to secondary education in preference to work compounds illiteracy. This means training places cannot be accessed or maintained and workplace qualifications achieved, all of which leads to the poverty that results in ill health impacting on the whole family $(266,281,282)$.

Geographical barriers are also considerable for Gypsies and Travellers, particularly given their nomadic way of life, since they are constantly being moved on from wherever they may be encamped regardless of how far this may move them from healthcare facilities $(72,74,262)$.

\subsubsection{Health-related benefits of travelling}

For some participants there are health-related benefits from the travelling lifestyle, including freedom, choice and the ability to live among extended family in a hostile world - important psychologically and for support and security (74). Strong regret was expressed by a group of Gypsy and Traveller participants that fresh air was lost when they had to 
move into housing. The ability simply to move on if housed neighbours were hostile was stated as important, and some of these Travellers had moved back into trailers for this reason (74).

\subsubsection{Health-related negative effects of travelling}

Some of the Gypsies and Travellers interviewed by Van Cleemput stated that, a diminishing choice of safe stopping places, and lack of basic amenities such as running water on unauthorised or poorly serviced sites, impact negatively on their health (74). There are also healthcare concerns about conditions on official rented sites, which are often in hazardous environments. Psychological effects such as a feeling of imprisonment on some rented sites are related to the loss of freedom to travel and the stress of being forcibly moved on from unofficial sites (74). Elderly Participants indicated that wet and damp conditions endured over the years results in arthritis and chest complaints (74).

For some participants in the study cited above, poor health has led to a move into housing; but the psychological effect and culture shock of relinquishing travelling cited above were seen by these respondents as counter benefits (74).

Gypsies and Travellers' valued travelling lifestyle is perceived as increasingly denied. Lack of choice of accommodation and poor site 140 
conditions are seen as indications of society's negative view of Travellers $(74,247)$.

\subsubsection{Accommodation and sites}

Many of the inequalities experienced by Gypsy and Traveller communities commonly derive from a lack of appropriate and safe sites (243). Whereas previously, planning policy favoured publicly owned sites under the control of the local authority, this has now given way to the practice of these communities providing their own sites (243). However, opposition from local residents, which is frequently overtly racist in language, repeatedly results in the refusal of planning permission to develop sites they have bought and own, though appeals against such decisions are often upheld (243).

Housing authorities are now required to undertake formal inspections of accommodation for Gypsies and Travellers (243). Hence, there is now hard evidence, such as variability of authorities' access to grants from the government, of the extent of under provision and deprivation in this area, in particular the paucity of residential and transit sites for those preferring not to settle in traditional housing. Although there are some good sites these are comparatively few. The majority are in unsatisfactory and unhealthy locations, such as under motorways or adjacent to sewage treatment plants. On these sites vermin, poor or no sanitation, leaking sewage and water pipes, and a lack of clean water, 
waste disposal facilities, hygiene facilities and fire safety precautions pose real dangers to health $(243,271)$.

Given the shortage of legal sites Gypsies and Travellers are faced with the only other option - namely that of illegal encampments and developments (243). This may result in repeated eviction processes frequently actioned by private companies (243). This inevitably disrupts children's education, openings for adult employment and access to health care and, together with the habitual daily trauma of relentless instability and lack of facilities, results in deteriorating health (243).

To escape from the endless round of evictions and/or to take advantage of essential services, accepting social housing is now becoming the reluctant option for many families (271). However, by taking this option they have to dislocate from their wider family circle and community, their culture and their support systems. They also typically find themselves in the most deprived and environmentally disadvantaged housing estates and the targets of hostility from equally disadvantaged neighbours towards their race and lifestyle $(243,274)$. Those who have moved into settled housing suffer from cultural deprivation arising from the loss of their traditional way of life, leading to mental illness $(247,282)$

According to Niner's retrospective study (283), too often accommodation that takes into account the cultural needs of specific groups, mainly 
Gypsies and Travellers, is unavailable. Consequently, those groups have to resort to unauthorised pitching on sites lacking even the most basic living requirements. The dearth of educational opportunities and access to health care inevitably result in continuous social exclusion (283).

These disparities with the rest of the population in educational opportunity and health care were emphasised in a report from the Institute for Public Policy Research (IPPR), (281). This called for a Traveller Task force to advise on the development of a high-level unit and supervise the provision of appropriate sites. Such sites were to come under the auspices of local development structures and conform to the new planning regulations currently being enforced. Only when such appropriate accommodation is provided will the struggle for the basics of civilised living, such as clean water, sanitation and emergency health care, and the stress of continual insecurity recede, enabling these communities to operate and acclimatise positively(243).

\subsubsection{Mental health}

Gypsies and Travellers are regularly subjected to a range of stressinducing factors including unemployment, racism, bereavement, and discrimination - by both public services and the public at large - as well as chronic accommodation issues (284). Parry et al (247)in an epidemiological survey recorded almost three times as much anxiety as in other communities, with just over twice the incidence of depression. 
The feeling that there is no escape from a very poor campsite can lead to long-term ill-health, especially in women (247). There are comparatively few legal sites nationally, following the removal in 1994 of local authorities' legal obligation to provide permanent sites for Travellers' trailers (243). This has produced constant anxiety over eviction from illegal sites, which affects the physical and mental health of the whole community, and coping strategies involving heavy smoking and alcohol and drug abuse(247, 266).

Depression and anxiety can also be linked to a move into permanent housing, reflecting and resulting from attendant experiences of discrimination and racism and a sense of bereavement from losing the community life (243, 285). Similarly Richardson et al (253) demonstrated that, where the law has affected their right to live on a site, or where they have moved to escape violence, in common with traditional Gypsies and other Travelling people, new Travellers, also reported symptoms of anxiety and depression (253).

The housing charity Shelter, which also took part in the consultation of experience of working with Gypsies and Travellers, recorded a need for research to be carried out among housed Travellers into the effects of permanent housing on their mental health (243). A specialist Traveller team referred to "Travellers' psychological aversion to housing and how 
housing can impact on Travellers' mental and physical health" (243, 286).

\subsection{Combating the Problems}

Cemlyn et al (243) reported some suggestions to combat gypsy and Traveller problems. Far from simply waiting for others to address their problems and assert their rights, many Gypsy and Traveller organisations are proactively striving, together with both voluntary organisations and statutory bodies on occasion, to introduce and promote initiatives. The aim is to ensure their access to health and social care services, enable their children to enjoy a higher standard of education and develop opportunities for training, thereby improving their chances of employment. They also work to enable their participation in satisfying and worthwhile leisure activities and keep their cultural heritage and identity alive, as well as encouraging political and community involvement (243).

Some have cooperated with local authorities in an effort to reduce the ubiquitous hostility by combating the ignorant, inaccurate and negative propaganda through the circulation of true information about their needs and culture. Furthermore, those Gypsies and Travellers who have assimilated into the wider community, perhaps by winning seats on local and county councils or playing active parts in national or international 
organisations, are able to use their positions to raise awareness of the needs of their difficulties. This can only be for the good of all (243).

It will take concerted urgent action by the range of organisations, both public and private, and the various authorities with whom Gypsies and Travellers interact, in addition to the public at large, before those minority groups can enjoy the same rights, and access services on the same terms, as everyone else. All branches of the media have a part to play here, too, not only through proactively speaking out against racism and discrimination but also by taking stock of the way they address Gypsy and Traveller news stories and attendant issues in their own outlets. Until then, the quality of life of Gypsies and Travellers will continue to suffer enormous damage as a direct result of the problems outlined (243).

\subsection{Summary}

Essential work needs to be undertaken to remove the barriers and improve access to healthcare services for Gypsies and Travellers in ways that are compatible with their traditional lifestyle. Furthermore, their particular beliefs and circumstances need to be fully understood and appreciated when designing services to improve their health(74).

The literature reviews in Chapters 3 and 4 have focussed on these "at risk" groups and described how the data for the previous research was 
collected and used. Chapter 5 explains the method and methodology involved in research for this thesis. 


\section{CHAPTER FIVE}

\section{CHILDREN'S ACCESS TO MEDICINES}

\section{METHODOLOGY}

\subsection{Introduction}

This chapter will highlight the research methods that were used in order to achieve the aims and answer the questions of this study. This will help to identify if there are any problems in relation to children's access to medicines in several different "at risk" groups involving Asylum Seekers and Refugees, and Gypsies and Travellers respectively in the East Midlands region of the UK. It will clarify the research strategy and design, the method of data collection and the reasons for choosing them. This chapter will also describe the procedure of ethical approval. It will end by describing the method of data analysis. 


\subsection{Aims}

The aims of the study were:

I. to determine the average number of medicines used by children over the last month and the last six months by means of a semi-structured interview;

II. to compare the number of medicines received by children from different "at risk" groups - children of Asylum Seekers and Refugees (Group A), Gypsy and Traveller communities (Group B) with a control group of children;

III. to explore diversity in attitudes towards receiving treatment for certain medical conditions by parents of these "at risk" groups.

\subsubsection{Primary objective}

The primary endpoint of the study is to compare the number of medicines received by children in the "at risk" groups with a control group of children to determine any differences in the number of received medicines and whether they related to differences in their access to health care or attitudes towards treatment. 


\subsubsection{Secondary objective}

The secondary endpoint of the study is to explore whether attitudes towards treatment are different between parents of "at risk" groups and the control group.

\subsubsection{Hypotheses}

This study is guided by three hypotheses:

1. Children from "at risk" groups are likely to receive fewer medicines than other children.

2. Problems in accessing health care influence the number of medicines children receive.

3. Diversity in parental attitudes towards certain medical conditions, such as epilepsy, may influence the number of medicines children receive.

\subsection{Theory of Research Methodology}

\subsubsection{Introduction}

The methodology which was used in this research involved both quantitative and qualitative methods. Quantitative methods are used to compare the number of prescribed medicines received by the "at risk" groups with the control group over the past month and six months. The qualitative element is aimed at exploring and describing parental attitudes and whether they affect the treatment given. Johnson \& 
Christensen (287) reported that "qualitative research seeks a deeper understanding of the given research problem or of a phenomenon from the perspectives of the study sample". Different issues can be considered in qualitative research, such as the values, opinions, behaviours and social contexts of the research sample. This means that the qualitative is different from the quantitative, as it searches for a deeper explanation of the research questions or phenomena rather than searching for the relationship between cause and effect (287).

Quantitative and qualitative research methods differ fundamentally in the epistemologies from which they derive and type of information they can deliver (288). Each has its applications and limitations, and while one or the other may be clearly more appropriate for data collection in some research projects, that data collection in others benefits from the use of both. It is therefore necessary for researchers to understand fully the strengths and limitations of each in order to select the appropriate method for their own work $(289,290)$. Since both qualitative and quantitative methods have been used in this study in order to increase the robustness of the data, the fundamentals of both methods are briefly outlined below. 


\subsubsection{Quantitative Research}

The quantitative method, which may be regarded as traditional, positive, experimental or empirical, relies on statistics, measuring and analysing not the processes between variables but the causal relationships between such variables (291).

Enabling numerical results and findings to be presented visually in tables and graphs, it conveys the major attraction of a sense of scientific respectability and staunch, independent objectivity (291). Furthermore, areas which have already been researched by others, and in which there are already existing theories, known variables and an established body of literature, may be re-examined (292).

Data is often gathered through questionnaires, by setting up equipment and experiments and working with selected comparative groups or variables, all of which is, however, time-consuming to prepare and operate (293).

In this study, the demonstration of causal relationships between identifiable and measurable variables plays a critical role; and quantitative forms of presentation, such as graphs and tables, will be used to present some of the research findings. 


\subsubsection{Qualitative Research}

A universal definition of qualitative research is far more elusive, since it relies on no distinctive theory or paradigm. As described by Denzin et al (294), it is widely interdisciplinary. Unlike quantitative research, it may be described as interpretative, exploratory, without a single methodology, and a field of enquiry in its own right in which, though the variables are often unknown, context is of great importance. According to Banister et al (295), it aims to identify and encapsulate what it is within us that leads us to say what we do about our actions. It involves 'exploration, elaboration and systematisation of the significance of an identified phenomenon and the illuminative representation of the meaning of a delimited issue or problem,' and identifies problems and defines situations through human beings rather than scientific instruments (296).

\subsubsection{Strengths and weaknesses}

There are strengths and weaknesses in both qualitative and quantitative methods of research. A number of these strengths and weaknesses in both methods were classified by Johnson and Onwuegbuzie (297). 


\subsubsection{Quantitative Research}

\section{Strengths}

Quantitative Research according to Johnson and Onwuegbuzie (297) can:

- test and validate theories of how and why phenomena occur;

- test hypotheses that existed prior to the data collection;

- generalise research findings when data are based on an adequate number of randomised samples;

- generalise a research finding when it has been replicated in many different populations and subpopulations;

- provide precise, quantitative, numerical data;

- lead to data analysis that is relatively less time consuming (using statistical software);

- produce research results that are relatively independent of the researcher.

\section{Weaknesses}

In Quantitative Research the researcher might inadvertently (297):

- use categories and theories that may not reflect local constituencies' understandings;

- miss out on phenomena occurring because of the focus on theory or hypothesis testing rather than on theory or hypothesis generation (called the confirmation bias); 
- produce knowledge that may be too abstract and general for direct application to specific local situations, contexts, and individuals.

\subsubsection{Qualitative Research}

\section{Strengths}

Qualitative Research according to Johnson and Onwuegbuzie (297) can:

- base the data on the participants' own categories of meaning;

- be useful for studying a limited number of cases in depth;

- be useful for describing complex phenomena;

- provide individual case information;

- provide understanding and description of people's personal experiences of phenomena;

- describe, in rich detail, phenomena as they are situated and embedded in local contexts;

- allow the researcher to identify relevant contexts and settings;

- produce data which lend themselves to the exploration of how and why phenomena occur. 


\section{Weaknesses}

In Qualitative Research the researcher might (297):

- produce knowledge specific to a few that may not relate generally to other people or other settings. That is, findings may be unique to the relatively few people included in the research study;

- find it difficult to make quantitative predictions;

- find it more difficult to test hypotheses and theories;

- take more time to collect the data as compared to quantitative research;

- find data analysis time consuming;

- inadvertently reach conclusions more easily influenced by his own personal biases and idiosyncrasies.

It has been necessary to adopt both quantitative and qualitative methods and an interpretive paradigm as the basis for this study's research methodology, to capture the breadth and richness of participants' experience in a natural context (298). 


\subsection{Research Methods}

\subsubsection{Interviews}

\subsubsection{Introduction}

An interview is a structured conversation, designed to produce a certain outcome, between the interviewer and interviewee(s) $(294,296)$. Though they may be time-consuming to undertake and subjective in nature, and the responses difficult to analyse and evaluate, interviews may produce rich results for the researcher (299). Interviewees have the opportunity to express themselves using their own words, from their own viewpoints and in the language which is most natural to them $(300,301)$. This is more likely to reveal the detailed information being sought. Interviews are prepared with a view to constructing knowledge between the participants in order to generate rather than collect information(302).

The personal interview is a highly valuable way in which to amass indepth data for both qualitative and quantitative research (300). Participants may have individual biases, or uncertain recall, resulting in errors at times (303). The exact wording of questions and the order in which they are asked may likewise influence their responses, and therefore the results of the research (304). However, the participation rate tends to be higher than for questionnaires requiring self-completion, since respondees are likely to feel more involved in, and therefore motivated by, the process (303). Furthermore, if interviews are 
conducted in comfortable, familiar surroundings, participants are more likely to express their views and feelings more freely (305).

\subsubsection{Semi-Structured Interviews}

In both qualitative and quantitative research, interviews may range from structured to semi-structured and highly structured, depending on their purpose and context $(300,304)$. Many varied types of interview may be used ranging from the highly structured formal interview, offering little if any scope for flexibility in either sequence or content, to informal conversations allowing the interview to develop and adjust during the interview process $(300,306)$.

The semi-structured interview, standing as it does between the structured and unstructured, and containing elements of both, is fundamentally a set of fairly well structured questions predetermined by the interviewer. The exact wording of each question and/or the overall order in which questions may be asked may vary for each participant. The line of enquiry, however, will be the same for all (303). This structure permits similar data to be collected systematically from each interviewee, while allowing an interview to be flexible and adapted to each participant or workplace, thereby enabling individual issues and insights to be explored as they arise $(302,304)$. 


\subsubsection{Defining semi-structured interviews}

Individual interviews, defined by Wilson and Goodall (307) as "a communication process in which two or more people interact within a relational context by asking and answering questions designed to achieve a specific purpose," were central to the data-gathering process in this project. Anderson (308) defines semi-structured interviewing as "a specialized form of communication between people for a specific purpose associated with some agreed subject matter". Bryman (305), recognising the need for flexibility within the research process, defines the semistructured interview as "a context in which the interviewer has a series of questions that are in the general form of an interview schedule but is able to vary the sequence of the questions".

"Displaying empathy and acceptance, conveying respect and creating an ethos of trust" is, according to Burns (301), essential for successful interviewing. Creating a relaxing atmosphere encourages the interviewee to trust and relate to the researcher, and talk openly and uninhibitedly about how he/she feels. For interviewees who might not feel very confident in the interview process, such an approach might well reduce any negative impact such feelings might have on the interview (309).

The interviewer should take the role of listener rather than that of leader in what he/she intends to be relaxed conversations, gently guiding the discussions as might be necessary to ensure that all the main issues had 
been included. While interviewees are able to ask the researcher to explain any questions which they may not fully understand, the researcher can explore answers more deeply and invite participants to amplify their replies - all of which is advantageous for the accumulation of detailed data (310). According to Hutchinson (311), "Interviews permit researchers to verify, clarify or alter what they thought happened, to achieve a full understanding of an incident and to take into account the 'lived' experience of participants"(311).

\subsubsection{Benefits of using a semi-structured interview}

A semi-structured interview aims to collect rich data clarifying participants' backgrounds and perspectives and drawing out accurate information about their experiences and views.

The interviewer is required to ensure comparable findings through the use of identically worded questions. Yet he also needs to include more open questions allowing in-depth exploration of his subject. The semistructured interview can exploit the best features of both structured and unstructured interviews, while incorporating further important features that distinguish them and increase their suitability for this type of research $(305,309,312)$. 
With a semi-structured interview, the interviewer predetermines the topics to be covered and prepares a list of questions or 'interview guide' (305). Since this gives the interview structure and direction while still allowing for flexibility, it is recommended by Patton (313). The flexibility that permits the researcher to respond himself to a participant's replies by posing additional questions for clarification, and to explore and expand on any new and relevant ideas that might emerge, is perceived by Merriam (314) as a core advantage.

\subsubsection{The limitations of using semi-structured interviews}

To help to ensure that the information gathered from using a particular research method is both valid and ethical, its limitations, many of which are outlined in the relevant literature and relate to the process of conducting the interviews, should be understood.

One of the weaknesses identified by Patton (313) is the danger that, in the ebb and flow of the interview itself, significant topics, and therefore important information, may be omitted. To gain the confidence to access the rich data offered by interviewees the researcher has to appreciate the necessity of following the interview schedule in moving through the questions. However, the flexible interview structure enables a variety of approaches to be taken in devising and sequencing an interview, which may in turn lead to widely differing responses and a reduction in their comparability. Although generalisations are not a key feature of 
qualitative research, the responses of the parents in these groups were compared and contrasted as the researcher sought to analyse and categorise their experiences (313).

A further shortcoming of the semi-structured interview that might prove challenging to both researcher and participant is that it inevitably depends on the language skills of the interviewee (315). For instance, participants may not be sufficiently articulate in their own or another language to able to describe their perceptions adequately, or they may interpret or understand individual words and concepts differently from the interviewer. Not all individual participants may have the intellectual capacity for critical thought (315).

This research was planned to encourage the participants involved in this study to explore their experiences and develop their understanding of them. The aim of the interviews was to find out about their ideas and perceptions of access to medicines and health care for their children over two time scales (the last month and the last six months).

\subsubsection{Ethical Considerations}

Both before a qualitative research project can begin, and throughout its whole process, the researcher has to address a number of ethical considerations and design the project to take into account the well-being 
and interest of those taking part (316). Each researcher has to take responsibility for the ethics within his/her research, and should not ignore the importance of ethical consideration $(314,317)$.

\subsubsection{Informed Consent}

No study-specific interventions will be undertaken before informed consent has been obtained. The process for obtaining participant informed consent or assent and parent / guardian informed consent should be in accordance with the Research Ethics Committee (REC) guidance, Good Clinical Practice (GCP) and any other regulatory requirements that might be introduced. The investigator or their nominee and the participant or other legally authorised representative shall both sign and date the Consent Form before the person can participate in the study.

Informed consent, the most basic of ethical principles and one which derives from participants' right to full control over their own lives and the way they live them (300), rules that they must freely agree to take part without pressure of any kind, and in full knowledge of the nature of the research, why it is being undertaken and its risks, benefits and aims (301, $318,319)$. 


\subsubsection{Voluntary participation}

It is essential that those taking part should be aware that not only must their participation be entirely of their own freewill, but also that should they wish to withdraw their cooperation at any point, they are entirely free to do so (320).

There should be no criticism of any who either withdrew or declined to participate in the first instance. The investigator should inform the participant of any relevant information that emerges during the course of the study, and should discuss with them whether they wish to continue with the study. If necessary they will be asked to sign revised consent forms. If the consent form is amended during the study, the investigator should follow all applicable regulatory requirements pertaining to approval of the amended consent form by the REC and use of the amended form (including for ongoing participants)(320).

\subsubsection{Privacy and confidentiality}

Bishop and Glynn (321) consider it essential to protect the identity of all participants in research projects. As Anderson (318) indicates, an understanding between researcher and participant that guarantees confidentiality and anonymity is of paramount importance. The researcher is bound to design the project in such a way that this guarantee can be honoured (318). Though the researcher himself might 
be able to identify participants from the data given, not only does he have to keep this information completely confidential but he also has to present it in such a way that it is impossible for any subsequent reader to make the same connection $(300,318)$.

\subsection{Methodology of Project}

\subsubsection{Introduction}

The difficulties associated with interviewing parents from the identified "at risk" groups such as their communities to which access in difficult without using a specific support group, language communication problems and a reluctance to give information due to their precarious status are well recognised. This study, however, specifically focussed on these groups to determine whether or not their access to drug therapy was sub-optimal.

In the East Midlands there are two key organisations, Refugee Action and Derbyshire Gypsy Liaison Group, involved with Refugees and Asylum Seekers, and Gypsies and Travellers respectively. Both support groups were contacted by the main investigator (my supervisor) to discuss with them the project and to ensure that they were fully supportive. Both organisations were keen to collaborate with the research. 
Familiarity with an interviewee's background and culture is fundamental to the effective collection and interpretation of social data. It is therefore essential for the research group to verse themselves in the lifestyle, health history and cultural norms of each participant (322). Refugee Action suggested and organised a full day's training on refugees and asylum seekers. Alongside other members of the research group, I attended the training before attempting to approach parents. This course gave an overview on Asylum Seeker and Refugee cultures, backgrounds, languages, and on the legal differences between Asylum Seekers and Refugees. I found the course was very useful and made me familiar with the problems faced by Refugees in order to understand their needs. It helped me overcome some of the issues we faced in our research during the interviews. For example, some of the potential participants were unhappy about providing any information due to their refugee status or their enclosed community until I explained the purpose of the study and its importance to them in great detail.

The research group also had extensive discussions with Derbyshire Gypsy Liaison Group. It is clearly impossible to undertake interviews with Asylum Seekers and Refugees, and Gypsies and Travellers without the involvement of such organisations, and their support and comments have been incorporated into the questions included in the interviews. These two organisations were heavily involved in assisting the researchers to make contact with the parents of children from these "at risk" groups. 
They assisted in providing an initial contact point for these parents and helped facilitate interviews.

\subsubsection{Terminology}

For the purpose of this study, the terms Asylum Seekers and Refugees are used interchangeably (i.e. Refugees denotes Asylum seekers and Refugees groups). The terms Gypsies and Travellers are used interchangeably as well despite differences between these categories (i.e. Travellers denotes Gypsies and Travellers groups).

\subsubsection{Interview schedule and guide}

In preparation for the study, the semi-structured interview schedule was revised with the research group and clinical psychologists from the NHS who were experienced in this kind of research. Comments were also obtained from both Refugee Action and Derbyshire Gypsy Liaison Group.

The interview determines accessibility to health care and also attitudes towards receiving treatment for the following medical conditions: epilepsy, asthma and pain. It also records medicines actually administered to the children by parents over the past month and six months. Furthermore, difficulties in relation to obtaining medicines were explored. 
The aim of this study was to explore the way in which individuals perceived their access to health care and, most importantly, to learn from each individual's experience.

The schedule of interview for groups of participating parents contained both types of question: closed and open-ended questions. It consisted of 43 questions divided into five parts (see Appendix A1).

The first part consisted of questions eliciting socio-demographic information including details of:

- family structure

- country of origin

- employment status

- number of years in the present accommodation and current locality

- $\quad$ link with local community.

The second part asked about:

- GP registration

- parents' health

- $\quad$ children's health

- $\quad$ immunisation status. 
The third part asked about:

- the number of illnesses and medicines received by the children during the past month

- $\quad$ the prescriber of such medication

- $\quad$ any barriers experienced in obtaining such medication

- whether any home remedies such as herbal medicines were used.

The fourth section examined aspects covered in the third part, but during the past six months.

The fifth part concerned general parental attitudes towards the treatment of certain medical conditions such as pain, asthma, and epilepsy, and whether those attitudes affect the treatment given. These health conditions were chosen because they are common problems in children and require medicines.

All these questions were designed to assess barriers to the accessibility and affordability of health care and medicines.

\subsubsection{Conduct of interviews}

Semi-structured interviews were used for the parents of children of different ages. The interviews were performed in accordance with the 
Qualitative Research Review Guidelines - RATS (127) (see Appendix B). The data assembled for this research comprises information drawn from these semi-structured interviews. The same interviews and procedures were used for all the participants in this research.

Semi-structured interviews enabled the participating parents to describe their experiences in accessing health care services. The interviews allowed me as a researcher to gain a better understanding of the cultures, beliefs and contextual backgrounds that influenced the interviewees' thoughts on access to medicine and health care.

\subsubsection{Participants}

This study aimed to include 50 parents in each of the three groups. This number was felt to be achievable based on the discussions with Nottingham Refugee Action and the Derbyshire Gypsy Liaison Group.

This study included:

I. parents who applied for asylum and those parents who got a decision on their asylum claim as refugees;

II. parents from Gypsy and Traveller communities;

III. parents from a random control group who volunteered in a local shopping centre to take part in the research.

However, the following were excluded: 

I. those resident illegally;
II. those who refused or withdrew consent;

III. those with mental incapacity, unable to give valid consent;

IV. those who did not match the inclusion criteria.

Participants were recruited from November 2010 till January 2012. I initially focused on the recruitment of Refugees and Asylum Seekers. This was done through close collaboration with Refugee Action in Nottingham. The initial approach was from a member of Refugee Action. Parents from this group routinely visit the office of Refugee Action in Nottingham to be advised in many aspects of their daily lives. At the office, once they came to the reception desk they were given general information about the study and asked if they would be happy to be involved. I was then introduced to the parents as a researcher, and provided more details about the study both verbally and by giving them an information sheet. For those who could not read, I read to them both the information sheet and the consent form to clarify everything before we started the interviews. If the parents gave consent, I then conducted the interview in a private room within the offices of Refugee Action.

Many significant difficulties were encountered during this stage of research which consumed much time and effort. I had to go from Derby to Nottingham at least twice a week to do the interviews with 
participating parents. However, many times I went there and spent all day and none of the parents who came to the Refugee Action office was happy to be involved. Furthermore, recent funding cuts by the government led these charities to close their offices in Nottingham and Derby and move them to Leicester. Due to this situation, I decided to approach Asylum Seekers and Refugees through a Muslim community centre in Derby where some participants were recruited. All these factors made this stage of the data collection very difficult and it consequently took longer than we expected. This part of our study took about one year to be completed since we started in November to 2010 and finished in November 2011.

Once I had completed all the interviews with Refugees, I then focused my attention on recruiting Gypsies and Travellers. This was done in conjunction with Derbyshire Gypsy Liaison Group. I had several meetings with members of this group and it was agreed that they would introduce me and the other researcher to parents of traveller children. This was done by visiting campsites throughout Derbyshire. All the interviews took place in their caravans. Many of the traveller communities are wary of men approaching the female members of the community. In view of this, I had to interview the female parents alongside the female research nurse. I am pleased to say that during the course of the interviews with the women of the traveller community, they accepted me as an honest 
and conscientious researcher. Recruitment of this group took about four months to be completed, from October 2011 to January 2012.

In order to interview the control group, the head office of the local shopping centre in Derby (Westfield) was contacted by the main investigator to obtain approval for recruiting parents from people shopping in this centre. By arrangement with the managers of the Westfield, the interviewers (I and the research nurse) randomly questioned passers-by in a designated area. Interviewers were identified by wearing T-shirts with the University of Nottingham logo and carrying a distinctive poster (see Appendix A2).

A 1:1 case-control study was conducted. An appropriate control was selected carefully to match each case to minimise any bias that may influence the results. Therefore, 50 control parents were selected from 67 participants who were interviewed as potential controls. The control group of parents was selected randomly from parents who volunteered to participate in this study. They were selected from white British subjects in order to assess the effect of cultural and ethnicity differences in parental pattitudes towards treatment of asthma and epilepsy. The interviews were carried out using the same procedures as those of other groups. The children of the control group had a similar age distribution to those of the "at risk" group. 


\subsubsection{Ethical Considerations}

This section identifies and addresses the ethical considerations specific to this research project and highlights the particular areas that need to be addressed when conducting research into vulnerable populations.

The UK has strict ethical regulations for researchers, especially where children are involved, so before anything else I had to apply for ethical approval to conduct this study. Approval was obtained from the Medical School Research Ethics Committee at the University of Nottingham (see Appendix A3). The committee required an undertaking that participants were to be assured that anonymity would be observed through the report; that they should be informed of the overall aims of the project and that completed interview schedules would be securely retained at the University of Nottingham.

Discussions were held with the Medical School Research Ethics Committee in relation to where the control group should be obtained. The Medical School Research Ethics Committee originally suggested that parents should be recruited from outpatient clinics. Unfortunately, in order to recruit parents from an NHS outpatient clinic, we would have had to submit a separate ethical application to the NHS Ethics Committee. It was therefore agreed with the Medical School Research Ethics 
Committee that it would be more appropriate to obtain a control group from a local shopping centre.

\subsubsection{Informed consent}

The participants were fully informed of the purpose of the project in which they would be involved initially by members of the relevant charities and then by the researcher. The information sheet which was given at the beginning by the researcher provided a brief introduction to the research topic and indicated what a participant might expect during the interview (see Appendix A4). It was felt that this approach would not only reassure interviewees and reduce any anxiety they might have concerning the project, but also encourage them to start thinking about what they might want to say in the interview, which was intended to be relatively informal and a positive and enjoyable experience for all involved. I consistently tried to make sure that they understood all the relevant information given to them either verbally or in the information sheet and asked the interpreter to explain everything to those who did not speak English.

When satisfied that all fully understood the implications of participating, those willing to take part on these terms indicated their informed consent by signing a short statement to that effect (see Appendix A5). The consent form was signed and dated by the participant before he/she entered the study. One copy of this was given to the participant and 
another was kept by the investigator. The consent form confirmed in writing the agreement to participate. I reassured participants of the importance of the research and that any information provided would be handled professionally and treated in strict confidence by the research team at the University of Nottingham.

\subsubsection{Voluntary participation}

It was made clear from the beginning, by the researches, that participants could ask questions and raise concerns at any time during their participation in the project. They were informed of their right to withdraw at any time up until the writing of the first draft of the report without need for explanation. It was explained to them that their entry into the study was entirely voluntary. They were made aware that they could withdraw at any time without affecting the quality or quantity of their future medical care, or loss of any benefits to which they would otherwise be entitled.

\subsubsection{Privacy and confidentiality}

In this project, to maintain anonymity each participant was given an identity code for all information recorded. Therefore, the investigators are confident that the guarantees of privacy and confidentiality given to the participants have been honoured and maintained throughout the research process. All papers from the study were and will be held 
securely, in a locked cupboard or cabinet. Access to the information was limited to the investigators and any relevant regulatory authorities. All data, including the study database, was stored on a secure dedicated computer and access was restricted to investigators by user identifiers and passwords. The timeline of the research is described in figure 5.1(below). 


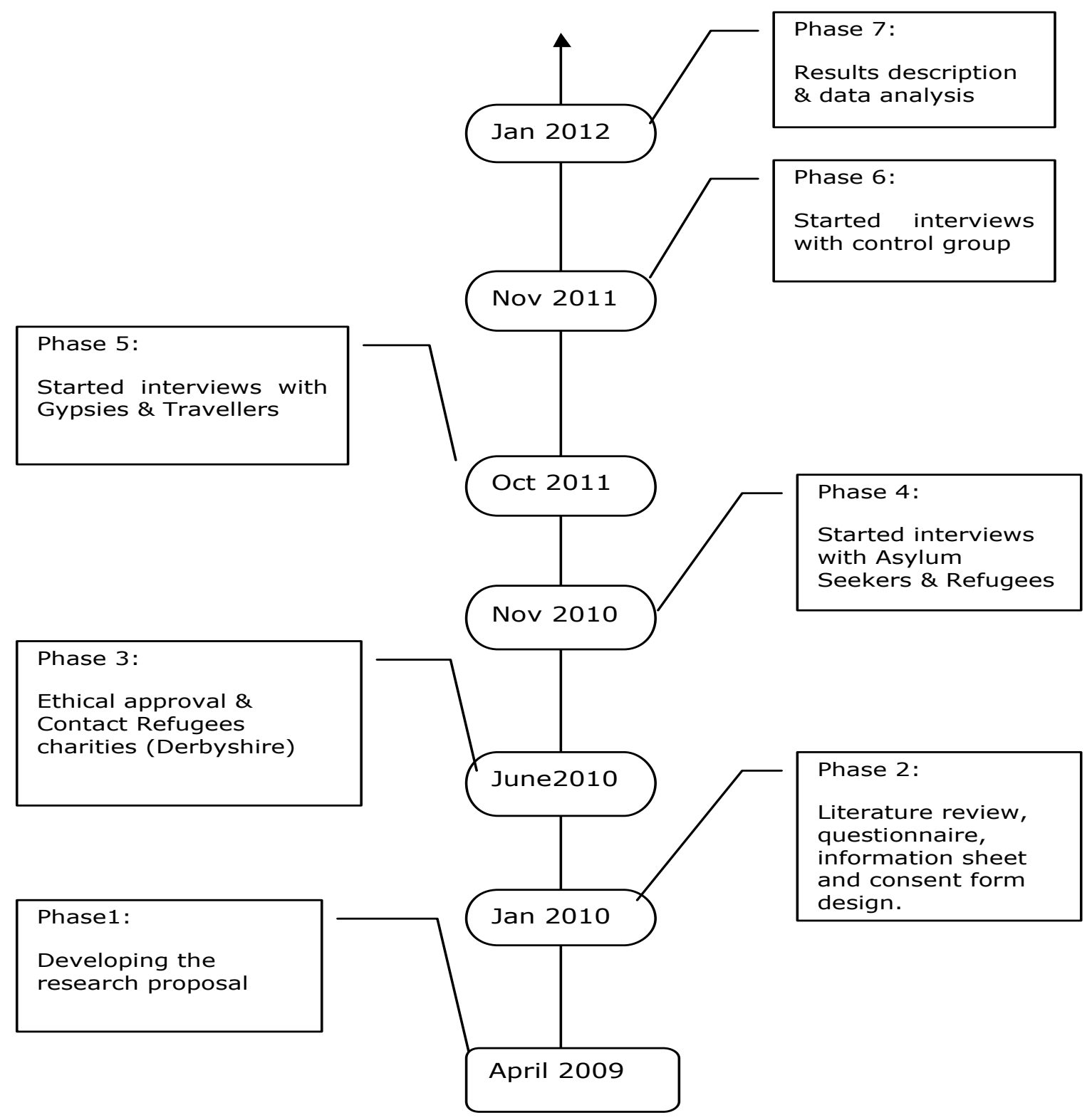

Semi-structured interviews were used with the intention to allow new viewpoints to emerge freely. We (I and research nurse) first introduced 
ourselves to the interviewees as researchers in the Academic Division of Child Health at the University of Nottingham, undertaking a study on the issues that might affect children's access to medicines.

All potential interviewees were initially contacted face to face, so that the nature and purpose of the study could be explained. Two researchers (the research nurse and I) were always present during the interviews. The questioning was undertaking by one investigator and the other took the role of writing. The responses to each question were written down immediately to make sure that all answers were fully understood and documented properly. We also explored the responses to questions to check that we had accurately interpreted the answers. Interviews lasted from 15 to 35 minutes, and all were transcribed verbatim. Interviews were undertaken orally in the language of the participant. If the Asylum Seeker and Refugee parents did not speak English as their first language, an interpreter was present throughout the interview. Translator services at the office were available to assist with discussion and to explain the participant information sheets and consent forms. For those who speak Arabic I took the role of translator as my first language is Arabic. Consent forms and information sheets were also available in other languages such as Arabic and French.

The location of the interviews depended upon the group, and preferences of the parents. The majority of the interviews took place in the offices of 
the support groups, community centres and a local shopping centre (controls) . Parents were approached at the offices of one of the support groups and given the choice of participating in the interview in the office or at home. Control parents were randomly questioned in a designated area in the Westfield mall in Derby.

\subsubsection{Data entry and analysis}

I scrutinised the individual parents' semi-structured interview transcripts carefully to make sure that all questions were properly answered. The data from the semi-structured interview transcripts for the individual parents were read through several times. Then, substantive parts that related to the research questions were analysed and classified into different categories.

The analysis started with coding. Numbers were used to code the participants, while SPSS (Statistical Package for the Social Sciences) software (version 17.0) was used to analyse the data. Statistical comparisons between groups were conducted using an independent sample t-test and nonparametric tests such as Mann-Whitney and Chisquare tests. The t-test was used to compare the continuous data such as the parents' ages, how long they had been in their present accommodation and number of days since their last visit to a GP. The Mann-Whitney test was used for categorical data such as gender, occupation and health status. The Chi-square test was used to determine 
the frequency of illnesses they had suffered and medicines used during the last month and six months. These tests were used as appropriate tests to determine whether differences existed between the "at risk" and control groups in their access to health care and medicines.

These statistical tests were used for the categorical answers in the semistructured interviews. Once I had established the themes for quantitative and qualitative answers descriptive statistics were used around these themes.

\subsection{Summary}

The purpose of this methodology was to provide a clear framework for the research process involved and to outline the procedures used to gather information within the research. This chapter has also been concerned with outlining data collection and analysis. It has highlighted and addressed the ethical considerations relevant to this research and followed diligently to ensure the rights and safety of participants.

Following the description of the method and methodology used for this thesis, the next chapter describes the findings of this study with regard to Asylum Seekers and Refugees. 


\section{CHAPTER SIX}

\section{RESULTS AND DISCUSSION}

\section{Asylum Seekers and Refugees}

\subsection{Introduction}

This chapter presents the key findings relating to the access of the "at risk" group comprising Asylum Seekers and Refugees, to health care and medicines in the East Midlands region of the UK. The intention of this chapter is to analyse, collate and discuss the responses from the two participant groups of parents.

The presentation of the findings is divided into three sections. The first section addresses the sociodemographic characteristics of the participating parents. The second section addresses the children's health status and their use of health services. The third section presents the parents' attitudes towards health care access and the treatment of certain medical conditions (pain, asthma, and epilepsy). The discussion then considers the key findings. 


\subsection{Participants}

\subsubsection{Sociodemographic characteristics}

One hundred and thirty seven families were invited to participate. 100 families agreed to participate in this part of the study. For each family, one parent was interviewed. A total of 37 parents declined to participate in the study. The majority of the interviewed parents were females (56) and 44 were males. Their median age was 35 years (range 19-58 years). Fifty parents formed the group of Asylum Seekers and Refugees, and the other 50 parents formed the control group. The 100 families had a total of 216 children who were also involved in this part of the study. One hundred and seventeen of these children were in the "at risk" group (Asylum Seekers and Refugees), and 99 children were in the control group. Most of the children (211) lived with both parents; as for the remaining five children, the mother or the father was the primary custodian for them.

\subsubsection{Asylum Seekers and Refugees}

The families from the first, "at risk" group of the study comprised 50 parents of Asylum Seekers and Refugees. The majority were male (38). Sixteen parents declined to participate in the study. Those who participated were predominantly Iraqi, Pakistani, Nigerian, and Afghani. The rest were from various different countries, specifically Ethiopia, Zimbabwe, Somalia, Vietnam, Tunisia, Iran, Sudan, Kenya, East Africa, The Gambia, and Zambia (table 6.1). 
Table 6.1: Country of origin of "at risk" group (Asylum Seekers and Refugees)

\begin{tabular}{lc}
\hline Country of Origin & No. of Participants \\
\hline Iraq & 20 \\
Pakistan & 6 \\
Nigeria & 4 \\
Afghanistan & 4 \\
Ethiopia & 2 \\
Zimbabwe & 2 \\
Somalia & 2 \\
Not stated & 2 \\
Others & 8 \\
\hline
\end{tabular}

The youngest Refugee parent was 24 years old, and the oldest was 58 years old. The median age of the parents was 36 years, and all were born outside the UK. The foreign-born parents had lived in the UK for a median of 6.25 years. Only 18 were authorised residents as refugees. Seventeen did not state their status of residency. Fourteen had stated that their cases were under consideration, and one had received a refusal and lodged an appeal. Only 11 of the parents said they spoke English poorly and five said they did not speak it at all. Participants were asked about the reasons for leaving their country of origin.

The majority of them indicated that they left their country of origin for several reasons. The most common reason was "unsafe" with the next most common reason being "politics" (figure 6.1). 
Figure 6.1: Reasons for leaving country of origin

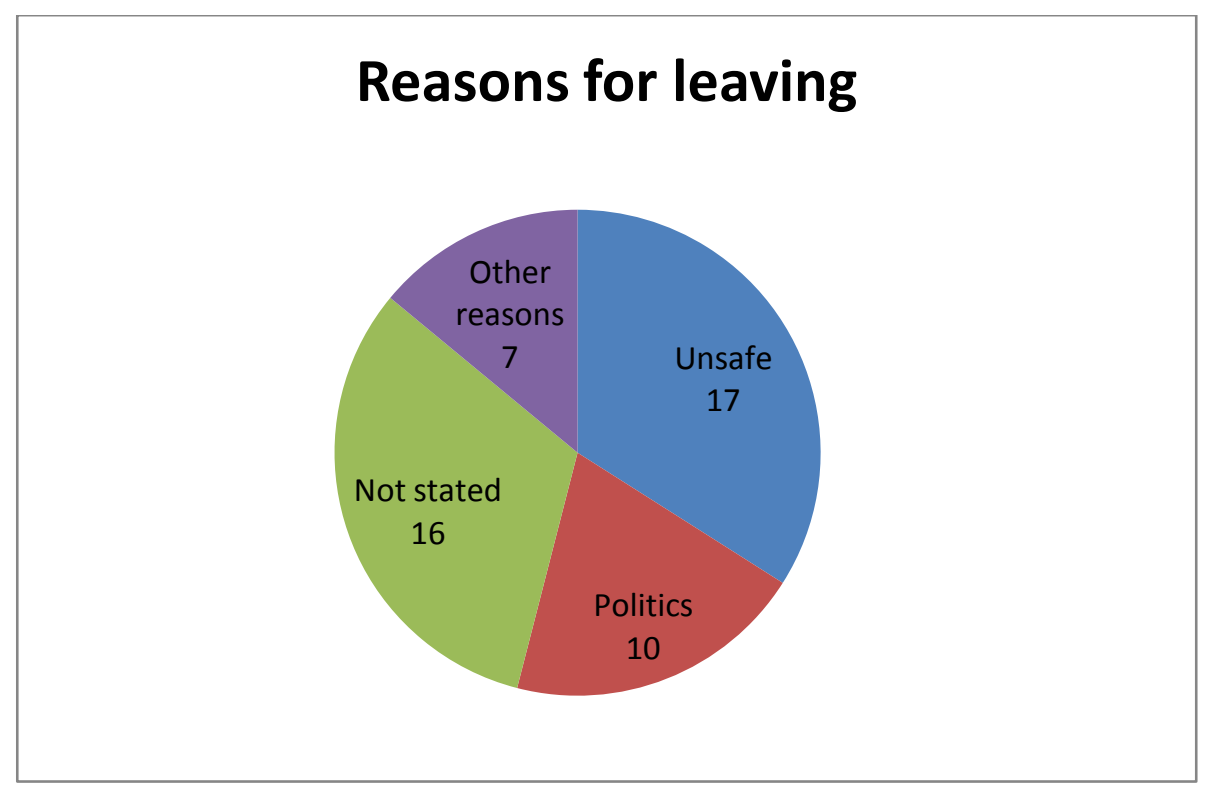

The majority of the participating parents (32) were normally fit and well. However, more than one third of these parents (18) reported that they had chronic illnesses (four chronic severe back pain, four depression, two diabetes, two disabilities, and six different illnesses).

The employment status report showed that over half (27) the parents were currently unemployed, 18 were employed, and five did not state their occupation. The median number of years in the present accommodation and current location were 2.25 and 4.75 years, respectively. The level of links with locality was relatively high (92\%) table (6.2). Most of them stated that they had good links with neighbours and friends in their local area. Only four had moved recently to a new 
area and thus had poor links with the locality. The demographics of the participants are detailed in table (6.2).

\subsubsection{Control Group}

Fifty families agreed to participate in the control group. For each family, one parent was interviewed. The majority were females (44). Twenty one parents declined to participate in the study. All the parents who participated in the control group were British citizens who have at least one child and live in the East Midlands area. Their ages ranged from 19 to 46 years with a median age of 34.5 years. Most of the participating parents (45) were normally fit and well. However, five of the parents in the control group reported health problems (three asthma and two stress and depression). Over half the participants (26) in this group were employed and 24 were housewives.

The median number of years in the present accommodation and current location was relatively high (7.4 and 17.5 years, respectively). This finding reveals the high rate of links and contacts with the local community (table 6.2). 
Table 6.2: Sociodemographics of parents

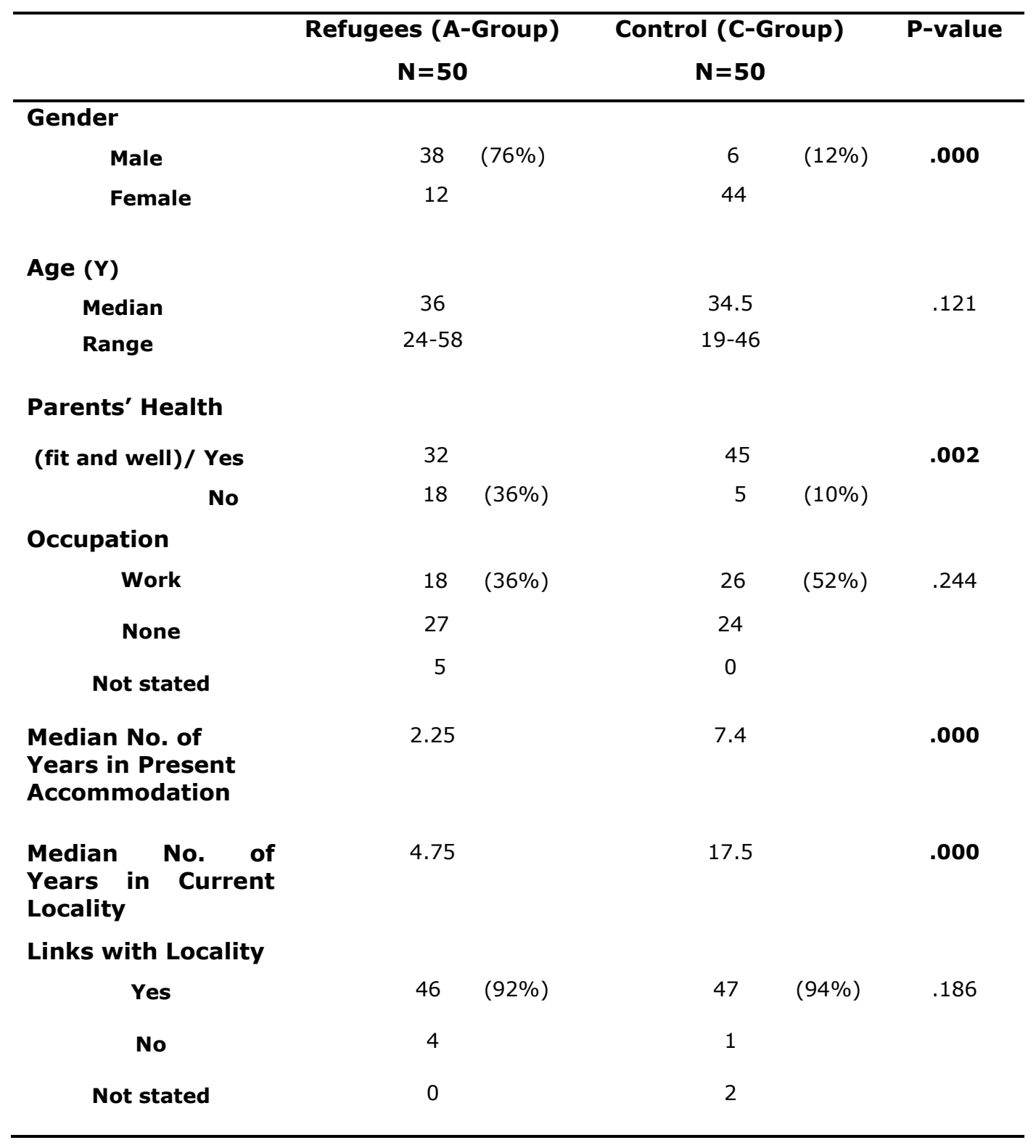

The results showed no significant difference between the control group and the Refugee parents in terms of the parents' ages, t-Test $(p=0.12$; table 6.2). 
The Refugee and control groups showed a significant difference in the number of male and female parents, with the Refugee group having fewer participating female parents, Mann-Whitney Test $(p=\leq .001$; table 6.2). However, the number of working and non-working parents in both groups was not significantly different, Mann-Whitney Test $(p=0.24$; table $6.2)$.

Overall, 77 of the parents from both groups were well and in good health. Refugee parents were more likely to have health problems, MannWhitney Test $(p=.002$; table 6.2$)$. Of the 18 Refugee parents who were unwell, four were patients suffering mental health problems mainly chronic depression as they referred this to their refugee status. All four were on antidepressant treatment. Others, however, said they had had depression prior to the study.

Male Refugee parents were more likely to report good health compared to female Refugees. In contrast, the control group's female parents were in better health than the male parents.

As anticipated, the Refugees had lived for a significantly shorter duration in their present accommodation and current locality compared to the control group, t-Test ( $p=\leq .001$; table 6.2). However, the groups did not differ in terms of their links with their surrounding community. 


\subsection{Access to Health Care and Medicines}

The parents were asked about their experiences with the health care system in the UK during the past month as well as during the past six months. Two main themes emerged from the data collected, which were subjectively organised into the following areas: general access to health care and medicines, children's health, and attitudes towards treatment of some medical conditions such as pain, asthma, and epilepsy.

\subsubsection{General Access to Health care and Medicines}

\subsubsection{Asylum seekers and Refugees}

The results showed that 14 was the median number of days since their last visit to the GP (either regarding their own health or their children's). Only one family had not visited the GP during the past month or the past six months. None of them claimed to face any difficulty registering with the GP. However, nine of them experienced difficulties while visiting the GP or hospital and while obtaining medicines. Specifically, they claimed to have problems with communication (language) or affording the travel costs to access the healthcare services. Most of them (45) did not pay for prescribed medicines for their children. Four stated that they purchased OTC medicines directly from a chemist. Nearly one third (16) of the participants reported that they normally used a home remedy for their ill children. These home remedies were either prepared at home (such as 
boiling herbs, honey with ginger mixed in warm water, etc.) or given by friends and relatives. Some of the other supplemental preparations that they reported using included vitamins, cod liver oil, and gripe water, which are all available on shelves at local chemists. Parents indicated that they most often took their ill children to GPs or to walk-in centres, but rarely to hospital emergency department (table 6.3).

\subsubsection{Control group}

The results showed that 15 was the median number of days since their last visit to the GP (either regarding their own health or their children's). Five families had not visited the GP during the past month or the past six months.

None of the participants mentioned that they experienced any difficulty accessing health care and medicines. About half of them (24) indicated that they would prefer to purchase analgesics directly from chemists rather than go to the GP to get a prescription. Eleven parents indicated that they often give their children home remedies at home or provide them with other products they bought from the supermarket or chemist (such as Calpol and vitamins). They preferred to contact their GPs or use NHS Direct when their children became ill (table 6.3). 
Table 6.3: General access to health care and medicines

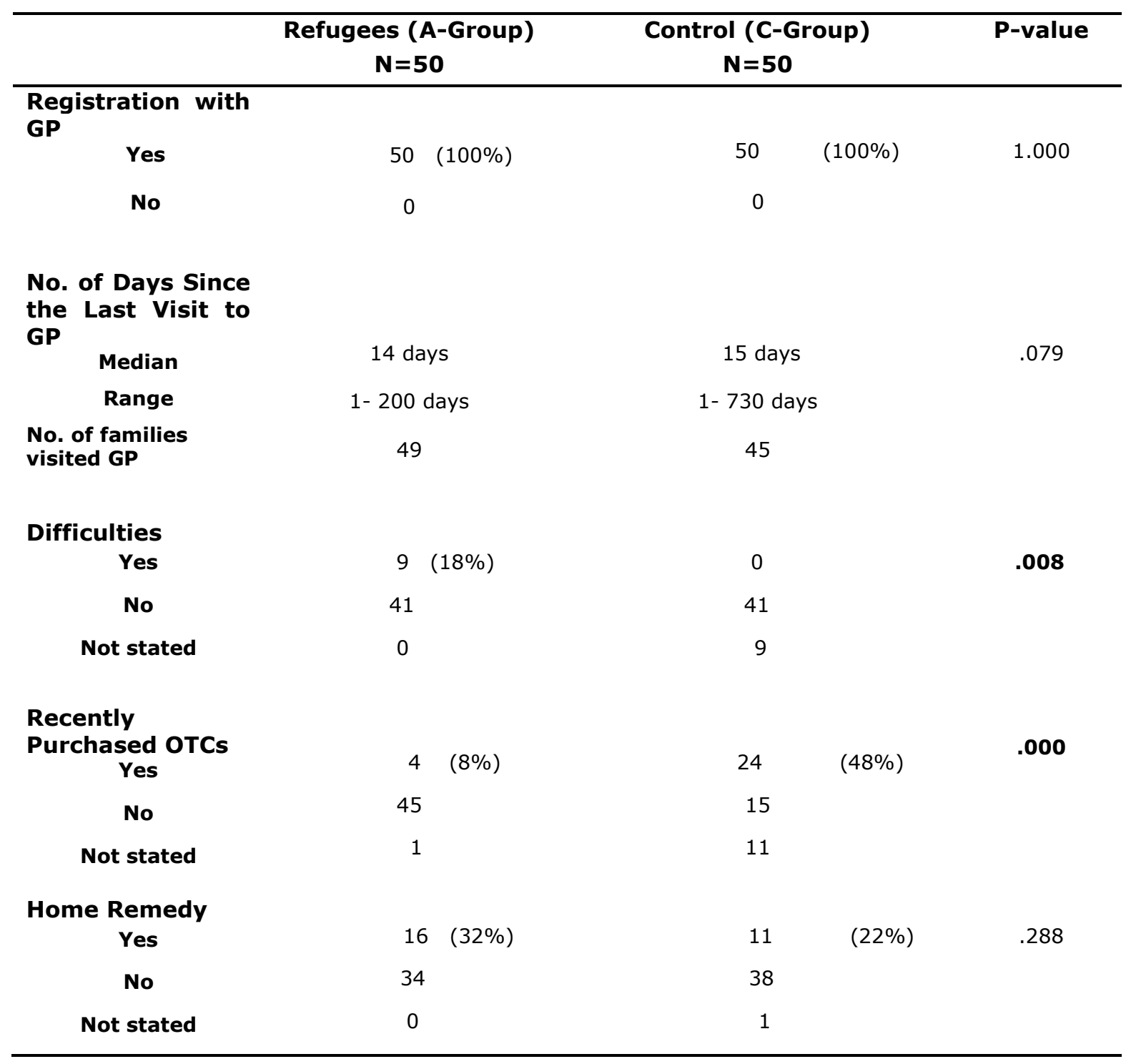

The Refugee and control groups did not differ in terms of having registered with a GP or use of homeopathic or herbal medicine at home for their ill children. In addition, the groups did not show any significant difference in the number of days since their last visit to a GP (either by themselves or with their children) table (6.3). 
Refugee parents were more likely to report difficulties with accessing health care compared to parents in the control group, Mann-Whitney test $(p=.008$; table 6.3). Specifically, the former indicated that they experienced some difficulties while obtaining medicines, such as language barriers, travel costs to the hospital and detention of parent by immigration authorities. In contrast, none of the control parents mentioned any difficulty while accessing health care or obtaining medicines.

Parents in the control group were more likely to purchase OTC drugs such as analgesics from local chemists compared to parents in the Refugee group, Mann-Whitney Test ( $p=\leq .001$; table 6.3).

\subsubsection{Children's health}

\subsubsection{Asylum Seekers and Refugees}

The total number of children in the Asylum seekers and Refugees group was 117 , with a median number of two children per family. Their ages ranged from 0.2 to 18 years with a median age of five years.

Most of the Refugee children (113) were in good health. Only four children had chronic medical conditions such as congenital heart disease, asthma, cancer, and poor growth. The results also revealed that most of 
the children (116) were up-to-date with their immunisations according to the information obtained from parents (table 6.4).

\subsubsection{Control group}

There were 99 children in the control group, again with a median of two children per family. Their ages ranged from 0.2 to 15 years with a median age of four years.

Most of the children in this group (92) were normally fit and well. Seven children had a chronic health condition. Four children had asthma, one had epilepsy, one had ADHD, and one had arthritis.

All the control children were fully immunised. All parents were aware of and understood the importance of their child being immunised (table 6.4). 
Table 6.4: Data for the children

\begin{tabular}{|c|c|c|c|c|}
\hline \multirow{3}{*}{$\begin{array}{l} \\
\text { Median No. of } \\
\text { Children/Family }\end{array}$} & \multirow{2}{*}{$\begin{array}{c}\text { Refugees (A-Group) } \\
\mathrm{N}=117\end{array}$} & \multirow{2}{*}{\multicolumn{2}{|c|}{$\begin{array}{c}\text { Control (C-Group) } \\
\qquad \mathrm{N}=99\end{array}$}} & \multirow[t]{2}{*}{ P-value } \\
\hline & & & & \\
\hline & 2 & 2 & & .224 \\
\hline \multicolumn{5}{|l|}{ Age $(Y)$} \\
\hline Median & 5 & 4 & & .130 \\
\hline IQR & $2.25-8$ & $1.9-8$ & & \\
\hline Range & $0.2-18$ & $0.2-15$ & & \\
\hline \multicolumn{5}{|l|}{ Children's Health } \\
\hline (fit and well)/Yes & 113 & 92 & & .225 \\
\hline No & $(3.4 \%)$ & 7 & $(7 \%)$ & \\
\hline \multicolumn{5}{|l|}{ Child } \\
\hline \multicolumn{5}{|l|}{ Immunisation } \\
\hline Yes & $(99 \%)$ & 99 & $(100 \%)$ & .358 \\
\hline No & $(1 \%)$ & 0 & & \\
\hline
\end{tabular}

The Refugee and control groups did not significantly differ in terms of number of children. Furthermore, children of both groups did not show any significant difference in the children's reported health, age, and immunisation status (table 6.4).

\subsubsection{Number of illnesses and medicines in the last month}

Of the 117 children from the Refugee group, 33 (28\%) experienced a total of 34 illnesses during the last month. The median number of illnesses reported was one illness per child (range of 1-3 illnesses). 
A total of 46 medicines were prescribed to 30 of the 33 children who experienced illnesses in the last month (median 1 medicine/child) (table 6.5). Thirty seven ( $80 \%)$ of the 46 medicines were prescribed by a doctor either from a GP or A\&E department at the hospital and the remainder were OTC medicines (table 6.6).

Thirty-five children from the control group (35\%) experienced illnesses in the last month. A total of 53 medicines were taken by 30 of these children (median 1 medicine/child) table (6.5). Twenty one (40\%) of the 53 medicines were prescribed by a doctor either from a GP or A\&E department at the hospital and the remainder were OTC medicines (table 6.6).

Table 6.5: Number of illnesses and medicines in the last month

\begin{tabular}{|c|c|c|c|c|c|c|}
\hline & \multirow{2}{*}{$\begin{array}{l}\text { No. of Children } \\
\text { with an Illness }\end{array}$} & \multirow{2}{*}{$\begin{array}{l}\text { Total No. of } \\
\text { Illnesses }\end{array}$} & \multirow{2}{*}{$\begin{array}{l}\text { Total No. of } \\
\text { Medicines }\end{array}$} & \multicolumn{3}{|c|}{ No. of Medicines/ Ill Child } \\
\hline & & & & Median & IQR & Range \\
\hline $\begin{array}{l}\text { Refugees } \\
\text { (A-Group) }\end{array}$ & 33 & 34 & 46 & 1 & $1-2$ & $1-3$ \\
\hline $\begin{array}{l}\text { Control } \\
\text { (C-Group) }\end{array}$ & 35 & 35 & 53 & 1 & $1-2$ & $1-4$ \\
\hline P-value & & .458 & .638 & & & \\
\hline
\end{tabular}


There was no difference in the number of illnesses reported by the Refugee children over the past month compared to the control children, Chi-Square Test ( $p=0.45$; table 6.5).

Additionally, there was no difference in the number of medicines used by the Refugee children during the past month and the control children, ChiSquare Test $(p=0.63$; table 6.5). Children in the control group, however, were more likely to receive OTC medicines with regards to types of received medicines, while the Refugee children were more likely to receive prescribed medicines ( $p=\leq .001$; table 6.6$)$.

Table 6.6: Medicines in the last month

\begin{tabular}{lcc}
\hline & Prescribed Medicines & OTC Medicines \\
\hline Refugee Group & $37(80 \%)$ & $9(20 \%)$ \\
Control Group & $21(40 \%)$ & $32(60 \%)$ \\
P-value & .000 & .000 \\
\hline
\end{tabular}

Analgesics/antipyretics were the group of medicines most likely to be used in both groups of children over the last month (Figure 6.2). 
Figure 6.2: Medicines in the last month

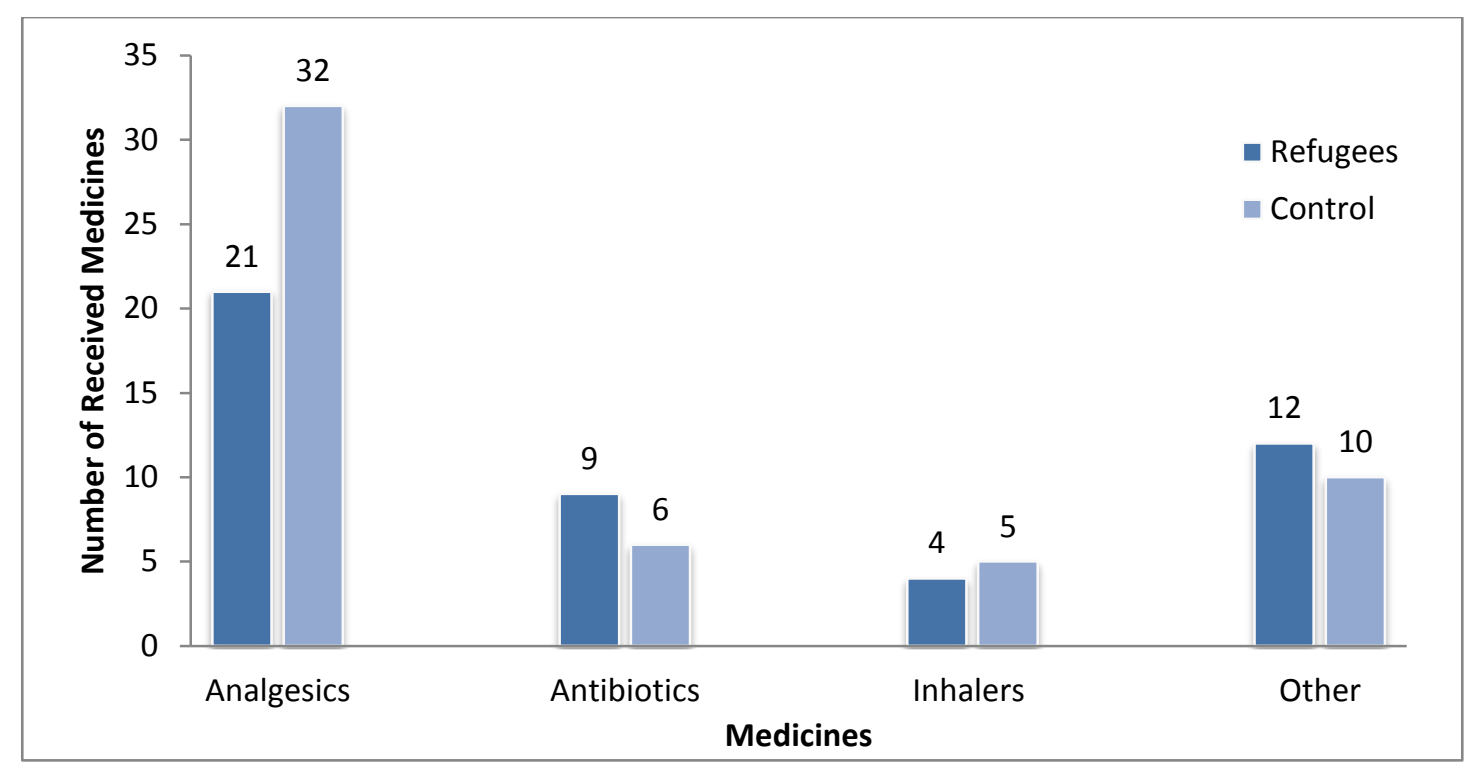

\subsubsection{Number of illnesses and medicines in the last six months}

Twice as many children experienced an illness in the past six months (154) than over the past month (68).

Eighty-five (72\%) of the 117 children from the Refugees group experienced a total of 100 illnesses (15 experienced at least two illnesses). The results also showed that not all ill children received medicines. Sixty-six of the 85 children who experienced illnesses received a total of 91 medicines (table 6.7 ). Seventy four $(81 \%)$ of the 91 medicines were prescribed by a doctor either from a GP or A\&E department at the hospital and the remainder were OTC medicines (table $6.8)$. 
Sixty-nine $(69 \%)$ of the children from the control experienced a total of 85 illnesses (16 experienced at least 2 illnesses) in the last six months. Sixty-one of these children received a total of 86 medicines (table 6.7). Thirty three (38\%) of the 86 medicines were prescribed by a doctor either from a GP or A\&E department at the hospital and the remainder were OTC medicines (table 6.8).

Table 6.7: Number of illnesses and medicines in the last six months

\begin{tabular}{|c|c|c|c|c|c|c|}
\hline & \multirow{2}{*}{$\begin{array}{l}\text { No. of Children } \\
\text { with an Illness }\end{array}$} & \multirow{2}{*}{$\begin{array}{l}\text { Total No. of } \\
\text { Illnesses }\end{array}$} & \multirow{2}{*}{$\begin{array}{l}\text { Total No. of } \\
\text { Medicines }\end{array}$} & \multicolumn{3}{|c|}{ No. of Medicines/IIl child } \\
\hline & & & & Median & IQR & Range \\
\hline $\begin{array}{l}\text { Refugees } \\
\text { (A-Group) }\end{array}$ & 85 & 100 & 91 & 1 & $1-2$ & $1-3$ \\
\hline $\begin{array}{l}\text { Control } \\
\text { (C-Group) }\end{array}$ & 69 & 85 & 86 & 1 & $1-2$ & $1-3$ \\
\hline P-value & & .424 & .951 & & & \\
\hline
\end{tabular}

There was no difference in the number of illnesses reported by the Refugee children over the past six months compared to the control children, Chi-Square Test ( $p=0.42$; table 6.7). 
Similarly, there was no difference in the number of medicines used by the Refugee children during the past six months and the control children, Chi-Square Test ( $p=0.95$; table 6.7). Children in the control group were, however, more likely to receive OTC medicines with regards to types of received medicines, while the Refugee children were more likely to receive prescribed medicines ( $p=\leq .001$; table 6.8 ).

\section{Table 6.8: Medicines in the last six months}

\begin{tabular}{lcc}
\hline & Prescribed Medicines & OTC Medicines \\
\hline Refugee Group & $74(81 \%)$ & $17(19 \%)$ \\
Control Group & $33(38 \%)$ & $53(62 \%)$ \\
P-value & .000 & .000 \\
\hline
\end{tabular}

Analgesics/antipyretics were the group of medicines most likely to be used in both groups of children over the last six months (Figure 6.3). 
Figure 6.3: Medicines in the Last Six Months

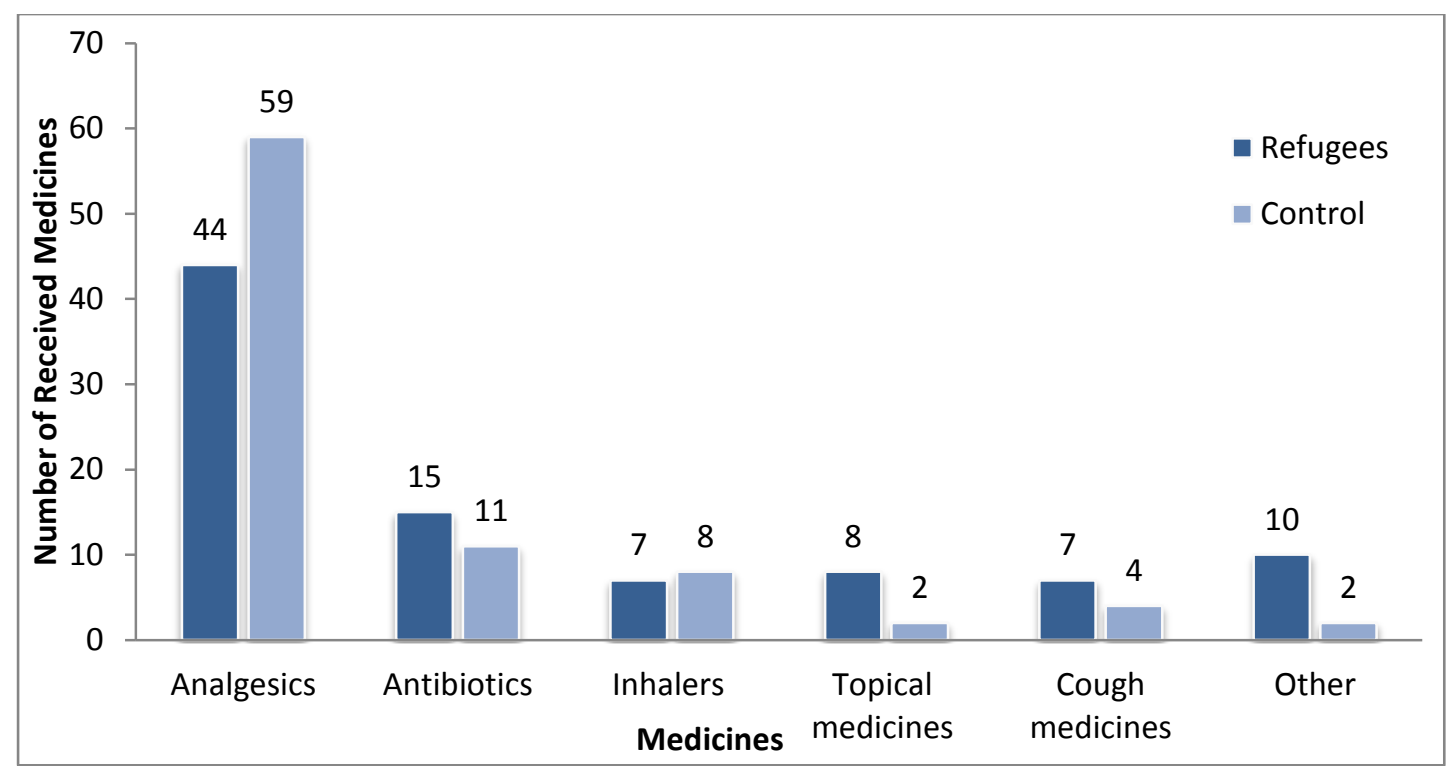

\subsubsection{Attitudes}

The third main theme is the attitudes of participating parents towards the treatment of three medical conditions: pain, asthma, and epilepsy.

\subsubsection{Attitudes towards pain (earache)}

Attitudes towards pain were different between the two groups. Most of the control parents (44) reported that they would give a medicine (such as an analgesic) for earache. In contrast, only 22 Refugee parents would give a medicine. This difference in the parents' attitudes towards earache was statistically significant, Mann-Whitney Test $(p=\leq .001$; table 6.9$)$. 
Table 6.9: Attitudes towards medical conditions

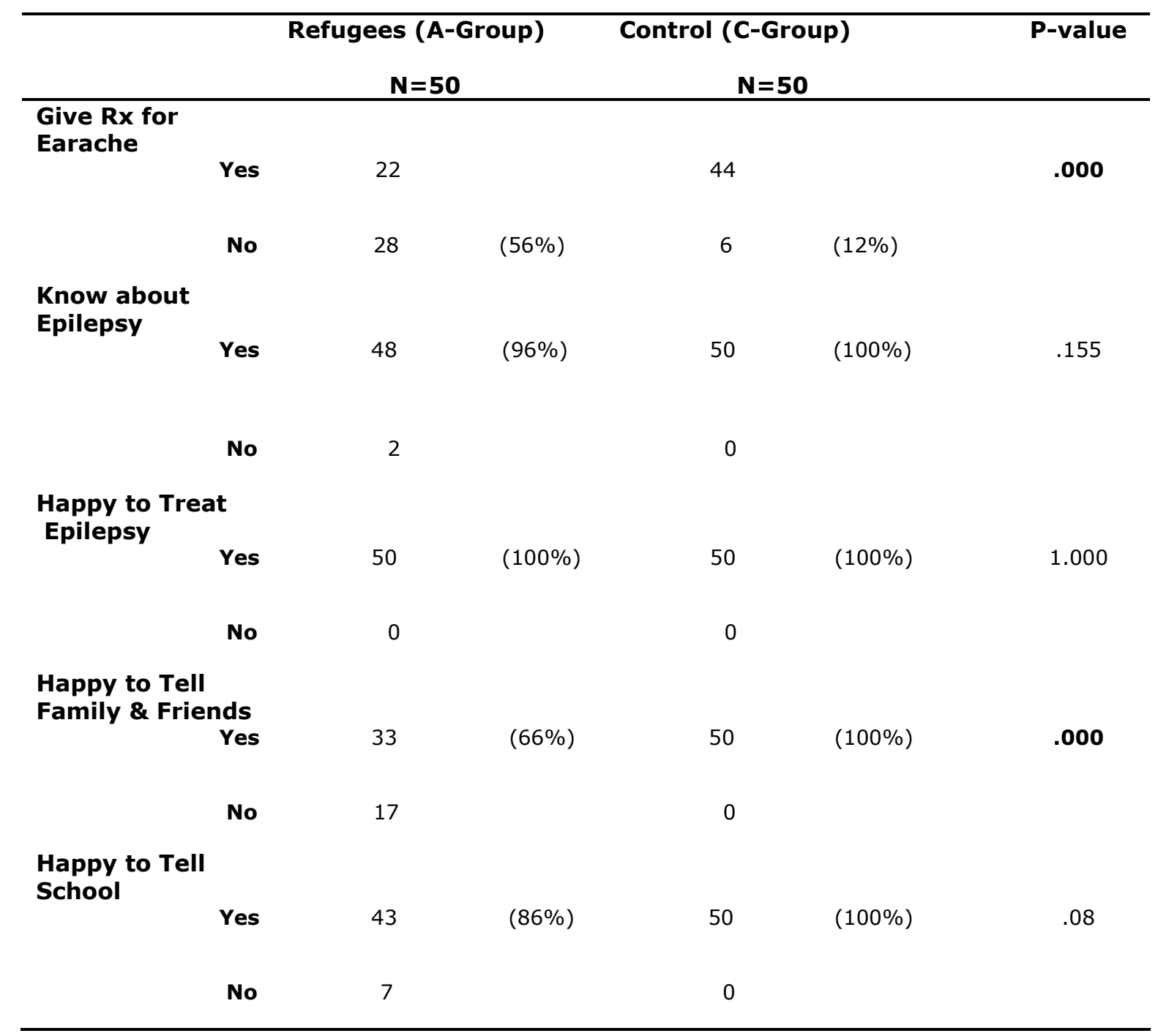

Parents from both groups who expressed their willingness to give analgesics such as paracetamol and/or ibuprofen indicated that they would start by exploring the possible causes, such as foreign bodies, and/or put a few drops of olive oil in the ear, then give pain relief. 
Twenty-eight of the Refugee parents reported that they would prefer to see their GP before giving any treatment. Parents, who said they would prefer not to start giving medicine at home, would try first to get a medical opinion by contacting their doctors or ringing NHS Direct. They would prefer to see the doctor first to diagnose the problem before giving treatment. However, a few of them said that they would prefer to try other options before they contacted their GPs. They would first try a warm bandage or breast feeding, and then they would take the child to A\&E or see a GP.

Common responses of Asylum Seeker and Refugee parents are summarised in tables 6.21, (see Appendix D1) and those belonging to the Control group are summarised in table 6.24, (see Appendix D2).

\subsubsection{Attitudes towards asthma}

Parents in both groups held a variety of views regarding the condition of asthma. Thirteen parents from the control group reported that they were aware of the risks involved in asthma and understood the importance of medication. Eight of the Refugee parents expressed their awareness of asthma. Some of them already had experience, since a member of the family had asthma and they would know what to expect. Therefore, they would not panic or feel too worried about it. 
Thirty Refugee parents and 28 control parents expressed their willingness to follow the instructions of doctors by giving inhalers for asthma. All these parents from both groups indicated that they would use inhalers for asthma if the medicines helped their child's condition. Twelve Refugee parents and nine control parents showed concern. They said that they would be worried and anxious about the health risks of this condition, so they would seek advice on how to control it in the case of a severe attack or if it appeared to be harming their child's health.

In general, there was no noticeable difference between the attitudes of the parents in either group towards the treatment of asthma. Common responses of Asylum Seeker and Refugee parents are summarised in tables 6.22, (see Appendix D1) and those belonging to the Control group are summarised in table 6.25, (see Appendix D2).

\subsubsection{Attitudes towards epilepsy}

Most of the parents in both groups (98) possessed good knowledge of the condition of epilepsy and the importance of treatment. Only two participants, who were both female Refugee parents, reported that they had not heard of the condition of epilepsy (fits and seizures). All parents, irrespective of their group, reported that they would consult a doctor if their child were to develop epilepsy and would give regular treatment. 
Generally, results indicated that parents from both groups were aware of the importance of treatment, so they would not hesitate to give medicines or to see the doctor regularly when recommended. Therefore, they did not show any significant difference in their attitude towards treatment of epilepsy, Mann-Whitney Test ( $p=0.15$; table 6.9). However, a few of them mentioned that they would be concerned about this illness, which would affect them emotionally. Their emotions, however, would not prevent them from giving the recommended treatment. Common responses of Asylum Seeker and Refugee parents are summarised in table 6.23, (see Appendix D1) and those belonging to the control group are summarised in table 6.26, (see Appendix D2).

Seventeen of the Refugee parents (12 males and 5 females) said that they would not inform friends and relatives about their child's epilepsy. In contrast, none of the control parents said they would do so. This difference in the parents' attitudes towards epilepsy was statistically significant, Mann-Whitney Test $(p=\leq .001$; table 6.9).

There was a trend for Refugee parents to be less likely to inform the school of their child's epilepsy condition compared to the control group. Nevertheless, this difference in the parents' attitudes was not statistically significant, Mann-Whitney Test $(p=0.08$; table 6.9$)$. It is worth noting that some of those Refugee parents who were happy to tell the school 
indicated that they preferred to tell only the head teacher or the class teacher about their child's condition.

Overall, the parents of the Refugee children were less likely to inform friends and school about their child's epilepsy. This decision may arise from concerns over stigma or from different cultural beliefs.

\subsection{Discussion}

The investigations detailed in this chapter revealed some interesting comparisons between both parents and children in the Refugee and control groups. Overall the Refugee parents were more prone to health problems, especially depression, than the control group.

The Refugee group did not show any significant difference in terms of parents' age and their occupation compared with the control.

\section{Accommodation and current locality}

Widespread dissatisfaction among Refugees over the location of housing, which was concentrated wherever local authorities have made it available rather than near others from the same or similar ethnic or cultural backgrounds has been previously reported (119). Refugees have been dispersed to places away from London and the south-east with no 
influence in the choice of where they were sent by either themselves or the local people in the new places, which created resentment(146).

My group of Refugees parents had lived for shorter periods of time in their present accommodation and current locality than those in the control group. Refugees may be itinerant as they may be required to relocate from one area to another depending on their individual circumstances or they may not have been in the UK so long. Those Asylum Seekers who did not have Refugee status yet, or those awaiting the outcomes of appeals, had no rights to housing by local authorities. These could be reasons for their enforced mobility and shorter stays in accommodation and localities compared with the control group.

However, though the length of time Refugees had been in their current locality tended to be shorter than that of the more settled control group, both groups described similarly positive links with their local communities. My group had links with the local community and they were already in contact with Refugee Action. This would explain their good links despite the length of their stay in present accommodation and current locality as they had taken time to seek out the local group. 


\section{Parental health}

Asylum Seekers and Refugees may be at higher risks of health problems since most of them come from countries where there is upheaval and violent conflict $(188,191)$. Depression and PTSD are more common. These conditions are known to be consequences of political oppression, torture, bereavement and separation from families, friends, social environment, locality and homeland. Additionally, anxiety about their future contributes to the high incidence of mental illness (119). Previous surveys on Asylum Seekers' and Refugees' health in the UK have found a high rate of mental health problems such as anxiety and stress. These health problems are severe enough to impact on them for life $(120,161)$.

As anticipated parents from the Refugee group, in my sample, were more likely to have health problems than those in the control group. The former reported a variety of health conditions as before in addition to a range of disabilities. Parents who reported feeling depression and stress referred this to both their refugee status and issues they often encounter in their daily lives.

\section{Registration with GPS}

Difficulties in obtaining full registration with a GP, and the entitlement to benefits this brings, are identified as major barriers to accessing health care, treatment and medicines for Asylum Seekers and Refugees (119). 
Previous studies indicate difficulties in obtaining GP registration in the UK $(150,178,194,323)$. These studies have suggested that full registration with a general practice would enable Asylum Seekers and Refugees to access all mainstream services and to benefit fully from the UK healthcare system.

The literature also revealed that Asylum Seekers and Refugees from countries with no developed system of primary care will often have a poor knowledge of the UK health care system especially if they do not have any guidance (120). They therefore expect hospital referral for some medical conditions that in the UK are normally treated in primary care. Minority group children in some developed countries are affected disproportionately by their parents' lack of knowledge of the healthcare system in the host country and how to access healthcare services ( 31 , 43). A national survey in the US indicated that certain ethnic minority groups encounter particular barriers to health care arising from a lack of information about, and familiarity with, the services available (156).

Based on the results of this study, parents from the Refugee group who took part in the study expressed a good basic understanding of the English health system. None of the parents, in both the Refugee and the control groups, experienced any difficulty in registration with GPs. Neither did they differ in terms of the median number of days since their last visit to a GP (either by themselves or with their children) or use of 
homeopathic and herbal medicines at home for their ill children. This positive knowledge of my study group might be related to, their links with the Refugee Action.

\section{Homeopathic and home remedies}

Previous studies also found that the use of home remedies presented other significant barriers to health care $(210,324)$. A high percentage of the population from Asian and African countries depends on traditional medicines for their health care and herbal medicines are the most common form. Parents in some vulnerable groups in the US, for example, preferred to use a combination of OTC preparations and home remedies as the treatment of first resort for fever, cough, rashes, diarrhoea and vomiting, rather than seeking professional medical care (210).

However, the Refugee parents in this study did not show any difference in terms of using homeopathic or herbal medicines compared with control group.

\section{Difficulties in accessing health care and medicines}

Previous studies reported that, though Asylum Seekers and Refugees may have free access to NHS services in theory, in practice language barriers in consultations may make these very hard to access $(146,170$, 171). Language communication barriers are encountered when trying to 
travel to healthcare facilities, at the reception desk and when trying to make appointments, as well as in the consulting room (119). Similar conclusions were reached by another study in the US, showing that parents from Latino immigrants indicated language problems as the greatest barrier to accessing health care both for themselves and their children. Many of them who spoke English, either not very well or not at all, did not bring their children for primary or emergency health care $(186,324)$. Others said that, because of poor communication with health professionals due to language problems, their children received poor medical care resulting from misdiagnosis and inappropriate medication(187).

Similarly, while all participating parents in this study reported that the NHS met their needs, especially in registering with GPs, some factors impacting on their access were mentioned. These included language problems and a lack of financial resources.

Only nine out of the 50 Refugee parents were more likely to report difficulties in accessing health care and obtaining medicines than parents in the control group. Specifically, the former indicated that they experienced problems such as language barriers when they contacted the GP. Six parents had difficulty in speaking English and expressed their need for an interpreter during the interviews. On arrival in a new country, Refugees often have communication difficulties due to language problems 
with health workers. They are often unable to give an adequate medical history and this may prevent or delay appropriate treatment.

Access to health care and medicines is also affected by poverty, and many Refugees live below the poverty line (126). Asylum Seekers are forbidden from working and therefore prevented from supplementing their income. As a result they are trapped in poverty. Absolute dependence is likely to have serious consequences for their health and access to health (147). An American study indicated that large numbers of children from the Asylum Seekers and Refugees in some developed countries suffered from absolute lack of access to medicines, caused mainly by rising unemployment and decreasing or no health insurance (140). Those without insurance were less likely than indigenous children to access health care and medicines $(44,45)$. Furthermore, those Asylum Seekers still awaiting decisions on their application or appeals are forbidden to work, and this creates an economic barrier (cannot pay for transportation) to their access to health care and medicines (126).

Two Refugee parents in this study felt travel costs to healthcare services such as a hospital could be another factor that affected their access to obtain health care and medicines. They felt that because of such financial problems they may miss appointments at the hospital, or face difficulty in obtaining medicines from a chemist. 
A study conducted in Australia on mental health difficulties among some detained families revealed that having a parent in detention caused additional barriers in the form of family disruption (167). Consequently stress was a major problem in these families. Parents reported a marked decrease in their parenting abilities as a result of detention, which caused them distress.

Parents from the Asylum seeker and Refugee group in this study felt that detention was another barrier to their access to health care and medicines. Only one Asylum Seeker mother reported that the father had been detained. As a result, the family was leaderless and suffering psychologically and the mother had neither the knowledge nor the ability to cope. She stated that, all of these create barriers to their access to health care.

\section{OTC medicines}

In recent years a significant culture change has taken place in the way health care is accessed in the UK, gradually taking the focus away from GPs and giving more responsibility to local community pharmacists. 
The background to this culture change started when the government, in a drive to effect improvements to the NHS, published "The NHS Plan" in July 2000. This Plan in part introduced the idea of 'patient-centred care'. It made proposals to integrate the pharmacy more within the NHS, in order to improve the patient care. Community pharmacists were afforded new roles which took the focus away from their dispensing role. Later on in 2005, through a strategic document, the Pharmacy service was classified into three distinct parts; 'essential', 'advanced' and 'enhanced'. The objective of these new services, in the main, was aimed at making patient access to medicines better and also to reduce the burden on GPs (325).

It is the 'enhanced' service which is of particular interest to my study. Minor ailment schemes are a primary example of this pharmacy service at a local level. In practice what the minor ailment scheme entails is that a patient can go to the community pharmacist to seek advice and receive treatment subject to the problem being a minor ailment. This 'filter' which sieves out a significant proportion of ailments that a GP normally deals with allows, in theory at least, the GP to focus on providing a quality service for the more serious conditions.

The Pharmacy White Paper in 2008 reinforced this message by giving support to minor ailment schemes as the way forward in terms of increasing health care capacity without compromising the safe and effective delivery of healthcare. Clear definitions have to be given for 
minor ailments as well as the specific list of medicines and the types of patients that are eligible. For example the typical minor ailments include conditions such as constipation, hay fever, coughs and colds and patients could be elderly patients, children or those on low income. This scheme removed the payment barrier where those who are exempt from prescription charges can be supplied with limited formulary medications free of charge by the community pharmacist for minor ailments (325, 326).

Patients have been generally supportive of the scheme but had reservations about privacy and confidentiality and also the choice between the pharmacist and GP (327). Importantly they also highlighted that the scheme was lacking for some ailments.

The minor ailment scheme commenced in April 2009 and the objectives were consistent with minor ailment schemes in general, i.e. reducing the burden on GPs by redirecting certain less serious conditions to pharmacists. A study has clearly demonstrated that more than $50 \%$ of patients who used this scheme would have otherwise accessed other branches of the NHS (325). This would have cost an extra $£ 6000$ per month. This demonstrates significant cost saving as a result of introducing the new scheme (325). 
Recently, efforts were made to explore the impact of the minor ailment scheme on deprived ethnic communities. Understandably, delivery of healthcare to these minorities presents its own unique challenges because they are typically the most disadvantaged groups in the community. They tend to have greater health needs than the general community.

The difficult issue of healthcare for Asylum Seekers and Refugees is well highlighted. A group of over 500 Refugees arrived in a south London community in early 2001(328). They were mainly Kosovan/Albanian but some were Middle Eastern and some from sub-Saharan Africa. Although they only remained in the area for 5-14 days, considerable pressure was put on the primary care services. The local practices were already strained in terms of capacity before the influx of Refugees and this resulted in many of them not being able to register with a local general practice. The problem was further accentuated by the fact that most of them did not have sufficient money to purchase medicines for minor illness. The net effect of this situation resulted in a significant number of Refugees attending local hospital A\&E departments and many of them arriving via emergency ambulance because they did not have access to any transport (328). 
Parmentier et al (328) piloted and evaluated what is essentially a version of the minor ailment scheme tailored to effectively deal with the Refugee situation. After understanding that they were steered away from obtaining OTC medications due to cost i.e. obtaining a prescription from the GP is free of charge but OTC medicine has to be bought at market prices for minor illnesses, they looked at how they could facilitate Refugees to avoid using the GP in the first instance. To reduce the burden on the primary local care service from Refugees a voucher system was brought in. This voucher could then be presented at the specified local pharmacy and exchanged for a medication on the predetermined list.

This scheme proved hugely successful in reducing GP consultations for minor illnesses. 184 Refugees were issued a total of 200 vouchers over five months. Only $1 \%$ of those issued a voucher consulted a GP. Although a user satisfaction survey could not be carried out, because standardised satisfaction ratings are difficult to implement across several languages, the success of the scheme is demonstrated by the high proportion of vouchers taken to participating pharmacists (328).

My study found that Asylum Seeker and Refugee parents were less likely to purchase OTC analgesics than those in the control group. This may be for one of two reasons. Firstly, the financial situation for Refugees and Asylum Seekers is extremely difficult. Such families are unlikely to be 
able to afford OTC analgesics. The other reason is that the majority of Refugee parents felt they would prefer to take their children to the doctor when they become ill. None of the participating parents mentioned any reasons for this, though they could include the fear of any parent of giving medicines without medical advice. Taking cultural factors and lack of knowledge about use of medicines into account amongst this group could be other reasons for not giving OTC analgesics.

This study also did not cover the issue of language being a barrier to accessing the minor ailment scheme. It has identified that this issue also needs consideration when looking at access. In particular this is demonstrated by the general inability of the Refugee parents to communicate with pharmacists to explain the condition of their child especially those who poorly or did not speak English at all. They feel that the GP is able to diagnose the condition even if they do not speak English well. Another issue could be the lack of knowledge of the scheme and how to access it. When questioned on the options available to them, they only referred to GP and Hospital access and not the 'minor ailment' scheme which is available in Derby.

\section{Children's health and immunisation}

Children in both Refugee and control groups were well balanced in terms of number, health, age and immunisation status. 
Children of Asylum Seekers and Refugees who come from unsafe countries may not have had the opportunity to complete their immunisations (120). Primary care in the home country may be poor, with low immunisation rates and limited or no records being kept or available (119). These children may be less likely than indigenous children to receive essential immunisation. Lack of records often lead to their missing of subsequent vaccinations (140).

In contrast, the vast majority of children from the Refugee group involved in this study had a high rate of immunisation and good health status, reported by the parents. This high rate indicated that parents of Refugees were aware of the importance of immunisation and their ability to access NHS services freely. I assume a possible explanation for this positive result is that all the Refugee participants in this study were already in contact with Refugee Action, and they may therefore be assumed to be aware of the healthcare system.

\section{Number of illnesses and medicines}

Recent research in North America has revealed that in both the USA and Canada, children of different ethnic minority groups and/or those without insurance may be less likely than indigenous children to access health care (45-47). They found that black American children were less likely 
than their white counterparts to receive a prescription medicine. Similarly, uninsured American children were less likely than those with private insurance to receive a prescription medicine (46). A recent prospective study in Canada highlighted that premature white Canadian neonates were more likely to receive a variety of medicines and interventions than aboriginal (Northern First Americans, Inuit and Metis) premature neonates (47). Another study, however, found no difference in the treatment of children from different ethnic backgrounds presenting with long bone fractures in the emergency departments (138).

An American study examining the relationship between immigration status and access to health care, found that citizens' children had easier access than non-citizens' (141). Those children whose parents had lived in the US for less than five years were less likely to have health insurance than other groups within the population. It also recorded that these children received fewer prescriptions, and were at a higher risk of not getting specific treatment plans for certain medical conditions, than white children or African American children.

In EU countries, the provision of health care for Asylum Seekers varies widely in availability and quality. It is worth noticing that in some EU countries where asylum applications are refused, their rights to health care are restricted to emergency treatment. Problems of access for Asylum Seekers are also compounded by the length of time the asylum 
claims process may take, which can range from a few months to several years. In Germany, for example, Asylum Seekers and Refugees are given access to the same health care as German nationals only three years after arrival. However, in Luxembourg, this is granted after three months (43).

In the UK, free access to the NHS was formerly offered to failed asylum seekers. They are entitled to all NHS services and though they can be registered with a GP, can only be issued with an exemption certificate for prescription, dental and optical care charges once accommodation has been allocated(126, 147). Since 2004 the government has strict regulations for failed Asylum Seekers and they only have access to some primary care which could soon be withdrawn $(43,115)$. The current situation is that failed Asylum Seekers are only allowed access to emergency treatment or the continuation of treatment that they had already been receiving from NHS hospitals. Children, however, would still be allowed free health care (132).

The findings of this study revealed that both Refugee and control children reported similar number of illnesses in both the past month and the past six months; and number of medicines used over both periods. Asylum Seekers and Refugees in the UK have free access to NHS services and this makes their situation different to those in other countries that have a 
health insurance system. Moreover, no failed Asylum Seekers were included in my group of parents.

Refugee children did not differ from the control children in relation to the number of medicines they received. This finding is reassuring in that it suggests that Asylum Seekers and Refugees are able to access health care and medicines as well as the indigenous population. However, all the parents in this study were already in contact with Refugee Action, a support group specifically set up to help Refugees and guide them. There may well be - almost certainly are - others who have not yet encountered Refugee Action or similar charities or organisations, who are therefore not in the system. Their access to medicines may be very different. These refugees are, however, outside the scope of this study. There is still much further research to be undertaken in this field.

\section{Attitudes towards health conditions}

Two main findings emerged from this part of the study. Firstly, Refugee parents are less likely to, give analgesics for earache. Secondly, they are less likely to inform others about their epileptic children. They will be discussed further in the next sections. 


\section{Pain (earache)}

The findings of this study revealed that attitudes to the treatment of earache showed some differences but also similarities. Twice as many of the control group parents would give an analgesic for earache as those in the Refugee group. All those in both groups who said they would do this also said they would explore the causes of the pain first. Some would also try alternative treatments before using medication. Those who would not give analgesics initially would try to obtain a medical opinion; and would also apply alternative treatment first.

The cultural background of a family may contribute to variations in assessment and management of pain experience in children. Previous studies have revealed the influence of cultural differences to the attitude towards pain (329-331). Different ethnic groups and cultures have different norms for the management of pain.

Failure to understand the nature of experienced pain in children could act as an initial barrier to effective or optimal treatment. Denying pain in childhood, minimising the significance symptoms, hesitating to give effective analgesics, and cultural myth that children do not experience pain are the most common barriers to effective management of pain in children. 
Concerns regarding using pain medications because of serious side effects or the development of dependency and tolerance sometimes inhibit parents from giving such medicines effectively. Fear of tolerance and the belief that giving analgesics early in pain will result in analgesics not working later, when the pain is greater are barriers to the effective management of pain in children $(331,332)$. However, the results of my study did not detect any evidence for the effect of these barriers in the parent's attitudes towards pain treatment.

\section{Epilepsy}

The attitudes to the treatment of epilepsy showed also both differences and similarities. Most parents in both groups reported a good knowledge of epilepsy and the importance of treatment for it, with only two (both Refugee mothers) not having heard of it. All said they would consult a doctor and treat it regularly. Some felt epilepsy in the family would cause them concern, but their anxieties would not lead them to avoid or prevent treatment.

In keeping with previous literature, the findings of this study are supportive in that Refugee parents were less likely to inform relatives and friends about their child's epilepsy, possibly from fear of stigma or for cultural reasons. Whereas only two thirds of the Refugee parents would tell their families and friends if their children were sufferers, all the 
control group parents said they would. There was also a trend for Refugee parents to be less likely to inform the school of their child's epilepsy. Of those Refugee parents who would do so, some would only tell the head teacher or class teacher.

Results of this study also show that the cultural beliefs of Refugees may impact on their children's access to medicines and management. Concerns over stigma could be a factor that influences parents' attitudes towards its treatment. It is worth noting that Asylum Seeker and Refugee parents from Southern Asia (such as Pakistan and Afghanistan) who took part in this study, though they were few, appear less inclined to tell others about their child's epilepsy. Informing those people who are often with the child, such as, relatives, neighbours, good friends and teachers, would impact on child's management of seizures. It is essential to tell them so that they know how to help if their child has a seizure.

Some ethnic groups seeking asylum in the UK may avoid seeking health care due to the stigma associated with their refugee status $(126,213$, 214). The impact of stigma might affect the chance of these groups accessing medicines and medical care. The perceived stigma associated with medical diagnosis of epilepsy is a potential barrier in accessing Western health services by some ethnic groups (215). For example, south-east Asian Refugees believe that alternative Asian treatment for 
psychiatric disorders is better than Western health care. Confidence in their indigenous treatment and fear of shame induces a reluctance to seek healthcare and treatment $(218,333)$.

Across the world and throughout history, there have been negative attitudes about epilepsy. Epilepsy has been considered as contagious or a form of mental illness which cannot be treated (334). Negative attitudes towards epilepsy among some communities were associated with various factors including lower level of education, older age and not having heard of or witnessed anyone having a seizure (335).

The consequences of epilepsy in terms of stigma differ around the world, depending on the cultural and community health background. Many parents in some cultures don't want to report cases of children's epilepsy (336).

A study was conducted on the issue of epilepsy and identity in a minority ethnic group (people of Pakistani origin) living in the UK (334). It provides some interesting insights on their experience of stigma and discrimination. It was noted that in this community the issue of marriage was "central to the experience of stigma and Prejudice" (334). Most men are unwilling to accept a proposal from a girl who has epilepsy. Epilepsy is thought to be a hereditary disorder. Some families also stated that 
they would restrict a person with epilepsy from marrying someone from their household (335).

There is also a misbelief that women with epilepsy cannot bear children. Thus, female patients with epilepsy often remain single. Women from this community experience many more difficulties in coping with pressure from society and family. Therefore, they conceal their epilepsy during marriage negotiations $(337,338)$. Some people don't allow their child to play with children with epilepsy. They think that epileptics should be isolated from the normal population. Fear of encountering negative attitudes among their community have led parents with an epileptic child to restrict their social activities and so become socially isolated(339).

Limited knowledge and misconception about epilepsy may explain the limited access to its treatment in some developing countries (340). The low rate of treatment or treatment gap of this condition in such countries is often influenced significantly by several barriers. These barriers include cultural beliefs, poverty, stigma, limited number of both qualified healthcare staff and unavailability of healthcare services and essential anti epileptic drugs (AEDs). People in some communities are often unaware of effective treatment that is available at specialised health centres. Traditional remedies such as massage, prayers and traditional healers are commonly used. 
Unfortunately, a number of health professionals in these devolving countries, for example in Lao, shared the population traditional beliefs and practices, especially stigma when regarding the matter of marrying (340). They may be reluctant to diagnose or prescribe AEDs. They are also unaware of long-term treatment. Treatment of epileptic children in the psychiatric department instead of on a paediatric ward may increase the people's confusion of epilepsy as a mental illness $(68,340)$. A survey was undertaken in 2009 to assess attitudes towards epilepsy with doctors working with children in Lao (340). It was noted that a number of them had never diagnosed epilepsy or prescribed AEDs. Few had received basic training in epilepsy and its management. Lack of guidelines concerning epilepsy leads doctors to treat it according to their own experiences.

Diagnosis and management of epilepsy in children by reducing or stopping the recurrence of seizures will impact positively on, family's acceptance of the illness and the psychological consequence on the child (341). My study findings reveal that there are some similarities to the previous finding in literature especially to those related to parents' cultural beliefs and stigma towards epilepsy treatment.

\section{Asthma}

More control group parents than Refugee parents were aware of asthma and its risks. Some already had personal experience of it in their families, 
and would therefore know what to expect. Attitudes regarding treatment were broadly similar between the two groups. Virtually the same number of parents in each group was willing to follow a doctor's instructions regarding inhalers and would use them if they proved effective.

\subsection{Summary}

The findings of this study are reassuring in that access to health care and medicines for children of Refugees interviewed was good. It is recognised that only Asylum Seekers and Refugees who had made contact with Refugee Action were included within this study. Asylum Seekers and Refugees outside of the system, especially those living illegally within the UK, may not have the same access to health care and medicines. Despite the positive access to health care and medicines, there were several issues identified in a small number of parents which are listed below.

- $18 \%$ of Asylum Seekers and Refugees encountered barriers such as language skills and lack of financial resources.

- Financial difficulty in purchasing OTC medicines was identified as a significant problem for some Asylum Seeker and Refugee families.

- Asylum Seeker and Refugee parents were less likely to give analgesia to children in pain based on the scenarios. This 
may be related to the desire to see a doctor before the administration of analgesia or due to cost.

- Stigma associated with the medical diagnosis of epilepsy appeared to be a greater problem in Asylum Seeker and Refugee families. Refugee parents were more likely to choose not to inform others about their child's epilepsy.

Access to health care is an essential human right. Children are dependent upon both their parents and the health system for ensuring access to health care. This study has identified problems both within the system and also in relation to parental beliefs that may affect the access to health care and treatment for children. It is important that both of these potential barriers are addressed in order to improve the health of children of Asylum Seekers and Refugees.

In the same way that Chapter 6 gives and discusses the findings for Asylum Seekers and Refugees, Chapter 7 gives and discusses the findings for Gypsies and Travellers. 


\section{CHAPTER SEVEN}

\section{RESULTS AND DISCUSSION}

\section{Gypsies and Travellers}

\subsection{Introduction}

Chapter seven presents the findings relating to the access of the "at risk" group comprising Gypsies and Travellers, to health care and medicines in the East Midlands region of the UK. The intention of this chapter is to analyse, collate and discuss the responses from the two participant groups of parents.

The presentation of this chapter's findings is divided into three sections. The first section addresses the sociodemographic characteristics of the participating parents. The second section addresses children's health status and use of health services. The third section presents the parents' attitudes towards health care access and the treatment of certain medical conditions (pain, asthma, and epilepsy). The discussion then considers the key findings. 


\subsection{Participants}

\subsubsection{Socio demographic characteristics}

The parents of 97 families agreed to participate in this part of the study. Forty seven families formed the "at risk" group and 50 formed the control group. For each family, one parent was interviewed. Most of the interviewed parents were females (91) and only six were males. The overall median age of the 97 interviewed parents was 33 years (range 18-51).

Fifty families of Gypsies and Travellers were initially included in this study. However, three of these families had children with an age range of 16 18 years, which falls well outside that ( 0.2 to 15 years) of the remaining 47 families. These three families were therefore excluded, to avoid any effect of these outliers on the overall results.

The 50 families of the control group in this part of the study included 45 of the 50 families from the control group in the previous part of the study (described in chapter 6). In order to ensure a control group of children with similar ages to the children of the Travellers, we excluded five families who only had young children. Five new families were then recruited to replace the excluded ones. 
The 97 families had a total of 218 children who were also involved in this part of the study. One hundred and thirteen of these children were in the "at risk" group, and 105 children were in the control group. Ages of the children in both groups ranged between 0.2 and 15 years. Most of them (209) lived with both parents; as for the remaining nine children, the mother or the father was the primary custodian for them.

\subsubsection{Gypsies and Travellers}

This second "at risk" group comprised 47 families. For each family, one parent was interviewed and all these parents were females. Four parents declined to participate in the study. All those who participated were British citizens. Their ages ranged between 18 and 51 years, with a median of 30 years. Sixteen of the parents had chronic illnesses. Six reported chronic anaemia, four had hypertension, three had depression and three had asthma (table 7.1).

The non-working rate was high with a high number of participating housewives (43). The median number of years in the present accommodation or site was only six months. The median number of years in the current location (the East Midlands area) however was eight years. About half of the parents (23) had good links with the local community. The remaining 24 parents did not mention the status of their relationship with the community (table 7.1). 


\subsubsection{Control Group}

Fifty families agreed to participate in the control group. For each family, one parent was interviewed. The majority (44) were females. All the parents who participated as controls were British citizens who have at least one child and live in the East Midlands area. Parents' ages ranged between 19 and 46 years with a median of 36.5 years. Most participating parents (45) were normally fit and well. However, five of the parents reported a chronic illness. Three had asthma, and two reported stress and depression.

The employment status report showed that 30 of the participants in the control group were employed, and the remaining 20 were housewives.

The median number of years in the present accommodation and current location was relatively high (7 and 21.5 years, respectively). This finding obviously reflects the high rate of links with the local community (table 7.1). 
Table 7.1: Socio demographics of parents

\begin{tabular}{|c|c|c|c|c|c|}
\hline & \multicolumn{2}{|c|}{$\begin{array}{c}\text { Travellers ( } \mathrm{T}- \\
\text { Group) } \\
\mathrm{N}=47\end{array}$} & \multicolumn{2}{|c|}{$\begin{array}{c}\text { Control (C-Group) } \\
\qquad N=50\end{array}$} & P-value \\
\hline \multicolumn{6}{|l|}{ Gender } \\
\hline Male & 0 & & 6 & $(12 \%)$ & .015 \\
\hline female & 47 & & 44 & & \\
\hline \multicolumn{6}{|l|}{ Age (Y) } \\
\hline Median & 30 & & 36.5 & & .039 \\
\hline Range & $18-51$ & & $19-46$ & & \\
\hline \multicolumn{6}{|l|}{$\begin{array}{l}\text { Parents' Health } \\
\text { (fit and well)/ }\end{array}$} \\
\hline No & 16 & $(32 \%)$ & 5 & $(10 \%)$ & \\
\hline \multicolumn{6}{|l|}{ Occupation } \\
\hline Work & 4 & $(8.5 \%)$ & 30 & $(60 \%)$ & .000 \\
\hline None & 43 & & 20 & & \\
\hline $\begin{array}{l}\text { Median No. of } \\
\text { Years in Present } \\
\text { Accommodation }\end{array}$ & 0.5 & & 7 & & .000 \\
\hline $\begin{array}{l}\text { Median No. of } \\
\text { Years in Current } \\
\text { Locality }\end{array}$ & 8 & & 21.5 & & .000 \\
\hline \multicolumn{6}{|l|}{ Linkswith Locality } \\
\hline Yes & 23 & $(49 \%)$ & 48 & $(94 \%)$ & 1.000 \\
\hline No & 0 & & 0 & & \\
\hline Not stated & 24 & & 2 & & \\
\hline
\end{tabular}

The Travellers and controls showed a significant difference between the number of male and female parents in each group. The Traveller groups only included female parents, whereas the control group had six male parents, Mann-Whitney Test ( $p=0.01$; table 7.1). 
The parents of traveller children (median age 30 years) were significantly younger than the control parents (median age 36.5 years), t-test $(p=0.03 ;$ table 7.1$)$.

The two groups also differed significantly in term of occupation, with the traveller group reporting a significantly higher number of non-working parents compared to the controls, Mann-Whitney Test $(p=\leq .001$; table 7.1).

Traveller parents reported significantly poorer health compared to the controls, Mann-Whitney Test ( $p=0.004$; table 7.1). Sixteen of the Traveller parents, and 5 of the control parents reported that they were not well.

As anticipated, the Travellers had lived for a significantly shorter time in their present accommodation and current locality compared to the controls, t-test $(p=\leq .001$; table 7.1$)$. This is mainly related to their continuous travelling around the country.

\subsection{Access to Health Care and Medicines}

The parents were asked about their experiences with the health care system in the UK during the past month as well as during the past six months. Two main themes emerged from the data collected, which were 
subjectively organised into the following areas: children's health and use of health services, attitudes towards treatment and knowledge of some medical conditions such as pain, asthma, and epilepsy.

\subsubsection{General Access to Health Care and Medicines}

\subsubsection{Gypsies and Travellers}

None of the Traveller parents claimed to face any difficulty in registering with the GPs or in obtaining medicines. The median number of days since their last visit to the GP was 12.5 days. Nine families had not visited the GP during the past month or the past six months.

Two thirds (32) of them did not pay for medicines for their children, and six of them stated that they purchased OTC medicines directly from a chemist (table 7.2). Seventeen of the parents reported that they used medicines and vitamins, cod liver oil, etc for their ill children. Parents indicated that they obtained these medicines either from a chemist or from friends or relatives (table 7.2). They often preferred to take their children to an emergency department or to walk-in centres when they became ill. 


\subsubsection{Control group}

The median number of days since their last visit to the GP (either parents alone or with children) was 15 days. Six families had not visited the GP during the past month or the past six months.

None of the parents said they experienced any difficulty in accessing health care and medicines. Half the parents (25) indicated that they would prefer to purchase analgesics for their ill children directly from chemists rather than go to the GP to get a prescription. Twelve parents indicated that they normally give their children some medicines at home, such as analgesics and vitamins, which they bought from chemists or were given by neighbours. They often preferred to contact their GP or use NHS Direct when their children were ill (table 7.2). 
Table 7.2: General access to health care and medicine

\begin{tabular}{|c|c|c|c|}
\hline & $\begin{array}{c}\text { Travellers (T- } \\
\text { Group) } \\
\text { N=47 }\end{array}$ & $\begin{array}{l}\text { Control (C- } \\
\text { Group) } \\
\text { N=50 }\end{array}$ & P-value \\
\hline \multicolumn{4}{|l|}{$\begin{array}{l}\text { Registration with } \\
\text { GP }\end{array}$} \\
\hline No & 0 & 0 & \\
\hline $\begin{array}{l}\text { No. of Days Since } \\
\text { the Last Visit to GP } \\
\text { Median }\end{array}$ & 12.5 days & 15 days & .883 \\
\hline Range & $1-730$ days & $1-730$ days & \\
\hline $\begin{array}{l}\text { No. of families visited } \\
\text { GP }\end{array}$ & 38 & 44 & \\
\hline \multicolumn{4}{|l|}{ Difficulties } \\
\hline No & 40 & 44 & \\
\hline Not stated & 7 & 6 & \\
\hline \multicolumn{4}{|l|}{ Recently Purchased } \\
\hline \multicolumn{4}{|l|}{ OTCs } \\
\hline Yes & $6 \quad(12.8 \%)$ & $25 \quad(50 \%)$ & .000 \\
\hline No & 32 & 15 & \\
\hline Not stated & 9 & 10 & \\
\hline $\begin{array}{c}\text { Home Remedy } \\
\text { Yes }\end{array}$ & $17 \quad(36.2 \%)$ & 12 (24\%) & .215 \\
\hline No & 30 & 37 & \\
\hline No stated & 0 & 1 & \\
\hline
\end{tabular}

The Traveller and control groups did not differ in terms of having registered with a GP or in the use of home remedies or herbal medicines at home for their ill children. In addition, there was no significant difference between the groups in the number of days since their last visit to a GP (either by themselves or with their children). 
Both the Traveller and control parents also reported that they did not often experience any difficulty in obtaining medicines or accessing healthcare services.

Traveller parents, however, were significantly less likely to purchase OTC medicines such as analgesics for their ill children, in contrast to the control group, Mann-Whitney Test ( $p=\leq .001$; table 7.2).

\subsubsection{Children's Health}

\subsubsection{Gypsies and Travellers}

The total number of children in the "at risk" group was 113 , with a median number of two children per family. The children's ages ranged from 0.2 to 15 years (median 6 years). The majority (81) of them were normally fit and well. Approximately one third (32) of the Traveller children had a chronic illness. The majority (24) of them were asthmatic. Four children had a disability, two had diabetes and two had epilepsy.

The results revealed that the majority (101) of the Traveller children were up-to-date with their immunisations. However, 12 of them had not received their immunisations (table 7.3 ). 


\subsubsection{Control group}

There were 105 children in the control group, with a median of two children per family. Their ages ranged from 0.2 to 15 years with a median age of 5 years.

Most of the control children (98) were in good health. Seven children had a chronic illness; four had asthma, one had epilepsy, one had ADHD and one had arthritis. All the control children were fully immunised (table 7.3).

\section{Table 7.3: Data for the children}

\begin{tabular}{|c|c|c|c|c|}
\hline & $\begin{array}{c}\text { Traveller (T- } \\
\text { Group) } \\
\mathbf{N}=113\end{array}$ & \multicolumn{2}{|c|}{$\begin{array}{l}\text { Control (C-Group) } \\
\qquad \mathrm{N}=105\end{array}$} & P-value \\
\hline $\begin{array}{l}\text { Median no. of } \\
\text { Children/Family }\end{array}$ & 2 & 2 & & .143 \\
\hline \multicolumn{5}{|l|}{ Age $(Y)$} \\
\hline Median & 6 & 5 & & .897 \\
\hline IQR & $2.75-9.5$ & $2.25-10$ & & \\
\hline Range & $0.2-15$ & $0.2-15$ & & \\
\hline \multicolumn{5}{|l|}{ Children's Health } \\
\hline (fit and well) /Yes & 81 & 98 & & .000 \\
\hline No & $32 \quad(28.3 \%)$ & 7 & $(6.7 \%)$ & \\
\hline \multicolumn{5}{|l|}{$\begin{array}{l}\text { Child } \\
\text { Immunisation }\end{array}$} \\
\hline Yes & $101 \quad(89.4 \%)$ & 105 & $(100 \%)$ & .001 \\
\hline No & $12 \quad(10.6 \%)$ & 0 & & \\
\hline
\end{tabular}

The Traveller and control groups did not significantly differ in terms of the number of children and the children's ages. 
There was a significant difference in the children's reported health. Traveller children were more likely to have poor health compared to the controls, Mann-Whitney Test ( $p=\leq .001$; table 7.3). They were also less likely to be fully immunised, Mann-Whitney Test $(p=.001$; table 7.3$)$.

\subsubsection{Number of illnesses and medicines in the last month}

In the last month, of the 113 children from the Traveller group, 34 (30\%) had experienced 35 illnesses with a median of one illness per child.

A total of 37 medicines (median 1 medicine/child) were prescribed to 30 of the 34 children who had experienced illnesses in the last month (table 7.4). Twenty nine (78\%) of the 37 medicines were prescribed by a doctor either from GP or A\&E department at the hospital and the remainder were OTC medicines (table 7.5).

Thirty-three children from the control group (31\%) had experienced illnesses in the last month.

A total of 49 medicines were taken by 28 of these children (median 2 medicines / child) (table 7.4). Nineteen (39\%) of the 49 medicines were prescribed by a doctor either from a GP or A\&E department at the hospital and the remainder were OTC medicines (table 7.5). 
Table 7.4: Number of illnesses and medicines in the last month

\begin{tabular}{|c|c|c|c|c|c|c|}
\hline & \multirow{2}{*}{$\begin{array}{l}\text { No. of Children } \\
\text { with an Illness }\end{array}$} & \multirow{2}{*}{$\begin{array}{l}\text { Total No. of } \\
\text { Illnesses }\end{array}$} & \multirow{2}{*}{$\begin{array}{l}\text { Total No. of } \\
\text { Medicines }\end{array}$} & \multicolumn{3}{|c|}{ No. of Medicines /IIl Child } \\
\hline & & & & Median & IQR & Range \\
\hline $\begin{array}{l}\text { Traveller } \\
\text { (T-Group) }\end{array}$ & 34 & 35 & 37 & 1 & $1-2$ & $1-2$ \\
\hline $\begin{array}{l}\text { Control } \\
\text { (C-Group) }\end{array}$ & 33 & 33 & 49 & 2 & $1-2$ & $1-4$ \\
\hline P-value & & .507 & .004 & & & \\
\hline
\end{tabular}

There was no difference in the number of reported illnesses between Traveller and the control children during the last month, Chi-Square Test $(p=0.50 ;$ table 7.4).

Traveller children were likely to receive a significantly lower number of medicines than the control children during the past month, Chi-Square Test ( $p=.004 ;$ table 7.4). This was due to the lower number of OTC medicines these children received. However, they actually received more prescribed medicines than the control group of children $(p=\leq .001$; table 7.5). 
Table 7.5: Medicines in the last month

\begin{tabular}{lcc}
\hline & Prescribed Medicines & OTC Medicines \\
\hline Traveller Group & $29(78 \%)$ & $8(22 \%)$ \\
Control Group & $19(39 \%)$ & $30(61 \%)$ \\
P-value & .000 & .000 \\
\hline
\end{tabular}

Analgesics/antipyretics were the most frequent group of medicines used by both groups over the last month. Antibiotics and inhalers were the two other groups of medicines frequently used, especially in the Travellers (figure 7.1).

Figure 7.1: Medicines in the last month

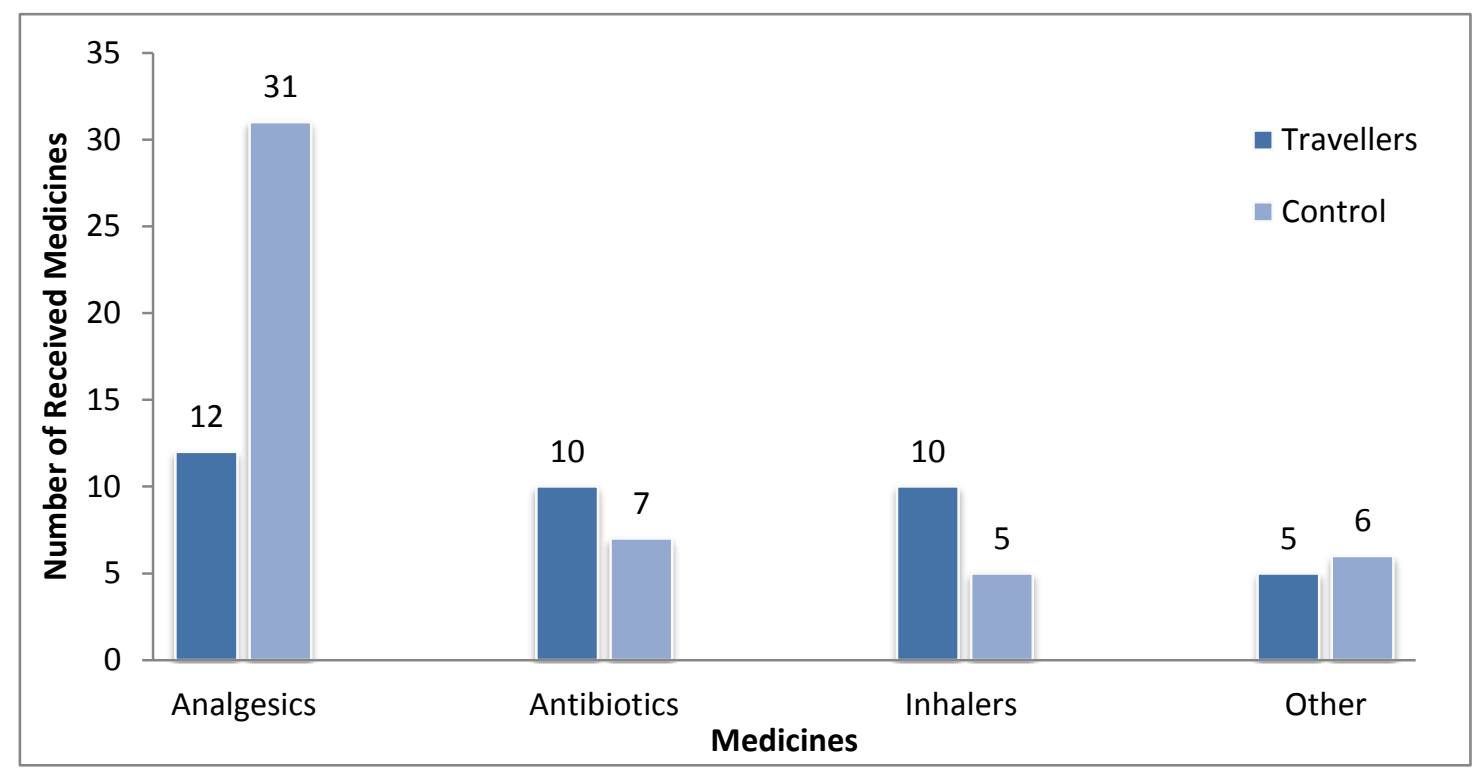




\subsubsection{Number of illnesses and medicines in the last six months}

Twice as many children experienced an illness in the past six months (126) than over the past month (67).

Fifty seven (50\%) of the 113 children from the Travellers group experienced a total of 70 illnesses. Fifty of the 57 children who experienced illnesses received a total of 64 medicines with a median of one medicine per ill child (table 7.6). Forty five (70\%) of the 64 medicines were prescribed by a doctor either from a GP or A\&E department at the hospital and the remainder were OTC medicines (table 7.7).

Sixty nine (66\%) of the 105 from the control children experienced a total of 78 illnesses in the last six months. Fifty-two of these children received a total of the 81 medicines (median 1/ill child) (table 7.6). Twenty nine (36\%) of 81 medicines were prescribed by a doctor either from a GP or A\&E department at the hospital and the remainder were OTC medicines (table 7.7). 
Table 7.6: Number of illnesses and medicines in the last six months

\begin{tabular}{|c|c|c|c|c|c|c|}
\hline & \multirow{2}{*}{$\begin{array}{c}\text { No. of Children } \\
\text { with Illness }\end{array}$} & \multirow{2}{*}{$\begin{array}{c}\text { Total No. of } \\
\text { Illnesses }\end{array}$} & \multirow{2}{*}{$\begin{array}{l}\text { Total No. of } \\
\text { Medicines }\end{array}$} & \multicolumn{3}{|c|}{ No. of Medicines/III Child } \\
\hline & & & & Median & IQR & Range \\
\hline $\begin{array}{l}\text { Traveller } \\
\text { (T-Group) }\end{array}$ & 57 & 70 & 64 & 1 & $1-2$ & $1-3$ \\
\hline $\begin{array}{l}\text { Control } \\
\text { (C-Group) }\end{array}$ & 69 & 78 & 81 & 1 & $1-2$ & $1-4$ \\
\hline P-value & & .165 & .034 & & & \\
\hline
\end{tabular}

There was no difference between the number of illnesses reported by the Traveller children over the past six months and by the control children, Chi-Square Test $(p=0.16$; table 7.6).

Traveller children received a significantly lower number of medicines than the control children over the past six months, Chi-Square Test $(p=.034$; table 7.6). This was due to the lower number of OTC medicines these children received. However, they actually received more prescribed medicines than the control group of children $(p=\leq .001 ;$ table 7.7$)$. 
Table 7.7: Medicines in the last six months

\begin{tabular}{lcc}
\hline & Prescribed Medicines & OTC Medicines \\
\hline Traveller Group & $45(70 \%)$ & $19(30 \%)$ \\
Control Group & $29(36 \%)$ & $52(64 \%)$ \\
P-value & .000 & .000 \\
\hline
\end{tabular}

Analgesics/antipyretics were the most frequent group of medicines used by both groups over the past six months. Antibiotics and inhalers were the two other groups of medicines frequently used, especially in the Travellers (figure 7.2).

Figure 7.2: Medicines in the last six months

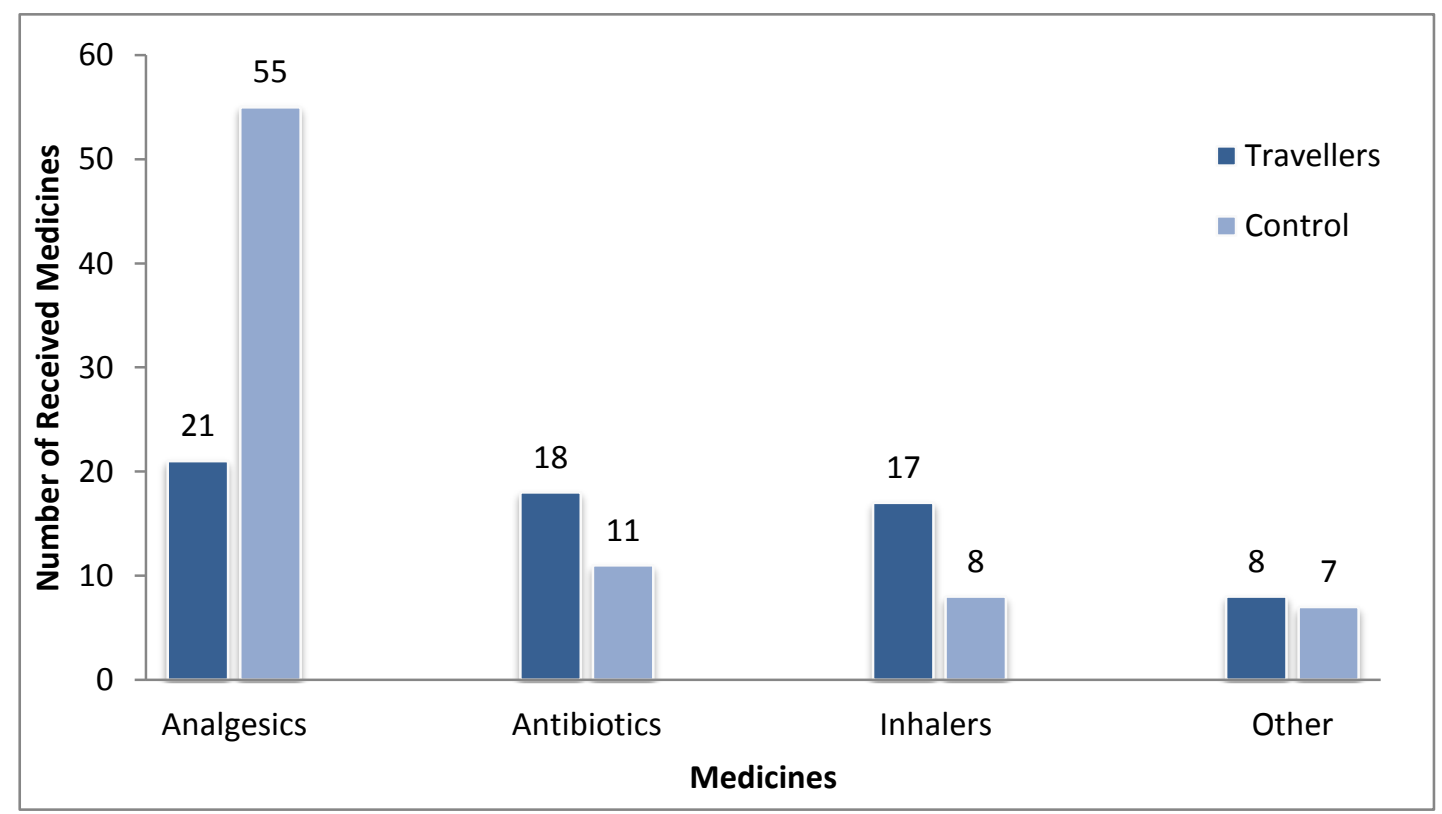




\subsubsection{Attitudes}

The third main theme is the attitudes of the participating parents towards the treatment of certain medical conditions such as pain, asthma, and epilepsy.

\subsubsection{Attitudes towards pain (earache)}

The majority of parents in both groups said they would give analgesics for earache. However, a significantly higher number of parents in the Traveller group would not give analgesics for earache without consulting a doctor, Mann-Whitney Test $(p=.003$; table 7.8). Fifteen Traveller parents and four control parents would not give analgesics. 


\begin{tabular}{|c|c|c|c|c|c|}
\hline & \multicolumn{2}{|c|}{$\begin{array}{c}\text { Travellers (T- Group) } \\
\qquad \mathrm{N}=47\end{array}$} & \multicolumn{2}{|c|}{$\begin{array}{l}\text { Control (C-Group) } \\
\qquad \mathrm{N}=\mathbf{5 0}\end{array}$} & P-value \\
\hline Yes & 32 & & 46 & & .003 \\
\hline No & 15 & $(32 \%)$ & 4 & $(8 \%)$ & \\
\hline \multicolumn{6}{|l|}{$\begin{array}{l}\text { Know about } \\
\text { Epilepsy }\end{array}$} \\
\hline No & 0 & & 0 & & \\
\hline \multicolumn{6}{|l|}{$\begin{array}{l}\text { Happy to Treat } \\
\text { Epilepsy }\end{array}$} \\
\hline No & 0 & & 0 & & \\
\hline \multicolumn{6}{|l|}{$\begin{array}{l}\text { Happy to Tell } \\
\text { family \& friends }\end{array}$} \\
\hline No & 0 & & 0 & & \\
\hline \multicolumn{6}{|l|}{$\begin{array}{l}\text { Happy to Tell } \\
\text { School }\end{array}$} \\
\hline No & 0 & & 0 & & \\
\hline
\end{tabular}

Parents from both groups who preferred not to start giving medicine for earache at home, indicated that they would try to contact their GPs or ring the NHS Direct in order to get a medical opinion. They would prefer to see the doctor first to diagnose the problem before giving treatment. However, a few of the parents would try other options before they contacted their GPs or gave any medicine. They would first try to comfort 
him/her with a warm bandage to the ear, and then take the child to A\&E or to see a GP.

Overall, Traveller parents were less likely to give an OTC analgesic for treating earache than the control parents. Common responses of Gypsy and Traveller parents are summarised in table 7.20, (see Appendix F) and those belonging to the control group are summarised in table 6.24, (see Appendix D2).

\subsubsection{Attitudes towards asthma}

The majority of Traveller and control parents did not show a noticeable difference in their attitudes towards asthma. Notably, results indicated a high incidence of asthma in both groups and a number of parents and children were asthmatic.

Twenty of the Traveller parents but only 13 of the control parents indicated that they were aware of the risk of asthma and understood the importance of medication. Six parents from both groups revealed that they already had experience of asthma and they would know what to expect. Therefore, they would not panic or feel too worried about it.

The majority of the parents in both groups ( 24 from the Travellers and 30 from the controls) expressed their willingness to follow the 
instructions of doctors by giving inhalers for asthma. These parents indicated that they would use inhalers for asthma if the medicines helped their child's condition. Seven control parents and three Traveller parents said that they would be worried and anxious about the health risks of this condition, so they would seek advice on how to control it in the case of a severe attack or if it appears to be harming their child's health.

In general, parents from both groups had a high level of awareness about asthma and of using inhalers. Common responses of Gypsy and Traveller parents are summarised in tables 7.21, (see Appendix F) and those belonging to the control group are summarised in table 6.25, (see Appendix D2).

\subsubsection{Attitude towards epilepsy}

All parents, irrespective of their group, had similar attitudes towards the condition of epilepsy. They expressed good knowledge and understanding of its health risks. They did not show any significant difference in their attitudes towards the treatment of epilepsy or telling others such as friends and schools about their child's epilepsy (table 7.8).

Parents from both groups showed awareness of the importance of treatment. They would not hesitate to give medicines or to consult a doctor if their child were to develop epilepsy. However, a few of them 
said they would be very concerned about this illness. Their emotions would not, however, prevent them from giving the recommended treatment. Common responses of Gypsy and Traveller parents are summarised in tables 7.22, (see Appendix F) and those belonging to the control group are summarised in table 6.26, (see Appendix D2).

Overall, both groups of parents had a high level of knowledge and awareness of epilepsy. They considered that their children's health is one of their responsibilities. Therefore, they would do whatever was best for their children.

\subsection{Discussion}

This chapter has presented the results of semi-structured interviews of parents from Traveller and control groups. The interviews covered a wide range of themes, including the sociodemographics of participating parents, access to health care and medicines, children's health, and parental attitudes towards pain, asthma, and epilepsy. The Traveller parents were significantly younger than the control group parents, though the children in both groups were similar in number and age.

\section{Occupation}

The male Gypsies and Travellers tend towards self-employment (272), preferably in family groups. Employment is usually in fields such as 
market trading, gardening, building and collecting and dealing in scrap metal. Due to literacy problems stemming from their cultural reluctance to accessing secondary education, they find it difficult to find other work. They often live in poverty with all its attendant and problematic implications for health care for both adults and children $(261,262)$.

The findings of this study found that, significantly more Traveller parents were unemployed than those in the control group. This may be attributable to high number of housewives in the Traveller group. The women are usually responsible for the care of the children.

\section{Accommodation and current locality}

Geographical barriers are considerable for Gypsies and Travellers, particularly given their nomadic way of life, since they are constantly being moved on from wherever they may be encamped regardless of how far this may move them from healthcare facilities $(72,74,262)$.

As anticipated, the length of time Gypsies and Travellers had been in their present accommodation and current locality was significantly shorter than that of the more settled control group. One possible reason is their lifestyle, as they tend to be on the move from one area to

another around the country. Their travelling pattern and chronic 
accommodation issues might act as barriers on their access to health care.

\section{Parental health}

A previous study reported that the health of Gypsies and Travellers is demonstrably worse than the rest of the population, even when compared with other deprived groups (254). They have a high rate of long-term illness and disability.

They are also regularly subjected to a range of stress-inducing factors including unemployment, racism, bereavement, chronic accommodation issues, and discrimination - by both public services and the public at large (284). There are comparatively few legal sites nationally, following the removal in 1994 of local authorities' legal obligation to provide permanent sites for Travellers' trailers. This has produced constant anxiety over eviction from illegal sites, which affects the health and mental health of the whole community $(247,266)$.

When compared with a control group from a deprived local area, a study identified much greater self-reported depression and anxiety rates in the Gypsy and Traveller group(255). They also had a greater risk of early death from chronic diseases (255). 
The finding of this study supported the literature that Gypsy and Traveller parents were significantly more prone to ill health problems. They reported a variety of health conditions such as long-term illnesses in addition to a range of disabilities. These all may have a negative impact on their quality of life. Their poor health may be directly attributed to unsatisfactory and unhealthy locations, lack of hygiene facilities, social hardship and a poor environment. Additionally, chronic accommodation issues may result in deteriorating health.

Depression was a significant problem for several Traveller parents. Some of them reported considerable anxiety and significant levels of stress and depression. They felt that there was no escape from a very poor campsite. They expressed concern, over eviction from illegal sites, and about future life.

\section{Registration with GPs}

Previous studies have highlighted the negative attitude and behaviour of some GPs which may create barriers for Travellers (243, 248, 249). The most common problem for Travellers is difficulty in accessing primary care through GPs because of the latter's insistence on their having a permanent address. Other GPs will only provide temporary registration, thereby excluding them from screening and a range of other services. In 
extreme cases, registration is allegedly refused altogether $(250,251)$. Those who move most frequently have the greatest problems. As a result of being compulsorily moved on, Travellers have to depend increasingly on walk-in centres and A\&E departments. Follow-up is therefore difficult, especially in the absence or difficulty of GP registration. This results in interruption, delays and discontinuity in medical treatment (253).

However, neither Traveller nor control groups, who took part in this study, had experienced problems in registering with a GP. There was also no significant difference between the groups in the number of days since the last visit to a GP, with or without a child.

Difficulty was described by only one Traveller parent when visiting a local GP. This parent, who had moved to the East Midlands, said that her new local GP asked her next time to go back to the GP where she was registered.

\section{OTC medicines}

Gypsies and Travellers are constantly being moved on from wherever they may be encamped regardless of how far this may move them from healthcare facilities. The typical isolation of their accommodation sites may make it difficult for them to reach health services and obtain 
medicines (263). Furthermore, they often live in poverty with all its attendant and problematic implications in obtaining health care and medicines $(261,262)$.

This study shows that the "at risk" group were less likely to purchase OTC medicines compared to the control group. The lower number of purchased medicines could be due to their health beliefs or attitudes towards illnesses or due to financial difficulties. Additionally, campsites are generally placed far away from services, such as a local pharmacy or supermarket. These factors may all contribute to the lower number of OTC medicines used by their children.

Another factor could be the variety of illnesses that the "at risk" children groups experienced, such as asthma, chest infection, eczema, pneumonia and meningitis. All those presenting with these conditions consulted a doctor whether in a GP surgery or in a hospital A\&E department. Therefore, being issued a free NHS prescription for the above illnesses, is a considerable reason for not needing to purchase OTC medicines.

\section{Children's health}

A study in the UK reported that Gypsy and Traveller's children were suffering higher rates of illness than their peers (261). The traditional nomadic way of life of Gypsies and Travellers creates barriers of its own 
that have major implications for children's health. A lack of safe, healthy sites and the constant fear of eviction from roadside and illegal sites, all may have a negative impact on physical and psychological health of children from this "at risk" group $(261,262)$.

It has also been found that infant mortality among these communities was three times higher than in the population at large (259). Stillbirth and miscarriage rates were also found to be high (254). Alcohol abuse often causes premature death among young members of these groups (260).

The findings of my study indicate that the Traveller children reported significantly poorer health than those in the control group. My results show that about $30 \%$ of the children from the Traveller group reported a variety of health conditions. The incidence of asthma (21\%) was relatively high among children in this group. Some Traveller families reported that all their children were currently asthmatic or had had asthma prior to the study. The chronic, wet and damp conditions of inadequate campsites may be a contributory factor to asthma and other respiratory problems. Increased levels of smoking by parents may also be a contributory factor but unfortunately we did not obtain information from parents regarding smoking habits. Many of the interviewed parents from this group stated that their child was fit and well. However, when 
we asked them about their attitudes towards asthma, some said that their children were currently asthmatic and often suffered from breathing difficulties. Many Travellers did not consider asthma an illness.

\section{Immunisation}

It has previously been reported that the immunisation rates were significantly lower for Gypsy and Traveller children than for the general population (267). Lack of knowledge and illiteracy, resulting in the inability to read promotional literature are significant factors in compounding the low rates. Furthermore, district child health record systems and parental recall methods are unreliable for this mobile population. Evidence suggests that parental choice not to have vaccines, perhaps due to pollution taboos or adverse MMR TV campaigns, still plays a significant role in the low figures (266). Other parents have been shown to believe that pertussis and measles were 'normal' or even 'strengthening' illnesses. Many unvaccinated Gypsy and Traveller children caught measles in the 2006-7 epidemic, leading to numerous health problems and, in one instance, death $(267,268,342)$.

Another study compared a group of Gypsy and Traveller children to a control group (266). This study revealed that Traveller and Gypsy children had significantly lower rates for the completion of immunisation programmes for pertussis, measles, diphtheria/tetanus and poliomyelitis 
than the control group. It also indicated that the low immunisation rates were attributable to both poor access to health services and the rejection of certain vaccines by the Traveller and Gypsy parents.

The findings of this study indicate that the completion rate for the primary course of all types of immunisations was significantly lower among Traveller children than those in the control group. This may be due to their parents choosing not to have their children immunised.

Those parents from the Traveller group who did not give their children the essential vaccines indicated that they do not like MMR. This is due partly to their cultural beliefs and traditions and partly to their fear of side effects such as fever after immunisation. Increasing parental awareness of the importance of immunisation in relation to child health is required to improve immunisation rates in children of Travellers.

\section{Number of experienced illnesses}

Gypsies and Travellers' access to health care services has been investigated in previous studies $(248,249)$. These studies indicate that, for a wide variety of reasons, Gypsies and Travellers tend to make less use of health services than other members of the population, despite having a greater need of them. 
States of health are described in terms of restrictions on ability to perform daily tasks. A survey by Van Cleemput et al (74) indicated that some Gypsies and Travellers described an inability to obtain relief for unmanageable symptoms, and were resigned to a low expectation of improvement (74). Acceptance and expectation of ill-health is also pervasive. This acceptance is consistent with an inverse relationship of access to health care in relation to need, though the relevance of some symptoms is not always understood $(72,74)$.

The findings of this study were not consistent with what has previously been found in the literature. Although, the children of Travellers were more likely to have health problems, they did not differ in the number of reported illnesses experienced over the previous month and six months in comparison with the control children.

\section{Number of medicines}

Traveller children were found to have received a lower number of medicines during the previous month and six months. The parents were less likely to purchase OTC medicines and OTC analgesics/antipyretics in particular. There are two possible explanations for the lower number of OTC medicines. One is the preference of parents for not giving any medicine without consulting a doctor. The other is that the parents could 
not afford to purchase medicines for their children. Other contributory factors are the practical problems associated with purchasing OTC medicines if the family lives some distance from a pharmacy. This distance may be of major importance, especially if it is the mother who is expected to purchase the OTC medicines and the father who has the transport (243, 261, 262). Unfortunately we did not ask specific questions regarding the individual role of parents but this is an area for future research

\section{Attitudes towards health conditions}

Attitudes to the treatment of earache pain, asthma and epilepsy showed both differences and similarities.

\section{Pain (earache)}

Whereas parents in both groups would give an analgesic for earache, more Travellers would not give an analgesic without consulting a doctor than those in the control group. Travellers were also less likely to give an OTC medicine. Those in both groups who preferred not to give analgesics at home would try to obtain a medical diagnosis by approaching a GP or going to a hospital A\&E department.

Historically, many children with pain did not receive analgesia. This included children undergoing major cardiac surgery in hospital. This was because of the misconception that children did not feel pain. It is 
increasingly being recognised that children do experience pain and it is important that they receive adequate analgesia. Previous studies have highlighted attitudes within the Gypsies and Travellers' community regarding treatment with medicines (343). These have included a lack of belief in prescribed treatment, concern about side effects or wanting nothing to do with mainstream medicine $(252,343)$. It is not clear from my studies whether parents of Traveller children were reluctant to give analgesia because they did not feel the treatment of pain was important or whether they had concerns regarding the need for a medical review of their child before giving analgesia or cost.

\section{Asthma}

There was a high level of awareness of asthma, and use of inhalers to control it, in both groups. The incidence of asthma among the parents and children in both groups was high and they therefore knew what to expect. Because of this familiarity, neither group would panic in the event of a severe attack. Attitudes regarding treatment were broadly similar between the two groups, with parents in both being willing to follow a doctor's instructions regarding inhalers and to use them if they proved effective for their children.

\section{Epilepsy}

Parents in both groups also had a good knowledge of epilepsy and the importance of treatment for it, and understood the risks. They had similar attitudes towards it and said they would consult a doctor and use 
medication to treat it. Both groups also had similar attitudes towards telling their families, friends and school if their children were sufferers.

Overall, both groups took responsibility for their children's health and would do whatever was best for them.

\subsection{Summary}

This study has identified several issues that may affect access of Gypsy's and Traveller's children to health care and medicines.

- Poor health among Gypsies and Traveller communities (both in adults and children) has been identified as one of the major problems associated with their traditional nomadic way of life and chronic accommodation issues. This study revealed that both parents and children from this "at risk" group have poorer health than the control group.

- The attitude of some Gypsy and Traveller parents not to immunise their children is a significant barrier to good health for the children from this community. Research needs to be performed as to what the barriers to immunisation are within the Traveller community. 
- Purchasing OTC medicines identified as a significant problem for some Gypsy and Traveller families. This could be due to the desire to consult a doctor before treatment or financial difficulties.

- Gypsy and Traveller parents were less likely to give analgesics to children in pain based on the scenarios. This may be related to the desire to see a doctor before the administration of analgesia or inability to pay for OTC medicines.

Access to health care is an essential human right. Children are dependent upon both their parents and the health system for ensuring access to health care. This study has identified problems both within the system and also in relation to parental beliefs that may affect the access to health care and treatment for children. It is important that both of these potential barriers are addressed in order to improve the health of children of Gypsies and Travellers.

With all the descriptions, discussions and evaluations in place in Chapters 1-7, Chapter 8 summarises the research undertaken for this thesis, draws conclusions from it and suggests paths for further research in this area. 


\section{CHAPTER EIGHT}

\section{GENERAL DISCUSSION AND CONCLUSION}

\subsection{Aim}

The purpose of my thesis was to investigate the access to health care and safe and appropriate medicines for children. It looked at the quality of the medicines children receive and also access to medicines from defined "at risk" groups.

\subsection{Substandard and counterfeit medicines}

It is essential that medicines used for children are of a high quality and safe. The use of substandard and counterfeit drugs may result in inadequate treatment or toxicity. Unfortunately poor quality products still exist in both low-income and high-income countries $(66,67)$.

There are international efforts from organisations such as the WHO to reduce the risk of counterfeit medicines especially in children, by increasing health professionals' awareness of the issue. I started my research by highlighting the impact of diethylene glycol (DEG) in counterfeit and substandard medicines on children's health. 
Incidents of mass poisoning with DEG have occurred in a variety of countries over the last two decades. More than 300 children died as a consequence in Nigeria, Bangladesh, India, Argentina and Haiti. DEG may be present in medicines because the medicines are counterfeit and it has been used as an illegal solvent. It may also be present in substandard medicines due to contamination. The key issue for health professionals is that they do not often recognise the clinical presentation of DEG poisoning. My review of DEG toxicity highlighted the most common signs and symptoms following ingestion of DEG, to support early recognition and prevent further deaths. Health professionals need to be aware that counterfeit or substandard medicines may result in acute illnesses.

\subsection{Access}

My study of the access to medicines in children of Asylum Seekers/Refugees and Travellers involved the collection of both quantitative and qualitative data. Both sets of data highlighted issues regarding access in relation to health care and medicines.

All participating parents in my study had a good basic understanding of the English health system. None of them experienced any difficulty in registration with GPs. They reported that the NHS met their needs, especially in registering with GPs. There was an awareness among all the 
participating parents of how to use health care services. They knew where to go when their children became ill, saying they would take them to a GP, walk-in centre, or hospital emergency department. This may be related to their links with support groups such as Refugee Action and Derbyshire Gypsy Liaison group who often provide them with advice.

My study revealed that parents from "at risk" groups are more likely to have health problems than those in the control group. One third of both Refugee parents and Traveller parents reported a variety of chronic health conditions. These health problems may have a negative impact on their quality of life and that of their children.

It is worth noting that the Refugee parents were the group most likely to report difficulties in accessing health care. $18 \%$ indicated that they experienced some difficulties while obtaining medicines. The two main barriers identified were language and financial difficulties. Problems in relation to understanding or speaking English resulted in difficulties in communication with health workers. Financial difficulties were such that affording the bus fare to visit a health centre/hospital was a major issue.

Children from the Travellers' group were more likely to have significantly poorer health than those in the control group. The incidence of asthma 
was relatively high (22\%) among children in this group. Inadequate accommodation is likely to have been a contributory factor $(344,345)$.

The completion rate for the primary course of all types of immunisations was significantly lower among Traveller children than other groups. The reluctance of some parents in this group to immunise their children may have a substantial negative impact on their children's future health.

\subsubsection{Access to medicines}

Traveller children received a lower number of medicines during the previous month and six months. This was related to the lower number of OTC medicines used in this group. There are several possible explanations for the lower use of OTC medicines. Firstly, Travellers often live in poverty and may have major financial problems which make the purchase of OTC medicines difficult. Distance may also be of importance, especially when campsites are generally placed far away from services, such as a local pharmacy or supermarket. Another possible explanation is the preference of these parents for not giving any medicine without consulting a doctor.

Perhaps most interesting is the tendency of parents in both "at risk" groups not to purchase OTC analgesics. This may be for any of the following reasons. Firstly, the financial situation for these families can be 
extremely difficult. Such families are unlikely to be able to afford OTC analgesics. Cultural factors and lack of knowledge about the use of medicines amongst these groups could also be reasons for the preference of some parents to take their children to the doctor when they become ill.

\subsubsection{Attitudes}

My study revealed that attitudes to the treatment of certain medical conditions such as pain, asthma and epilepsy, showed some differences but also similarities.

Participating parents expressed different attitudes towards the treatment of pain. Parents from "at risk" groups were less likely to give analgesics for treating earache than those in the control group who expressed their knowledge of the condition and its treatment by giving OTC analgesics. Parents from "at risk" groups said that they initially would try to obtain a medical opinion by consulting a doctor. It is possible that the reluctance to initially treat pain with OTC analgesics relates to different cultural attitudes towards pain in children. It is also possible that the financial difficulties experienced by parents from both of the "at risk" groups are such that they rarely consider purchasing OTC analgesics.

With regard to informing others about epilepsy once one of their children was diagnosed as epileptic, parents showed different attitudes. More than 
one third of parents from the Refugee group were reluctant to tell others about their child's epilepsy. They said they would prefer not to inform friends and/or other relatives about it. There was also a trend for Refugee parents to be less likely to inform the school of their child's epilepsy. Of those parents who would do so, some would only tell the head teacher or class teacher. Cultural beliefs and concerns over stigma could be significant factors that influence parents' attitudes towards management of their children's epilepsy (340). Limited knowledge and misconceptions about epilepsy and its managements may explain these findings.

The findings of this study support the literature regarding the existence of barriers and attitudes that may affect access of "at risk" children to health care and medicines. Although this study suggests that at risk groups have good access to healthcare and medicines, it is clear that they need more support to enable them to have better access and overcome any barrier they may encounter.

\subsection{Limitations}

While many interesting findings materialised from this pilot study, there are some obvious limitations that must be considered:

- Those in the sample may not be representative of the whole population of "at risk" groups in the UK. By increasing the number 
of samples, and extending the study to include more areas in the UK, access to health care and medicines in the "at risk" groups could be more comprehensively observed.

- There were difficulties in accessing these groups directly, since they have fairly enclosed communities. Their reluctance to go into detail might relate to their fear of such information being used against them. It is thus possible that a number of parents chose not to participate in this study. The recent reduction of funding by the new government to charities supporting these minorities has also made the situation significantly worse. Refugee Action in Nottingham was closed last year due to funding cuts. It is possible that without support from charities such as Refugee Action, access to healthcare and medicines for the children of these groups will deteriorate.

- Interviews were conducted only with Asylum Seekers and Refugees who had made contact with Refugee Action in Nottingham and thus were in the system. However, there may be Asylum seekers or Refugees who have not made contact with a charity who are having difficulties accessing health care.

\subsection{Future studies}

The following are suggestions for future studies:

- Studies in other geographical parts of the UK. 
- Studies involving other "at risk" children's groups such as children in care.

- Interviews with parents from "at risk" groups in relation to attitudes towards immunisations and OTC medicines.

- Studies of Refugees and Asylum Seekers who have not made contact with charities such as Refugee Action.

- An evaluation of the impact of the parents' education on their children's health and their access to health care and medicines.

\subsection{Recommendations}

There are some recommendations for better access for "at risk" groups:

- Increasing the awareness of such groups of schemes such as the community pharmacy minor ailment scheme where available.

- Increasing the awareness of children's immunisation in specific groups as a parental responsibility serving the child's best interests.

- Availability of support groups and interpreters will contribute to better access for "at risk" groups. 


\subsection{Conclusion}

Children's access to appropriate and safe medicines is essential for achieving good child health. The use of counterfeit and substandard medicines often results in treatment failure or significant toxicity. The cases of DEG toxicity highlighted in this thesis illustrate the tragic consequences of the impact of substandard and counterfeit medicines on children's health. Health professionals need to be aware of the existence of counterfeit and substandard medicines and their presentation.

The findings of this pilot study indicate that in our area, the East Midlands, healthcare services are available to both the "at risk" groupsAsylum Seekers/Refugees and Travellers. Asylum Seekers and Refugees, however, may encounter some barriers in their access to health care and medicines. Differences in cultural beliefs, language and financial problems, are all considered as potential barriers to access for this group. To benefit fully from the UK healthcare system they need access to language classes as well as interpreters. Without such services they cannot communicate properly with health and social workers and receive appropriate care.

The main barriers identified in the Travellers group were in relation to attitudes towards immunisation and OTC medicines. It is likely that cultural differences and financial difficulties were the main contributory 
factors to the lower immunisation rates and the use of OTC medicines respectively.

Parental attitude towards management and treatment of health conditions are a significant factor in their child's health. It is hoped that the implications of these findings will be recognised within the NHS and lessons learned for improving access to health services for these groups. 


\section{REFERENCES}

1. Zucker H, Rägo L. Access to essential medicines for children: the World Health Organization's global response. Clinical Pharmacology \& Therapeutics. 2007;82(5):503-505.

2. Summersett GM, Richards GE, Melzer SM, Sugarman JR, Kletter GB. Effectiveness of a rural pediatric diabetes management program. Pediatric Diabetes. 2003;4(3):137-142.

3. Choonara I. Children's medicines-a global problem. Archives of Disease in Childhood. 2009;94(6):467.

4. Liebman MN. Personalized medicine: a perspective on the patient, disease and causal diagnostics. Personalized Medicine. 2007;4(2):171-174.

5. Charen T. The etymology of medicine. Bulletin of the Medical Library Association. 1951;39(3):216.

6. MacLeod S, Peterson R, Wang Y, Li Z, Gui Y, Schaller J. Challenges in international pediatric pharmacology. Pediatric Drugs. 2007;9(4):215-218.

7. Cantani A. Bronchiolitis in infants. European Review for Medical and Pharmacological Sciences. 1999;3:195-196.

8. Eber E, Zach M. Long term sequelae of bronchopulmonary dysplasia (chronic lung disease of infancy). Thorax. 2001;56(4):317-323.

9. Choonara I, Conroy S. Unlicensed and off-label drug use in children: implications for safety. Drug Safety. 2002;25(1):1-5.

10. Turner S LA, Nunn AJ, Choonara I. Unlicensed drug use on paediatric wards. BMJ. 1998; 316: 343-345.

11. Berkovitch $\mathrm{M} \mathrm{Cl}$, Jacqz-Aigrain $\mathrm{E}$ et al. Improving research and access to children's medicines worldwide. Paed Perinat Drug Therapy 2008; 8: 138-139.

12. McIntyre J, Conroy S, Avery A, Corns H, Choonara I. Unlicensed and off label prescribing of drugs in general practice. Archives of Disease in Childhood. 2000;83(6):498-501.

13. Choonara I. Improving children's medicines. Archives of Disease in Childhood. 2006;91(7):550-551.

14. Conroy $\mathrm{S} \mathrm{Cl}$, Impicciatore $P$ et al. Survey of unlicensed and off- label drug use in paediatric wards in European countries. BMJ. 2000; 320: 79-82.

15. Choonara I. Regulation of drugs for children in Europe. BMJ. 2007; 335: 12211222. 
16. Ragupathy R, Tordoff J, Norris P, Reith D. Access to children's medicines in the United Kingdom, Australia and New Zealand in 1998, 2002 and 2007. Pharmacy World \& Science. 2010;32(3):386-393.

17. Nunn T, Williams J. Formulation of medicines for children. British Journal of Clinical Pharmacology. 2005;59(6):674-676.

18. WHO. Report of the Partners Meeting on Better Medicines for Children, WHO Headquarters, Geneva, Switzerland 13-14 May 2009. Available from: www.who.int/childmedicines/progress/Partners Meeting June2009.pdf. Accessed October 2009.

19. Schirm E, Tobi H, De Vries T, Choonara I, Berg L. Lack of appropriate formulations of medicines for children in the community. Acta Paediatrica. 2003;92(12):14861489.

20. Standing J, Tuleu C. Paediatric formulations--getting to the heart of the problem. International Journal of Pharmaceutics. 2005;300(1-2):56-66.

21. Choonara I, Bauchner H. Publishing the evidence for children's medicines. Archives of Disease in Childhood. 2008;93(10):815-815.

22. McCarthy $\mathrm{C}$, Hewitt $\mathrm{S}$, Choonara I. Pain in young children attending an accident and emergency department. Journal of Accident \& Emergency Medicine. 2000;17(4):265-267.

23. Wardlaw $T$, Salama $P$, Johansson EW, Mason E. Pneumonia: the leading killer of children. Lancet. 2006;368(9541):1048-1049.

24. Gans-Brangs KR, Plourde PV. The evolution of legislation to regulate pediatric clinical trials: Present and continuing challenges. Advanced Drug Delivery Reviews. 2006;58(1):106-115.

25. Bonetta L. Pediatric study of medicines becomes mandatory. Nature Medicine. 2000;6(10):1069-1069.

26. Wendler D, Varma S. Minimal risk in pediatric research. Ophthalmology. 2006;149(6):855-861.

27. Tauer CA. Testing drugs in pediatric populations: the FDA mandate. Accountability in Research. 1999;7(1):37.

28. Grieve J, Tordoff J, Reith D, Norris P. Effect of the pediatric exclusivity provision on children's access to medicines. British Journal of Clinical Pharmacology. 2005;59(6):730-735.

29. Attaran A. How do patents and economic policies affect access to essential medicines in developing countries?. Health Affairs. 2004;23(3):155. 
30. Dunne J. The European Regulation on medicines for paediatric use. Paediatric Respiratory Reviews. 2007;8(2):177-183.

31. Pecoul $B$, Chirac $P$, Trouiller $P$, Pinel J. Access to essential drugs in poor countries: a lost battle? . JAMA. 1999;281(4):361.

32. Yamin A. Not just a tragedy: Access to medications as a right under International Law. Boston University. International Law Journal. 2003;21:325.

33. Pemberton S, Gordon D, Nandy S, Pantazis C, Townsend P. Child rights and child poverty: can the international framework of children's rights be used to improve child survival rates?. PLoS Medicine. 2007;4(10): 1567-1570.

34. Griffith $\mathrm{R}$, Tengnah $\mathrm{C}$. Equality and anti-discrimination legislation in health care. British Journal of Community Nursing. 2010;15(3):130.

35. Kar SS PH, Mohanta GP. Concept of essential medicines and rational use in public health. Indian Journal of Community Medicine. 2010;35:10-13.

36. Hogerzeil HV. Essential medicines and human rights: what can they learn from each other? Bulletin of the World Health Organization. 2006;84(5):371-375.

37. Quick J. Essential medicines twenty-five years on: closing the access gap. Health Policy and Planning. 2003;18(1):1-3.

38. Hogerzeil H. The concept of essential medicines: lessons for rich countries. BMJ. 2004;329(7475):1169.

39. Schuklenk U, Ashcroft R. Affordable access to essential medication in developing countries: conflicts between ethical and economic imperatives. Journal of Medicine and Philosophy. 2002;27(2):179.

40. Banerjee A, Hollis A, Pogge T. The Health Impact Fund: incentives for improving access to medicines. Lancet. 2010;12(9709):166.

41. Ashcroft R. Access to essential medicines: A Hobbesian social contract approach. Developing World Bioethics. 2005;5(2):121-141.

42. Watal J. Access to essential medicines in developing countries: does the WTO TRIPS agreement hinder it?. Science, Technology and Innovation Discussion Paper. 2000;8.

43. Norredam M, Mygind A, Krasnik A. Access to health care for asylum seekers in the European Union-a comparative study of country policies. The European Journal of Public Health. 2006;16(3):285.

44. Redlener I. Overcoming barriers to health care access for medically underserved children. The Journal of Ambulatory Care Management. 1993;16(1):21. 
45. Pletcher M J KSG, Kohn M A, Gonzales R. Trends in opioids prescribing by race/ethnicity for patients seeking care in US emergency departments. JAMA .2008; 299: 70-78.

46. Chen A Y CRKR. Factors associated with prescription drug expenditures among children: an analysis of the medical expenditure panel survey. Pediatrics. 2002; 109: 728-732.

47. Reime B TAW, Lee $S \mathrm{~K}$, Canadian Neonatal Network. Treatment differences between Aboriginal and white infants admitted to Canadian neonatal intensive care units. Paed Perinat Epidemiol. 2007; 21: 532-540.

48. Videau J, Fundafunda B. Generic drugs: the hidden issues of quality and cost. WHO Drug Information. 2000;14(2):77-81.

49. Obaid A. Quality of ceftriaxone in Pakistan: reality and resonance. Pakistan Journal of Pharmaceutical Sciences. 2009;22(2):220.

50. Taylor RB, Shakoor O, Behrens RH, Everard M, Low AS, Wangboonskul J, et al. Pharmacopoeial quality of drugs supplied by Nigerian pharmacies. The Lancet. 2001;357(9272):1933-1936.

51. Wondemagegnehu E. Counterfeit and substandard drugs in Myanmar and Viet Nam. Geneva: World Health Organization. 1999. WHO/EDM/QSM/99.3. Available at: www.WHO.Int/medicines/pdf/S2276e/S2276e.pdf.

52. Shakoor O, Taylor R, Behrens R. Assessment of the incidence of substandard drugs in developing countries. Tropical Medicine \& International Health. 1997;2(9):839-845.

53. Angaran D. Quality assurance to quality improvement: measuring and monitoring pharmaceutical care. American Journal of Hospital Pharmacy. 1991;48(9):1901.

54. Cockburn R, Newton P, Agyarko E, Akunyili D, White N. The global threat of counterfeit drugs: why industry and governments must communicate the dangers. PLoS Medicine. 2005;2(4):302.

55. Newton PN, Fernandez FM, Green MD, Primo-Carpenter J, White NJ. Counterfeit and substandard anti-infectives in developing countries. Antimicrobial Resistance in Developing Countries. 2010:413-443.

56. Caudron JM, Ford N, Henkens M, Mace C, Kiddle - Monroe R, Pinel J. Substandard medicines in resource - poor settings: a problem that can no longer be ignored. Tropical Medicine \& International Health. 2008;13(8):1062-1072.

57. Burns W. WHO launches taskforce to fight counterfeit drugs. Bulletin of the World Health Organization. 2006;84:689-690.

58. Outterson K, Smith R. Counterfeit drugs: the good, the bad and the ugly. Albany Law Journal of Science and Technology. 2006;15:525-543. 
59. Nayyar GML, Breman JG, Newton PN, Herrington J. Poor-quality antimalarial drugs in southeast Asia and sub-Saharan Africa. The Lancet Infectious Diseases. 2012;12(6):488-496.

60. Chaplin S. Counterfeit medicines: a cause for concern in the UK?. Prescriber. 2007;18(14):16-21.

61. Reidenberg M, Conner B. Counterfeit and substandard drugs. Clinical Pharmacology \& Therapeutics. 2001;69(4):189-193.

62.

http://www.mhra.gov.uk/Safetyinformation/Generalsafetyinformationandadvic e/Adviceandinformationforconsumers/counterfeitmedicinesanddevices/Falsified MedicineRecallsandpreviouslyseencounterfeits/index.htm. Accessed 5 September 2011.

63. Wertheimer A, Santella T. Counterfeit drugs: defining the problem and finding solutions. Expert Opin. Drug Safety. 2005;4(4):619-622.

64. O'Brien KL SJ, Hecdivert C et al, for the Acute Renal Failure Investigation Team. Epidemic of pediatric deaths from acute renal failure caused by diethylene glycol poisoning. JAMA. 1998; 279: 1175-1180.

65. Milne CP. Racing the Globalization of Infectious Diseases: Lessons from the Tortoise and the Hare. New England Journal of International and Comparative Law. 2004;11:1-89.

66. Bonati M. Once again, children are the main victims of fake drugs. Archives of Disease in Childhood. 2009;94(6):468.

67. Newacheck PW, Hughes DC, Stoddard JJ. Children's access to primary care: differences by race, income, and insurance status. Pediatrics. 1996;97(1):26.

68. Barennes H, Tran D, Latthaphasavang V, Preux P, Odermatt P. Epilepsy in Lao PDR: From research to treatment intervention. Neurology Asia. 2008;13:27-31.

69. de Boer H M MM, Sander J W. The global burden and stigma of epilepsy. Epilepsy Behav .2008; 12: 540-546.

70. Amoroso C ZA, Somerville E, Grove N. Epilepsy and stigma. Lancet. 2006; 367: 1143-1144.

71. Wadsworth M. Inequalities in child health. Archives of Disease in Childhood. 1988;63(4):353.

72. Van Cleemput P. Health care needs of travellers. Archives of Disease in Childhood. 2000; 82: 32-37. 
73. Reeves $\mathrm{M}$ dWG, Murshali $\mathrm{H}$ et al. Access to health care for people seeking asylum in the UK. British Journal of General Practice. 2006; 56: 306-308.

74. Van Cleemput P, Parry G, Thomas K, Peters J, Cooper C. Health-related beliefs and experiences of Gypsies and Travellers: a qualitative study. BMJ. 2007;61(3):205210.

75. Marraffa J, Holland MG, Stork CM et al. Diethylene glycol: widely used solvent presents serious poisoning potential. Journal Emergency Medicine. 2008; 35: 401406.

76. Hanif M MM, Ronan A, Rahman D, Donovan JJ, Bennish ML. Fatal renal failure caused by diethylene glycol in paracetamol elixir: the Bangladesh epidemic. BMJ.1995; 311: 8-91.

77. Okuonghae HO II, Lawson JO, Nwana EJC. Diethylene glycol poisoning in Nigerian children. Ann Trop Pediatr. 1992; 12: 235-238.

78. Singh J DA, Khare S et al. Diethylene glycol poisoning in Gurgaon, India, 1998. Bull World Health Organ. 2001; 79: 88-95.

79. Ferrari LA GL. Clinical parameters, post-mortem analysis and estimation of lethal dose in victims of a massive intoxication with diethylene glycol. Forensic Science International. 2005; 153: 45-51.

80. Geiling EMK CP. Pathologic effects of elixir of sulfanilamide (diethylene glycol) poisoning. JAMA. 1938; 111: 919-926.

81. Bowie MD MD. Diethylene glycol poisoning in children. South Africa Medical Journal. 1972; 46: 931-934.

82. Cantarall MC FJ, Camps J, Sans M, Piera L. Acute intoxication due to topical application of diethylene glycol. Annals of Internal Medicine Journal. 1987; 106: 478-479.

83. Lin B-L ZZ-X, Chong U-T et al. Venous diethylene glycol poisoning in patients with preexisting severe liver disease in China. World Journal of Gastroenterology. 2008; 14: 3236-3241.

84. Pandya S. An unmitigated tragedy. BMJ. 1988; 297: 117-119.

85. Hari P JY, Kabra SK. Fatal encephalopathy and renal failure caused by diethylene glycol poisoning. Journal of Tropical Paediatrics. 2006; 52: 442-444.

86. Alfred S CP, Wigmore T, Stachowski E, Graudins A. Delayed neurologic sequelae resulting from epidemic diethylene glycol poisoning. Clinical Toxicology. 2005; 43: 155-159.

87. Rentz ED LL, Mujica OJ et al. Outbreak of acute renal failure in Panama in 2006: a case-control study. Bull World Health Organ.2008; 86: 749-756. 
88. www.nytimes.com/2009/02/07/world/africa/07nigeria.html. Accessed 16 Nov 2009.

89. The US Food and Drug Administration. FDA advises consumers to avoid toothpaste from China containing harmful chemical. FDA News. 2007; 7-97.

90. Pérez E L, Tomás I, Diz P. Letter to the editor: toothpastes with diethylene glycol. Med Oral Patol Oral Cir Bucal. 2008; 13: E222-E223.

91. Gautam CS UA, Singal GL. Spurious and counterfeit drugs: a growing industry in the developing world. Postgraduate Medical Journal. 2009; 85: 251-256.

92. Newton PN MR, Fernandez $\mathrm{F}$ et al. Manslaughter by fake artesunate in Asia - will Africa be next?. PLoS Med. 2006; 3: e197.

93. www.eaasm.eu/Media centre/News/April 2008. Accessed 16 Nov 2009.

94. Couper M. Strategies for the rational use of antimicrobials. Clinical Infectious Diseases. 1997;24(Supplement 1):S154-S156.

95. Clarkson A CS, Burroughs K, Choonara I. Surveillance for adverse drug reactions in children: a paediatric regional monitoring centre. Paediatric and Perinatal Drug Therapy. 2004; 6: 20-23.

96. Nahata M. Safety of "inert" additives or excipients in paediatric medicines. Arch Dis Child Fetal Neonatal Ed. 2009; 94: F392-F393.

97. Brophy PD TM, Gardner J, Bunchman TE, Smoyer WE. Childhood diethylene glycol poisoning treated with alcohol dehydrogenase inhibitor fomepizole and hemodialysis. American Journal of Kidney Diseases. 2000; 35: 958-962.

98. Borron SW BF, Garnier R. Intravenous 4-methylpyrazole as an antidote for diethylene glycol and triethylene glycol poisoning. A case report. Veterinary and Human Toxicolology. 1997; 39: 26-28.

99. Brabander N WM, de Decker K, de Weerdt A, Jorens PG. Fomepizole as a therapeutic strategy in paediatric methanol poisoning. A case report and review of the literature. European Journal of Pediatrics. 2005; 164: 158-161.

100. Bestic M BM, Reed M. Fomepizole: a critical assessment of current dosing recommendations. Journal of Clinical Pharmacolology. 2009; 49: 130-137.

101. Saladino R SM. Accidental and intentional poisonings with ethylene glycol in infancy: Diagnostic clues and management. Pediatric emergency care. 1991; 7: 93.

102. Lepik KJ, Levy AR, Sobolev BG, et al. Adverse drug events associated with the antidotes for methanol and ethylene glycol poisoning: a comparison of ethanol and fomepizole. Annals of Emergency Medicine. 2009; 53: 439-450.

103. Sivilotti MA. Ethanol: Tastes Great! Fomepizole: Less Filling!. Annals of Emergency Medicine. 2009; 53: 451-453. 
104. Aday LA, Andersen RM. Equity of access to medical care: a conceptual and empirical overview. Medical Care. 1981;19(12):4-27.

105. Millman ML. Access to health care in America: Nationall Academy Press. Washington DC; 1993. Available at: http://www.nap.edu/catalog/2009.html.

106. Rogers A, Flowers J, Pencheon D. Improving access needs a whole systems approach. BMJ. 1999;319(7214):866.

107. Penchansky R, Thomas JW. The concept of access: definition and relationship to consumer satisfaction. Medical Care. 1981:127-140.

108. Maxwell RJ. Quality assessment in health. BMJ. 1984;288(6428):1470-1471.

109. Cunningham WE, Hays RD, Ettl MK, Dixon WJ, Liu RCC, Beck CK, et al. The prospective effect of access to medical care on health-related quality-of-life outcomes in patients with symptomatic HIV disease. Medical care. 1998:295-306.

110. Hull SA, Boomla K. Primary care for refugees and asylum seekers: If the NHS stops free care for all groups, charities may offer the only safety net. BMJ. 2006;332(7533):62.

111. Office of the High Commissioner for Human Rights. International covenant on economic, social and cultural rights. Article 12. 1976. Available at: www.unhchr.ch/html/menu3/b/a cescr.htm.

112. Gulliford $M$, Morgan $M$, Hughes $D$, Beech $R$, Figeroa-Munoz J, Gibson $B$, et al. Access to Health Care: Report of a scoping exercise for the National Co-ordinating Centre for NHS Service Delivery and Organisation $R \& D$ (NCCSDO). London: NCCSDO. 2001.

113. Gulliford M, Figueroa-Munoz J, Morgan M, Hughes D, Gibson B, Beech R, et al. What does' access to health care'mean?. Journal of Health Services Research \& policy. 2002;7(3):186.

114. St Clair PA, Smeriglio VL, Alexander CS, Connell FA, Niebyl JR. Situational and financial barriers to prenatal care in a sample of low-income, inner-city women. Public Health Reports. 1990;105(3):264.

115. Hargreaves S, Holmes A, Friedland JS. Charging failed asylum seekers for health care in the UK. Lancet. 2005;365(9461):732-733.

116. Phillips J. Asylum seekers and refugees: what are the facts? Department of Parliamentary Services, Canberra. 2010.

117. United Nations High Commission for Refugees (UNHCR), 2011 Global trends, Geneva, 20 June 2011, [viewed 19 november 2011]. Available from: http://www.unhcr.org/statistics. 
118. United Nations High Commission for Refugees (UNHCR), 2008 Global trends, Geneva, June 2009, p. 3, [viewed 13 April 2011]. Available from: http://www.unhcr.org/4a375c426.html.

119. Jones D, Gill PS. Refugees and primary care: tackling the inequalities. BMJ. 1998;317(7170):1444.

120. Burnett A, Peel M. Asylum seekers and refugees in Britain: Health needs of asylum seekers and refugees. BMJ. 2001;322(7285):544.

121. Cherrill $\mathrm{J} \mathrm{HH}$, Cocking $\mathrm{C}$ et al. Clinical trials: the viewpoint of children with a chronic illness compared to healthy children. Archives of Disease Childhood. (In press).

122. Hall P. Failed asylum seekers and health care. BMJ. 2006;333(7559):109.

123. UNHCR, Convention relating to the status of refugees, UNHCR, Geneva, 2007, p. 16, [viewed 9 March2011]. Available from: http://www.unhcr.org/3b66c2aa10.pdf .

124. Britons confused over refugees: The Guardian, April 2011, p.8, [viewed 18 April 2011]. Available from: http://www.guardian.co.uk/.

125. Dussán KB, Galbraith EM, Grzybowski M, Vautaw BM, Murray L, Eagle KA. Effects of a refugee elective on medical student perceptions. BMC Medical Education. 2009;9(1):15.

126. Burnett A, Peel M. What brings asylum seekers to the United Kingdom?. BMJ. 2001;322(7284):485.

127. Chris H, Jonathan C, Nicholas S. Fit for purpose yet. The Independent Asylum Commission's Interim Findings. London; 2008. Available at: www.independent asylum commission.org.UK.

128. www.fph.org.uk/uploads/bs aslym seeker health.pdf . Accessed October 2010

129. UNHCR, 'Who are refugees?', UNHCR webpage, [viewed 19 April 2011]. Available from: http://unhcr.org.ua/main.php?article id=5\&view=full .

130. International Organization for Migration (IOM). World migration 2003: managing migration - challenges and responses for people on the move, Chapter 5. Health an Essential Aspect of Migration Management. IOM Publications, 2003, [viewed 8 June 2010]. Available at: www.iom.int/jahia/webdav/site/myjahiasite/ shared/shared/mainsite/published_docs/books/wmr2003/chap05p85_96.pdf.

131. François G, Hambach R, Van Sprundel M, Devillé W, Van Hal G. Inspecting asylum seekers upon entry-a medico-ethical complex. The European Journal of Public Health. 2008;18(6):552.

132. Newdick C. Treating failed asylum seekers in the NHS. BMJ. 2009;338:b1614. 
133. Sundquist J, Johansson SE. The influence of exile and repatriation on mental and physical health. Social Psychiatry and Psychiatric Epidemiology. 1996;31(1):21-28.

134. Goldfeld AE, Mollica RF, Pesavento BH, Faraone SV. The physical and psychological sequelae of torture. JAMA. 1988;259(18):2725.

135. Laban CJ, Gernaat HBPE, Komproe IH, Schreuders BA, De Jong JTVM. Impact of a long asylum procedure on the prevalence of psychiatric disorders in Iraqi asylum seekers in The Netherlands. The Journal of Nervous and Mental Disease. 2004;192(12):843.

136. Bischoff A, Bovier PA, Isah R, Franoise G, Ariel E, Louis L. Language barriers between nurses and asylum seekers: their impact on symptom reporting and referral. Social Science \& Medicine. 2003;57(3):503-512.

137. Keller AS, Rosenfeld B, Trinh-Shevrin C, Meserve C, Sachs E, Leviss JA, et al. Mental health of detained asylum seekers. The Lancet. 2003;362(9397):1721-1723.

138. Yen K KM, Stremski E S, Gorelick M H. Effect of ethnicity and race on the use of pain medications in children with long bone fractures in the emergency department. Annals of Emergency Medicine. 2003; 42: 41-47.

139. Wasserman RC, Croft CA, Brotherton SE. Preschool vision screening in pediatric practice: a study from the Pediatric Research in Office Settings (PROS) Network. Pediatrics. 1992;89(5):834.

140. Wood PR, Hidalgo HA, Prihoda TJ, Kromer ME. Hispanic children with asthma: morbidity. Pediatrics. 1993;91(1):62.

141. Halfon N, Wood DL, Valdez RB, Pereyra M, Duan N. Medicaid enrollment and health services access by Latino children in inner-city Los Angeles. JAMA. 1997;277(8):636.

142. Newacheck PW, Hughes DC, Cisternas $M$. Children and health insurance: an overview of recent trends. Health Affairs. 1995;14(1):244.

143. Hahn BA. Children's health: racial and ethnic differences in the use of prescription medications. Pediatrics. 1995;95(5):727.

144. Finkelstein JA, Brown RW, Schneider LC, Weiss ST, Quintana JM, Goldmann DA, et al. Quality of care for preschool children with asthma: the role of social factors and practice setting. Pediatrics. 1995;95(3):389.

145. Gilthorpe MS, Lay-Yee R, Wilson RC, Walters S, Griffiths RK, Bedi R. Variations in hospitalization rates for asthma among black and minority ethnic communities. Respiratory Medicine. 1998;92(4):642-648.

146. Melzak S, Kasabova S. Working with children and adolescents from Kosovo. London: Medical Foundation for the Care of Victims of Torture. (Medical Foundation Series) 1999. Available at: www.torture care.org.UK. 
147. Booth ML, Bernard D, Quine S, Kang MS, Usherwood T, Alperstein G, et al. Access to health care among Australian adolescents young people's perspectives and their sociodemographic distribution. Journal of Adolescent Health. 2004;34(1):97103.

148. Connelly J, Schweiger M. The health risks of the UK's new asylum act. BMJ. 2000;321(7252):5.

149. Adams KM, Gardiner LD, Assefi N. Healthcare challenges from the developing world: post-immigration refugee medicine. BMJ. 2004;328(7455):1548.

150. Feldman R. Primary health care for refugees and asylum seekers: a review of the literature and a framework for services. Public Health. 2006;120(9):809-816.

151. Aldous J, Bardsley M, Daniell R, Gair R, Jacobson B, Lowdell C, et al. Refugee health in London. London: Health of Londoners' project, East London and City Health Authority. 1999.

152. Wilson R. Improving the health of asylum seekers in Northern and Yorkshire: a report on service provision and needs. Northern \& Yorkshire Public Health Observatory, Tandem Communications and Research. 2002.

153. Healy J, McKee M. Asylum Seekers and Refugees in the United Kingdom. Accessing Healthcare. 2004;1(9):183-207.

154. Trafford P, Winkler F. Refugees and primary care Participative development in general practice. London, the Royal College of General Practitioners; 2000.

155. Three Boroughs Primary Health Care Team, Refugee Health Team LSL. December 2005. Available from: http://www.threeboroughs.nhs.uk/index.php?PID=0000000223.

156. Hargreaves S. New report highlights negative health effects of UK asylum system. Lancet. 2000;356(9248):2168.

157. Andersen R, Lewis SZ, Giachello AL, Aday LA, Chiu G. Access to medical care among the Hispanic population of the southwestern United States. Journal of Health and Social Behavior. 1981;22(1):78-89.

158. Ramsay R, Turner S. Refugees' health needs. The British Journal of General Practice. 1993;43(376):480.

159. Romero-Ortuno R. Eligibility of non-residents for NHS treatment: failed asylum seekers should not be denied access to free NHS care. BMJ. 2004;329(7467):683.

160. World Health Organization. Revision of the International Health Regulations 2005. WHA58.3. Available at: www.who.int/csr/ihr/WHA58 3-en.pdf. [veiwed 6 March 2010].

161. Directive C. 9/EC of 27 January 2003 laying down minimum standards for the reception of asylum seekers. Official Journal of the European Union. 2003;6:2003. 
162. Weekers J, Siem H. Is compulsory overseas medical screening of migrants justifiable?. Public Health Reports. 1997;112(5):396.

163. Burnett A, Peel M. Asylum seekers and refugees in Britain: The health of survivors of torture and organised violence. BMJ. 2001;322(7286):606.

164. World Health Organization. The right to know - new approaches to HIV testing and counselling. 2003. WHO/HIV2003.08. Available at: www.who.int/hiv/pub/vct/pub34/en/index.html [viewed 12 March 2010].

165. UNAIDS/IOM. UNAIDS/IOM statement on HIV/AIDS-related travel restrictions. June 2004, [veiwed 12 March 2010]. Available at: www.iom.int/jahia/webdav/site/myjahiasite/shared/shared/mainsite/activities/ health/UNAIDS IOM statement travel restrictions.pdf.

166. Silove D, Steel Z, Mollica R. Detention of asylum seekers: assault on health, human rights, and social development. Lancet. 2001;357(9266):1436-1437.

167. Mares S, Jureidini J. Psychiatric assessment of children and families in immigration detention-clinical, administrative and ethical issues. Australian and New Zealand Journal of Public Health. 2004;28(6):520-526.

168. Malloch MS, Stanley E. The detention of asylum seekers in the UK. Punishment \& Society. 2005;7(1):53.

169. Steel Z, Momartin S, Bateman C, Hafshejani A, Silove DM, Everson N, et al. Psychiatric status of asylum seeker families held for a protracted period in a remote detention centre in Australia. Australian and New Zealand journal of public health. 2004;28(6):527-536.

170. Fazel M, Silove D. Detention of refugees. BMJ. 2006;332(7536):251.

171. Robjant $K$, Hassan R, Katona C. Mental health implications of detaining asylum seekers: systematic review. The British Journal of Psychiatry. 2009;194(4):306.

172. Lewis MA, Rachelefsky G, Lewis CE, Leake B, Richards W. The termination of a randomized clinical trial for poor Hispanic children. Archives of Pediatrics and Adolescent Medicine. 1994;148(4):364.

173. Flores G, Farrell E, Cook K, Rock S, Morton J, Teele J. Preventable pediatric hospitalizations and suboptimal use of services despite universal coverage. Ambulatory Child Health. 1996;1:223-234.

174. Gergen PJ, Ezzati T, Russell H. DTP immunization status and tetanus antitoxin titers of Mexican American children ages six months through eleven years. American Journal of Public Health. 1988;78(11):1446.

175. Hogan H. Meeting health needs of asylum seekers: white paper will make access to health care more difficult. BMJ. 1999;318(7184):671. 
176. Singer R. Asylum seekers: an ethical response to their plight. Lancet. 2004;363(9424):1904.

177. Williams PD. Why failed asylum seekers must not be denied access to the NHS. BMJ. 2004;329(7460):298.

178. Montgomery S, Le Feuvre P, Dar S, von Kaehne P. Health care for asylum seekers. BMJ. 2000;321(7265):893-893.

179. Murphy A, Lynch M, Bury G. " Céad Míle Fáilte"--an assessment of the screening of 178 Bosnian refugees to Ireland. Irish medical journal. 1994;87(6):174.

180. Wilson R. Improving the health of asylum seekers: An overview. Occasional Paper No 5, Northern and Yorkshire Public Health Observation Wolfson Research Institute, University of Durham; 2002. website: www.NYPHO.org.uk.

181. Johnson M. Asylum Seekers in dispersal-healthcare issues. Home Office Online report, 2003; 13(03). Available from:[http:/ / www.nrac.scot.nhs.uk/docs/NHS Boards/Glasgow/Asylum\%20seekers\%20in\%20 dispersal\%20-\%20healthcare\%20issues.pdf]. Accessed in April 2010.

182. Hakesley-Brown R. Refugee Nurses Task Force: An Update. Asylum Seeker Newsletter. 2004;13:8.

183. Gosling R, Lambeth S. The Needs of Young Refugees in Lambeth, Southwark and Lewisham: A Report: Community Health South London NHS Trust; 2000.

184. Burnett A, Fassil Y. Meeting the Health Needs of Refugee and Asylum Seekers in the UK: An Information and Resource Pack for Health Workers (London: Directorate of Health and Social Care, Department of Health). 2002.

185. Kansu F. Assessing the health needs of Turkish and Kurdish speaking women in Hackney. London: Open Doors Sexual Health Project, St Leonard's Primary Care. 1997.

186. Department of Health, East of England Regional Assembly, Medical Foundation for Victims of Torture, Refugee Council, University of East London, West Norfolk Primary Care NHS Trust. HARPWEB-Health for asylum seekers and refugees portal. Available from: http://www.harpweb.org.uk/index.php.

187. Cornelius LJ. Barriers to medical care for white, black, and Hispanic American children. Journal of the National Medical Association. 1993;85(4):281.

188. Mendoza FS, Ventura SJ, Valdez RB, Castillo RO, Saldivar LE, Baisden K, et al. Selected measures of health status for Mexican-American, mainland Puerto Rican, and Cuban-American children. JAMA. 1991;265(2):227.

189. Bhui K, Audini B, Singh S, Duffett R, Bhugra D. Representation of asylum seekers and refugees among psychiatric inpatients in London. Psychiatric Services. 2006;57(2):270. 
190. Carey-Wood J, Duke K, Karn V. The settlement of refugees in Britain. London: HMSO; 1995. (Home Office Research Study 141.)

191. Patel N, Fatimilehin I. Racism and mental health. C. Newnes, G. Holmes, \& D. C (Eds.), Thinking About Psychiatry and The Future of the Mental Health System. Ross-on-Wye: PCCS Books. 1999.

192. Bhui K, Abdi A, Abdi M, Pereira S, Dualeh M, Robertson D, et al. Traumatic events, migration characteristics and psychiatric symptoms among Somali refugees. Social Psychiatry and Psychiatric Epidemiology. 2003;38(1):35-43.

193. Cowen T, Project RHA. Unequal treatment: findings from a refugee health survey in Barnet: Barnet Voluntary Service Council; 2001.

194. Fassil Y. Looking after the health of refugees. BMJ. 2000;321(7252):59.

195. Shrestha NM, Sharma B, Van Ommeren M, Regmi S, Makaju R, Komproe I, et al. Impact of torture on refugees displaced within the developing world. JAMA. 1998;280(5):443-448.

196. London Assembly, Mayor of London. Access to primary care: a joint London Assembly and Mayor of London scrutiny report. London: Greater London Authority; 2003.

197. Harris K, Maxwell C. A needs assessment in a refugee mental health project in north-east London: extending the counselling model to community support. Medicine, Conflict and Survival. 2000;16(2):201-215.

198. Thompson K. Experiences of a refugee support psychology service. London: Waltham Forest. 2002.

199. Webster A, Jaimes CR. The mental health needs of refugees in Lambeth: results of a consultation exercise with refugee community organisations. Refugee Outreach Team Community Health South London NHS Trust, South London and the Maudsley NHS Trust, London. 2000.

200. Wilson R. Yorkshire and Humberside Refugee Support Centre. Findings of research into mental health services for refugees and asylum seekers, and perceptions of need among service providers, Yorkshire and Humberside Region. Yorkshire and Humberside Refugee Support Centre. 2003.

201. Uba L. Cultural barriers to health care for southeast Asian refugees. Public Health Reports. 1992;107(5):544.

202. Carlin J, Sokoloff B. Mental health treatment issues for Southeast Asian refugee children. Southeast Asian mental health: treatment, prevention, services, training, and research, edited by T. Owan. US Department of Health and Human Services, DHHS Publication No.(ADM). 1985;85:1399. 
203. Brainard J, Zaharlick A. Changing health beliefs and behaviors of resettled Laotian refugees: Ethnic variation in adaptation. Social Science \& Medicine. 1989;29(7):845-852.

204. Tung TM. The Indochinese Refugees as Patients. Journal of Refugee Resettlement. 1980;1(1):53-60.

205. Thao X. Southeast Asian refugees of Rhode Island: the Hmong perception of illness. Rhode Island Medical Journal. 1984;67(7):323.

206. Egawa J, Tashima N, Murase K, Project PAMHR. Indigenous healers in Southeast Asian refugee communities: Pacific Asian Mental Health Research Project; 1982.

207. Aronson L. Traditional Cambodian health beliefs and practices. Understanding Cambodian traditions will facilitate their care in a Western setting. Rhode Island Medical Journal. 1987;70(2):73.

208. Faller HS. Perinatal needs of immigrant Hmong women: surveys of women and health care providers. Public Health Reports. 1985;100(3):340.

209. Deinard AS, Dunnigan T. Hmong Health Care--Reflections on a Six-Year Experience. International Migration Review. 1987;21(3):857-865.

210. U.S. General Accounting Office: Asian Americans: a status report. U.S. Government Printing Office, Washington, DC, March 1990.

211. Muecke MA. In search of healers-Southeast Asian refugees in the American health care system. Western Journal of Medicine. 1983;139(6):835.

212. Mikhail BI. Hispanic mothers' beliefs and practices regarding selected children's health problems. Western Journal of Nursing Research. 1994;16(6):623.

213. Mental health care system works to meet needs of Southeast Asian refugees. Refugee Rep 6: 1-5 (1985).

214. Lin-Fu JS. Population characteristics and health care needs of Asian Pacific Americans. Public Health Reports. 1988;103(1):18.

215. Link BG, Phelan JC. Stigma and its public health implications. Lancet. 2006;367(9509):528-528.

216. Farina A, Allen JG, Saul BBB. The role of the stigmatized person in affecting social relationships. Journal of Personality. 1968;36(2):169-182.

217. Bhatia R, Wallace P. Experiences of refugees and asylum seekers in general practice: a qualitative study. BMC Family Practice. 2007;8(1):48.

218. Kmietowicz Z Z Doctors turn away refugees, conference told. BMJ. 2001;323(7314):653. 
219. Corrigan P. How stigma interferes with mental health care. American Psychologist. 2004;59(7):614.

220. Wong EC, Marshall GN, Schell TL, Elliott MN, Hambarsoomians K, Chun CA, et al. Barriers to mental health care utilization for US Cambodian refugees. Journal of Consulting and Clinical Psychology. 2006;74(6):1116.

221. Leong FTL, Lau ASL. Barriers to providing effective mental health services to Asian Americans. Mental Health Services Research. 2001;3(4):201-214.

222. Sue DW, Sue D. Counseling the culturally different: Theory and practice: John Wiley \& Sons; 1990.

223. O'Mahony JM, Donnelly TT. The influence of culture on immigrant women's mental health care experiences from the perspectives of health care providers. Issues in Mental Health Nursing. 2007;28(5):453-471.

224. Bhui K, Stansfeld S, Hull S, Priebe S, Mole F, Feder G. Ethnic variations in pathways to and use of specialist mental health services in the UK Systematic review. The British Journal of Psychiatry. 2003;182(2):105-116.

225. Commander $M$, Cochrane R, Sashidharan S, Akilu F, Wildsmith E. Mental health care for Asian, black and white patients with non-affective psychoses: pathways to the psychiatric hospital, in-patient and after-care. Social Psychiatry and Psychiatric Epidemiology. 1999;34(9):484-491.

226. Reidpath DD, Chan KY, Gifford SM, Allotey P. 'He hath the French pox': stigma, social value and social exclusion. Sociology of Health \& IIIness. 2005;27(4):468489.

227. Lipsedge M. Mental health: access to care for black and ethnic minority people'. Access to Health Care for People from Black and Ethnic Minorities. London: Royal College of Physicians. 1993.

228. Hoang GN, Erickson RV. Cultural barriers to effective medical care among Indochinese patients. Annual Review of Medicine. 1985;36(1):229-239.

229. Ishisaka $\mathrm{H}$, Nguyen $\mathrm{Q}$, Okimoto J. The role of culture in the mental health treatment of Indochinese refugees. Southeast Asian Mental Health: Treatment, Prevention, Services, Training and Research. Washington, DC, US DHHS. 1985:4163.

230. Gong-Guy E, Cravens RB, Patterson TE. Clinical issues in mental health service delivery to refugees. American Psychologist. 1991;46(6):642.

231. Lum R. A community-based mental health service to Southeast Asian refugees. Southeast Asian Mental Health: Treatment, Prevention, Services, Training, and Research. Washington, DC: US Department of Health and Human Services. 1985. 
232. Gibbs JT, Fuery D. Mental health and well-being of black women: Toward strategies of empowerment. American Journal of Community Psychology. 1994;22(4):559-582.

233. James SA, LaCroix AZ, Kleinbaum DG, Strogatz DS. John Henryism and blood pressure differences among black men. II. The role of occupational stressors. Journal of Behavioral Medicine. 1984;7(3):259-275.

234. Gorst-Unsworth C, Goldenberg E. Psychological sequelae of torture and organised violence suffered by refugees from Iraq. Trauma-related factors compared with social factors in exile. The British Journal of Psychiatry. 1998;172(1):90.

235. McAfee B. Instead of medicine. Report of the Bosnian mental health pilot project. Refugee Action: London; 1998.

236. Epstein H. A life in the day of Perico Rodriguez. Sunday Times. 1996 Feb 18.

237. Watters $\mathrm{C}$. The mental health needs of refugees and asylum seekers: key issues in research and service development. Current issues of asylum law and policy. Aldershot: Ashgate. 1998:282-297.

238. Noël MP, Robert $A$, Brysbaert $M$. Does language really matter when doing arithmetic? Reply to Campbell. Cognition. 1998;67(3):365-373.

239. Hall AG. Medicaid's impact on access to and utilization of health care services among racial and ethnic minority children. Journal of Urban Health. 1998;75(4):677-692.

240. Riportella-Muller R, Selby-Harrington ML, Richardson LA, Donat PL, Luchok KJ, Quade D. Barriers to the use of preventive health care services for children. Public Health Reports. 1996;111(1):71.

241. Peters J, Parry GD, Van Cleemput P, Moore J, Cooper CL, Walters SJ. Health and use of health services: a comparison between Gypsies and Travellers and other ethnic groups. Ethnicity \& Health. 2009;14(4):359-377.

242. www.kent.gov.uk/.../gypsies and travellers/definition.aspx. Accessed Jan 2010.

243. Cemlyn S, Greenfields M, Burnett S, Matthews $Z$, Whitwell C. Inequalities experienced by Gypsy and Traveller communities: $A$ review: Equality and Human Rights Commission; 2009.

244. Home R. Negotiating security of tenure for peri-urban settlement: travellergypsies and the planning system in the United Kingdom. Habitat International. 2002;26(3):335-346.

245. Traveller Health: A National Strategy 2002-2005,Irish Medical Journal, http://www.imj.ie.

246. Okely J. The traveller-gypsies. The Journal of Intercultural Studies. 1984; 5(4): 6164. 
247. Parry G, Van Cleemput P, Peters J, Walters S, Thomas K, Cooper C. Health status of Gypsies and Travellers in England. BMJ. 2007;61(3):198-204.

248. Hawes D. Gypsies, Travellers and the Health Service a study in inequality. Bristol the Policy Press; 1997.

249. Jenkins M. No Travellers! A report of Gypsy and Traveller Women's experiences of Maternity Care. London: Maternity Alliance. 2004.

250. Scottish Executive. Response to the Equal Opportunities Committee Report 2001: Inquiry Into Gypsy Travellers And Public Sector Policies. Edinburgh: Scottish Executive. Available at: http://cci.scot.nhs.uk/library3/government/gtoctober00.asp. [Accessed 1 September 2008].

251. Scottish Executive. Fair for All: Improving the Health of Ethnic Minority Groups and the Wider Community in Scotland. Edinburgh, The Stationery Office. 2001.

252. Beach $\mathrm{H}$. Comparing the use of an Accident and Emergency Department by children from two Local Authority Gypsy sites with that of their neighbours. Public Health. 2006;120(9):882-884.

253. Richardson J, Bloxsom J, Greenfields M. East Kent Gypsy and Traveller Accommodation Assessment Report (2007-2012). 2007.

254. Parry G, Van Cleemput P, Peters J, Moore J, Walters S, Thomas K, et al. The health status of gypsies and travellers in England. Report of Department of Health Inequalities in Health Research Initiative Project. 2004;121:7500.

255. Roberts AA, J. Lewis, H. \& Wilkinson, C. Community Practitioners' and Health Visitors' Assocation (CPHVA) Annual Conference, Coronary Heart Disease and Mental Health in Gypsies and Travellers in Wrexham: Redressing the balance. Torquay, 31 Ocotober -2 November 2007. Available at:

http://www.amicus-cphva.org/pdf/B2.2\%20Helen\%20Lewis.pdf

256. Dorset Health Authority / Friends Families and Travellers (FFT). Report of the Pilot Health Promotion Project with Travellers in Dorset 1997-98. Brighton: Friends, Families and Travellers Support Group. 1999

257. Saunders R. The Forgotten Minority. Diabetes Update. 2007:26-29.

258. Pahl JM, Vaile MSB. Health and health care among travellers. University of Kent Health Services Research Unit, Canterbury: Cambridge Univ Press; 1986.

259. Baker M. Gypsies and Travellers: The Leeds Baseline Census 2004-2005. Leeds Racial Equality Council, Leeds. 2005.

260. Brack JM, S. Travellers' Last Rights: responding to death in acultural context. Dublin: Parish of the Travelling People. 2007. 
261. Pahl J, Vaile M. Health and health care among travellers. Journal of Social Policy. 1988;17(02):195-213.

262. Feder G. Traveller gypsies and primary care. The Journal of the Royal College of General Practitioners. 1989;39(327):425.

263. Lawrence H. On the road to better health. Emergency nurse: the journal of the RCN Accident and Emergency Nursing Association. 2007;15(5):12.

264. Lynch E. Travellers' tales. Nursing standard (Royal College of Nursing (Great Britain): 1987). 2006;20(41):20.

265. Jeffrey J, Davis J, Hoult H. Afro-Caribbean and travelling families' health needs. Health visiting specialist and higher level practice. 2000:373-397.

266. Feder GS, Vaclavik T, Streetly A. Traveller Gypsies and childhood immunization: a study in east London. The British Journal of General Practice. 1993;43(372):281.

267. Hollinger M, Farrell B. Traveller Gypsies and childhood immunization. The British Journal of General Practice. 1993;43(376):482.

268. Cohuet S, Morgan O, Bukasa A, Heathcock R, White J, Brown K, et al. Outbreak of measles among Irish travellers in England, March to May 2007. Euro Surveill. 2007;12(6):E070614.

269. Carr-Hill S. Health care for travellers. BMJ (Clinical research ed.). 1987;294(6579):1098.

270. Mayall D. Gypsy-travellers in nineteenth-century society: Cambridge Univ Pr; 1988.

271. Clark C, Greenfields M. Here to Stay: The Gypsies and Travellers of Britain: University of Hertfordshire Press; 2006.

272. Greenfields M. Gypsies, Travellers and legal matters. Here to stay: The Gypsies and Travellers of Britain. 2006:133-81.

273. Dion X. Gypsies and Travellers: cultural influences on health. Community Practitioner. 2008;81(6):31-34.

274. Van Cleemput P. Social exclusion of Gypsies and Travellers: health impact. Journal of Research in Nursing. 2010;15(4):315.

275. Greenfields M, Home R. Assessing Gypsies and Travellers needs: Partnership working and'The Cambridge Project'. Romani Studies. 2006;16(2):105-131.

276. Heron S, Barry J, Fitzgerald M, Mac Lachlan M. The psychosocial health of Irish Traveller mothers. Cultivating pluralism: Psychological, social and cultural perspectives on a changing Ireland. 2000:93-116.

277. Lehti A, Mattson B. Health, attitude to care and pattern of attendance among gypsy women-a general practice perspective. Family Practice. 2001;18(4):445. 
278. Pill R, Stott NCH. Concepts of illness causation and responsibility: some preliminary data from a sample of working class mothers. Social Science \& Medicine. 1982;16(1):43-52.

279. Smart H, Titterton M, Clark C. A literature review of the health of Gypsy/Traveller families in Scotland: the challenges for health promotion. Health Education. 2003;103(3):156-165.

280. Linthwaite P, Sampson K, Fund StC. The health of Traveller mothers and children in East Anglia: Save the Children; 1983.

281. Crawley H. Moving forward: the provision of accommodation for Travellers and Gypsies: Institute for Public Policy Research; 2004.

282. Spencer L, Ritchie J, Lewis J, Dillon L. Quality in Qualitative Evaluation: A framework for assessing research evidence. Social Research. 2003(21/08/05).

283. Niner P. Accommodating nomadism? An examination of accommodation options for Gypsies and Travellers in England. Housing Studies. 2004;19(2):141-159.

284. Appleton L, Hagan T, Goward P, Repper J, Wilson R. Smail's contribution to understanding the needs of the socially excluded: the case of gypsy and traveller women. Clinical Psychology. 2003;24:40-46.

285. Greenfields M. Gypsies, Travellers and accommodation. 2009.

286. Goward P, Repper J, Appleton L, Hagan T. Crossing boundaries. Identifying and meeting the mental health needs of Gypsies and Travellers. Journal of Mental Health. 2006;15(3):315-327.

287. Johnson B, Christensen LB. Educational research: Quantitative, qualitative, and mixed approaches: Sage Publications, Inc; 2007.

288. Roundtree $\mathrm{K}$, Laing T. Writing by degree: a practical guide to writing theses and research papers. Longman, Auckland. 1996.

289. Miles MB, Huberman AM. Qualitative data analysis: An expanded sourcebook. 1994. Beverly Hills: Sage Publications. 1994.

290. Miles MB, Huberman AM. Qualitative data analysis: Sage Publ.; 1999.

291. Denscombe M, Corporation E. The good research guide: Open Univ. Press; 1998.

292. Creswell JW. Qualitative Inquiry and Research Design: Choosing among Five Approaches [with CD-ROM]. SAGE Publications (CA). 2006:416.

293. Bouma GD, Ling R, Wilkinson L. The research process: Oxford University Press, Oxford; 1993.

294. Denzin NK, Lincoln YS. The discipline and practice of qualitative research. Handbook of Qualitative Research. 2000;2:1-28. 
295. Banister P, Burman E, Parker I, Taylor M, Tindall C. Qualitative methods in psychology: Open University Press; 1995.

296. Maykut PS, Morehouse R, Morehouse RE. Beginning qualitative research: $A$ philosophic and practical guide: Routledge; 1994.

297. Johnson RB, Onwuegbuzie AJ. Mixed methods research: A research paradigm whose time has come. Educational Researcher. 2004;33(7):14-26.

298. Kvale S. Interviews: An introduction to qualitative research interviewing: Sage Publications, Inc; 1996.

299. Bell J. Doing your research project: a guide for first-time researchers in education, health and social science: Open Univ Pr; 2005.

300. Cohen L, Manion L, Morrison K, Morrison KRB. Research methods in education: Psychology Press; 2007.

301. Bums R. Introduction to research methods. New South Wales: Longrnan. 2000.

302. Patton MJ. Qualitative research on college students: Philosophical and methodological comparisons with the quantitative approach. Journal of College Student Development. 1991.

303. Robson C. Real world research: A resource for social scientists and practitionerresearchers: Wiley-Blackwell; 2002.

304. Fontana A, Frey JH. The interview: From structured questions to negotiated text. Handbook of Qualitative Research. 2000;2:645-672.

305. Bryman A. Social research methods . Oxford University Press, Oxford: CSIRO; 2001.

306. Briggs CL. Learning how to ask: A sociolinguistic appraisal of the role of the interview in social science research: Cambridge Univ Pr; 1986.

307. Wilson GL, \& Goodall, H. L. The Craft of Interviewing. New York: McGraw Publishing. 1991.

308. Anderson GJ. Fundamentals of educational research: Routledge; 1998.

309. Bogdan RC, Biklen SK. Qualitative research in education. An introduction to theory and methods: Allyn \& Bacon, A Viacom Company, 160 Gould St., Needham Heights, MA 02194; Internet: www. abacon. com.; 1998.

310. Keats DM. Interviewing: A practical guide for students and professionals: Univ of New South Wales; 1999.

311. Hutchinson SA, Campus JS. Education and Grounded Theory1. Qualitative Research in Education: Focus and Methods. 1988:122.

312. Flick U. An introduction to qualitative research: Sage Publications Ltd; 2009. 
313. Patton MQ. How to use qualitative methods in evaluation: Sage; 1994.

314. Merriam SB. Qualitative Research and Case Study Applications in Education. Revised and Expanded from" Case Study Research in Education.": Jossey-Bass Publishers. Avalable at: www.josseybass. com. 1998.

315. Liedtka JM. Exploring ethical issues using personal interviews. Business Ethics Quarterly. 1992;2(2):161-181.

316. Stringer ET. Action research in education: Prentice Hall; 2003.

317. Robson K, Robson M. "Your place or mine? Ethics, the researcher and Internet» In Ethical Dilemmas in qualitative research, sous la direction de $T$. Welland et $\mathrm{L}$. Pugsley. Burlington: Ashgate; 2002.

318. Anderson GL. Toward authentic participation: Deconstructing the discourses of participatory reforms in education. American Educational Research Journal. 1998;35(4):571.

319. Goodwin WL, Goodwin LD. Understanding quantitative and qualitative research in early childhood education: Teachers College Pr; 1996.

320. Tolich M, Davidson C. Starting fieldwork: An introduction to qualitative research in New Zealand: Oxford Univ Pr; 1999.

321. Bishop R, Glynn T. Culture counts: changing power relations in education. (Palmerston North, Dunmore Press). 1999.

322. Oppenheim AN. Questionnaire design, interviewing and attitude measurement: Pinter Pub Ltd; 1998.

323. Djuric G, Daye S. A rapid health care needs assessment report on the health needs of asylum seekers and refugees living in the London borough of Hounslow. Hounslow Primary Care Trust, London. 2003.

324. Holl JL, Szilagyi PG, Rodewald LE, Byrd RS, Weitzman ML. Profile of uninsured children in the United States. Archives of Pediatrics and Adolescent Medicine. 1995;149(4):398.

325. Baqir W, Todda A, Learoyda T, Sima Y, Mortona L. Cost effectiveness of community pharmacy minor ailment schemes. International Journal of Pharmacy Practice. 2010;18(Supplement 2):3.

326. Pumtong S, Boardman HF, Anderson CW. Pharmacists' perspectives on the Pharmacy First Minor Ailments Scheme. International Journal of Pharmacy Practice. 2008;16(2):73-80.

327. Vohra S. A community pharmacy minor ailment scheme-: effective, rapid and convenient. Pharmaceutical journal. 2006;276(7406):754-756. 
328. Parmentier H, Golding S, Ashworth M, Rowlands G. Community pharmacy treatment of minor ailments in refugees. Journal of Clinical Pharmacy and Therapeutics. 2004;29(5):465-469.

329. Banoub-Baddour S, Laryea M. Children in pain: A culturally sensitive perspective for child care professionals. Journal of Child \& Youth Care. 1991.

330. Pfefferbaum B, Adams J, Aceves J. The influence of culture on pain in Anglo and Hispanic children with cancer. Journal of the American Academy of Child \& Adolescent Psychiatry. 1990;29(4):642-647.

331. Craig KD, Lilley CM, Gilbert CA. Barriers to optimal pain management in infants, children, and adolescents social barriers to optimal pain management in infants and children. The Clinical Journal of Pain. 1996;12(3):232.

332. Schechter NL. The undertreatment of pain in children: an overview. Pediatric Clinics of North America. 1989;36(4):781.

333. Link BG, Cullen FT, Struening E, Shrout PE, Dohrenwend BP. A modified labeling theory approach to mental disorders: An empirical assessment. American Sociological Review. 1989;54(3):400-423.

334. Rhodes PJ, Small NA, Ismail $\mathrm{H}$, Wright JP. 'What really annoys me is people take it like it's a disability', epilepsy, disability and identity among people of Pakistani origin living in the UK. Ethnicity and Health. 2008;13(1):1-21.

335. Jacoby A. Epilepsy and stigma: An update and critical review. Current Neurology and Neuroscience Reports. 2008;8(4):339-344.

336. Lim YJ, Chan SY, Ko Y. Stigma and health-related quality of life in Asian adults with epilepsy. Epilepsy Research. 2009;87(2-3):107-119.

337. Santosh D, Kumar TS, Sarma PS, Radhakrishnan K. Women with onset of epilepsy prior to marriage: Disclose or conceal?. Epilepsia. 2007;48(5):1007-1010.

338. Radhakrishnan K, Pandian J, Santhoshkumar T, Thomas S, Deetha T, Sarma P, et al. Prevalence, knowledge, attitude, and practice of epilepsy in Kerala, South India. Epilepsia. 2000;41(8):1027-1035.

339. Shafiq $M$, Tanwir M, Tariq A, Kasi $P$, Zafar M, Saleem A, et al. Epilepsy: Public knowledge and attitude in a slum area of Karachi, Pakistan. Seizure. 2007;16(4):330-337.

340. Barennes H, Sengkhamyong K, Sambany EM, Koffi PN, Chivorakul P, Empis G, et al. Children's access to treatment for epilepsy: experience from the Lao People's Democratic Republic. Archives of Disease in Childhood. 2011;96(3):309-313.

341. Datta SS, Premkumar TS, Fielding S, Chandy S, Kumar S, Eagles J, et al. Impact of pediatric epilepsy on Indian families: influence of psychopathology and seizure related variables. Epilepsy \& Behavior. 2006;9(1):145-151. 
342. Nursing Times. Measles Hits Travellers. News report 31/5/2007. London: The Nursing Times. 2007

343. Hall V, Sadouni M, Fuller A. Gypsy and Travellers' experience of using urgent care services within NHS Brighton and Hove boundaries. 2009.

344. Eggleston PA. Environmental causes of asthma in inner city children. Clinical Reviews in Allergy and Immunology. 2000;18(3):311-324.

345. Platts Mills T, Erwin E, Heymann P, Woodfolk J. Is the hygiene hypothesis still a viable explanation for the increased prevalence of asthma?. Allergy. 2005;60:2531. 


\section{APPENDICES}

\section{APPENDIX A}

\section{A1: Interview questions}

\section{Children's Access to Medicines in the East Midlands \\ Parental interview}

\section{A. BACKGROUND}

Age (years):

Male / Female

No. of adults living in the home:

No. of children:

Age of children:

Occupation:

Country of birth:

If applicable

Country left:

Reasons for leaving:

Date of entry to the UK:

Have you had a decision on your asylum claim:

Duration of time in present accommodation:

Duration of time in current locality:

Contacts in current locality:

Links with community: 


\section{B. HEALTH}

Are you registered with a GP?

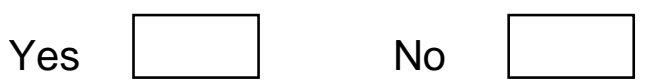

If no, why is that?

Date of last visit to GP:

Are you well?

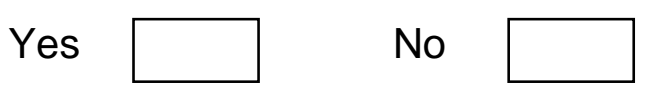

Are you on any medicines?

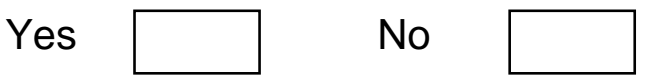

If so, which medicine and from whom do you obtain the medicine?

Are your children normally fit and well?

Yes

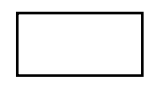

No

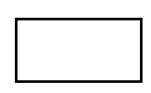

If not, please give details.

What do you normally do when your child is unwell?

Have your children received their immunisations?

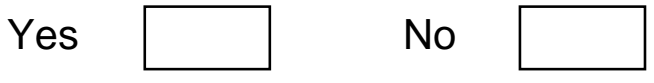

If so, which? 


\section{LAST MONTH}

Have any of the children been ill in the last month?

Yes

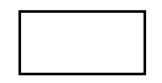

No

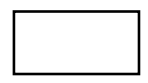

If so, have they seen a health professional? If so, state which type?

Have any of your children received any medicines in the last month?

Yes

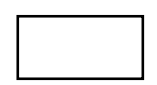

No

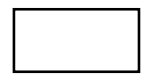

If so, which medicines?

Were the medicines prescribed and, if so, by whom?

Where did you get the medicines from?

Did you have to pay for the medicines?

Yes

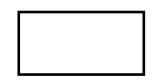

No

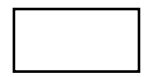

Were there any difficulties in obtaining the medicines? (Include travel costs)

Yes

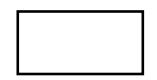

No

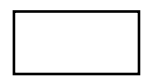

Have any of your children received any medicines (including herbal or homeopathic remedies) in the last month that you have bought from a chemist or obtained from any other individual?

Yes

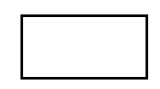

No

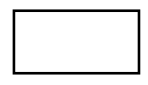


If so, which medicines and from whom?

\section{LAST SIX MONTHS}

Have any of the children been ill in the last six months?

Yes

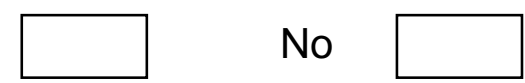

If so, have they seen a health professional? If so, state which type?

Have any of your children received any medicines in the last six months?

Yes

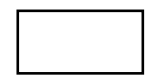

No

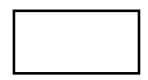

If so, which medicines?

Were the medicines prescribed and, if so, by whom?

Where did you get the medicines from?

Did you have to pay for the medicines?

$$
\text { Yes }
$$

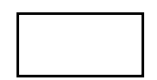

No

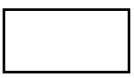

Were there any difficulties in obtaining the medicines? (Include travel costs)

Yes

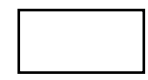

No

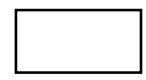


Have any of your children received any medicines (including herbal or homeopathic remedies) in the last six months that you have bought from a chemist or obtained from any other individual?

Yes

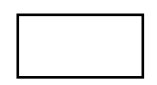

No

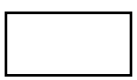

If so, which medicines and from whom?

\section{E. GENERAL}

If your child was crying with earache, what would you do?

Would you give your child any medicine for the earache?

Yes

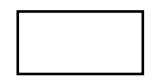

No

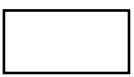

If so, which medicines?

If your child developed asthma (difficulty breathing, wheezy) and required an inhaler, how would you feel about that?

Have you heard of the condition epilepsy (seizures, fits)?

Yes

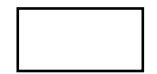

No

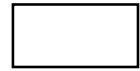

If your child developed epilepsy and required regular treatment, would you want your child to see a doctor regularly?

Yes

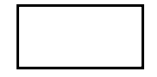

No

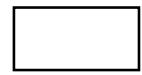

If yes, which doctor would you take them to? 
If the doctor recommended your child received medicine for epilepsy on a daily basis for the next two years, how would you feel about that?

Would you be happy to inform your friends/relatives that your child has epilepsy?

Yes

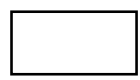

No

Would you be happy to inform the school that your child has epilepsy?

Yes

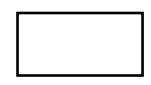

No

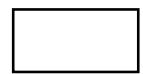

We would value your comments on the way you were approached to participate in this research.

Do you think we could have approached you in a more appropriate manner? 
A2: Westfield Poster

$$
\begin{aligned}
& \text { ARE YOU A } \\
& \text { PARENT? } \\
& \text { POUL } \\
& \text { WOULD YOU LIKE TO } \\
& \text { HELP OUR RESEARCH } \\
& \text { BY ANSWERING A } \\
& \text { FEW QUESTIONS } \\
& \text { ABOUT MEDICINES } \\
& \text { FOR CHILDREN? }
\end{aligned}
$$




\section{A3: Ethic's Committee approval}

Direct line/e-mail

+44 (0) 1158231063

Louise.Sabir@nottingham.ac.uk

Professor Imti Choonara

Dear Professor Choonara

\section{Ethics Reference No: G/06/2010 - Please quote this number on all} correspondence

Study Title: Children's access to medicines in the East Midlands a pilot study. Lead

Investigator: Professor Imti Choonara, Professor of Child Health

Co Investigators: Dr Helen Sammons, Associate Professor, Child Health, SCS, Janine Chercil, Research Nurse, Division of Child Health, SCS, Saad Alkhatani, PhD Student, Division of Child, Rachel Hillian Medical Statiistician, Health, SCS Derby, Claire Millward, Clinical Psychologist, Division of Child Health, Derby SCS, Dr Parag Tambe, SpR. Raediatric Clinical Pharmacology, Division Child Health SCS Derby.

Thank you for your letter dated $25^{\text {th }}$ August 2010 responding to the issue of recruitment raised by the Committee and enclosing revised version of:

- Protocol final version 3.0 dated $25 / 8 / 2010$

- Parental Interview questionnaire

- Recruitment Poster

These have been reviewed and are satisfactory and the study is approved.

Approval is given on the understanding that the Conditions of Approval set out below are followed.

\section{Conditions of Approval}

You must follow the protocol agreed and any changes to the protocol will require prior Ethic's Committee approval.

This study is approved for the period of active recruitment requested. The Committee also provides a further 5 year approval for any necessary work to be performed on the study which may arise in the process of publication and peer review. 
You promptly inform the Chairman of the Ethic's Committee of

(1) Deviations from or changes to the protocol which are made to eliminate immediate hazards to the research subjects.

(ii) Any changes that increase the risk to subjects and/or affect significantly the conduct of the research.

(iii) All adverse drug reactions that are both serious and unexpected.

(iv) New information that may affect adversely the safety of the subjects or the conduct of the study.

(v) The attached End of Project Progress Report is completed and returned when the study has finished.

Yours sincerely

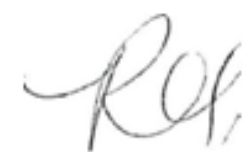

Professor R C Spiller

Chairman, Nottingham University Medical School Research Ethics

Committee 
A4: Information Sheet

\title{
\begin{tabular}{l|l} 
Nit & $\begin{array}{l}\text { The University of } \\
\text { Nottingham }\end{array}$
\end{tabular}
} INFORMATION DOCUMENT

\section{Children's access to medicines in the East Midlands - a pilot study}

\author{
Investigators : Prof Imti Choonara, Dr Helen Sammons, Dr Parag Tambe
}

Postgraduate student Saad Alkahtani, Research Nurse Janine Cherrill

We are inviting you to take part in a research study. Research is a way we try to find out the answers to questions. This is part of a research study to find out what you think about healthcare in the UK. Before you decide whether to take part, it is important that you understand what the project is about and what you will have to do. Please take time to read this and ask if there is anything that is not clear.

\section{Why are we doing this research study?}

We would like to find out what you think about of healthcare in the UK. We wish to determine whether all children receive medicines. We also wish to explore attitudes towards the treatment of medical conditions such as asthma, epilepsy and pain.

\section{Why have I been chosen?}

Because you are a parent and we want to know what you think.

\section{Do I have to take part?}

It is up to you to decide. You do not have to take part. If you say no, this will not affect you or your children. We will describe the study and go through this information, which we will then give to you. We will then ask you to sign a consent form to show that you have agreed to take part and you will be able to keep a copy of this. You are free to withdraw at any time, without giving a reason. This will not affect the standard of care you receive.

\section{What will you ask me to do?}

We will ask you a few questions.

\section{What will I get out of taking part in this project?}

The research will help to identify if there are any problems in relation to children's access to medicines in several different groups and will hopefully identify ways of improving children's access to medicines. This pilot study will give individuals who have difficulty accessing health care the opportunity to state their opinions about any barriers to their children receiving medicines that they require. 


\section{Will my taking part in this study be private (confidential)?}

All information which is collected during the course of the research will be kept strictly confidential, and any information will have the name removed so that you cannot be recognised.

\section{What will happen if we don't want to carry on with the study?}

If you withdraw from the study, we will stop collecting data about your opinions on access to healthcare for your children.

\section{What if there is a problem?}

In case you have a complaint on your treatment by a member of staff or anything to do with the study, you can initially approach the lead investigator. If this achieves no satisfactory outcome, you should then contact the Ethics Committee Secretary, Mrs Louise Sabir, Division of Therapeutics and Molecular Medicine, D Floor, South Block, Queen's Medical Centre, Nottingham, NG7 2UH. Telephone 01158231063. E-mail louise.sabir@nottingham.ac.uk

In the event that something does go wrong and you are harmed during the research and this is due to someone's negligence then you may have grounds for a legal action for compensation against the University of Nottingham but you may have to pay your legal costs.

\section{Who is organising this study?}

This study is being sponsored by the Academic Division of Child Health, University of Nottingham, Derbyshire Children's Hospital. The principal investigator is Professor Imti Choonara.

\section{Who has reviewed the study?}

All research is looked at by an independent group of people, called a Research Ethics Committee to protect your safety, rights, wellbeing and dignity. This study has been reviewed and approved by the University of Nottingham Medical School Ethics Committee.

\section{Thank you for reading this - please ask any questions if you need to} Further Information and contact details

Investigators:

Professor Imti Choonara

Professor in Child Health, University of Nottingham

Academic Division of Child Health

Clinical Sciences Building

Medical School

Derbyshire Children's Hospital

Derby DE22 3DT

01332724693

Dr Parag Tambe, Research Nurse Janine Cherrill or

Postgraduate Student Saad Alkahtani

01332724696 
Title of Project: Children's Access to Medicine in the East Midlands- a pilot study

Name of Investigators: Professor Imti Choonara, Dr Helen Sammons, Janine Cherrill, Saad Alkhatani, Claire Millward and Dr Parag Tambe

\section{Healthy Volunteer's Consent Form}

Please read this form and sign it once the above named or their designated representative, has explained fully the aims and procedures of the study to you

- I voluntarily agree to take part in this study.

- I confirm that I have been given a full explanation by the above named and that I have read and understand the information sheet given to me which is attached.

- I have been given the opportunity to ask questions and discuss the study with one of the above investigators or their deputies on all aspects of the study and have understood the advice and information given as a result.

- I agree to the above investigators contacting my general practitioner [and teaching or university authority if appropriate] to make known my participation in the study where relevant.

- I authorise the investigators to disclose the results of my participation in the study but not my name.

- I understand that information about me recorded during the study will be kept in a secure database. If data is transferred to others it will be made anonymous. Data will be kept for 7 years after the results of this study have been published.

- I understand that I can ask for further instructions or explanations at any time.

- I understand that I am free to withdraw from the study at any time, without having to give a reason for withdrawing.

- I confirm that I have disclosed relevant medical information before the study.

Name:

Address:

Telephone number:

Signature:

Date:

I confirm that I have fully explained the purpose of the study and what is involved to:

I have given the above named a copy of this form together with the information sheet.

Investigator's Signature:

Name:

Study Volunteer Number: 


\section{APPENDIX B}

\section{Qualitative research review guidelines - RATS}

\begin{tabular}{|c|c|c|}
\hline & ASK THIS OF THE MANUSCRIPT & THIS SHOULD BE INCLUDED IN THE MANUSCRIPT \\
\hline $\mathbf{R}$ & $\begin{array}{l}\text { Relevance of study question } \\
\text { Is the research question interesting? } \\
\text { Is the research question relevant to clinical } \\
\text { practice, public health, or policy? }\end{array}$ & $\begin{array}{l}\text { Research question explicitly stated } \\
\text { Research question justified and linked to the existing knowledge base } \\
\text { (empirical research, theory, policy) }\end{array}$ \\
\hline A & $\begin{array}{l}\text { Appropriateness of qualitative method } \\
\text { Is qualitative methodology the best approach } \\
\text { for the study aims? } \\
\text { Interviews: experience, perceptions, } \\
\text { behaviour, practice, process } \\
\text { Focus groups: group dynamics, convenience, } \\
\text { non-sensitive topics } \\
\text { Ethnography: culture, organizational } \\
\text { behaviour, interaction } \\
\text { Textual analysis: documents, art, } \\
\text { representations, conversations }\end{array}$ & $\begin{array}{l}\text { Study design described and justified e.g., why was a particular method } \\
\text { (i.e., interviews) chosen? }\end{array}$ \\
\hline $\mathbf{T}$ & $\begin{array}{l}\text { Transparency of procedures } \\
\text { Sampling } \\
\text { Are the participants selected the most } \\
\text { appropriate to provide access to type of } \\
\text { knowledge sought by the study? } \\
\text { Is the sampling strategy appropriate? }\end{array}$ & $\begin{array}{l}\text { Criteria for selecting the study sample justified and explained } \\
\text { theoretical: based on pre conceived or emergent theory } \\
\text { purposive: diversity of opinion } \\
\text { volunteer: feasibility, hard-to-reach groups }\end{array}$ \\
\hline & $\begin{array}{l}\text { Recruitment } \\
\text { Was recruitment conducted using appropriate } \\
\text { methods? } \\
\text { Is the sampling strategy appropriate? } \\
\text { Could there be selection bias? }\end{array}$ & $\begin{array}{l}\text { Details of how recruitment was conducted and by whom } \\
\text { Details of who chose not to participate and why }\end{array}$ \\
\hline & $\begin{array}{l}\text { Data collection } \\
\text { Was collection of data systematic and } \\
\text { comprehensive? } \\
\text { Are characteristics of the study group and } \\
\text { setting clear? } \\
\text { Why and when was data collection stopped, } \\
\text { and is this reasonable? }\end{array}$ & $\begin{array}{l}\text { Method (s) outlined and examples given (e.g., interview questions) } \\
\text { Study group and setting clearly described } \\
\text { End of data collection justified and described }\end{array}$ \\
\hline
\end{tabular}




\begin{tabular}{|c|c|c|}
\hline & $\begin{array}{l}\text { Role of researchers } \\
\text { Is the researcher (s) appropriate? How might } \\
\text { they bias (good and bad) the conduct of the } \\
\text { study and results? }\end{array}$ & $\begin{array}{l}\text { Do the researchers occupy dual roles (clinician and researcher)? } \\
\text { Are the ethics of this discussed?Do the researcher(s) critically examine } \\
\text { their own influence on the formulation of the research question, data } \\
\text { collection, and interpretation? }\end{array}$ \\
\hline & $\begin{array}{l}\text { Ethics } \\
\text { Was informed consent sought and granted? } \\
\text { Were participants' anonymity and } \\
\text { confidentiality ensured? } \\
\text { Was approval from an appropriate ethics } \\
\text { committee received? }\end{array}$ & $\begin{array}{l}\text { Informed consent process explicitly and clearly detailed } \\
\text { Anonymity and confidentiality discussed } \\
\text { Ethics approval cited }\end{array}$ \\
\hline $\mathbf{S}$ & $\begin{array}{l}\text { Soundness of interpretive approach } \\
\text { Analysis } \\
\text { Is the type of analysis appropriate for the } \\
\text { type of study? } \\
\text { thematic: exploratory, descriptive, hypothesis } \\
\text { generating } \\
\text { framework: e.g., policy } \\
\text { constant comparison/grounded theory: } \\
\text { theory generating, analytical } \\
\text { Are the interpretations clearly presented and } \\
\text { adequately supported by the evidence? } \\
\text { Are quotes used and are these appropriate } \\
\text { and effective? } \\
\text { Was trustworthiness/reliability of the data } \\
\text { and interpretations checked? }\end{array}$ & $\begin{array}{l}\text { Indicators of quality: Description of how themes were derived from the } \\
\text { data (inductive or deductive) } \\
\text { Evidence of alternative explanations being sought } \\
\text { Analysis and presentation of negative or deviant cases } \\
\text { Description of the basis on which quotes were chosen } \\
\text { Semi-quantification when appropriate } \\
\text { Illumination of context and/or meaning, richly detailed } \\
\text { Method of reliability check described and justified } \\
\text { e.g., was an audit trail, triangulation, or member checking employed? } \\
\text { Did an independent analyst review data and contest themes? How were } \\
\text { disagreements resolved? }\end{array}$ \\
\hline & $\begin{array}{l}\text { Discussion and presentation } \\
\text { Are findings sufficiently grounded in a } \\
\text { theoretical or conceptual framework? } \\
\text { Is adequate account taken of previous } \\
\text { knowledge and how the findings add? } \\
\text { Are the limitations thoughtfully considered? } \\
\text { Is the manuscript well written and accessible? }\end{array}$ & $\begin{array}{l}\text { Findings presented with reference to existing theoretical and empirical } \\
\text { literature, and how they contribute } \\
\text { Strengths and limitations explicitly described and discussed } \\
\text { Evidence of following guidelines (format, word count) } \\
\text { Detail of methods or additional quotes contained in appendix } \\
\text { Written for a health sciences audience }\end{array}$ \\
\hline
\end{tabular}




\section{APPENDIX C}

\section{Statistical analysis:}

\section{Asylum Seekers and Refugees}

Table 6.10: Comparison across Refugee and Control group (Independent sample t-test)

\begin{tabular}{|c|c|c|c|c|c|c|c|}
\hline & Group & $\mathbf{N}$ & Mean & SD & $\mathbf{T}$ & df & $\begin{array}{l}\text { Sig. (2- } \\
\text { tailed) }\end{array}$ \\
\hline \multirow[t]{2}{*}{ Parent age $(\mathrm{Y})$} & Refugee & 50 & 36.24 & 7.358 & 1.565 & 98 & .121 \\
\hline & Control & 50 & 34.10 & 6.274 & & & \\
\hline \multirow{2}{*}{$\begin{array}{l}\text { Duration in accommodation } \\
\text { (Y) }\end{array}$} & Refugee & 50 & 2.85 & 2.111 & -5.685 & 51 & .000 \\
\hline & Control & 50 & 12.89 & 12.307 & & & \\
\hline \multirow[t]{2}{*}{ Duration in locality (Y) } & Refugee & 50 & 5.43 & 3.440 & -7.272 & 55 & .000 \\
\hline & Control & 50 & 19.82 & 13.556 & & & \\
\hline \multirow[t]{2}{*}{ Last visit (D) } & Refugee & 49 & 27.65 & 36.112 & -1.794 & 92 & .079 \\
\hline & Control & 45 & 60.82 & 119.135 & & & \\
\hline
\end{tabular}


Table 6.11: Sociodemographics (Mann-Whitney Test)

\begin{tabular}{lcccc}
\hline \multirow{3}{*}{ Gender } & \multicolumn{4}{c}{ Ranks } \\
\cline { 2 - 5 } & Group & $\mathbf{N}$ & Mean Rank & Sum of Ranks \\
& Refugee & 50 & 34.50 & 1725.00 \\
Occupation & Control & 50 & 66.50 & 3325.00 \\
& Total & 100 & & \\
& Refugee & 45 & 45.00 & 2025.00 \\
Links with locality & Control & 50 & 50.70 & 2535.00 \\
& Total & 95 & & 2404.00 \\
& Refugee & 50 & 48.08 & 2447.00 \\
& Control & 48 & 50.98 & \\
Parents health & Total & 98 & & 2200.00 \\
& & & & \\
& Refugee & 50 & 44.00 & \\
\hline
\end{tabular}

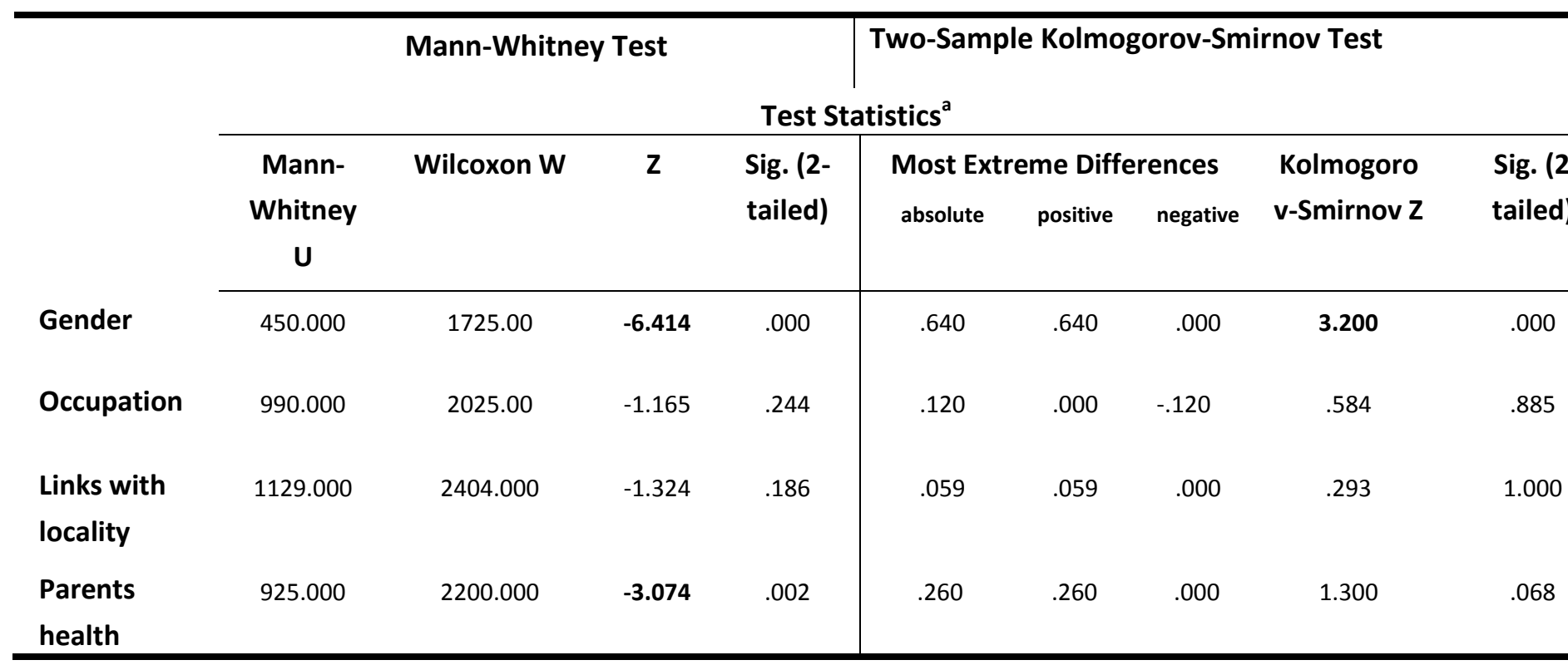

a. Grouping Variable: Group 
Table 6.12: General access to healthcare and medicines (Mann-Whitney Test)

\begin{tabular}{lcccc}
\hline & \multicolumn{3}{c}{ Ranks } \\
\cline { 2 - 4 } Reg with GP & Group & N & Mean Rank & Sum of Ranks \\
& Refugee & 50 & 50.50 & 2525.00 \\
Control & 50 & 50.50 & 2525.00 \\
Total & 100 & & 1690.00 \\
Refugee & 49 & 34.49 & 2226.00 \\
Control & 39 & 57.08 & 2464.00 \\
Total & 88 & & 1722.00 \\
Refugee & 50 & 49.28 & \\
& Control & 41 & 42.00 & 2617.00 \\
& Total & 91 & & 2333.00 \\
& Refugee & 50 & 52.34 & 47.61 \\
& Control & 49 & &
\end{tabular}

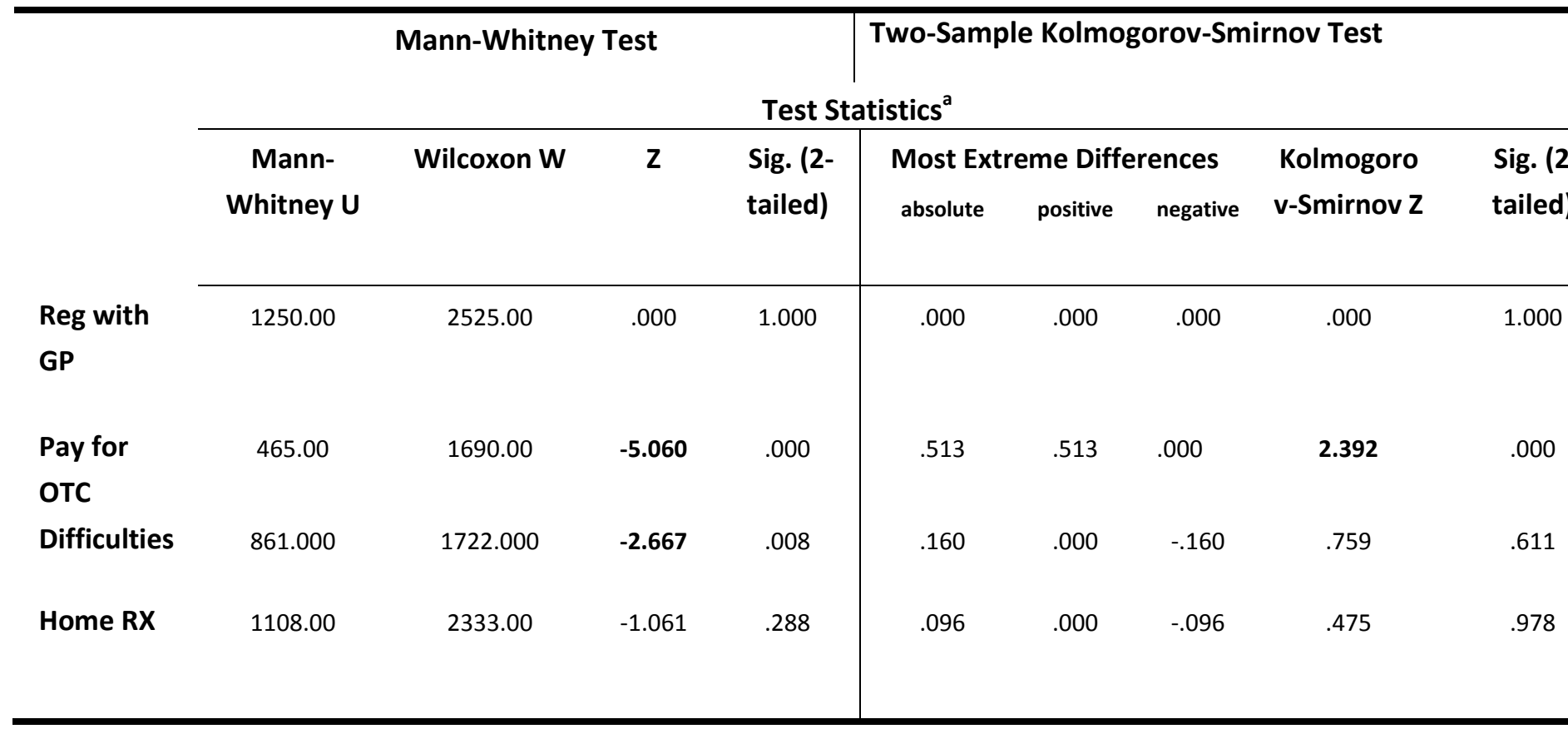

a. Grouping Variable: Group 
Table 6.13: Data for the children (Mann-Whitney Test)

\begin{tabular}{lcccc}
\hline & \multicolumn{3}{c}{ Ranks } \\
\cline { 2 - 5 } No. of & Group & $\mathbf{N}$ & Mean Rank & Sum of Ranks \\
children/family & Refugee & 50 & 53.88 & 2694.00 \\
& Control & 50 & 47.12 & 2356.00 \\
& Total & 100 & & \\
Child health & Refugee & 117 & 110.31 & 12906.00 \\
& Control & 99 & 106.36 & 10530.00 \\
& Total & 216 & & 13386.50 \\
Children Ages(Y) & Refugee & 117 & 114.41 & 10049.50 \\
& Control & 99 & 101.51 & \\
& Total & 216 & & 12645.00 \\
Immunisation & Refugee & 117 & 108.08 & 10791.00 \\
& Control & 99 & 109.00 & \\
\hline
\end{tabular}

\begin{tabular}{|c|c|c|c|c|c|c|c|c|c|}
\hline & & Mann-Whit & y Test & & Two-Samp & Kolmo & orov-Sm & rnov Test & \\
\hline & & & & Tes & tatistics ${ }^{a}$ & & & & \\
\hline & $\begin{array}{c}\text { Mann- } \\
\text { Whitney } \\
\text { U }\end{array}$ & $\begin{array}{l}\text { Wilcoxon } \\
\text { W }\end{array}$ & $\mathbf{Z}$ & $\begin{array}{l}\text { Sig. (2- } \\
\text { tailed) }\end{array}$ & $\begin{array}{c}\text { Most Ext } \\
\text { absolute }\end{array}$ & $\begin{array}{l}\text { me Diffe } \\
\text { positive }\end{array}$ & $\begin{array}{l}\text { rences } \\
\text { negative }\end{array}$ & $\begin{array}{l}\text { Kolmogoro } \\
\text { v-Smirnov Z }\end{array}$ & $\begin{array}{l}\text { Sig. }(2 \\
\text { tailed) }\end{array}$ \\
\hline $\begin{array}{l}\text { No. of } \\
\text { children/family }\end{array}$ & 1081.000 & 2356.000 & -1.217 & .224 & .160 & .000 & -.160 & .800 & .544 \\
\hline Child health & 5580.000 & 10530.000 & -1.214 & .225 & .037 & .000 & -.037 & .267 & 1.000 \\
\hline $\begin{array}{l}\text { Children } \\
\text { Ages(Y) }\end{array}$ & 5099.500 & 10049.500 & -1.515 & .130 & .159 & .011 & -.159 & 1.161 & .135 \\
\hline Immunisation & 5742.000 & 12645.000 & -.920 & .358 & .009 & .009 & .000 & .063 & 1.000 \\
\hline
\end{tabular}

a. Grouping Variable: Group 
Table 6.14: Frequency of illnesses experienced during the last month

\begin{tabular}{|c|c|c|c|c|c|c|}
\hline \multirow{3}{*}{$\begin{array}{c}\text { No of illnesses Last } \\
\text { Month }\end{array}$} & \multicolumn{4}{|c|}{ Group } & & \\
\hline & \multicolumn{2}{|c|}{ Refugee } & \multicolumn{2}{|c|}{ Control } & \multicolumn{2}{|c|}{ Total } \\
\hline & Count & $\%$ & Count & $\%$ & Count & $\%$ \\
\hline 1 & 32 & 97 & 35 & 100 & 67 & 98.5 \\
\hline 2 & 1 & 3 & 0 & .0 & 1 & 1.5 \\
\hline Total & 33 & 100.0 & 35 & 100.0 & 68 & 100.0 \\
\hline
\end{tabular}

\begin{tabular}{|l|c|c|c|}
\hline & Value & df & Exact. Sig. (2-sided) \\
\hline Pearson Chi-Square & $1.076^{\mathrm{a}}$ & 1 & .458 \\
Likelihood Ratio & 1.462 & 1 & .458 \\
Linear-by-Linear & 1.061 & 1 & .458 \\
Association & & & \\
N of Valid Cases & 68 & & \\
\hline \multicolumn{2}{|l|}{ a. 2 cells (50\%) have expected count less than 5. The minimum expected count is .49. } \\
\hline
\end{tabular}

Table 6.15: Frequency of medicine used during the last month

\begin{tabular}{|c|r|r|r|r|r|r|}
\hline \multirow{2}{*}{$\begin{array}{c}\text { No of medicines } \\
\text { Last Month }\end{array}$} & \multicolumn{4}{|c|}{ Group } & \multicolumn{2}{|c|}{} \\
\cline { 2 - 8 } & \multicolumn{2}{|c|}{ Refugee } & \multicolumn{2}{c|}{ Control } & \multicolumn{2}{c|}{ Total } \\
\cline { 2 - 8 } & Count & \multicolumn{1}{|c|}{$\%$} & Count & \multicolumn{1}{c|}{ Count } & $\%$ \\
\hline 1 & 15 & 50 & 10 & 33.4 & 25 & 41.7 \\
\hline 2 & 14 & 46.7 & 18 & 60 & 32 & 53.3 \\
\hline 3 & 1 & 3.3 & 1 & 3.3 & 2 & 3.3 \\
\hline 4 & 0 & .0 & 1 & 3.3 & 1 & 1.7 \\
\hline Total & 30 & 100.0 & 30 & 100.0 & 60 & 100.0 \\
\hline
\end{tabular}

\begin{tabular}{|l|c|c|c|}
\hline & Value & df & Exact. Sig. (2-sided) \\
\hline Pearson Chi-Square & $2.500^{\mathrm{a}}$ & 4 & .638 \\
Likelihood Ratio & 2.894 & 4 & .638 \\
Linear-by-Linear & 2.037 & 1 & .223 \\
Association & & & \\
N of Valid Cases & 60 & & \\
\hline \multicolumn{2}{|l|}{ a. 4 cells (50.0\%) have expected count less than 5. The minimum expected count is .50. } \\
\hline
\end{tabular}


Table 6.16: Medicines in the last month

\begin{tabular}{|c|r|r|r|r|r|r|}
\hline \multirow{2}{*}{$\begin{array}{c}\text { Medicines in the Last } \\
\text { Month }\end{array}$} & \multicolumn{4}{|c|}{ Group } & \multicolumn{2}{c|}{ Total } \\
\cline { 2 - 7 } & \multicolumn{2}{|c|}{ Refugee } & \multicolumn{2}{c|}{ Control } & \multicolumn{2}{c|}{$\%$} \\
\cline { 2 - 7 } & Count & \multicolumn{1}{c|}{$\%$} & Count & $\%$ & Count & $\%$ \\
\hline OTC Medicines & 9 & 20 & 32 & 60 & 41 & 41.4 \\
\cline { 2 - 7 } Prescribed medicines & 37 & 80 & 21 & 40 & 58 & 58.6 \\
\hline Total & 46 & 100.0 & 53 & 100.0 & 99 & 100.0 \\
\hline
\end{tabular}

\begin{tabular}{|l|c|c|c|}
\hline & Value & df & Exact. Sig. (2-sided) \\
\hline Pearson Chi-Square & $16.906^{\mathrm{a}}$ & 1 & .000 \\
Likelihood Ratio & 17.658 & 1 & .000 \\
Linear-by-Linear & 16.735 & 1 & .000 \\
Association & & & \\
N of Valid Cases & 99 & & \\
\hline a. 0 cells (0\%) have expected count less than 5. The minimum expected count is .19.05.
\end{tabular}

Table 6.17: Frequency of illnesses experienced during the last six months

\begin{tabular}{|c|r|r|r|r|r|r|}
\hline \multirow{2}{*}{$\begin{array}{c}\text { No of illnesses Last } \\
\text { 6- Months }\end{array}$} & \multicolumn{4}{|c|}{ Group } & \multicolumn{2}{|c|}{ Total } \\
\cline { 2 - 8 } & \multicolumn{2}{|c|}{ Refugee } & \multicolumn{2}{c|}{ Control } & \multicolumn{1}{c|}{$\%$} \\
\cline { 2 - 8 } & Count & \multicolumn{1}{c|}{$\%$} & Count & \multicolumn{1}{c|}{$\%$} & Count & 80 \\
\hline 1 & 70 & 82.4 & 53 & 76.8 & 123 & 20 \\
\cline { 2 - 8 } & 15 & 17.6 & 16 & 23.2 & 31 & 100.0 \\
\hline
\end{tabular}

\begin{tabular}{|l|c|c|c|}
\hline & Value & df & Exact. Sig. (2-sided) \\
\hline Pearson Chi-Square & $.727^{\mathrm{a}}$ & 1 & .424 \\
Likelihood Ratio & .724 & 1 & .424 \\
Linear-by-Linear & .723 & 1 & .424 \\
Association & 154 & & \\
N of Valid Cases & & \\
\hline
\end{tabular}


Table 6.18: Frequency of medicine used during the last six months

\begin{tabular}{|c|r|r|r|r|r|r|}
\hline \multirow{3}{*}{$\begin{array}{c}\text { No of medicines } \\
\text { Last six Months }\end{array}$} & \multicolumn{4}{|c|}{ Group } & \multicolumn{2}{|c|}{} \\
\cline { 2 - 8 } & \multicolumn{2}{|c|}{ Refugee } & \multicolumn{2}{c|}{ Control } & \multicolumn{2}{c|}{ Total } \\
\cline { 2 - 8 } & Count & \multicolumn{1}{|c|}{$\%$} & Count & \multicolumn{1}{c|}{$\%$} & \multicolumn{1}{c|}{ Count } & $\%$ \\
\hline \multirow{3}{*}{1} & 44 & 66.7 & 39 & 63.9 & 83 & 65.4 \\
2 & 19 & 28.8 & 19 & 31.2 & 38 & 29.9 \\
\cline { 2 - 8 } 3 & 3 & 4.5 & 3 & 4.9 & 6 & 4.7 \\
\hline Total & 66 & 100.0 & 61 & 100.0 & 127 & 100.0 \\
\hline
\end{tabular}

\begin{tabular}{|l|c|c|c|}
\hline & Value & df & Exact. Sig. (2-sided) \\
\hline Pearson Chi-Square & $.105^{\mathrm{a}}$ & 2 & .951 \\
Likelihood Ratio & .104 & 2 & .951 \\
Linear-by-Linear & .091 & 1 & .879 \\
Association & & & \\
N of Valid Cases & 127 & & \\
\hline a. 2 cells (33.3\%) have expected count less than 5. The minimum expected count is 3.02. \\
\hline
\end{tabular}

Table 6.19: Medicines in the last six month

\begin{tabular}{|c|c|c|c|c|c|c|}
\hline \multirow{3}{*}{$\begin{array}{l}\text { Medicines in the Last } \\
\text { Six Month }\end{array}$} & \multicolumn{4}{|c|}{ Group } & & \\
\hline & \multicolumn{2}{|c|}{ Refugee } & \multicolumn{2}{|c|}{ Control } & \multicolumn{2}{|c|}{ Total } \\
\hline & Count & $\%$ & Count & $\%$ & Count & $\%$ \\
\hline \multirow{2}{*}{$\begin{array}{c}\text { OTC Medicines } \\
\text { Prescribed medicines }\end{array}$} & 17 & 19 & 53 & 62 & 70 & 39.5 \\
\hline & 74 & 81 & 33 & 38 & 107 & 60.5 \\
\hline Total & 91 & 100.0 & 86 & 100.0 & 177 & 100.0 \\
\hline
\end{tabular}

\begin{tabular}{|l|c|c|c|}
\hline & Value & df & Exact. Sig. (2-sided) \\
\hline Pearson Chi-Square & $34.111^{\mathrm{a}}$ & 1 & .000 \\
Likelihood Ratio & 35.409 & 1 & .000 \\
Linear-by-Linear & 33.918 & 1 & .000 \\
Association & & & \\
N of Valid Cases & 177 & & \\
\hline a. 0 cells (0\%) have expected count less than 5. The minimum expected count is .34.01. \\
\hline
\end{tabular}


Table 6.20: Attitudes (Mann-Whitney Test)

\begin{tabular}{|c|c|c|c|c|}
\hline \multicolumn{5}{|c|}{ Ranks } \\
\hline \multirow{4}{*}{$\begin{array}{l}\text { Giving } R X \text { for } \\
\text { earache }\end{array}$} & Group & $\mathbf{N}$ & Mean Rank & Sum of Ranks \\
\hline & Refugee & 50 & 39.50 & 1975.00 \\
\hline & Control & 50 & 61.50 & 3075.00 \\
\hline & Total & 100 & & \\
\hline \multirow[t]{3}{*}{ Know epilepsy } & Refugee & 50 & 49.50 & 2475.00 \\
\hline & Control & 50 & 51.50 & 2575.00 \\
\hline & Total & 100 & & \\
\hline \multirow[t]{3}{*}{ Treat epilepsy } & Refugee & 50 & 50.50 & 2525.00 \\
\hline & Control & 50 & 50.50 & 2525.00 \\
\hline & Total & 100 & & \\
\hline \multirow[t]{3}{*}{ Inform friends } & Refugee & 50 & 43.50 & 2175.00 \\
\hline & Control & 50 & 57.50 & 2875.00 \\
\hline & Total & 100 & & \\
\hline \multirow[t]{3}{*}{ Inform school } & Refugee & 50 & 49.00 & 2450.00 \\
\hline & Control & 50 & 52.00 & 2600.00 \\
\hline & Total & 100 & & \\
\hline
\end{tabular}

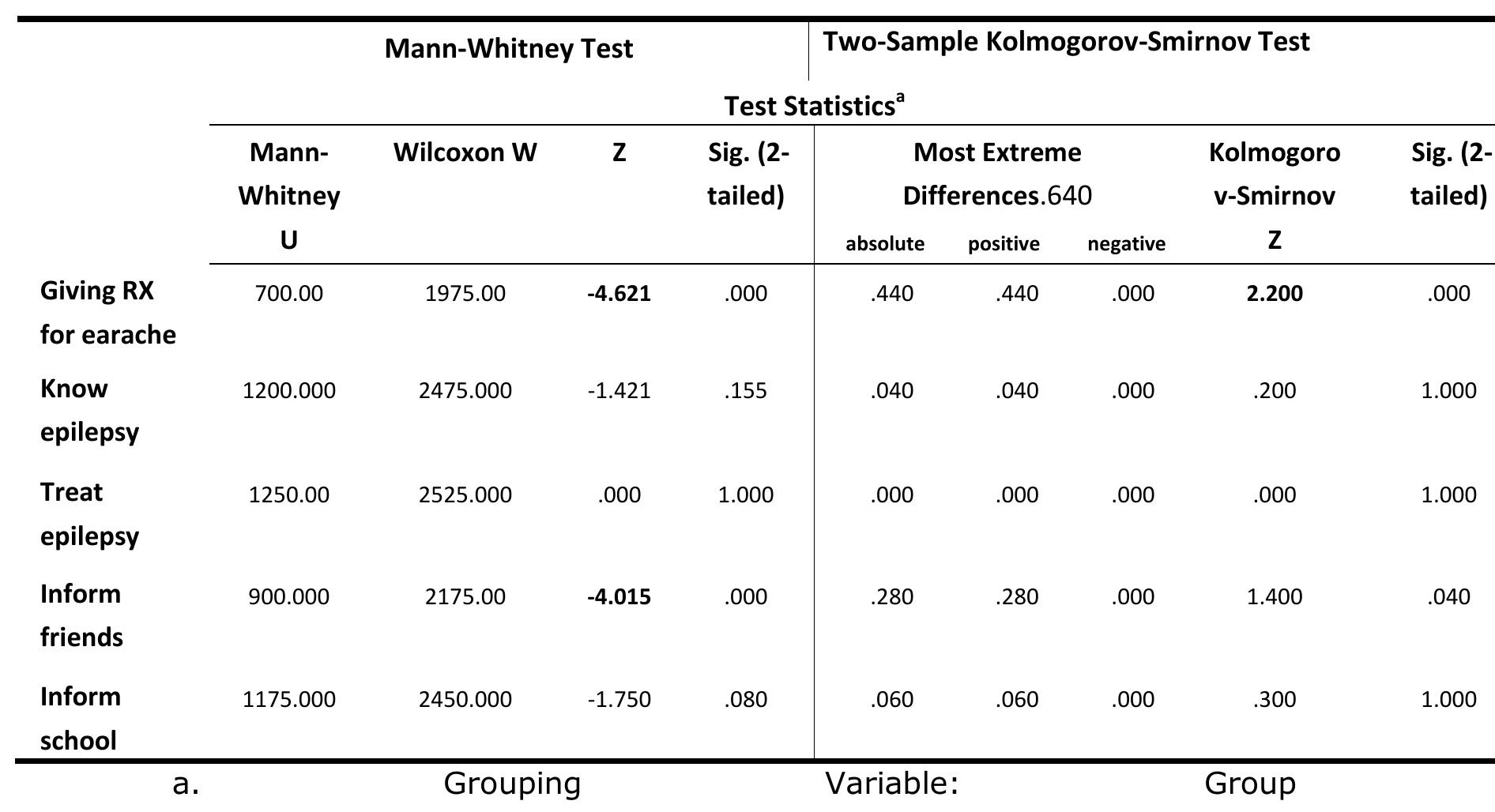




\section{APPENDIX D}

\section{D1: Attitudes tables}

\section{Asylum Seekers and Refugees}

Table 6.21: Categorisation of responses (pain)

\begin{tabular}{|c|c|}
\hline Inductive Categories & Participants' Responses \\
\hline Giving analgesics & $\begin{array}{l}\text { - Few drops of olive oil, then give paracetamol. If } \\
\text { still in pain, then take to GP. } \\
\text { - Check closely to determine whether to give } \\
\text { paracetamol or to contact GP. } \\
\text { - If night time, then give analgesics; if day time, } \\
\text { then contact GP. } \\
\text { - Administer Calpol; if pain persists, then contact } \\
\text { GP. } \\
\text { - Give pain killers and call GP if symptoms get } \\
\text { worse. } \\
\text { Child had ear infection in past, so would give } \\
\text { pain relief then monitor; if necessary, see GP. }\end{array}$ \\
\hline $\begin{array}{l}\text { Seeking advice or health } \\
\text { care }\end{array}$ & $\begin{array}{l}\text { - } \text { Ring NHS direct first, then administer Calpol. } \\
\text { - Take to GP or hospital. } \\
\text { - Would not give anything until doctor prescribes. } \\
\text { - Nothing to give, because it is difficult to } \\
\text { diagnose. } \\
\text { - Go to GP, because can't see inside ear and } \\
\text { would want a medical opinion. }\end{array}$ \\
\hline Other options & $\begin{array}{l}\text { - Monitor sleep, eating habits, and temperature } \\
\text { over a period of 5-7 days. If persists, then take } \\
\text { to the GP. } \\
\text { - Check inside the ear for any fluid discharge. } \\
\text { - Start with breast feeding; if pain persists, then } \\
\text { go to GP or a walk-in centre. } \\
\text { - First try a warm bandage, then take to A\&E. } \\
\text { - Comfort him, then seek another option. }\end{array}$ \\
\hline
\end{tabular}


Table 6.22: Categorisation of responses (asthma)

\begin{tabular}{|c|c|}
\hline Inductive Categories & Participants' Responses \\
\hline $\begin{array}{l}\text { Have experience and } \\
\text { knowledge }\end{array}$ & $\begin{array}{l}\text { - My youngest has had ongoing chest problems } \\
\text { and has been prescribed Ventolin, so it is ok to } \\
\text { give. } \\
\text { - Brother has asthma, so understand treatment is } \\
\text { necessary. } \\
\text { - Eldest has asthma, treat when unwell, so not } \\
\text { concerned about it. } \\
\text { - Mum has seasonal asthma and does not } \\
\text { consider it a real illness. } \\
\text { - I have asthma, so I know what to expect. } \\
\text { Will not panic, it is just a part of the } \\
\text { medication. } \\
\text { It does help to reduce child's distress and make } \\
\text { him/her comfortable. }\end{array}$ \\
\hline $\begin{array}{l}\text { Happy to follow the } \\
\text { instructions (administer } \\
\text { the inhalers) }\end{array}$ & $\begin{array}{l}\text { - Happy to treat child if one of those things helps. } \\
\text { - Would be happy to treat, wouldn't be fussed. } \\
\text { - Nothing, because it could be for any one. Happy } \\
\text { - Cannot see child suffering, so will give inhaler } \\
\text { as recommended. } \\
\text { - If it helped child's condition, then would feel } \\
\text { fine about it. }\end{array}$ \\
\hline Concerned & $\begin{array}{l}\text { - Concerned; seek advice for how to control } \\
\text { asthma. } \\
\text { - Anxious, upset, worried about whether it is a } \\
\text { severe attack/hurting, because child is in } \\
\text { trouble, and using an inhaler itself would not } \\
\text { bother me. } \\
\text { - Anxious; seek advice on risk. } \\
\text { - Upset and concerned for child. } \\
\text { - Not easy; do not know what to do. }\end{array}$ \\
\hline
\end{tabular}


Table 6.23: Categorisation of responses (epilepsy)

\section{Inductive categories $\quad$ Participants responses}

\begin{tabular}{|c|c|}
\hline $\begin{array}{l}\text { Feel happy to give child } \\
\text { medication and follow } \\
\text { advice }\end{array}$ & $\begin{array}{l}\text { - Know the condition, would not hesitate to give } \\
\text { medicine regularly. } \\
\text { - It is a health risk; would have to treat, so } \\
\text { wouldn't have a problem. } \\
\text { Eldest child epileptic, so understand importance } \\
\text { of treatment to control epilepsy. } \\
\text { - If medication is what is necessary to keep child } \\
\text { well, then would administer it. } \\
\text { - When doctor says to give the medicine, would } \\
\text { give it. } \\
\text { - Understand the risk, so have to give the } \\
\text { medicine. } \\
\text { Definitely would give the medicine. } \\
\text { Ok if it helps to control epilepsy and if it stops } \\
\text { seizures. }\end{array}$ \\
\hline $\begin{array}{l}\text { Concerned, but would } \\
\text { give medication }\end{array}$ & $\begin{array}{l}\text { - Worried, but if it was required and necessary } \\
\text { and we had the full information regarding the } \\
\text { drugs and side effects, we would proceed. } \\
\text { - Issue with having a diagnosis, but would not } \\
\text { panic about daily medicine if it was required. } \\
\text { - Very anxious and would discuss risks with } \\
\text { relevant people. } \\
\text { - If this happened, would be scarred and } \\
\text { distressed. } \\
\text { - Be worried, but give medication to protect my } \\
\text { child. } \\
\text { - Very concerned about condition, risks, and drug } \\
\text { side effects. } \\
\text { Depressed, but if medicine would help, then } \\
\text { would give } \\
\text { Wouldn't be happy, but if doctor recommended } \\
\text { this as best course of action, then would be } \\
\text { inclined to take his/her advice as the } \\
\text { professional. }\end{array}$ \\
\hline
\end{tabular}




\section{D2: Attitudes tables}

\section{Control group}

Table 6.24: Categorisation of responses (pain)

\begin{tabular}{|c|c|}
\hline Inductive categories & Participants responses \\
\hline Give analgesics & $\begin{array}{l}\text { - } \quad \text { pain killer, then check } \\
\text { - } \quad \text { administer Calpol if persists contact GP } \\
\text { give pain killers and call GP if symptoms got } \\
\text { - } \quad \text { give paracetamol and/or Ibuprofen, monitor the } \\
\text { situation if no improvement I would see GP } \\
\text { Child had ear infection in past, so I would give } \\
\text { pain relief then monitor and see GP if necessary }\end{array}$ \\
\hline $\begin{array}{l}\text { Seeking for advice or } \\
\text { healthcare }\end{array}$ & $\begin{array}{l}\text { - Ring NHS direct first, then calpol } \\
\text { - Take to walk in centre } \\
\text { - go to GP, can't see inside ear and would want a } \\
\text { medical opinion } \\
\text { - Take to the Doctor, keep ear warm when } \\
\text { outside }\end{array}$ \\
\hline Other options & $\begin{array}{l}\text { Would monitor sleep, eating habits, and } \\
\text { temperature over a period of 5-7 days. If } \\
\text { persists would take to the GP } \\
\text { - Check inside the ear for any fluid discharge }\end{array}$ \\
\hline
\end{tabular}


Table 6.25: Categorisation of responses (asthma)

\begin{tabular}{|c|c|}
\hline Inductive categories & Participants responses \\
\hline $\begin{array}{l}\text { Have experience and } \\
\text { knowledge }\end{array}$ & $\begin{array}{l}\text { - My youngest has had ongoing chest problems } \\
\text { - } \text { and has been prescribed Ventolin, so ok to give } \\
\text { necessary } \\
\text { - } \text { Eldest has asthma, treat when un well, so not } \\
\text { concerned about it } \\
\text { - Mum has seasonal asthma, does not consider it } \\
\text { - I have asthma, so would know what to expect } \\
\text { - I know it is not easy, so I have to treat him } \\
\text { A little bit concerned but providing they were } \\
\text { confident in using the inhaler, it would be ok }\end{array}$ \\
\hline $\begin{array}{l}\text { Happy follow the } \\
\text { instructions (give the } \\
\text { inhalers) }\end{array}$ & $\begin{array}{l}\text { - Happy to treat if it one of those things help } \\
\text { - Would be happy to treat, wouldn't be fussed } \\
\text { - Would give inhalers and hope he got better } \\
\text { about it } \\
\text { - Would look at possible external elements } \\
\text { causing it, but appreciate inhalers would help }\end{array}$ \\
\hline Concerned & $\begin{array}{l}\text { - Concerned, Seek advice in how to control } \\
\text { asthma } \\
\text { - Anxious, upset, worried about, what if it was a } \\
\text { sever attack/hurting because my child in } \\
\text { trouble, and using an inhaler itself would not } \\
\text { bother me } \\
\text { - Anxious, seek advice on risk }\end{array}$ \\
\hline
\end{tabular}


Table 6.26: Categorisation of responses (epilepsy)

\begin{tabular}{ll}
\hline Inductive categories & \multicolumn{1}{c}{ Participants responses } \\
\hline $\begin{array}{l}\text { Feel happy to give child } \\
\text { medication and follow }\end{array}$ & I know the condition. Not hesitate to give \\
advice & medicine regularly \\
- & It is health risk, would have to treat, so \\
& wouldn't have a problem \\
- & Eldest child epileptic, so understand importance \\
& of treatment to control epilepsy \\
- & If that what is needed to keep my child well, I \\
& would administer it \\
- & Happy to do what doctor recommended \\
- & Ok if it helps control epilepsy and stopped \\
& seizures \\
Mive medication & Whatever would help to make them better \\
- & Worried, but if it was required and necessary \\
& and we had had the full information regarding \\
& the drugs and side effects, we would proceed \\
- Issue with having a diagnosis but not panic by \\
-
\end{tabular}




\section{APPENDIX E}

\section{Statistical analysis:}

\section{Gypsies and Travellers}

Table 7.9: Comparison across Traveller and Control group (Independent sample t-test)

\begin{tabular}{lccccccc}
\hline & Group & $\mathbf{N}$ & Mean & SD & t & df & $\begin{array}{c}\text { Sig. (2- } \\
\text { tailed) }\end{array}$ \\
\cline { 2 - 7 } parent age (Y) & Traveller & 47 & 32.15 & 8.827 & $\mathbf{- 2 . 1 1 6}$ & 87.015 & .039 \\
& Control & 50 & 35.54 & 6.893 & & & \\
duration in & Traveller & 33 & 3.56 & 6.244 & $\mathbf{- 3 . 9 5 9}$ & 77.572 & .000 \\
accommodation (Y) & Control & 50 & 12.53 & 11.960 & & & \\
& & & & & & & \\
duration in locality(Y) & Traveller & 41 & 10.54 & 8.031 & $\mathbf{- 4 . 6 4 2}$ & 80.255 & .000 \\
& Control & 50 & 22.01 & 14.040 & & & \\
& & & & & & & \\
Last visit (D) & Traveller & 38 & 64.87 & 143.853 & -.148 & 75.101 & .883 \\
& Control & 44 & 69.32 & 129.081 & & & \\
\hline
\end{tabular}


Table 7.10: Sociodemographics (Mann-Whitney Test)

\begin{tabular}{lcccc}
\hline \multirow{3}{*}{ Gender } & \multicolumn{4}{c}{ Ranks } \\
\cline { 2 - 5 } & Group & N & Mean Rank & Sum of Ranks \\
& Traveller & 47 & 52.00 & 2444.00 \\
Occupation & Control & 50 & 46.18 & 2309.00 \\
& Total & 97 & & \\
& Traveller & 47 & 36.13 & 1698.00 \\
links with locality & Control & 50 & 61.10 & 3055.00 \\
& Total & 97 & & \\
& Traveller & 23 & 36.00 & 1728.00 \\
Parents health & Control & 48 & 36.00 & \\
& Total & 71 & & 2020.50 \\
& & & & 2732.50 \\
& Traveller & 47 & 42.99 & \\
\hline
\end{tabular}

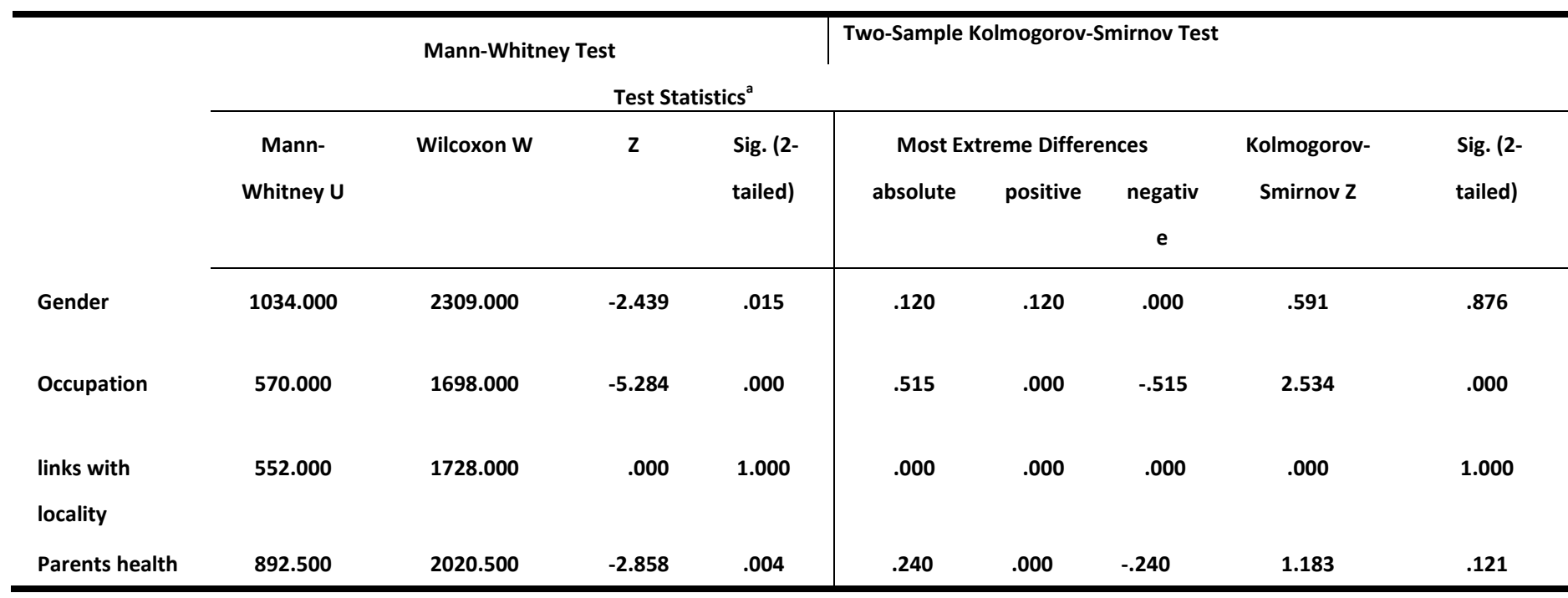

a. Grouping Variable: Group 
Table 7.11: General access to health care and medicines (Mann-Whitney Test)

\begin{tabular}{lcccc}
\hline & \multicolumn{3}{c}{ Ranks } \\
\cline { 2 - 5 } Reg with GP & Group & N & Mean Rank & Sum of Ranks \\
& Traveller & 47 & 49.00 & 2303.00 \\
Pay for RX & Control & 50 & 49.00 & 2450.00 \\
& Total & 97 & & 1146.00 \\
Traveller & 38 & 30.16 & 1935.00 \\
Difficulties & Control & 40 & 48.38 & 1700.00 \\
& Total & 78 & & 1870.00 \\
Home RX & Traveller & 40 & 42.50 & \\
& Control & 44 & 42.50 & 2414.00 \\
& Total & 84 & & 2242.00 \\
\hline
\end{tabular}

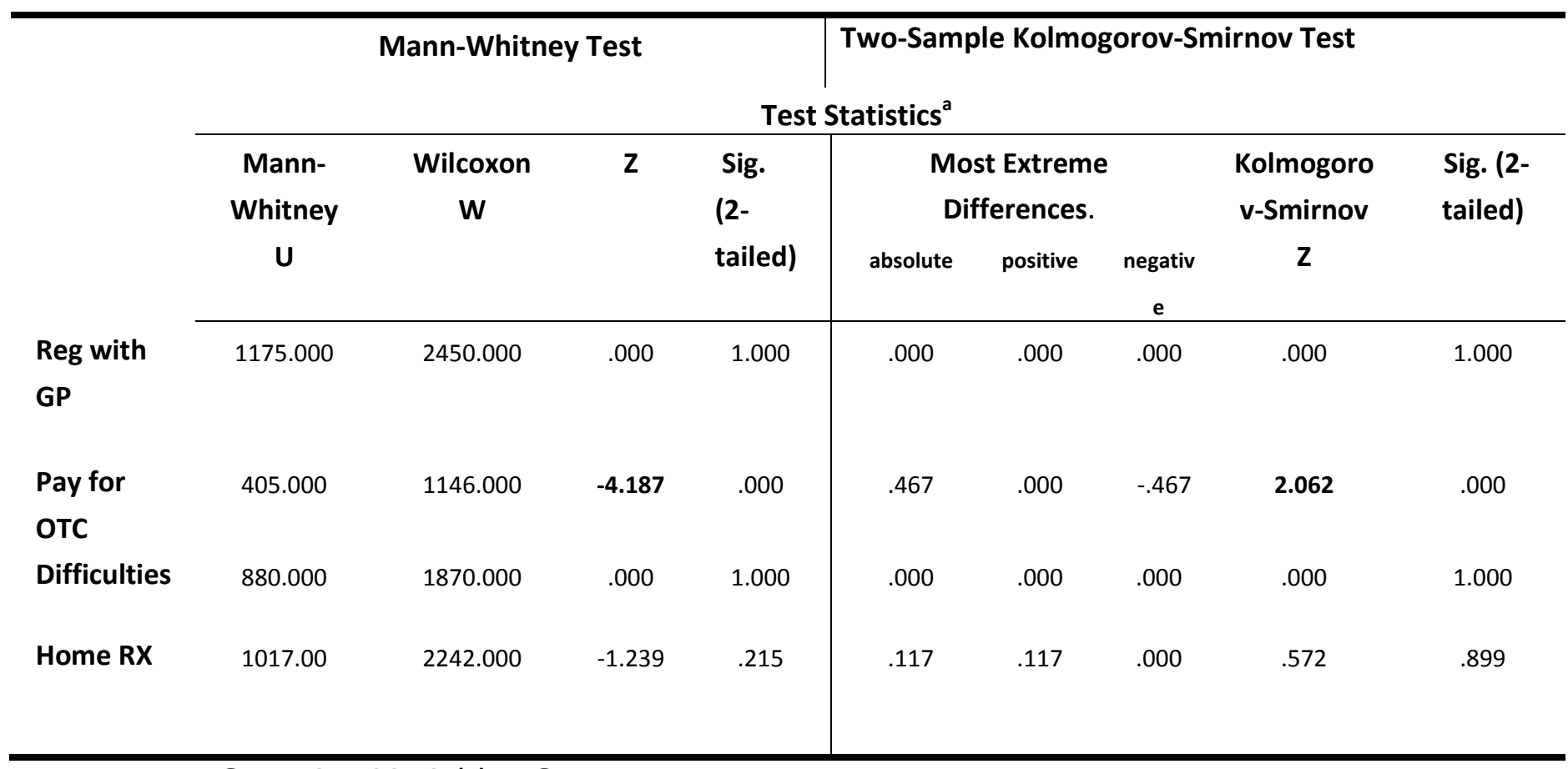

a. Grouping Variable: Group 
Table 7.12: Data for the children (Mann-Whitney Test)

\begin{tabular}{|c|c|c|c|c|}
\hline \multicolumn{5}{|c|}{ Ranks } \\
\hline & Group & $\mathbf{N}$ & Mean Rank & Sum of Ranks \\
\hline \multirow{3}{*}{$\begin{array}{l}\text { No. of } \\
\text { children/family }\end{array}$} & Traveller & 47 & 53.09 & 2495.00 \\
\hline & Control & 50 & 45.16 & 2258.00 \\
\hline & Total & 97 & & \\
\hline \multirow[t]{3}{*}{ Child health } & Traveller & 113 & 98.13 & 11089.00 \\
\hline & Control & 105 & 121.73 & 12782.00 \\
\hline & Total & 218 & & \\
\hline \multirow[t]{3}{*}{ Children Ages $(\mathrm{Y})$} & Traveller & 113 & 110.03 & 12433.50 \\
\hline & Control & 105 & 108.93 & 11437.50 \\
\hline & Total & 218 & & \\
\hline \multirow[t]{3}{*}{ Immunisation } & Traveller & 113 & 103.92 & 11743.50 \\
\hline & Control & 105 & 115.50 & 12127.50 \\
\hline & Total & 218 & & \\
\hline
\end{tabular}

\begin{tabular}{|c|c|c|c|c|c|c|c|c|c|}
\hline & \multicolumn{4}{|c|}{ Mann-Whitney Test } & \multicolumn{5}{|c|}{ Two-Sample Kolmogorov-Smirnov Test } \\
\hline & $\begin{array}{c}\text { Mann- } \\
\text { Whitney } \\
\text { U }\end{array}$ & $\begin{array}{c}\text { Wilcoxo } \\
\text { n W }\end{array}$ & $\mathbf{z}$ & $\begin{array}{l}\text { Sig. } \\
(2- \\
\text { tailed) }\end{array}$ & $\begin{array}{c}\text { Most Extr } \\
\text { absolute }\end{array}$ & $\begin{array}{l}\text { me Diffe } \\
\text { positive }\end{array}$ & $\begin{array}{l}\text { ences } \\
\text { negativ } \\
\text { e }\end{array}$ & $\begin{array}{c}\text { Kolmogoro } \\
\text { v-Smirnov } \\
\text { z }\end{array}$ & $\begin{array}{l}\text { Sig. (2- } \\
\text { tailed) }\end{array}$ \\
\hline $\begin{array}{l}\text { No. of } \\
\text { children/famil } \\
y\end{array}$ & 983.000 & 2258.000 & -1.466 & .143 & .154 & .154 & .000 & .758 & .613 \\
\hline Child health & 4648.000 & 11089.000 & -4.158 & .000 & .217 & .217 & .000 & 1.597 & .012 \\
\hline $\begin{array}{l}\text { Children } \\
\text { Ages(Y) }\end{array}$ & 5872.500 & 11437.500 & -.129 & .897 & .096 & .043 & -.096 & .706 & .702 \\
\hline Immunisation & 5302.500 & 11743.500 & -3.427 & .001 & .106 & .106 & .000 & .783 & .571 \\
\hline
\end{tabular}

a. Grouping Variable: Group 
Table 7.13: Frequency of illnesses experienced during the last month

\begin{tabular}{|c|c|c|c|c|c|c|}
\hline \multirow{3}{*}{$\begin{array}{c}\text { No of illnesses Last } \\
\text { Month }\end{array}$} & \multicolumn{4}{|c|}{ Group } & & \\
\hline & \multicolumn{2}{|c|}{ Traveller } & \multicolumn{2}{|c|}{ Control } & \multicolumn{2}{|c|}{ Total } \\
\hline & Count & $\%$ & Count & $\%$ & Count & $\%$ \\
\hline 1 & 33 & 97 & 33 & 100 & 66 & 98.5 \\
\hline 2 & 1 & 3 & 0 & .0 & 1 & 1.5 \\
\hline Total & 34 & 100.0 & 33 & 100.0 & 67 & 100.0 \\
\hline
\end{tabular}

\begin{tabular}{|l|c|c|c|}
\hline & Value & df & Exact. Sig. (2-sided) \\
\hline Pearson Chi-Square & $.985^{\mathrm{a}}$ & 1 & .507 \\
Likelihood Ratio & 1.371 & 1 & .507 \\
Linear-by-Linear & .971 & 1 & .507 \\
Association & & & \\
N of Valid Cases & 67 & & \\
\hline a. 2 cells (50.0\%) have expected count less than 5. The minimum expected count is 49. \\
\hline
\end{tabular}

Table 7.14: Frequency of medicine used during the last month

\begin{tabular}{|c|r|r|r|r|r|r|}
\hline \multirow{3}{*}{$\begin{array}{c}\text { No of medicines } \\
\text { Last Month }\end{array}$} & \multicolumn{4}{|c|}{ Group } & \multicolumn{2}{|c|}{} \\
\cline { 2 - 7 } & \multicolumn{2}{|c|}{ Traveller } & \multicolumn{2}{|c|}{ Control } & \multicolumn{2}{c|}{ Total } \\
\cline { 2 - 7 } & Count & \multicolumn{1}{|c|}{$\%$} & Count & \multicolumn{1}{c|}{$\%$} & \multicolumn{1}{c|}{ Count } & \multicolumn{1}{c|}{$\%$} \\
\hline \multirow{3}{*}{1} & 23 & 76.7 & 10 & 35.7 & 33 & 56.9 \\
\cline { 2 - 8 } 2 & 7 & 23.3 & 16 & 57.1 & 23 & 39.7 \\
\cline { 2 - 8 } 3 & 0 & .0 & 1 & 3.6 & 1 & 1.7 \\
4 & 0 & .0 & 1 & 3.6 & 1 & 1.7 \\
\cline { 2 - 7 } & 30 & 100.0 & 28 & 100.0 & 58 & 100.0 \\
\hline
\end{tabular}

\begin{tabular}{|l|c|c|c|}
\hline & Value & df & Exact. Sig. (2-sided) \\
\hline Pearson Chi-Square & $10.587^{\mathrm{a}}$ & 3 & .004 \\
Likelihood Ratio & 11.584 & 3 & .004 \\
Linear-by-Linear & 9.802 & 1 & .002 \\
Association & & & \\
N of Valid Cases & 58 & & \\
\hline \multicolumn{2}{|l|}{ a. 4 cells (50.0\%) have expected count less than 5. The minimum expected count is .48. } \\
\hline
\end{tabular}


Table 7.15: Medicines in the last month

\begin{tabular}{|c|c|c|c|c|c|c|}
\hline \multirow{3}{*}{$\begin{array}{l}\text { Medicines in the Last } \\
\text { Month }\end{array}$} & \multicolumn{4}{|c|}{ Group } & & \\
\hline & \multicolumn{2}{|c|}{ Traveller } & \multicolumn{2}{|c|}{ Control } & \multicolumn{2}{|c|}{ Total } \\
\hline & Count & $\%$ & Count & $\%$ & Count & $\%$ \\
\hline OTC Medicines & 8 & 22 & 30 & 61 & 38 & 44 \\
\hline Prescribed medicines & 29 & 78 & 19 & 39 & 48 & 56 \\
\hline Total & 37 & 100.0 & 49 & 100.0 & 86 & 100.0 \\
\hline
\end{tabular}

\begin{tabular}{|l|c|c|c|}
\hline & Value & df & Exact. Sig. (2-sided) \\
\hline Pearson Chi-Square & $13.407^{\mathrm{a}}$ & 1 & .000 \\
Likelihood Ratio & 13.984 & 1 & .000 \\
Linear-by-Linear & 13.251 & 1 & .000 \\
Association & & & \\
N of Valid Cases & 86 & & \\
\hline a. 0 cells (0\%) have expected count less than 5. The minimum expected count is .16.35. \\
\hline
\end{tabular}

Table 7.16: Frequency of illnesses experienced during the last six months

\begin{tabular}{|c|r|r|r|r|r|r|}
\hline \multirow{2}{*}{$\begin{array}{c}\text { No of illnesses Last } \\
\text { 6- Months }\end{array}$} & \multicolumn{4}{|c|}{ Group } & \multicolumn{2}{|c|}{} \\
\cline { 2 - 8 } & \multicolumn{2}{|c|}{ Traveller } & \multicolumn{2}{|c|}{ Control } & \multicolumn{2}{c|}{ Total } \\
\cline { 2 - 8 } & Count & \multicolumn{1}{|c|}{$\%$} & Count & \multicolumn{1}{c|}{$\%$} & Count & \multicolumn{1}{c|}{$\%$} \\
\hline 1 & 44 & 77.2 & 60 & 87 & 104 & 82.5 \\
\cline { 2 - 8 } 2 & 13 & 22.8 & 9 & 13 & 22 & 17.5 \\
\hline Total & 57 & 100.0 & 69 & 100.0 & 126 & 100.0 \\
\hline
\end{tabular}

\begin{tabular}{|l|c|c|c|}
\hline & Value & df & Exact. Sig. (2-sided) \\
\hline Pearson Chi-Square & $2.065^{\mathrm{a}}$ & 1 & .165 \\
Likelihood Ratio & 2.058 & 1 & .165 \\
Linear-by-Linear & 2.048 & 1 & .165 \\
Association & 126 & & \\
N of Valid Cases & & \\
\hline a. 0 cells (.0\%) have expected count less than 5. The minimum expected count is 9.95. \\
\hline
\end{tabular}


Table 7.17: Frequency of medicine used during the last six months

\begin{tabular}{|c|r|r|r|r|r|r|}
\hline \multirow{3}{*}{$\begin{array}{c}\text { No of medicines } \\
\text { Last six Months }\end{array}$} & \multicolumn{4}{|c|}{ Group } & \multicolumn{2}{c|}{} \\
\cline { 2 - 8 } & \multicolumn{2}{|c|}{ Traveller } & \multicolumn{2}{|c|}{ Control } & \multicolumn{2}{c|}{ Total } \\
\cline { 2 - 8 } & Count & \multicolumn{1}{|c|}{$\%$} & Count & \multicolumn{1}{c|}{$\%$} & \multicolumn{1}{c|}{ Count } & \multicolumn{1}{c|}{$\%$} \\
\hline \multirow{3}{*}{1} & 38 & 76 & 27 & 52 & 65 & 63.7 \\
\cline { 2 - 8 } & 10 & 20 & 22 & 42.3 & 32 & 31.4 \\
3 & 2 & 4 & 2 & 3.8 & 4 & 3.9 \\
4 & 0 & .0 & 1 & 1.9 & 1 & 1 \\
\cline { 2 - 8 } & 50 & 100.0 & 52 & 100.0 & 102 & 100.0 \\
\hline
\end{tabular}

\begin{tabular}{|l|c|c|c|}
\hline & Value & df & Exact. Sig. (2-sided) \\
\hline Pearson Chi-Square & $7.325^{\mathrm{a}}$ & 3 & .034 \\
Likelihood Ratio & 7.829 & 3 & .061 \\
Linear-by-Linear & 5.107 & 1 & .025 \\
Association & & & \\
N of Valid Cases & 102 & & \\
\hline a. 4 cells (50.0\%) have expected count less than 5. The minimum expected count is .49. \\
\hline
\end{tabular}

Table 7.18: Medicines in the last six months

\begin{tabular}{|c|c|c|c|c|c|c|}
\hline \multirow{3}{*}{$\begin{array}{l}\text { Medicines in the Last } \\
\text { Six Months }\end{array}$} & \multicolumn{4}{|c|}{ Group } & & \\
\hline & \multicolumn{2}{|c|}{ Traveller } & \multicolumn{2}{|c|}{ Control } & \multicolumn{2}{|c|}{ Total } \\
\hline & Count & $\%$ & Count & $\%$ & Count & $\%$ \\
\hline \multirow{2}{*}{$\begin{array}{c}\text { OTC Medicines } \\
\text { Prescribed medicines }\end{array}$} & 19 & 30 & 52 & 64 & 71 & 49 \\
\hline & 45 & 70 & 29 & 36 & 74 & 51 \\
\hline Total & 64 & 100.0 & 81 & 100.0 & 145 & 100.0 \\
\hline
\end{tabular}

\begin{tabular}{|l|c|c|c|}
\hline & Value & df & Exact. Sig. (2-sided) \\
\hline Pearson Chi-Square & $17.039^{\mathrm{a}}$ & 1 & .000 \\
Likelihood Ratio & 17.434 & 1 & .000 \\
Linear-by-Linear & 16.921 & 1 & .000 \\
Association & & & \\
N of Valid Cases & 145 & & \\
\hline a. 0 cells (0\%) have expected count less than 5. The minimum expected count is .31.34. \\
\hline
\end{tabular}


Table 7.19: Attitudes (Mann-Whitney Test)

\begin{tabular}{lcccc}
\hline & & \multicolumn{3}{c}{ Ranks } \\
\hline \multirow{2}{*}{ Giving RX for } & Group & $\mathbf{N}$ & Mean Rank & Sum of Ranks \\
earache & Traveller & 47 & 43.02 & 2022.00 \\
& Control & 50 & 54.62 & 2731.00 \\
Know epilepsy & Total & 97 & & 2303.00 \\
& Traveller & 47 & 49.00 & 2450.00 \\
Treat epilepsy & Control & 50 & 49.00 & \\
& Total & 97 & & 2303.00 \\
& Traveller & 47 & 49.00 & 2450.00 \\
Inform friends & Control & 50 & 49.00 & 2303.00 \\
& Total & 97 & & 2450.00 \\
& Traveller & 47 & 49.00 & 2303.00 \\
Inform school & Control & 50 & 49.00 & 2450.00 \\
& Total & 97 & & \\
\hline
\end{tabular}

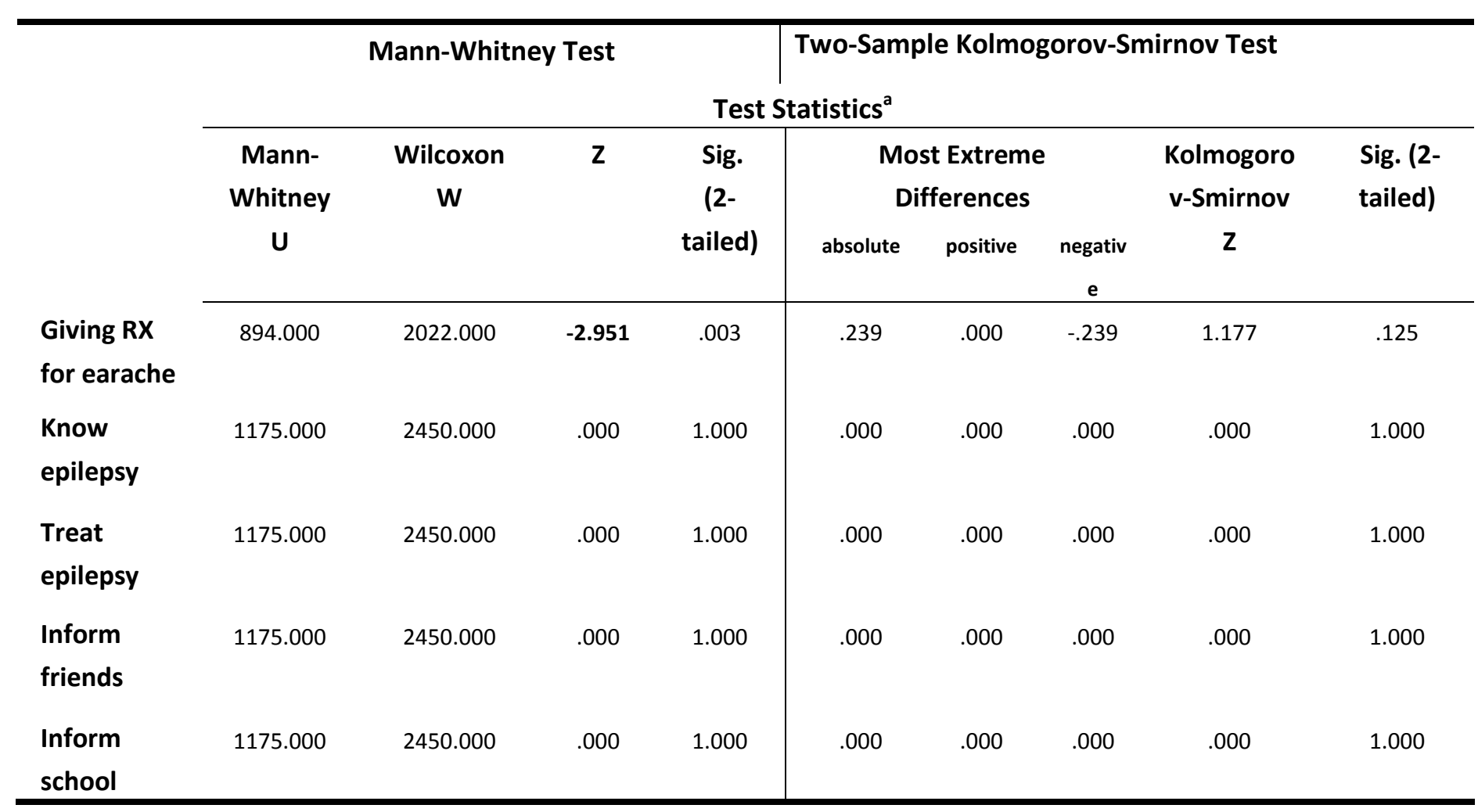

a. Grouping Variable: Grou 


\title{
APPENDIX F
}

\author{
Attitudes tables
}

\section{Gypsies and Travellers}

Table 7.20: Categorisation of responses (pain)

Inductive Categories

Participants' Responses

\begin{tabular}{ll}
\hline Give analgesics & - Give calpol and ear drops. \\
& - Give calpol, but still like it checked out. \\
& Give pain killer, and then check if no improvement takes \\
& - Give pain killer only if Dr prescribed. \\
- Give paracetamol and/or Ibuprofen, monitor the & \\
Seeking advice or health & - Situation if no improvement I would see the GP. \\
care & - Ttraight to the GP. \\
& - Take to walk in centre or A\&E. \\
& - Ring the NHS direct first. \\
& - Take to the doctor, keep ear warm when outside.
\end{tabular}

Other options

- Treat with warm bandage to ear, then if no better see the doctor.

- Phone the family first, then GP for advice.

- Comfort him and put ear drops.

- Comfort him, then see another option. 


\begin{tabular}{|c|c|}
\hline Inductive categories & Participants responses \\
\hline $\begin{array}{l}\text { Have experience and } \\
\text { knowledge }\end{array}$ & 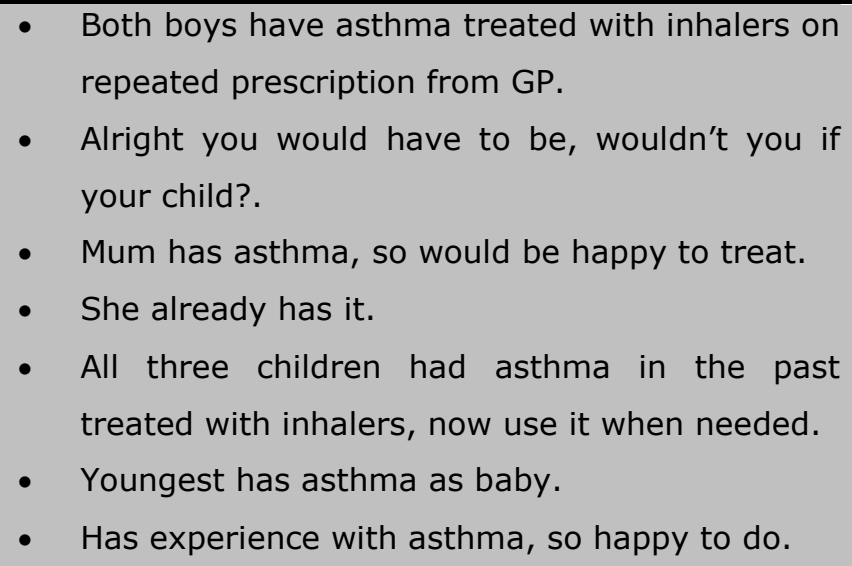 \\
\hline $\begin{array}{l}\text { Happy to follow the } \\
\text { instructions (give the } \\
\text { inhalers) }\end{array}$ & $\begin{array}{l}\text { - Would look at possible external elements } \\
\text { causing it, but appreciate inhalers would help. } \\
\text { - Just give it. } \\
\text { - Happy to treat if it made them better. } \\
\text { - Would treat as long as child kept healthy. }\end{array}$ \\
\hline Concerned & $\begin{array}{l}\text { - Worried but would go to the doctor. } \\
\text { - Wlightly concern, but ok. } \\
\text { inhaler than not. } \\
\text { - Shocked, devastated, frustrated, will give } \\
\text { medicine if necessary for health. } \\
\text { - Would try home cure first, an inhaler would be } \\
\text { a last resort. } \\
\text { Would make sure it was careful diagnosed, then } \\
\text { I will go for doctor opinion to make sure they } \\
\text { really needed. } \\
\text { - Not happy but would not ignore it and not } \\
\text { worried about inhalers. }\end{array}$ \\
\hline
\end{tabular}




\section{\begin{tabular}{ll}
\hline Inductive categories & Participants responses
\end{tabular}}

\begin{tabular}{|c|c|}
\hline $\begin{array}{l}\text { Feel happy to give child } \\
\text { medication and follow } \\
\text { advice }\end{array}$ & $\begin{array}{l}\text { - Happy to treat, knows what to do in event of a } \\
\text { - Weizures. } \\
\text { - } \text { stould expect it to be treated, would want medicine to } \\
\text { - Understand need to treat, so happy to do. } \\
\text { - Would just get on with it, do as doctor said. } \\
\text { - Brother had epilepsy, was treated with medicines, know } \\
\text { - what to do. } \\
\text { Would treat with regular medication as eldest child had } \\
\text { surgery and regular medication as a child. } \\
\text { Eldest had epilepsy, treated with anticonvulsant, } \\
\text { regular medication and visits to specialist, but has now } \\
\text { been fits free for } 2 \text { years. }\end{array}$ \\
\hline $\begin{array}{l}\text { Concerned, but would give } \\
\text { medication }\end{array}$ & $\begin{array}{l}\text { - Feel anxious, but happy to treat it. } \\
\text { - Would be upset, but happy to treat if looked after by } \\
\text { healthcare. } \\
\text { - } \text { Distressed, devastated, but happy to give if it helped } \\
\text { my child. } \\
\text { - Depressed, but if that would help I would give it. } \\
\text { - Will feel sad about they been ill, but do whatever would } \\
\text { help to make them better. }\end{array}$ \\
\hline
\end{tabular}

